B O N N E V I L L E P O W E R A D M I N I S T R A T I O Hydraulic Characteristics of the Lower Snake River during Periods of Juvenile Fall Chinook Salmon Migration

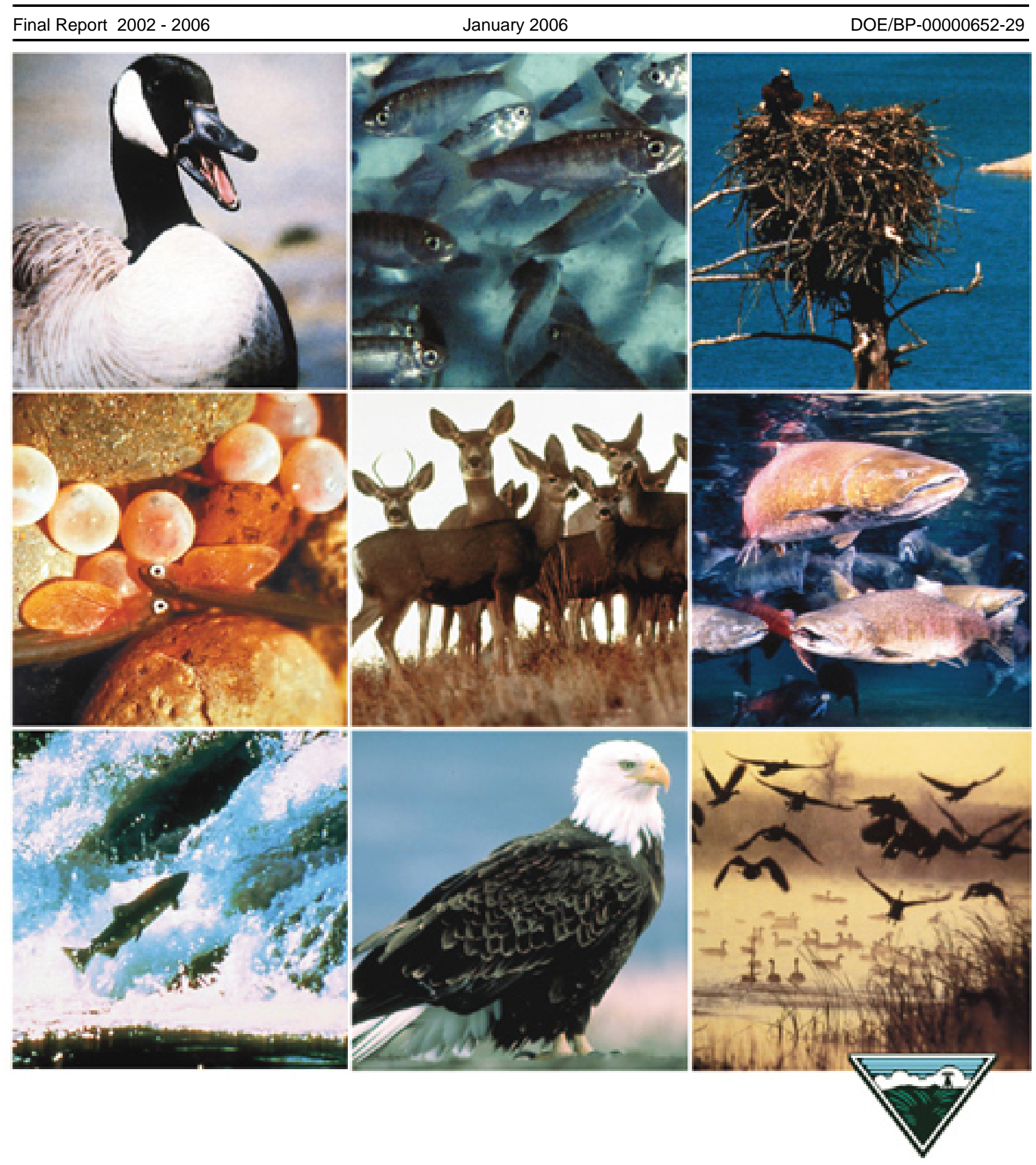


This Document should be cited as follows:

Cook, C., B. Dibrani, M. Richmond, M. Bleich, P. Titzler, T. Fu, "Hydraulic Characteristics of the Lower Snake River during Periods of Juvenile Fall Chinook Salmon Migration", 2002-2006

Final Report, Project No. 200202700, 176 electronic pages, (BPA Report DOE/BP-00000652-29)

\author{
Bonneville Power Administration \\ P.O. Box 3621 \\ Portland, OR 97208
}

This report was funded by the Bonneville Power Administration (BPA), U.S. Department of Energy, as part of BPA's program to protect, mitigate, and enhance fish and wildlife affected by the development and operation of hydroelectric facilities on the Columbia River and its tributaries. The views in this report are the author's and do not necessarily represent the views of BPA. 


\title{
Hydraulic Characteristics of the Lower Snake River During Periods of Juvenile Fall Chinook Salmon Migration
}

\author{
Final Project Report
}

April 2002 - January 2006

\author{
Prepared by: \\ Christopher B. Cook, Berhon Dibrani, Marshall C. Richmond, \\ Matthew D. Bleich, P. Scott Titzler, and Tao Fu \\ Pacific Northwest National Laboratory \\ P.O. Box 999 \\ Richland, Washington 99352
}

Prepared for:

U.S. Department of Energy

Bonneville Power Administration

Division of Fish and Wildlife

P.O. Box 3621

Portland, Oregon 97208-3621

Project number: 2002-027-00

Contract number: 652-00021

January 2006 


\section{Summary}

This report documents a four-year study to assess hydraulic conditions in the lower Snake River. The work was conducted for the Bonneville Power Administration, U.S. Department of Energy, by the Pacific Northwest National Laboratory.

Cold water released from the Dworshak Reservoir hypolimnion during mid- to late-summer months cools the Clearwater River far below equilibrium temperature. The volume of released cold water augments the Clearwater River, and the combined total discharge is on the order of the Snake River discharge when the two rivers meet at their confluence near the upstream edge of Lower Granite Reservoir. With typical temperature differences between the Clearwater and Snake rivers of $10^{\circ} \mathrm{C}$ or more during July and August, the density difference between the two rivers during summer flow augmentation periods is sufficient to stratify Lower Granite Reservoir as well as the other three reservoirs downstream.

Because cooling of the river is desirable for migrating juvenile fall Chinook salmon (Oncorhynchus tshawytscha) during this same time period, the amount of mixing and cold water entrained into Lower Granite Reservoir's epilimnion at the Clearwater/Snake River confluence is of key biological importance. Data collected during this project indicates the three reservoirs downstream of Lower Granite also stratify as direct result of flow augmentation from Dworshak Reservoir. These four reservoirs are also heavily influenced by wind forcing at the water's surface and during periods of low river discharge often behave like a two-layer lake. During these periods of stratification, lower river discharge, and wind forcing, the water in the upper layer of the reservoir is held in place or moves slightly upstream. This upper layer is also exposed to surface heating and may warm up to temperatures close to equilibrium temperature. The thickness (depth) of this upper warm layer and its direction of travel may be of key biological importance to juvenile fall Chinook salmon.

This report describes field data collection, modeling, and analysis of hydrodynamic and temperature conditions in the Lower Granite Reservoir during the summer flow augmentation periods of 2002, 2003, and 2004. Although temperature, and hence density, differences during flow augmentation periods between the Clearwater and Snake rivers were approximately equal $\left(7-12^{\circ} \mathrm{C}\right)$ for all four years, the discharge ratio varied which resulted in significant differences in entrainment of cooler Clearwater River water into the Lower Granite Reservoir epilimnion. However, as a direct result of system management, Lower Granite Dam tailrace temperatures were maintained near $20^{\circ} \mathrm{C}$ during all years. Primary differences in the other three lower Snake River reservoirs were therefore a result of meteorological conditions and dam operations, which produced variations in wind setup and surface heating.

Circulation patterns in all four lower Snake River reservoirs were numerically simulated for periods of 2002, 2003, 2004, and 2005 using CE-QUAL-W2. Simulation results show that these models are capable of matching diurnal and long-term temperature and velocity changes in the reservoirs. In addition, the confluence zone of the Clearwater and Snake rivers was modeled using the threedimensional non-hydrostatic model Flow3D.

Once calibrated and validated, the reservoir models were used to investigate downstream impacts of alternative reservoir operation schemes, such as increasing or decreasing the ratio of Clearwater to Snake 
river discharge. Simulation results were linked with the particle tracking model FINS to develop reservoir-integrated metrics that varied due to these alternative operation schemes. Findings indicate that significant alterations in water temperature throughout the lower Snake River are possible by altering hypolimnetic discharges from Dworshak Reservoir, which may also impact the behavior of migrating juvenile fall Chinook salmon during periods of flow augmentation. 


\section{Acknowledgments}

We sincerely appreciate the cooperation, assistance, and dedication of the following persons:

Bonneville Power Administration

- John Piccininni (Contracting Officer's Technical Representative)

OA Systems

- Kathryn Barko (lower Snake River data)

- Joe Carroll (lower Snake River data)

Pacific Northwest National Laboratory

- William Perkins (GIS, terrain sheltering for CE-QUAL-W2, and FINS particle tracking support)

- Cynthia Rakowski (technical review)

- John Serkowski (development of the Flow-3D model grid)

- Rose Urbina (text processing)

U.S. Army Corps of Engineers

- Michael Schneider (CE-QUAL-W2 bathymetry for Lower Granite Reservoir)

U.S. Department of Energy

- Office of Nonproliferation and National Security in conjunction with Sandia National Laboratories, Los Alamos National Laboratory, and Savannah River Technology Center (MTI satellite data). 


\section{Acronyms and Abbreviations}

2D

3D

ADCP

BPA

BRZ

CFD

cfs

$\mathrm{cm} / \mathrm{s}$

CTD

DEM

FCRPS

FMS

GIS

GPS

IHR

$\mathrm{kHz}$

kcfs

LWG

LGS

LMN

LWG FB

MAE

MASS1

$\mathrm{mS} / \mathrm{cm}$

MSL

MTI

MW

NMFS

NOAA

PNNL

Q

RM

RMS

US

USACE

USGS

WGS two-dimensional

three-dimensional

acoustic Doppler current profiler

Bonneville Power Administration

boat restricted zone

computational fluid dynamics

cubic feet per second

centimeters per second

conductivity temperature depth

digital elevation model

Federal Columbia River Power System

Fixed Monitoring Station

geographic information system

global positioning system

Ice Harbor

kilohertz

thousands of cfs

Lower Granite

Lower Goose

Lower Monumental

Lower Granite forebay

mean absolute error

Modular Aquatic Simulation System 1-D

milliSiemen/centimeter

mean sea level

Multispectral Thermal Imager

megawatt

National Marine Fisheries Service

National Oceanic and Atmospheric Association

Pacific Northwest National Laboratory

discharge

river mile

root mean square

United States

U.S. Army Corps of Engineers

U.S. Geological Survey

World Geodetic System 


\section{Contents}

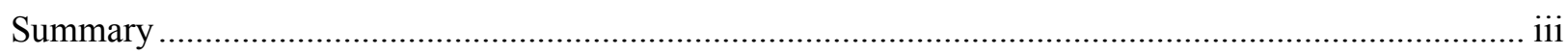

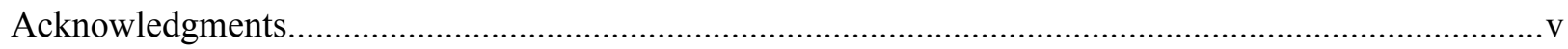

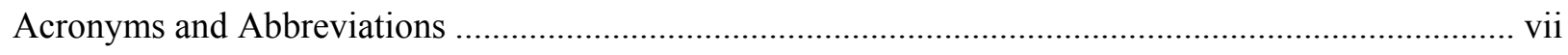

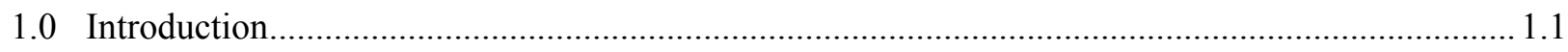

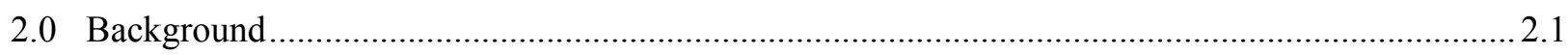

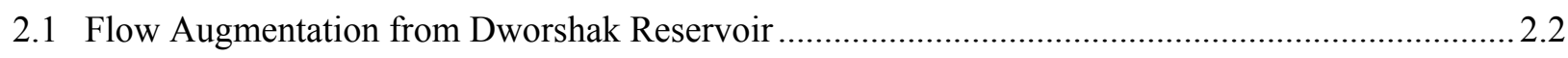

2.2 Load-Following Operation of the Lower Snake River Dams............................................ 2.4

2.3 Juvenile Chinook Salmon: Upper Temperature Limits and Water Quality Standards ............ 2.6

3.0 Lower Granite Reservoir: Field Monitoring Program ........................................................ 3.1

3.1 2003 and 2004 Water Temperature Measurements ............................................................... 3.1

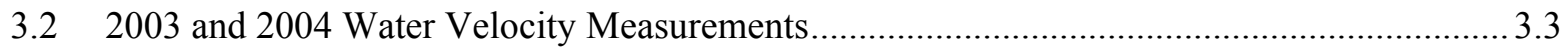

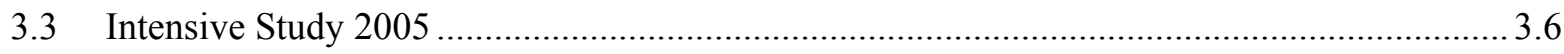

4.0 Lower Granite Reservoir: Current Structure and 3D Numerical Modeling .................................. 4.1

4.1 Quantity and Quality of Flow Entering Lower Granite Reservoir During Periods

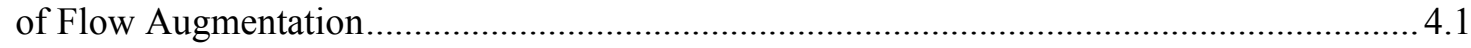

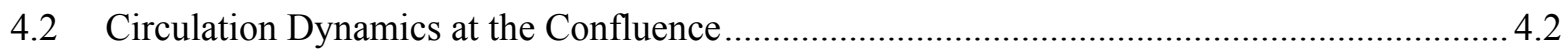

4.2.1 Small Temperature and Small Discharge Difference Circulation ............................ 4.6

4.2.2 Small Temperature and Large Discharge Difference Circulation ............................. 4.6

4.2.3 Large Temperature Difference Circulation ........................................................... 4.9

4.3 Thermal Benefit of Flow Augmentation near the Confluence ............................................ 4.11

4.4 Thermal Benefit of Flow Augmentation Downstream of Silcott Island............................. 4.13

4.5 Three-Dimensional Numerical Modeling of the Confluence ................................................ 4.19

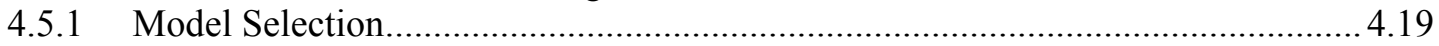

4.5.2 Simulated Hydraulic Conditions for the Small Temperature and Small Discharge Difference Circulation Pattern ............................................................ 4.20

4.5.3 Simulated Hydraulic Conditions for the Large Temperature Difference Circulation Pattern... 
5.0 Lower Snake River: General Current Structure ................................................................. 5.1

$5.1 \quad$ Wind Setup and Mid-Pool Warming .............................................................................. 5.1

5.2 Stratification Intensity Throughout the Snake River System ................................................ 5.6

6.0 Two-Dimensional Hydrodynamic and Water Quality Modeling of the Lower Snake River ........... 6.1

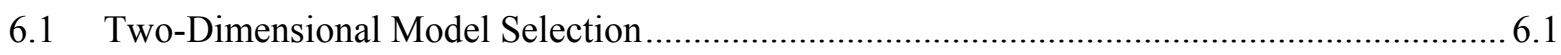

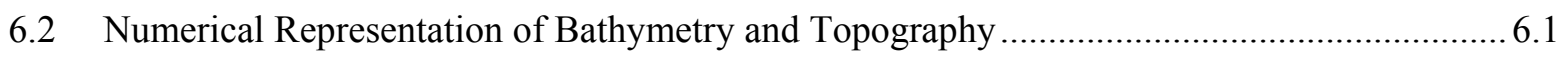

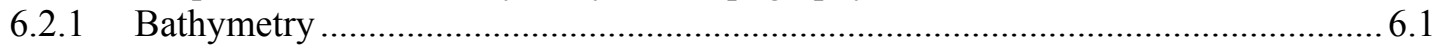

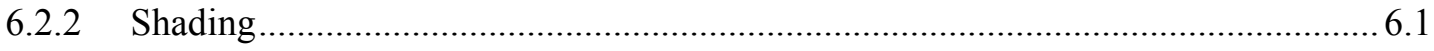

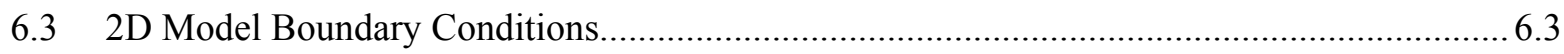

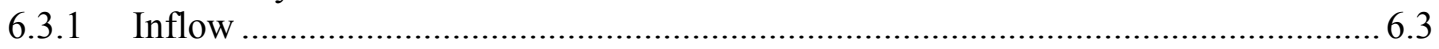

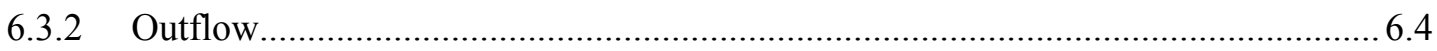

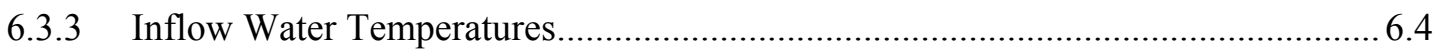

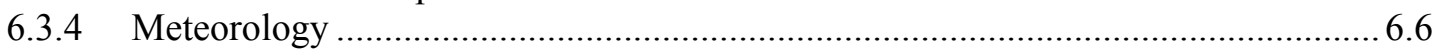

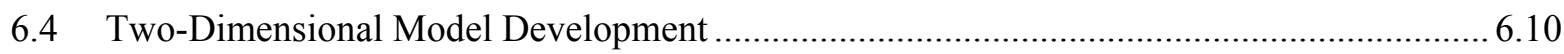

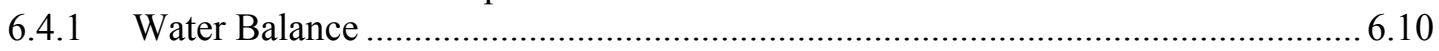

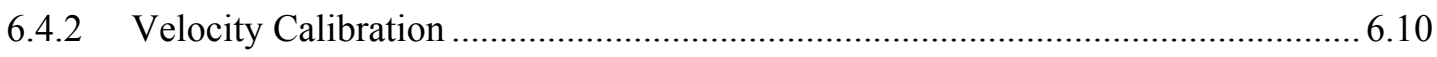

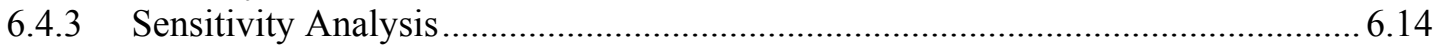

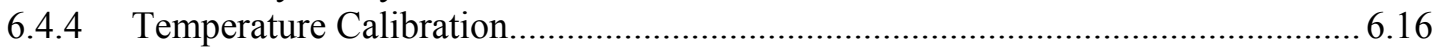

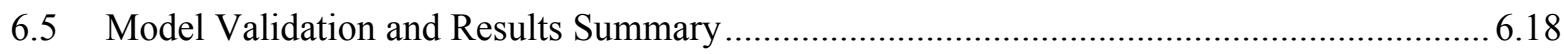

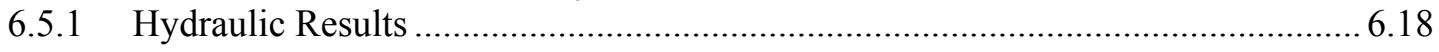

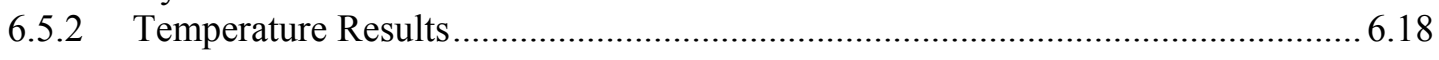

7.0 Management Scenarios and Reservoir-Integrated Metrics Computed Using FINS ...................... 7.1

7.1 Alteration of Inflows to Lower Granite Reservoir: Managing Vertical Temperature Gradients ........................................................................................................... 7.1

7.1.1 Raising Clearwater Discharge or Lowering Snake Discharge to Achieve a

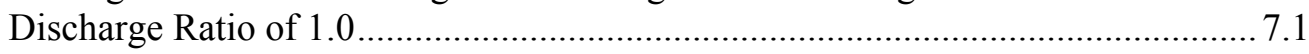

7.1.2 2004 Flow Augmentation Period: Discharge Ratio of 1.0 Plus Holding Clearwater River Inflow Temperatures Constant.................................................. 7.4

7.1.3 July 2002 Flow Augmentation Period: Discharge Ratio of 1.0 .............................. 7.5

7.2 Impacts of Lowering the Water Surface Elevation of Little Goose Pool .............................. 7.6

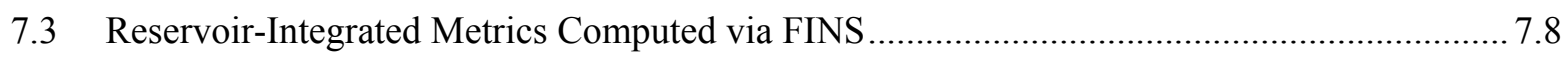

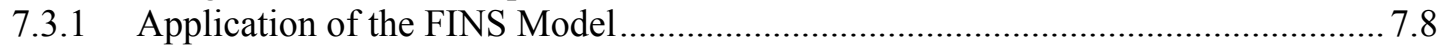

7.3.2 Reservoir-Integrated Metrics..................................................................... 7.10

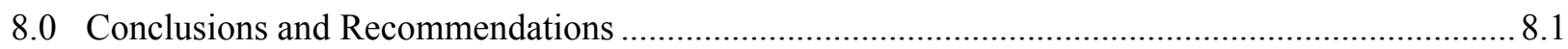




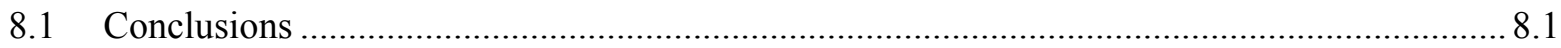

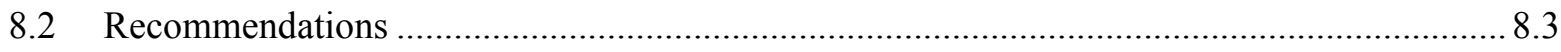

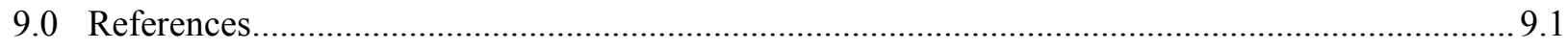

Appendix A - Observed Water Temperatures in Lower Granite Reservoir .......................................... A.1

Appendix B - Transects of Water Velocity during the 2005 Study .......................................................1

Appendix C - CE-QUAL-W2 Calibration and Validation Model Results ...............................................1

Appendix D - PIT-Tag Computed Migration Rates for Juvenile Fall Chinook Salmon ........................ D.1

\section{Figures}

2.1 Location of the Clearwater River, Snake River, and lower Snake River dams........................... 2.1

2.2 Water temperature profiles collected in Dworshak Dam forebay ............................................... 2.3

2.3 Dworshak Reservoir summer water surface elevations .......................................................... 2.3

2.4 Discharge hydrographs for the middle Snake River (Anatone) and major tributaries that enter the middle Snake River upstream between Anatone and the Hells Canyon Complex from

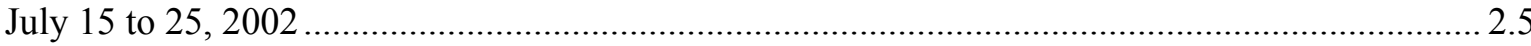

2.5 Discharge hydrographs for the middle Snake River (Anatone), Clearwater River upstream of Lower Granite Reservoir, and the lower Snake River at Lower Granite Dam (LWG) from

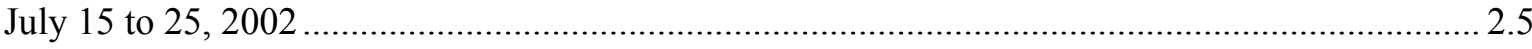

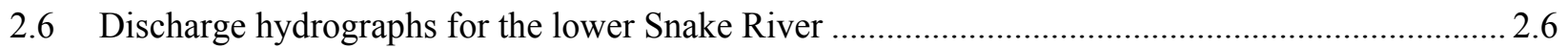

3.1 Open-water temperature logger deployment schematic .............................................................. 3.2

3.2 Bridge pier temperature logger deployment schematic ......................................................... 3.3

3.3 Lower Granite Reservoir water temperature measurement sites: field season 2003..................... 3.4

3.4 Lower Granite Reservoir water temperature measurement sites: field season 2004..................... 3.5

3.5 Point Velocity Measurement Sites, May 2003 …................................................................... 3.7

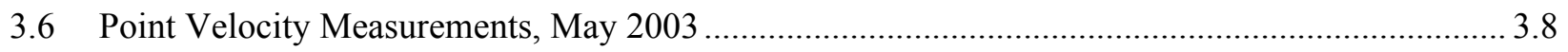

3.7 Point Velocity Measurement Sites, August 2003 ................................................................. 3.9

3.8 Point Velocity Measurements, August 2003 ...................................................................... 3.10

3.9 Transect of velocity measurements near the LGR forebay BRZ on August 11, 2003 ................. 3.11 
3.10 Point and bottom-mounted ADCP measurement sites: July 2005 ........................................... 3.12

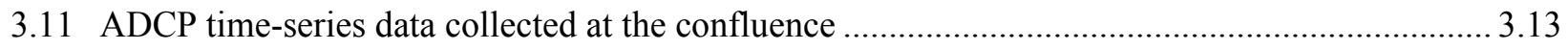

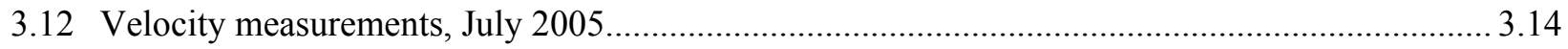

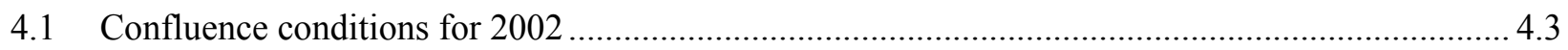

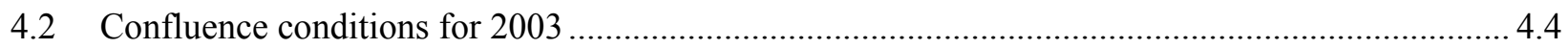

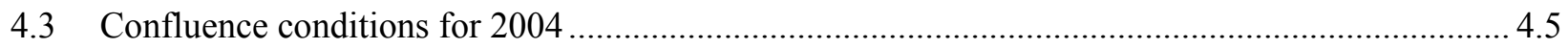

4.4 Daily-averaged observed water temperatures (upper) and differences (lower) for the Snake (Site 9) and Clearwater (Site 11) rivers during the study period.................................................... 4.6

4.5 Infrared satellite image of the confluence zone taken near midnight, April 4, 2002 ................... 4.7

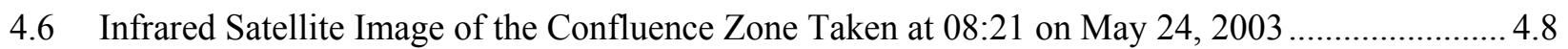

4.7 Specific Conductance and Temperature Profiles Collected on May 16, 2003 ............................... 4.8

4.8 MTI Satellite Derived Surface Water Temperatures on July 21, 2002 ....................................... 4.9

4.9 Infrared Satellite Image of the Confluence Zone Taken on May 24, 2003 at 08:21 .................. 4.10

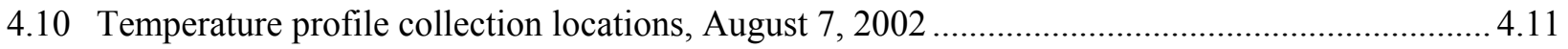

4.11 Daily-average water temperatures at Site 5a for 2002, 2003, and 2004................................. 4.12

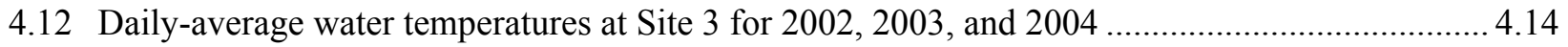

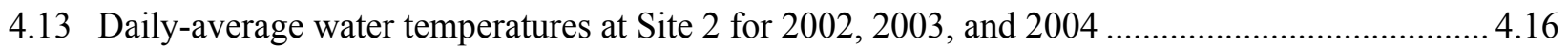

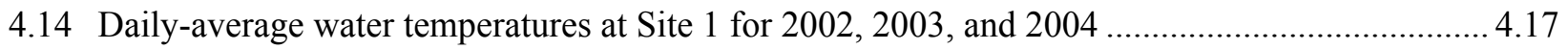

4.15 Daily-average water temperatures in LWG forebay BRZ for 2002, 2003, and $2004 \ldots \ldots \ldots \ldots \ldots \ldots . . .4 .18$

4.16 Extent of the coarse (left) and fine (right) domain 3D confluence zone model ..........................4.19

4.17 Temperature simulation results for April 4, 2002, at two elevations ....................................... 4.20

4.18 Contours of temperature (upper) and streamline tracks (lower) colored by temperature for

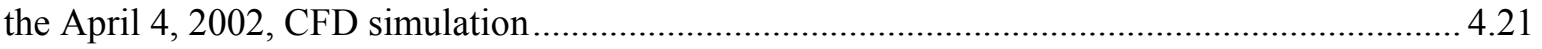

4.19 Temperature simulation results for July 21, 2002, at two elevations .........................................22

4.20 Contours of temperature (upper) and streamline tracks (lower) colored by temperature for the July 31,2002 , CFD simulation.

4.21 Two views of streamline tracks that migrate downstream the Clearwater River and then upstream along the bottom of the Snake River..... 
5.1 Little Goose Reservoir map showing location of temperature loggers ....................................... 5.2

5.2 Little Goose Reservoir water temperature time-series data during 2003 ................................... 5.2

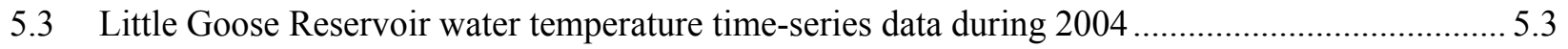

5.4 Schematic of wind-driven circulation pattern hypothesized to occur in the lower Snake River

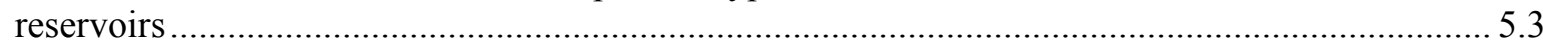

5.5 ADCP transect collected in Little Goose Pool on July 24, 2005 ................................................... 5.4

5.6 Lower Monumental Reservoir water temperature time-series data during 2003 .......................... 5.5

5.7 Lower Monumental Reservoir water temperature time-series data during 2004 .......................... 5.5

5.8 Ice Harbor Reservoir water temperature time-series data during 2003 ...................................... 5.6

5.9 Stratification intensity for lower Snake River reservoirs, 2002-2004 _....................................... 5.9

6.1 LGS Reservoir Storage-Elevation Curves............................................................................. 6.2

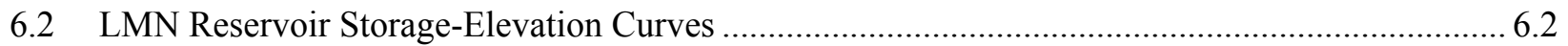

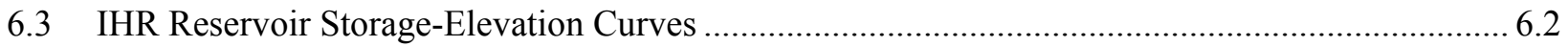

6.4 Area (in blue) which can be 'seen' by the computational node at center of the figure for Segment 24 (Central Ferry) in Little Goose Reservoir .................................................................. 6.3

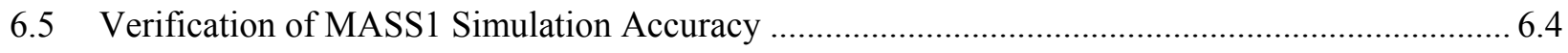

6.6 Temperature logger monitoring sites in the reservoir upstream of Little Goose Dam................... 6.5

6.7 Temperature logger monitoring sites in the reservoir upstream of Lower Monumental Dam......... 6.5

6.8 Temperature logger monitoring sites in the reservoir upstream of Ice Harbor Dam ..................... 6.6

6.9 Location of AgriMet meteorological stations used in during the study ...................................... 6.7

6.10 Observed air temperature from AgirMet Station LBRW (Rice Bar) ........................................... 6.8

6.11 Observed dew point temperature from AgirMet Station LBRW (Rice Bar)................................. 6.8

6.12 Observed wind speed from AgirMet Station LBRW (Rice Bar) ............................................... 6.8

6.13 Observed cloud cover from AgirMet Station LBRW (Rice Bar) ............................................. 6.9

6.14 Observed solar radiation from AgirMet Station LBRW (Rice Bar) …....................................... 6.9

6.15 Observed wind direction from AgirMet Station LBRW (Rice Bar) .......................................... 6.9

6.16 Observed and simulated water surface elevations during part of 2002 at the Lower Granite Dam forebay after applying the water balance adjustment 
6.17 Locations of ADCP Measurements in Lower Granite Reservoir.

6.18 Velocities at Mid-pool 3 in Lower Granite Reservoir

6.19 Velocities at Mid-pool 2 in Lower Granite Reservoir.

6.20 Velocities at Mid-pool 1 in Lower Granite Reservoir.

6.21 Velocities at BRZ in Lower Granite Reservoir.

6.22 Locations of ADCP Measurements in Little Goose Reservoir

6.23 Velocities at mid-pool site A in Little Goose Reservoir

6.24 Velocities at mid-pool 2003 site in Little Goose Reservoir

6.25 Velocities at mid-pool 2004 site in Little Goose Reservoir

6.26 Velocities at the forebay BRZ site in Little Goose Reservoir.

6.27 Comparison of average meteorological parameters collected at AgriMet Stations Rice Bar (LBRW) and Silcott Island (SILW) for August 2003 and 2004

6.28 Example comparison of observed and simulated data at mid-pool near the surface (left) and near bottom (right) for Little Goose Reservoir, 2003

6.29 Example comparison of observed and simulated data at the forebay BRZ near the surface (left) and near bottom (right) for Little Goose Reservoir, 2003

7.1 Lower Granite Reservoir and temperature monitoring sites

7.2 Simulation-Average Temperature Differences Between Historic and Management Scenario Results for Lower Granite Reservoir

7.3 Simulation-Average Temperature Differences Between Historic and Management Scenario Results for the 2004 Period

7.4 Simulation-Average Temperature Differences Between Historic and Management Scenario Results for Lower Granite Reservoir

7.5 Computed Temperature Differences (left) and Velocity Profiles (right) for Little Goose Pool

7.6 Computed histogram of migration rate for hatchery-raised juvenile fall Chinook salmon passing through Little Goose Pool: 2002 through 2004

7.7 Computed time-series results for two FINS particles introduced into the upstream end of Little Goose Reservoir (Lower Granite tailrace) on August 1, 2003 


\section{Tables}

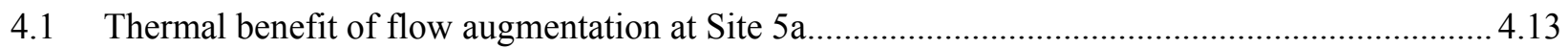

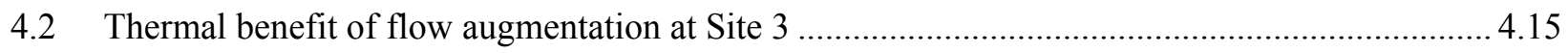

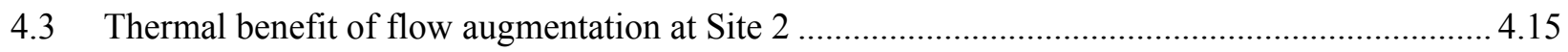

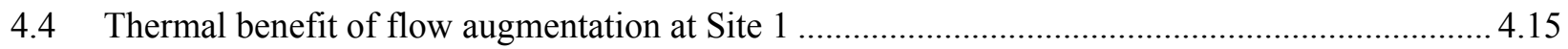

4.5 Thermal benefit of flow augmentation at the forebay BRZ ................................................... 4.15

5.1 Stratification intensity for lower Snake River reservoirs, 2002, as computed using forebay BRZ and FMS loggers ........................................................................................ 5.7

5.2 Stratification intensity for lower Snake River reservoirs, 2003, as computed using

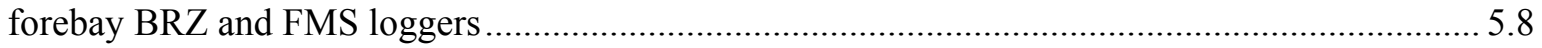

5.3 Stratification Intensity for lower Snake River reservoirs, 2004, as computed using

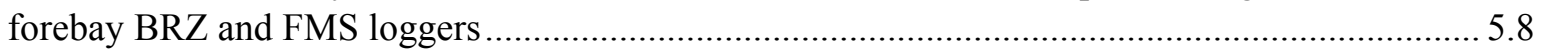

6.1 Comparison of model simulated results to observed data for each of the lower Snake River

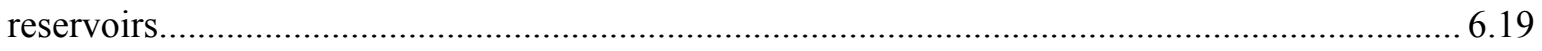

6.2 Starting and Ending Dates of the Calibration/Validation Comparisons ....................................... 6.19

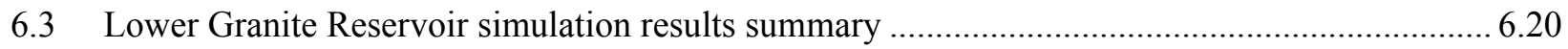

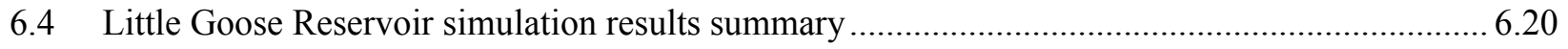

6.5 Lower Monumental Reservoir simulation results summary ................................................. 6.20

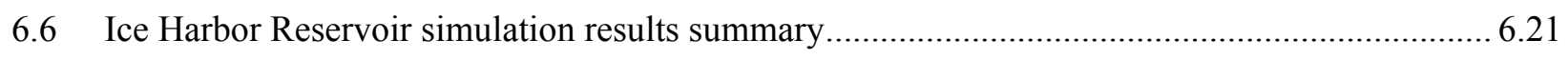

7.1 Migration rates for Little Goose Reservoir ..................................................................... 7.9

7.2 FINS-computed ensemble median particle information for all groups.................................... 7.11

7.3 FINS-Computed Median Particle Information: Little Goose Management Scenario................... 7.11 


\subsection{Introduction}

This report documents a four-year study to assess the impacts of cold water releases from Dworshak Reservoir on the lower Snake River system during periods of juvenile fall Chinook salmon (Oncorhynchus tshawytscha) migration. The work was conducted for the Bonneville Power Administration, U.S. Department of Energy, by the Pacific Northwest National Laboratory. In this report, emphasis is placed on the methodology and results associated with the second, third, and fourth years of the study. However, results are compared with findings across all project years to provide a comprehensive project summary. Methodologies employed during the first year are reported in Cook et al. (2003).

The objectives of this multiyear research project were to

- Determine via in situ monitoring (collected collaboratively by PNNL and others) the hydrodynamic characteristics of the four lower Snake River reservoirs during periods of juvenile fall Chinook salmon migration and covering the period proceeding, during, and after release of cold hypolimnetic water from Dworshak Dam.

- Develop hydrodynamic and water quality models that successfully reproduce the stratified, transient, and wind-driven circulation patterns in the four lower Snake River reservoirs during periods of juvenile fall Chinook salmon migration.

- Demonstrate the ability of these models (hydrodynamic, water quality, and post-processing) to produce reservoir-integrated metrics for comparison of alternative river management scenarios on the lower Snake River for future use by fisheries and river managers.

The suite of applied numerical models used during this project was developed in collaboration with a multi-agency group organized under Reasonable and Prudent Alternative 143 (RPA143) of the NOAA Fisheries 2000 Biological Opinion (Federal Columbia River Power System [FCRPS] 2000). Hydrodynamic and water quality data collection and dissemination also were coordinated under the RPA143 group. For example, under this project, field data were collected primarily in Lower Granite Reservoir, while separate efforts by the U.S. Army Corps of Engineers focused mainly on the reservoirs downstream of Lower Granite Reservoir. Collected data were shared immediately following the field season and were used by this project to validate numerical models downstream of Lower Granite Reservoir. The RPA143 group consists of representatives from most federal and state agencies involved with power generation, fisheries, and water quality management of the lower Snake River. RPA143 states

the Action Agencies shall develop and coordinate with NOAA Fisheries and EPA on a plan to model the water temperature effects of alternative Snake River operations. The modeling plan shall include a temperature data collection strategy developed in consultation with EPA, NOAA Fisheries and state and tribal water-quality agencies. The data collection strategy shall be sufficient to develop and operate the model and to document the effects of project operations.

Information generated by this study also helps meet RPA141 of the 2000 Biological Opinion (FCRPS 2000) as well. RPA 141 states "The Action Agencies shall evaluate juvenile fish condition due to disease 
in relation to high temperature impacts during critical migration periods. This evaluation should include monitoring summer migrants at lower Columbia and lower Snake river dams to clarify the possible link between temperature and fish disease and mortality. This information will be used to assess the long-term impacts of water temperature on juvenile fish survival." This project addresses this RPA by collecting water temperature data in Lower Granite Reservoir during periods of juvenile fall Chinook salmon migration. It also addresses the RPA by relating this data back to numerical models, which can then be used to generate reservoir-integrated metrics to compute how various management alternates impact the reservoir environment.

In this report, Chapter 2 provides detailed background on the Snake River basin and lower Snake River. Chapter 3 documents the PNNL field monitoring program in Lower Granite Reservoir. Current structure of Lower Granite Reservoir and how it was modeled three-dimensionally are detailed in Chapter 4. Chapter 5 provides information on the general current structure of the lower Snake River. In Chapter 6, two-dimensional hydrodynamic and water quality modeling of the lower Snake River are described in detail. Management scenarios and reservoir-integrated metrics computed using the FINS computer program are presented in Chapter 7. Conclusions and recommendations based on this study are provided in Chapter 8, followed by the references list in Chapter 9. Appendixes A through D provide detailed data collected during the study. 


\subsection{Background}

Construction of numerous hydroelectric dams within the Snake River basin has altered the thermal and hydraulic regime of the river for hundreds of kilometers. According to the National Marine Fisheries Service (NMFS), altered water temperatures and river discharges associated with operation of these dams, plus habitat loss and high mortality from harvest activities, were found to threaten and impact survival of fall Chinook salmon in the Snake River basin (NMFS 2004). Upper Snake River reaches near Marshing, Idaho, that were once historical spawning and rearing habitats were eliminated by the construction of Brownlee, Oxbow, and Hells Canyon dams (Groves and Chandler 1999; Connor et al. 2002). Juvenile fall Chinook salmon currently must migrate through kilometers of lower-velocity reservoirs instead of a higher-velocity free-flowing river to reach the Pacific Ocean. The NMFS was petitioned in the 1990s to list Snake River fall Chinook salmon under the Endangered Species Act, and from 1992 until today, the species status has been considered threatened (NMFS 1992).

The lower Snake River is today a series of reservoirs formed by Lower Granite, Little Goose, Lower Monumental, and Ice Harbor dams (see Figure 2.1). These dams, built in the 1960s and 1970s by the U.S. Army Corps of Engineers (USACE), have created lower Snake River conditions drastically different from those under which indigenous anadronmous fall Chinook salmon evolved. Alterations in flow velocity and water temperature due to existence and operation of the dams are difficult to quantify except from limited datasets such as those of Mains and Smith (1964). Their data, collected during the spring and summer of 1954 and 1955, show that the free-flowing currents at Central Ferry (approximately halfway between Little Goose and Lower Granite dams) were much higher than reservoir conditions experience today and ranged from 0.4 to $1.5 \mathrm{~m} / \mathrm{s}(1.4$ to $4.8 \mathrm{ft} / \mathrm{s})$ at low discharge $\left(476 \mathrm{~m}^{3} / \mathrm{s}\right.$ or $\left.16,800 \mathrm{cfs}\right)$ to 2.3 to $3.3 \mathrm{~m} / \mathrm{s}(7.7$ to $10.8 \mathrm{ft} / \mathrm{s})$ at high discharge $\left(5530 \mathrm{~m}^{3} / \mathrm{s}\right.$ or $\left.195,400 \mathrm{cfs}\right)$.

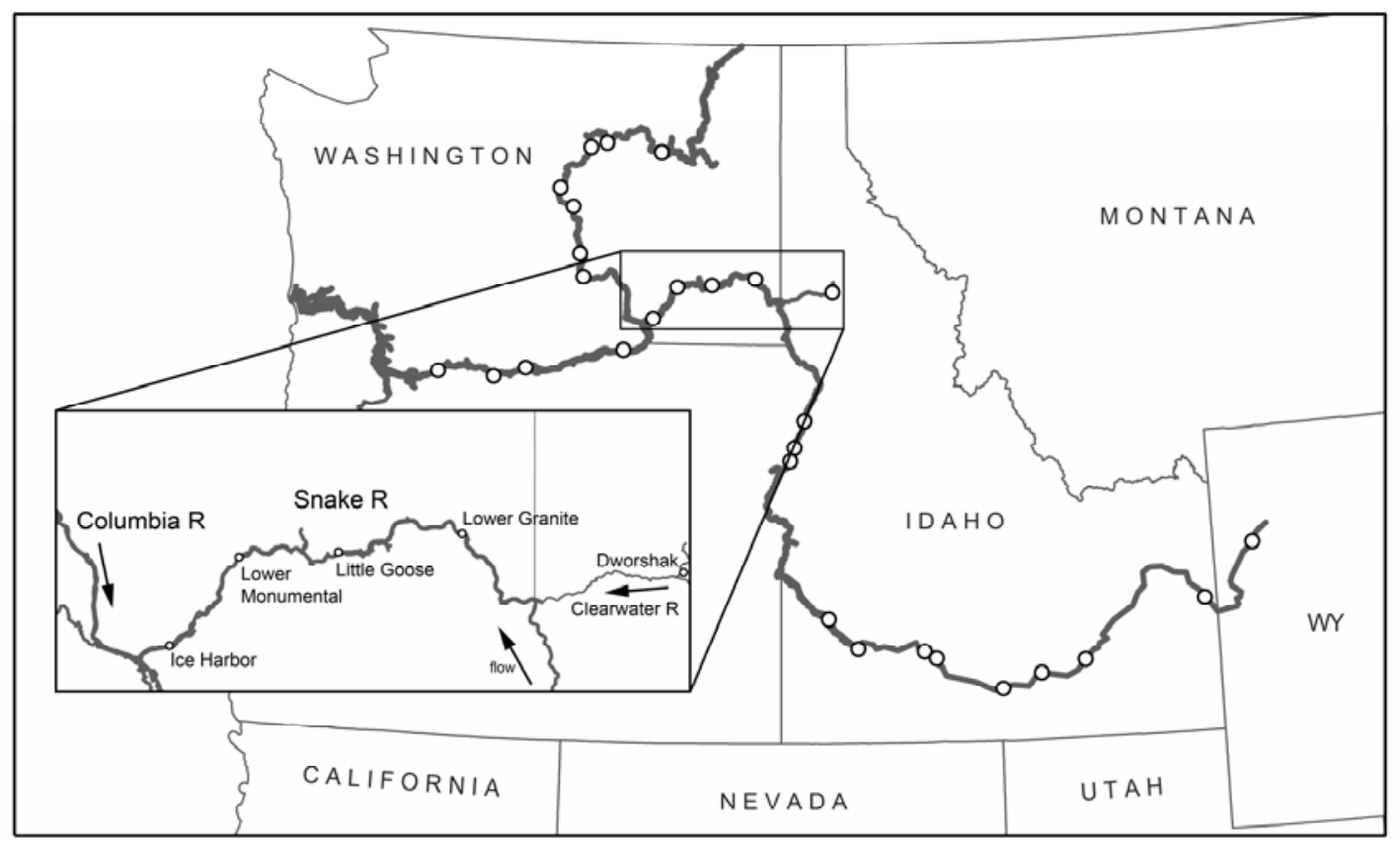

Figure 2.1. Location of the Clearwater River, Snake River, and lower Snake River dams 
Summer flow augmentation is typically implemented from late June/early July through September from Dworshak Reservoir to increase water velocities and decrease water temperatures in Lower Granite (LWG) Reservoir when juvenile fall Chinook salmon are rearing and migrating seaward. The later part of the summer flow augmentation also corresponds with adult fall Chinook salmon and steelhead movements into the Lower Snake River system. Historical profiles of water temperatures just upstream of Lower Granite Dam show that the water column remains stratified through the augmentation period because releases from Dworshak Reservoir are below equilibrium temperature. Before this study, little was known regarding the three-dimensional (3D) water velocity and temperature variations downstream of the confluence of the Snake and Clearwater rivers and how this thermal stratification is maintained in the reservoirs downstream of the confluence.

\subsection{Flow Augmentation from Dworshak Reservoir}

Hypolimnetic releases from Dworshak Dam have been used for the past decade to augment river flows in the lower Clearwater and Snake rivers and to decrease water temperatures in the lower Snake River during the summer months. Conflicting interests over these releases include the quantity of augmentation flow, temperature of the release, release timing, and duration of the release, including extending releases into the autumn.

Dworshak Dam's penstock intakes are equipped with adjustable gates for selective withdrawal of water between full pool (1,600 ft [487.7 m] MSL) and minimum pool (1,445 ft [440.4 m] MSL) elevations (USACE 1986). The selector gate withdrawal system is used to discharge water at a temperature suitable for fish production at the downstream Dworshak National Fish Hatchery. The selector gate system is also responsible for providing the majority of the cold water releases during flow augmentation, although the power intakes have a hydraulic capacity of $74 \mathrm{~m}^{3} / \mathrm{s}(2,600 \mathrm{cfs})$ for each of the two 90 -MW turbine units and $170 \mathrm{~m}^{3} / \mathrm{s}(6,000 \mathrm{cfs})$ for the 220 -MW unit (i.e., the total capacity is $\left.317 \mathrm{~m}^{3} / \mathrm{s}(11,200 \mathrm{cfs})\right)$. Water can also be released from Dworshak Dam via the spillway if the reservoir water surface elevation is above $1,545 \mathrm{ft}(470.9 \mathrm{~m})$ (spillway crest). If the elevation is below the spillway crest, or if colder hypolimnetic water is desired, water can be released via the low level regulating outlets (elevation 1,372 ft [418.2 m]) however the release temperature cannot be controlled.

The amount of cold water available from Dworshak Dam for flow augmentation has been decided by arbitration to be volume of water in the reservoir between elevation 1,600 ft (487.7 m) MSL (full pool) and 1,520 $\mathrm{ft}(463.3 \mathrm{~m}) \mathrm{MSL}$. This volume is approximately 1.2 million acre-feet ( 1.5 billion $\left.\mathrm{m}^{3}\right)$; however, it should be noted that it is not the total volume of cold water available in the reservoir during the summer months. Figure 2.2 displays profiles of water temperature near the dam in mid July and the end of September for 2004 and 2005. Because water can be withdrawn from the low-level regulating outlets until elevation 1,372 ft (418.2 m), additional hypolimnetic releases could have occurred past elevation $1,520 \mathrm{ft}(463.3 \mathrm{~m})$.

During the past 10 years, Dworshak Dam has been operated so that the reservoir is at full pool $(1,600 \mathrm{ft}[487.7 \mathrm{~m}])$ by the beginning of July and then drafted to the 1,520 $\mathrm{ft}$ (463.3 $\mathrm{m}$ ) elevation by early September (Figure 2.3). During the same period, scroll case water temperatures generally ranged between 6 and $12^{\circ} \mathrm{C}$. 


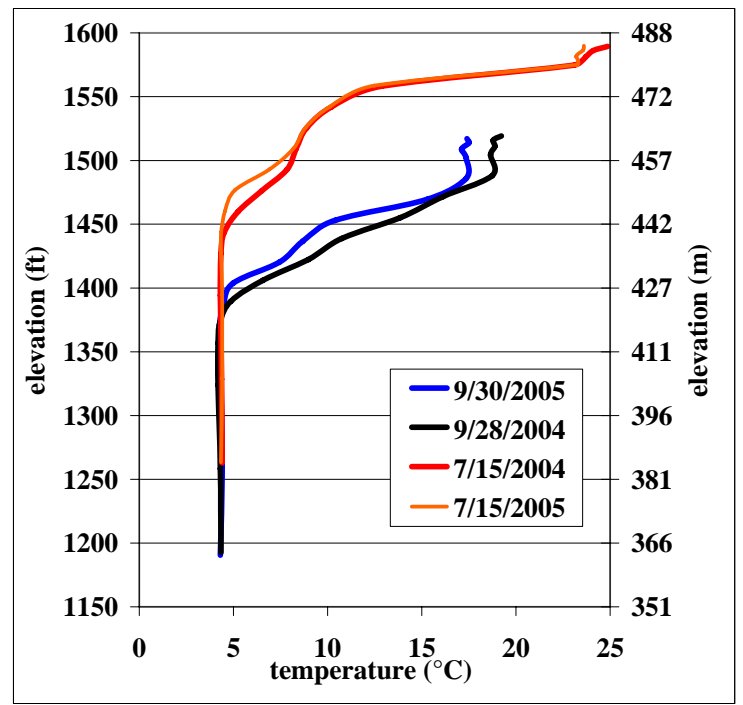

Figure 2.2. Water temperature profiles collected in Dworshak Dam forebay (Source: USACE 2005)

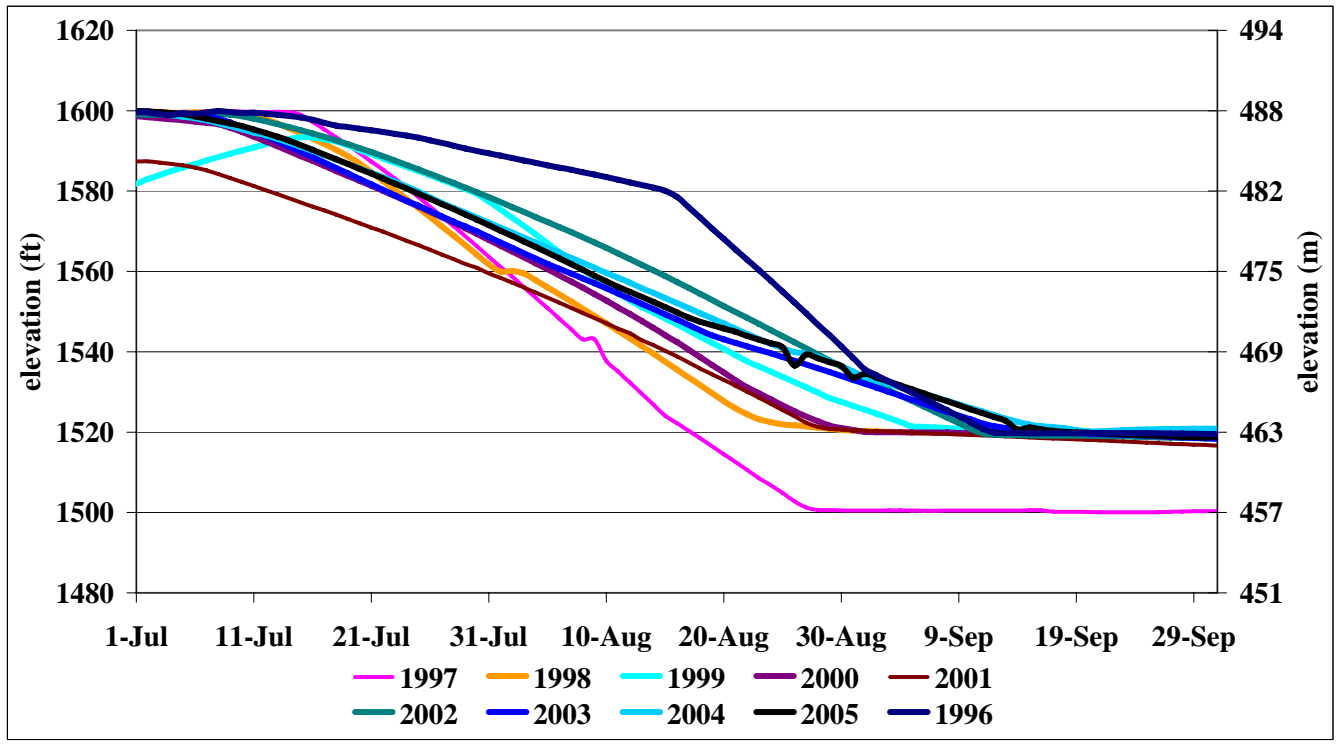

Figure 2.3. D Dorshak Reservoir summer water surface elevations (Source: DART 2005)

For the past several years, System Operational Requests (SORs) have been written by a team of state, federal, and tribal salmon managers requesting flow augmentation from Dworshak Dam. The SOR for 2005 operation of Dworshak Reservoir during the juvenile migration season was as follows (SOR 2005):

Continue outflows of $7 \mathrm{Kcfs}$ [198.22 $\left.\mathrm{m}^{3} / \mathrm{s}\right]$ at Dworshak through July 10, 2005, however, after July 7, 2005, increase outflows at Dworshak to $10 \mathrm{Kcfs}\left[183.17 \mathrm{~m}^{3} / \mathrm{s}\right]$ if temperatures at Lower Granite [tailrace] exceed $67^{\circ} \mathrm{F}\left(19.4^{\circ} \mathrm{C}\right)$ on a $24-\mathrm{hr}$ rolling average. On July 11,2005 , increase outflows to $10 \mathrm{Kcfs}\left[183.17 \mathrm{~m}^{3} / \mathrm{s}\right]$ until further notice. Continue to target $46-48^{\circ} \mathrm{F}\left[7.8\right.$ to $8.9^{\circ} \mathrm{C}$ ] outflow water temperature over the specified time.

This request was justified by the following research outcomes (SOR 2005): 
In the compilation of travel time and survival data by NOAA Fisheries 'Travel Time/Survival White Paper' (March 2000), NOAA Fisheries concludes that 'Estimated survival probability from release points in the Snake River Basin to Lower Granite Dam was significantly correlated with flow, water temperature and turbidity.' NOAA Fisheries also concludes that the high correlation among variables precludes the determination of effects of these variables individually. A flow travel time relationship has been established for sub-yearling chinook migrants. The flow travel time relationship has been confirmed consistently in various studies and monitoring programs. Recent information (Connor 2003a) has shown statistically significant relations between flow, temperature and survival for sub-yearling fall chinook.

Historical passage timing and distribution of fall chinook data show that $90 \%$ of the wild Chinook passage at Lower Granite occurs prior to August 30 and $97 \%$ of hatchery sub-yearling fall chinook of Clearwater and Snake River origin pass Lower Granite Dam prior to August 30. This dataset comprises fish of primarily Snake River origin. The limited data available for the Clearwater population indicate they pass Lower Granite Dam at a later date.

The SOR was also justified by stating that temperature is an important factor for migrating juveniles (see Section 2.3 of this report) and, for the lower Snake River, migration conditions for wild sub-yearling Snake River fall Chinook are improved by both increasing river discharge and lowering water temperature (SOR 2005). Higher summer flows were noted in the SOR to generally decrease Lower Granite Reservoir temperatures, depending on the ratio of cool Dworshak Dam discharge to the warmer upper Snake River discharge, which was also confirmed by research documented in this report.

\subsection{Load-Following Operation of the Lower Snake River Dams}

The Action Agencies, consisting of the Corps of Engineers, Bureau of Reclamation, and BPA, prepare a Water Management Plan each year for the Federal Columbia River Power System. As discussed in the 2005 Water Management Plan (2005), the four lower Snake River reservoirs are generally operated during the spring and summer salmon season within $1 \mathrm{ft}$ of the minimum operating pool (MOP) to increase the mean river velocity and hence reduce juvenile migration time.

Load following is the natural product of operating a cascade of hydroelectric dams with little inreservoir storage (i.e., run-of-river) to maximum profit. In reservoir systems where the forebay operating range is limited (e.g., within $1 \mathrm{ft}(0.3 \mathrm{~m})$ of MOP for the lower Snake River), the most upstream reservoir discharges all its inflow plus some forebay draft during daytime hours to maximize profit from hydroelectric power generation. Each hydroelectric dam downstream is operated in a similar manner. As one goes downstream, the inflow from each dam in the cascade then becomes progressively larger because of the daytime forebay draft that is then added from each upstream project. During nighttime, all reservoirs are refilled and the inverse operation occurs where the most downstream project must discharge the minimum amount of outflow in order to refill in time for the next cycle to begin. The load following process therefore shapes the outflow hydrograph from each dam in the cascade, with the largest variation of discharge amplitude occurring at the most downstream project.

The series of three graphics in Figures 2.4 through 2.6 illustrates the effects of load following on the lower Snake River reservoir system from July 15 to 25, 2002. Figure 2.4 displays discharge in the major 


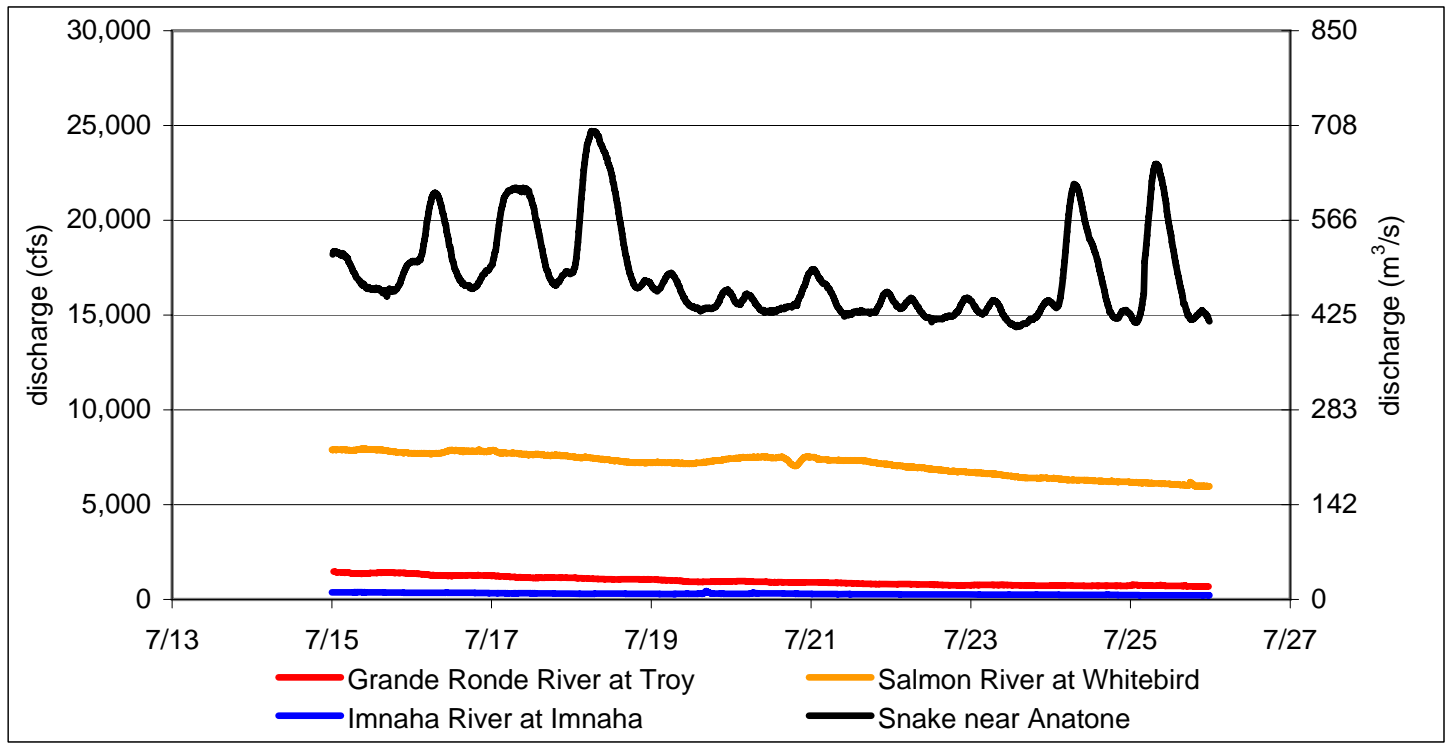

Figure 2.4. Discharge hydrographs for the middle Snake River (Anatone) and major tributaries that enter the middle Snake River upstream between Anatone and the Hells Canyon Complex from July 15 to 25,2002

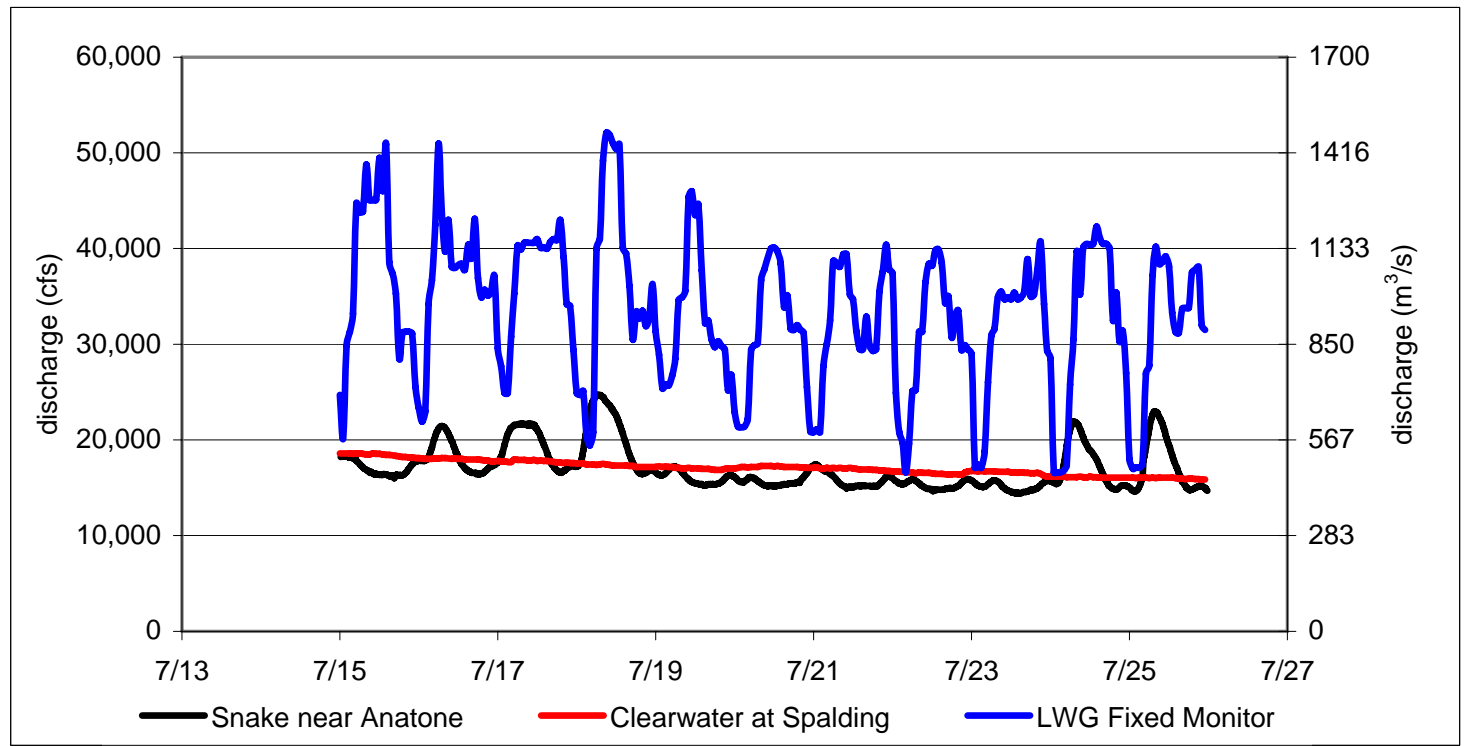

Figure 2.5. Discharge hydrographs for the middle Snake River (Anatone), Clearwater River upstream of Lower Granite Reservoir, and the lower Snake River at Lower Granite Dam (LWG) from July 15 to 25,2002 


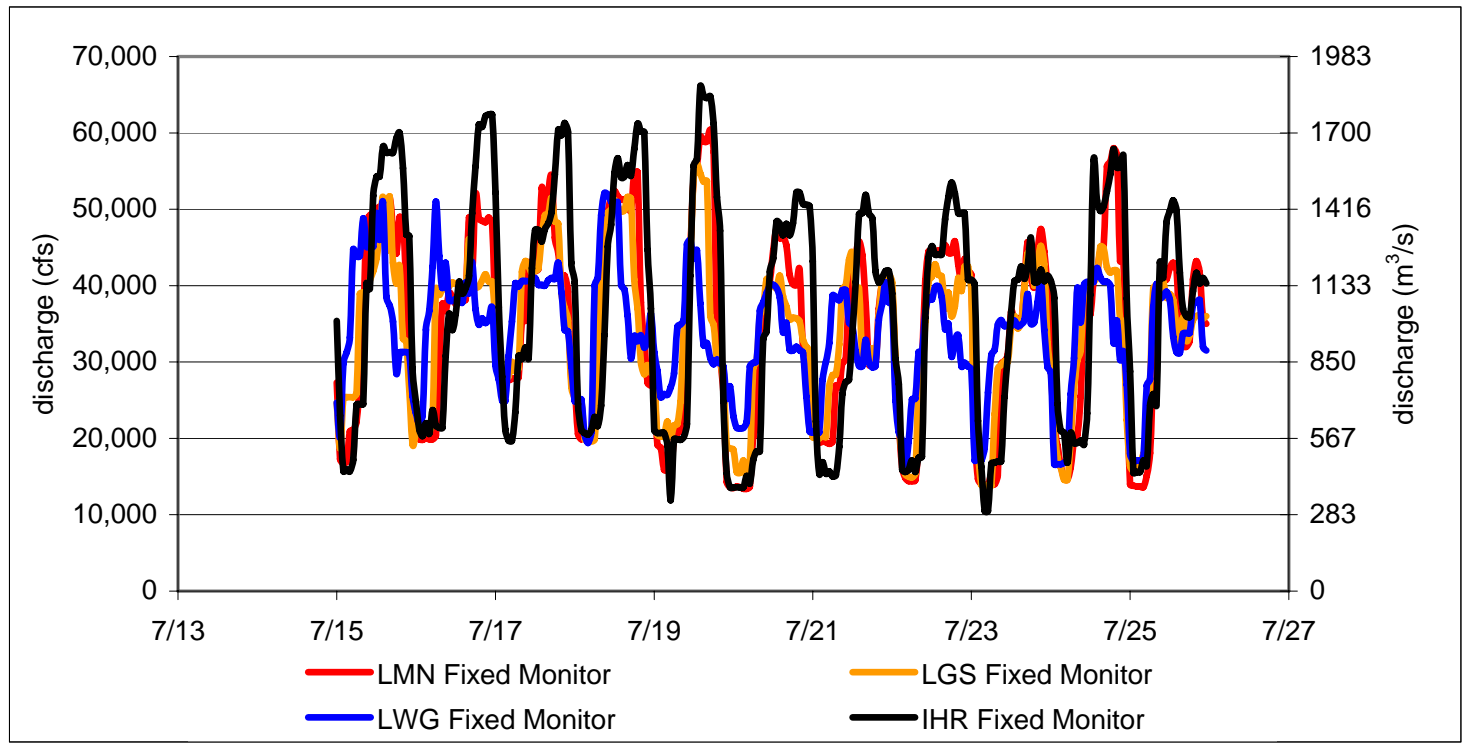

Figure 2.6. Discharge hydrographs for the lower Snake River. Note the increase in discharge amplitude traveling downstream from Lower Granite (smallest) to Ice Harbor (largest) from July 15 to $25,2002$.

Snake River tributaries between the Hells Canyon Complex and Anatone. Both the Imnaha River and Grand Ronde River contribute less discharge to the Snake River than the Salmon River during this period. At Anatone, variations in outflow from the Hells Canyon Complex are clearly visible in the hydrograph and vary daily during this period by up to $10 \mathrm{kcfs}\left(280 \mathrm{~m}^{3} / \mathrm{s}\right)$.

Continuing downstream and into Lower Granite Reservoir, Figure 2.5 compares discharge measured in the Snake River at Anatone with discharge in the lower Clearwater River just upstream of Lower Granite Reservoir. During this period of 2002, flows in the two rivers were approximately equal in magnitude; however, in 2003 and 2004, Snake River discharge at Anatone was generally larger. Because only minor groundwater and municipal outflows contribute to Lower Granite Reservoir downstream of Anatone and Spalding, the outflows from Lower Granite Dam without load following and a constant forebay elevation would be expected to follow the sum of the discharges at Anatone and Spalding. As Figure 2.5 shows, the actual outflow hydrograph from the dam varies by 20 to $30 \mathrm{kcfs}$ ( 560 to $850 \mathrm{~m}^{3} / \mathrm{s}$ ) during most days, with maximum outflows generally occurring during the afternoon and minimums outflows occurring a few hours after midnight.

Load following operations in the downstream reservoirs can be seen by examining Figure 2.6. The blue line, as in Figure 2.5, displays the magnitude of outflows from Lower Granite Dam. As one goes downstream through the system, maximum and minimum outflows from each dam downstream generally occur at the same time in each reservoir. However, the difference between daily maximum and minimum increases with each dam through the series.

It should also be noted that at MOP, the volume contained within $1 \mathrm{ft}$ of elevation rise for each lower Snake reservoir is approximately the same: $L W G=8,720$ acre- $\mathrm{ft}\left(1.1 \times 10^{7} \mathrm{~m}^{3}\right)$; LGS $=9,780$ acre-ft $\left(1.2 \times 10^{7} \mathrm{~m}^{3}\right) ; \mathrm{LMN}=6,667$ acre-ft $\left(8.2 \times 10^{6} \mathrm{~m}^{3}\right)$, and IHR $=8,300$ acre-ft $\left(1.0 \times 10^{7} \mathrm{~m}^{3}\right)$. Therefore, because the volumes available for load following draft are approximately equal, optimal load following 
oscillations induced by an upstream reservoir cannot be fully damped out by any one of the downstream reservoirs in the lower Snake River. Smaller load following oscillations induced by one of the upstream reservoirs may be able to be damped out by a single downstream reservoir if only part of the draft volume of the upstream reservoir was used.

\subsection{Juvenile Chinook Salmon: Upper Temperature Limits and Water Quality Standards}

Water temperature can significantly impact the health and survival of salmon, which are poikilothermic (cold-blooded). Brett (1952) studied thermal resistance of five species of juvenile salmon, including spring Chinook salmon. In this study, different groups of fish were acclimated to temperatures ranging from 5 to $24^{\circ} \mathrm{C}$ and then exposed to higher water temperatures until a minimum of $50 \%$ of the population died. Groups acclimated between 15 and $24^{\circ} \mathrm{C}$ were reported to resist water temperatures between 24.5 and $25^{\circ} \mathrm{C}$. Fish acclimated at $10^{\circ} \mathrm{C}$, however, were reported to only resist water temperatures between 24 and $24.5^{\circ} \mathrm{C}$, and for fish acclimated at $5^{\circ} \mathrm{C}$ the upper thermal limit was even lower at 22 to $22.5^{\circ} \mathrm{C}$.

Coutant (1973) conducted laboratory experiments with juvenile Chinook salmon and rainbow trout that were being thermally shocked at lethal and sub-lethal temperatures with different exposure times. When being exposed to sub-lethal temperatures, their recovery was studied as well as their behavior and survival around predators. Coutant (1973) determined that juvenile Chinook salmon were selectively preyed on after being exposed to temperatures between 26 and $30^{\circ} \mathrm{C}$ at $10 \%$ of the duration that caused obvious loss of equilibrium. Although most fish regained equilibrium on return to cooler water, their behavior remained abnormal. They exhibited disorientation, erratic bursts of swimming activity, and often an unnatural posture, which probably caused rapid discovery by the predators. Shocked fish showed some recovery from heat effects when returned to the initial temperature for 0.5 or 1 hour. A few fish, which were transferred to heated water temperature, did not show symptoms of loss of equilibrium but did so when returned to the holding temperature, experiencing a "cold shock."

McMichael et al. (1999) studied predation in the lower Yakima River in the 1997 and 1998 by three primary fish species on salmonids. Their results demonstrate a strong correlation between water temperature and predation. For example, a decrease of water temperature by $2^{\circ} \mathrm{C}$ would reduce salmonid losses to smallmouth bass by $23 \%$ in the Benton Reach due to lower metabolic rates and higher meal turnover times. Digestion rates of channel catfish (Ictalurus punctatus) and northern pikeminnow (Ptychoceilus oregonenis) would be similarly affected and would lead to similar results.

Chinook salmon exposed to higher water temperature may also experience a higher level of stress. Associated with this stress is a greater likelihood that disease will be able to overcome the host's defense systems and create a serious illness (Hicks 2002).

For this and other reasons, the water quality standards detailed in the Washington Administrative Code (WAC) includes the following for the lower Snake River: "Temperature shall not exceed a 1-DMax of $20.0^{\circ} \mathrm{C}$ due to human activities. When natural conditions exceed a 1-DMax of $20.0^{\circ} \mathrm{C}$, no temperature increase will be allowed which will raise the receiving water temperature by greater than $0.3^{\circ} \mathrm{C}$; nor shall such temperature increases, at any time, exceed $t=34 /(T+9)$." " $T$ " represents the background 
temperature as measured at a point or points unaffected by the discharge and representative of the highest ambient water temperature in the vicinity of the discharge, and "1-DMax" or "1-day maximum temperature" is defined as the highest water temperature reached on any given day. Depth of the measurement within the water column is not discussed. This measure can be obtained using calibrated thermometers or continuous monitoring probes having sampling intervals of $30 \mathrm{~min}$ or less (WAC 1997). At the time this report was written, new water quality standards have been proposed by the Washington State Department of Ecology. Although these updated rules were proposed in 2003, they have not yet been approved by the U.S. Environmental Protection Agency. The proposed 2003 rules, however, are identical to the 1997 rules for the lower Snake River. 


\subsection{Lower Granite Reservoir: Field Monitoring Program}

Field data were collected in 2002, 2003, 2004, and 2005 in Lower Granite Reservoir. In 2002, bathymetry data were collected at the beginning of the study (June to July 2002) to fill known data gaps. More than 70 self-contained temperature loggers were deployed throughout the reservoir. Water velocity surveys were performed in August and September to gather 3D measurements at locations covering a large portion of the reservoir. Finally, a meteorological station was deployed in July on Silcott Island (Chief Timothy State Park) that continually recorded atmospheric conditions at 15-min increments and posted these data to a website in almost real time. Detailed information on 2002 field data and results can be found in Cook et al. (2003). Methods, data, and results of field seasons 2003 and 2004 are described in the sections below. A one-week intensive study was conducted in Lower Granite Reservoir during the summer 2005 to gather further data about flow direction, velocities, and water temperatures around the confluence zone. An intensive two-day study was also conducted in Little Goose and Lower Monumental Reservoirs just prior to the Lower Granite Reservoir 2005 study (Chapter 5).

\subsection{3 and 2004 Water Temperature Measurements}

Two types of instruments were used by PNNL during the study to measure water temperature: selfcontained temperature loggers and a portable conductivity-temperature-depth (CTD) probe. The majority of the temperature loggers used during the study were manufactured by the Onset Computer Corporation under the brand name Optic StowAways. These loggers have a manufacturer's stated accuracy of $\pm 0.2^{\circ} \mathrm{C}$ within the temperature range of $-5^{\circ} \mathrm{C}$ to $37^{\circ} \mathrm{C}$; however, all loggers were also confirmed to be within this specification using a constant temperature water bath both before and after deployment. Several SeaBird SBE39 temperature and pressure loggers were used in the study at various locations around the reservoir. SBE39 temperature loggers were individually calibrated by the manufacturer to be accurate within $\pm 0.002^{\circ} \mathrm{C}$ between $-5^{\circ} \mathrm{C}$ to $35^{\circ} \mathrm{C}$. SBE39 pressure sensors used for this study had a maximum depth range of 20 or $100 \mathrm{~m}$ and were calibrated to be accurate within $0.1 \mathrm{~m}$. A portable conductivity, temperature, depth (CTD) probe, manufactured by the Hydrolab-Hach Company under the brand name MiniSonde4a, was used to collect profiles of temperature during the study. The CTD probe was calibrated by the manufacturer to a stated accuracy of $\pm 0.10^{\circ} \mathrm{C}$ within the temperature range of $-5^{\circ} \mathrm{C}$ to $50^{\circ} \mathrm{C}$. The CTD probe also measured pressure (100-m water depth range, accurate to $\left.\pm 0.3 \mathrm{~m}\right)$ and specific conductance $( \pm 1 \%$ of reading $\pm 0.001 \mathrm{mS} / \mathrm{cm})$. Calibration of the specific conductance sensor was checked and/or calibrated each day in the field using standard conductivity solutions.

At each site, loggers were suspended vertically in the water column using one of two methods. The two-weight open-water method (Figure 3.1) was used at sites without bridge piers. The thalweg weight, with a subsurface buoy attached, was lowered near the deepest portion of the channel. After the weight was lowered into position, the depth of the weight was measured using the CTD probe. A SBE39 pressure sensor, mounted on the subsurface buoy, was used as a redundant measure to confirm the depth. The SBE39 data monitored vertical movements of the buoys throughout the deployment, which infrequently occurred when drag forces caused by the buoy/temperature logger line (and induced by swiftly moving water at the site) were sufficient to counteract the upward buoyancy of the subsurface buoy. Although the depth of the sensor changed slightly over time, the pattern matched the overall water 


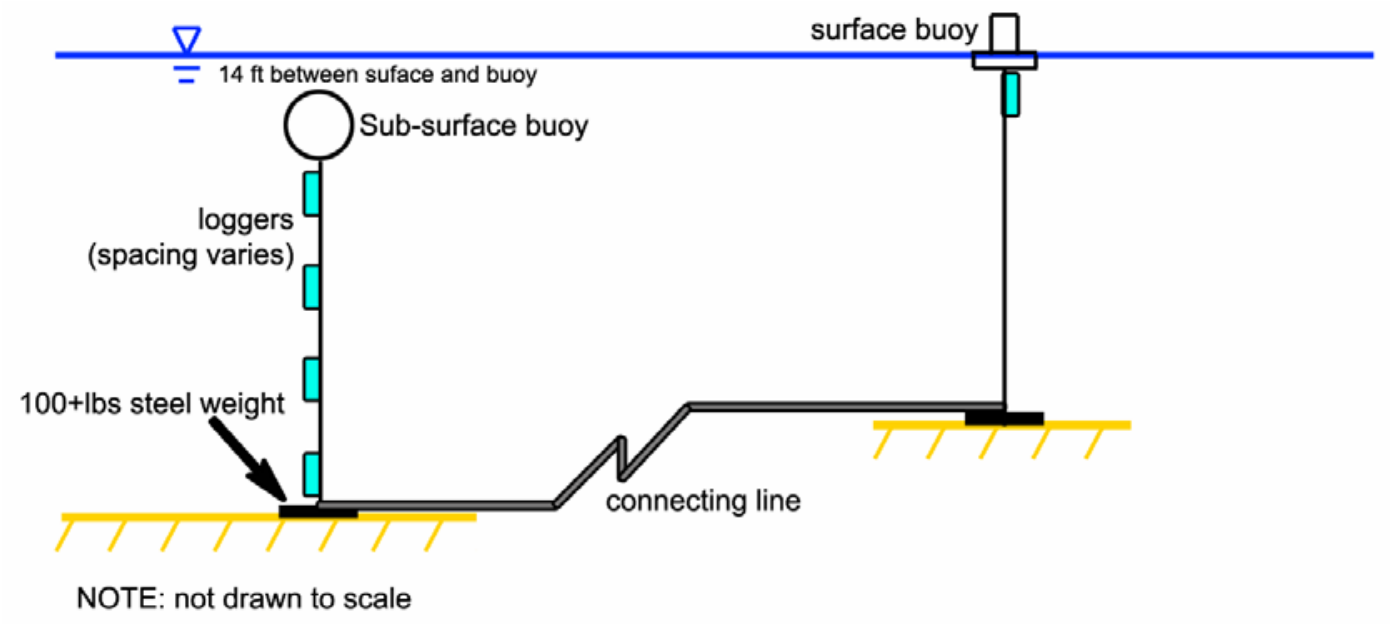

Figure 3.1. Open-water temperature logger deployment schematic

surface fluctuation of the reservoir during periods of flow augmentation (i.e., after the spring freshet). The largest difference between the CTD probe and SBE39 calculated depths was $0.3 \mathrm{~m}$. The depth of the weight was also verified by comparing CTD probe temperature profiles with the with logger data. If the weight depth was incorrect, the depth of the thermocline would not agree CTD probe and temperature logger data. At all sites and for all deployments, the error was verified to be within the accuracy of the pressure sensor.

Two lines went out from the thalweg weight (see Figure 3.1): one to a subsurface buoy that hung at least $4.3 \mathrm{~m}$ (14 ft) beneath the water surface, and a second connected an additional weight. The second weight was positioned close to shore and out of the navigation channel. This weight was also attached to second line that went up to a surface buoy. Distances between the two weights varied between $35 \mathrm{~m}$ and $145 \mathrm{~m}$; however, it was confirmed by multiple CTD probe transects across each open-water site that surface temperature differences between the subsurface and surface buoy were negligible. To simplify reporting, data gathered by the surface temperature loggers have been reported at the horizontal location of subsurface buoy.

The second deployment method was to attach temperature loggers to a wire rope, which was then secured to a bridge pier (see Figure 3.2). Only a single weight was used, and for all sites, the loggers were placed upstream of the bridge pier to minimize influence of the pier. After the weight was deployed, the depth of the weight was measured using the CTD probe. The angle of the line extending up to the bridge pier was measured before and after deployment to calculate logger depths. Bridge site logger measurements were also compared with CTD probe temperature profiles to check the agreement of isotherm depths.

In 2003, open water site (Figure 3.1) logger deployments occurred at Sites 1, 2, 3, 4, 6, and 7 (Figure 3.3). Bride pier (Figure 3.2) logger deployments occurred at Sites 5a and b (Red Wolf Bridge), 8a and b (Blue Bridge), 9 (Southway Bridge), 10 (Railroad Bridge), and 11 (Clearwater Memorial Bridge).

In 2004, open water sites logger deployments occurred at Sites 1, 2, and 3. Bridge pier logger deployments occurred at Sites 5a, 9, and 11. 


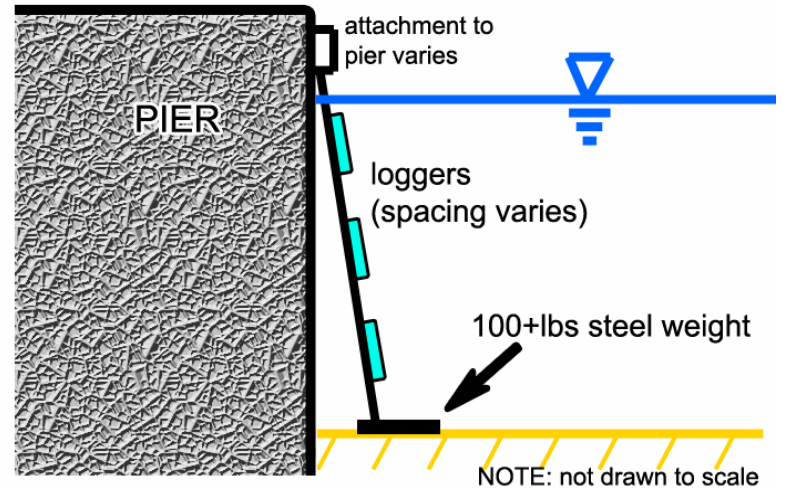

Figure 3.2. Bridge pier temperature logger deployment schematic

Time-series temperature logger data from 2003 and 2004 were released each year to the Action Agencies through coordination with the RPA143 group. Coordinate locations and graphics displaying temperature logger results from each site can be found in Appendix A.

\subsection{3 and 2004 Water Velocity Measurements}

Profiles of three-dimensional water velocity vectors (i.e., both magnitude and direction) were collected over four multi-day periods throughout Lower Granite Reservoir. The specific dates for these collections were August 22 through 24, 2002; September 4 through 6, 2002; May 14 through 16, 2003; and August 10 through 14, 2003. In addition, water velocity data were also collected in 2002 (see Cook et al. 2003) and in 2005 (see Section 3.3).

A boat mounted $600-\mathrm{kHz}$ RD Instruments ADCP was used to collect the water velocity profiles. The ADCP was programmed to collected information at depth increments of $1.0 \mathrm{~m}$ throughout the water column. In the hydraulically complex zone surrounding the Clearwater and Snake River confluence, the vertical resolution was increased, and data were collected at intervals of either 0.25 or $0.5 \mathrm{~m}$. Each velocity measurement collected by the ADCP was composed of several individual acoustic pings, which were then combined to form an ensemble average. By averaging the pings together over time, the ensemble error standard deviation due to random Doppler error can be decreased. Generally 22 pings were used to produce an associated error standard deviation of $1.5 \mathrm{~cm} / \mathrm{s}$. Ensembles were generally collected at a frequency of one reading every 6 seconds, and data were recorded for at least 10 minutes at each point.

Before data were collected in the field, the reservoir was divided into a series of cross-sections that spanned the entire reservoir. Profiles of water velocity were collected at three or four discrete points along each cross section during each of the field sampling periods. At each collection point, the following steps were followed:

1. The boat was anchored to minimize drift.

2. Horizontal position was gathered using a real-time differential global positioning system (GPS) with sub-meter accuracy.

3. Water velocity and GPS data were collected for at least $10 \mathrm{~min}$ at each point.

4. A temperature profile was collected using the CTD probe.

5. During the 10 -min period, the boat was maintained within $10 \mathrm{~m}$ of the starting location. 


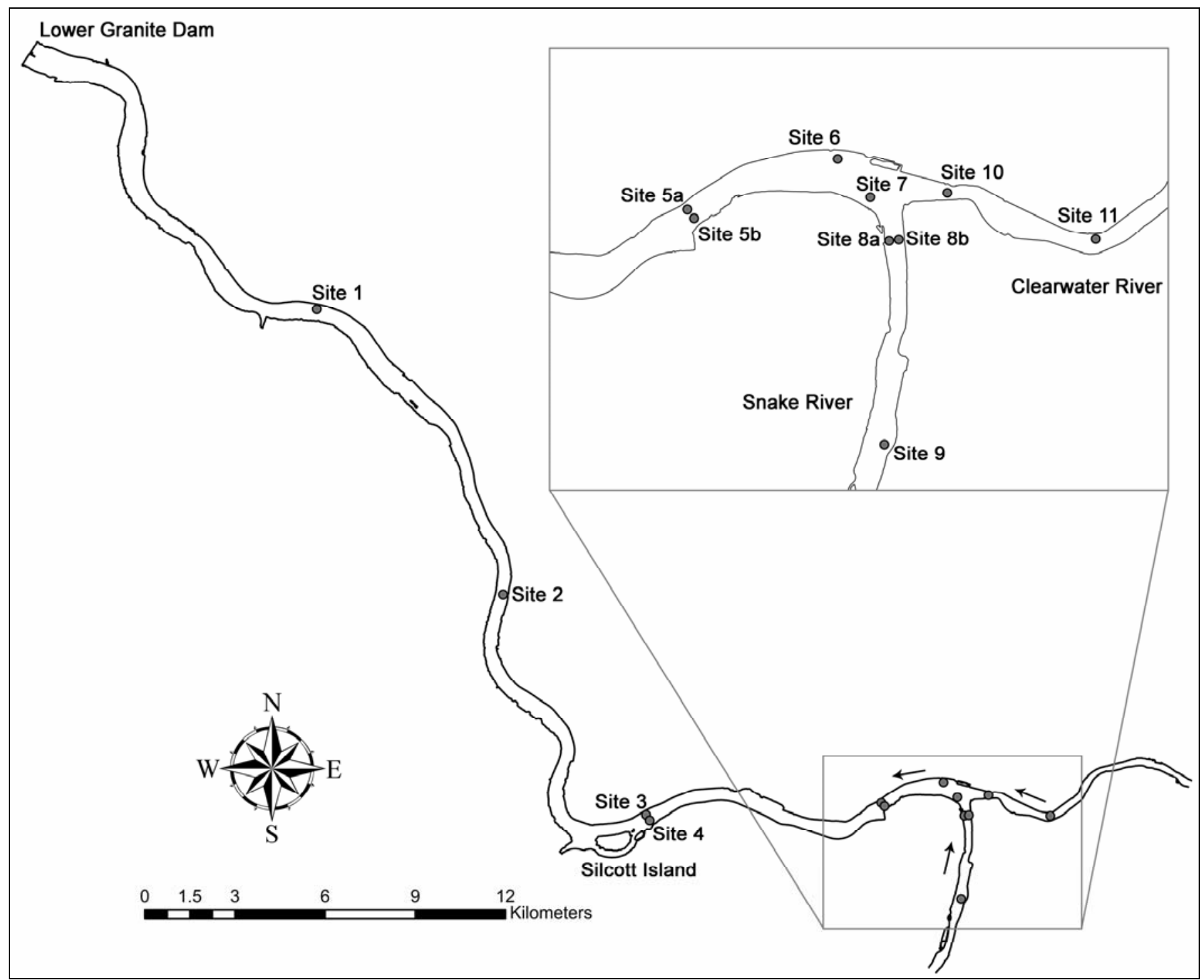

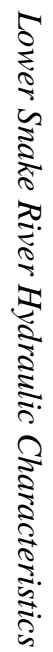

Figure 3.3. Lower Granite Reservoir water temperature measurement sites: field season 2003 


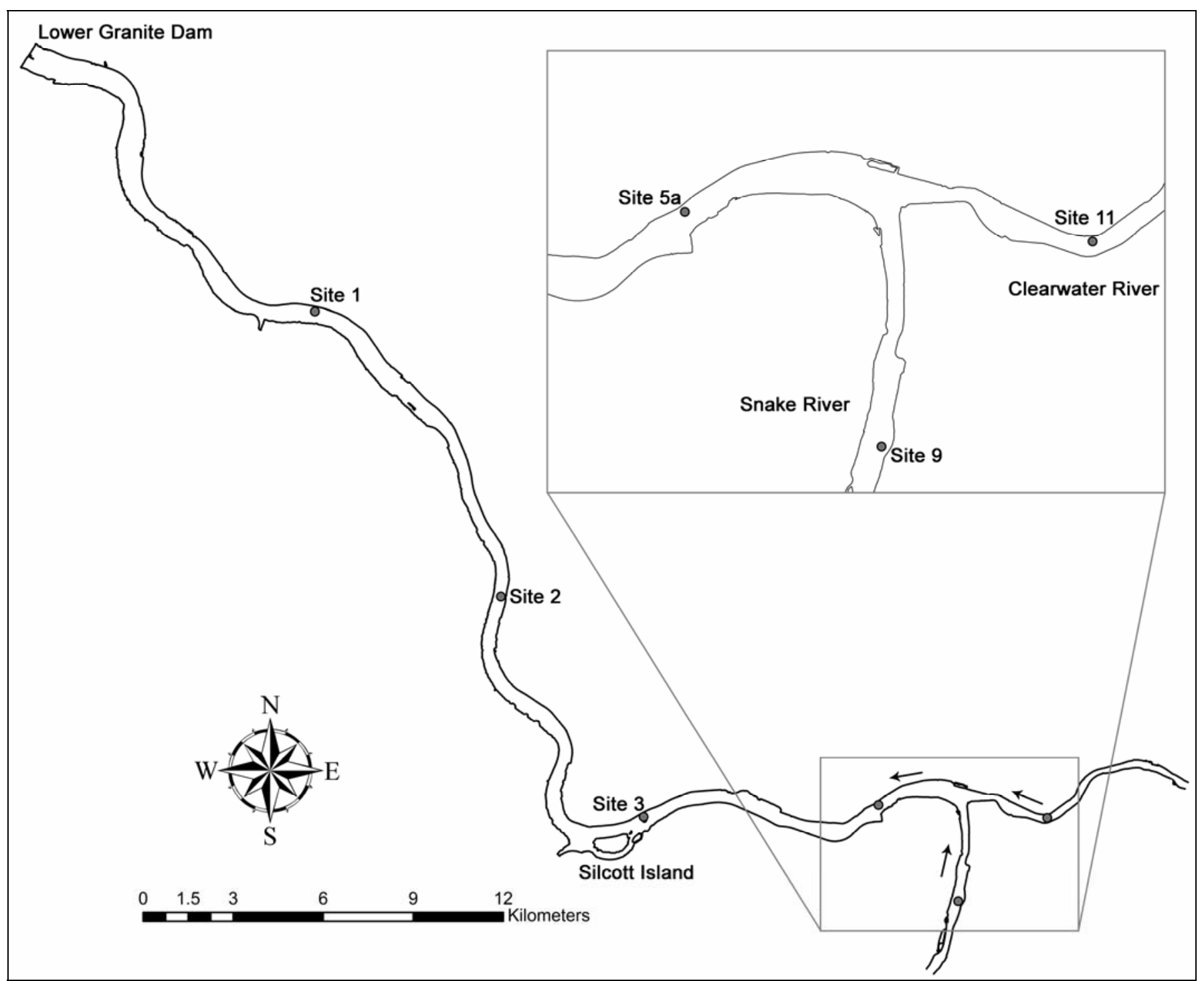

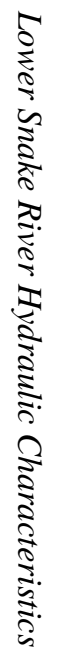

Figure 3.4. Lower Granite Reservoir water temperature measurement sites: field season 2004 
ADCP point data were processed to produce time-averaged profiles of velocity vector means and standard deviations at each collection point. Processed data were corrected to true north by applying an offset of 16.8 degrees (USGS 2002).

Summary graphics displaying results from the mobile 2003 mobile surveys are displayed in Figures 3.5 through 3.8. In May, the reservoir was only weakly stratified, and velocity differences at the confluence were minimal. This can be identified in the figure by noting that velocity vector arrows in Figure 3.6 are inline vertically at most locations. This figure should be compared to Figure 3.8, when the river was strongly stratified. Large differences in both direction and magnitude of the velocity vectors from top to bottom in the water column were noted. Unlike Figure 3.6, the arrows are no longer inline vertically, and seem to spin about the arrow's mid-point (point of the velocity measurement). Just upstream of the confluence in the Snake River, the cold water intrusion discussed in Section 4.3 (see Figure 4.10) and visualized with 3D modeling in Figure 4.21, is evident by noting the direction of bottom arrows in this zone. Several of the bottom velocity vectors are pointed upstream, however magnitudes are relatively small compare to the swiftly moving epilimnion.

Lateral transects of water velocity were collected at several locations around the reservoir as general spot checks of discharge and to examine rapid changes in hydraulic conditions near the confluence. Discharge transect lines are shown as blue lines in Figures 3.5 and 3.7.

Figure 3.9 displays a transect velocity profile collected in the vicinity of LWG Dam. The boat was driven from the left to the right shore with the ADCP mounted at the boat's gunwale, while the velocity profile was recorded over the full depth and distance with WinRiver software (RD Instruments). The blue line in the upper graphic shows the approximate location of the data collection. At the time of data collection, zero flow was passing over the spillway and $36.1 \mathrm{kcfs}$ was passing through the powerhouse. In the upper left section of the figure, a representative profile of water temperature, collected at the river's mid-point, is displayed. The reservoir was strongly stratified, with an overall temperature gradient of approximately $5^{\circ} \mathrm{C}$.

The highest velocities were observed in the hypolimnion, which is consistent with the $100 \%$ powerhouse $/ 0 \%$ spillway withdrawals. These data was collected just after a bend in the river, and the thalweg continued to bend back toward the left bank with distance downstream and toward the powerhouse. A distinct asymmetry of the high velocity zone favoring the right bank was noted, and the entire water column on the left bank side was nearly quiescent.

\subsection{Intensive Study 2005}

During the last week of July 2005, a field study was conducted to gather additional water velocity and temperature data in LWG reservoir near the confluence and to investigate a mid-pool water temperature anomaly (see Section 5.1). Profiles and transects of water velocities were also collected in the reservoirs upstream of LMN and LGS dams, and graphics displaying results from those surveys can be found in Appendix B. 


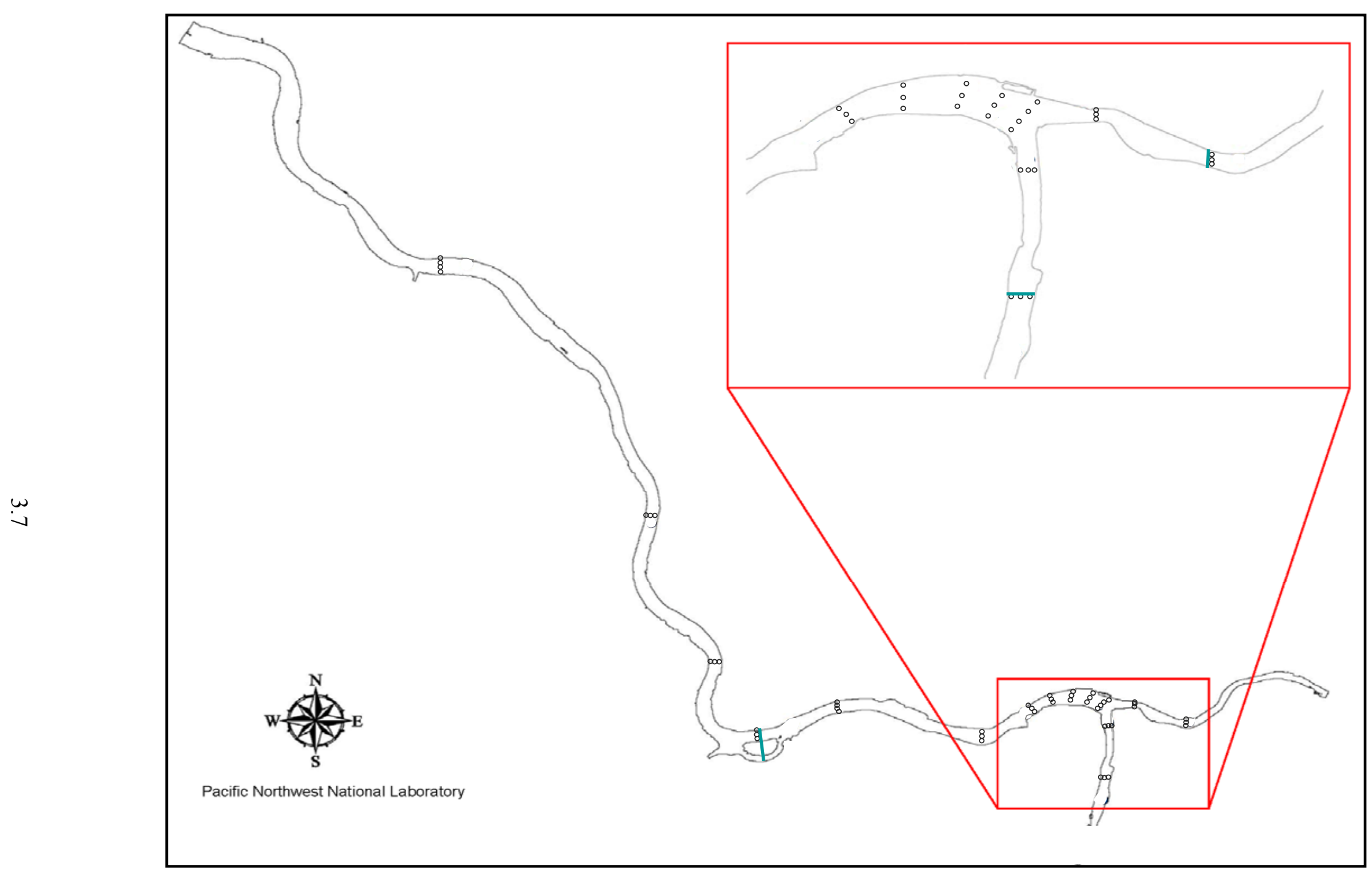

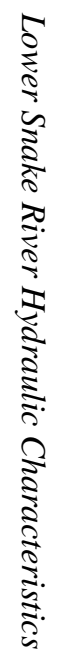

Figure 3.5 Point Velocity Measurement Sites, May 2003 


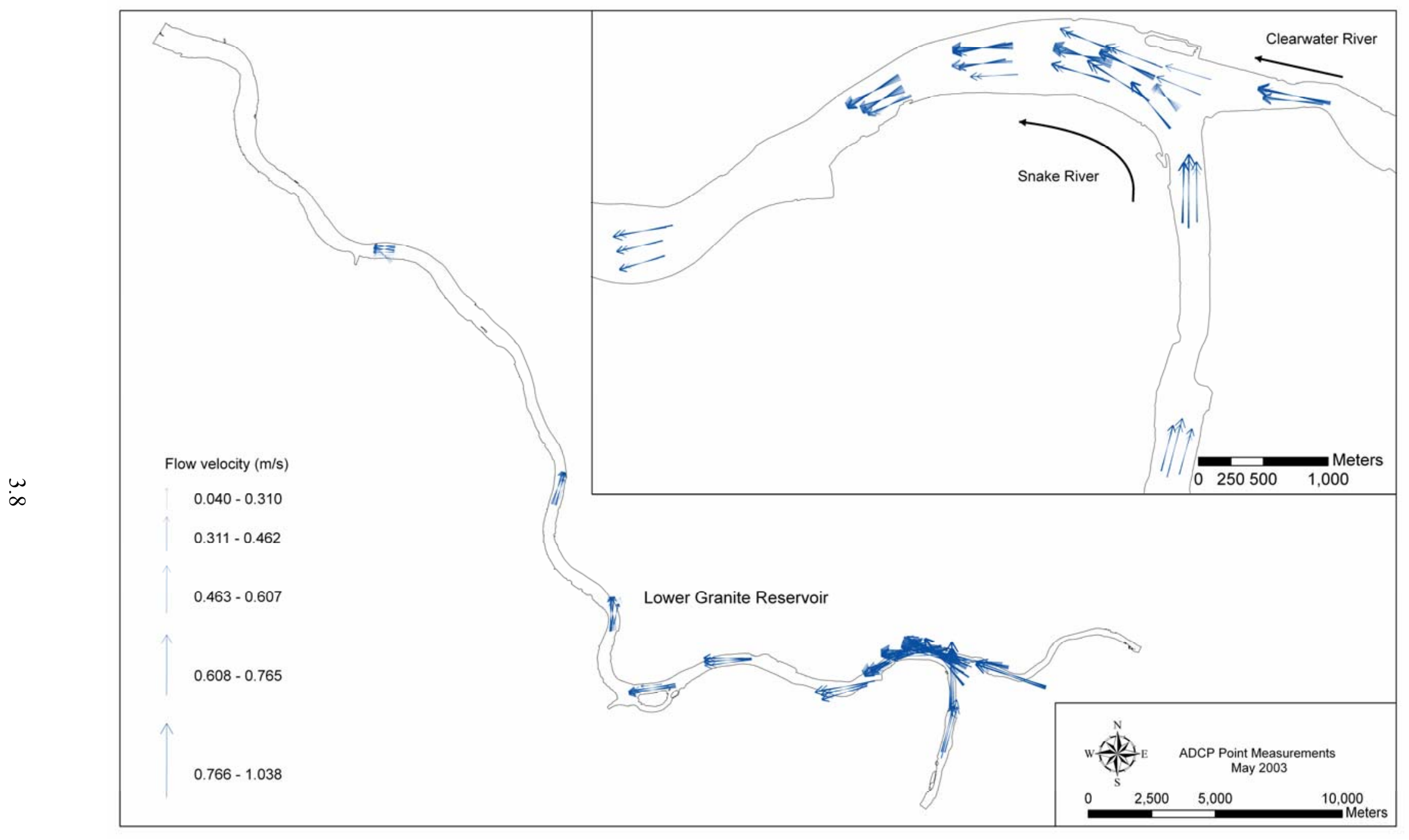

Figure 3.6. Point Velocity Measurements, May 2003 


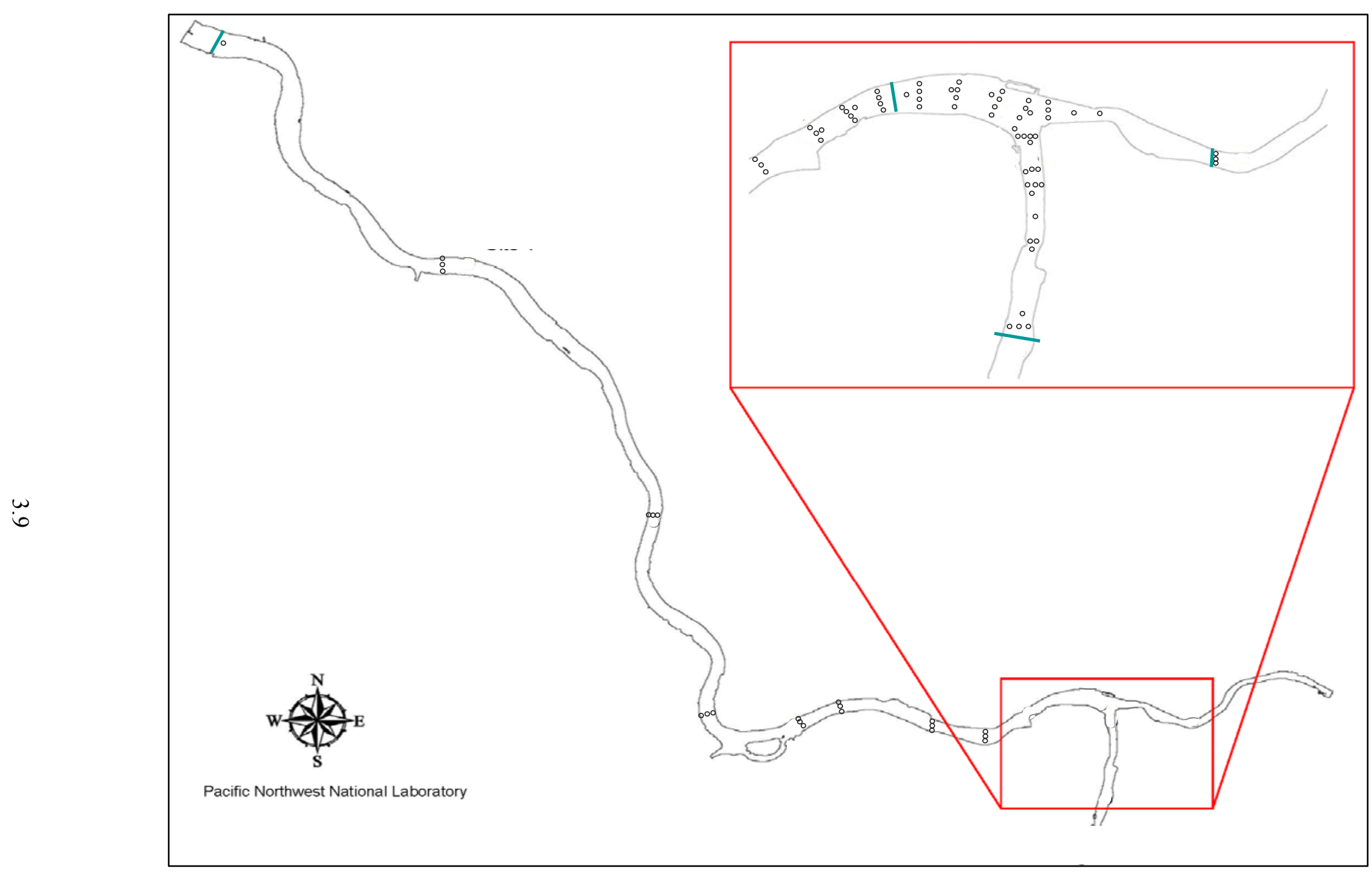

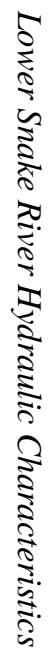

Figure 3.7. Point Velocity Measurement Sites, August 2003 


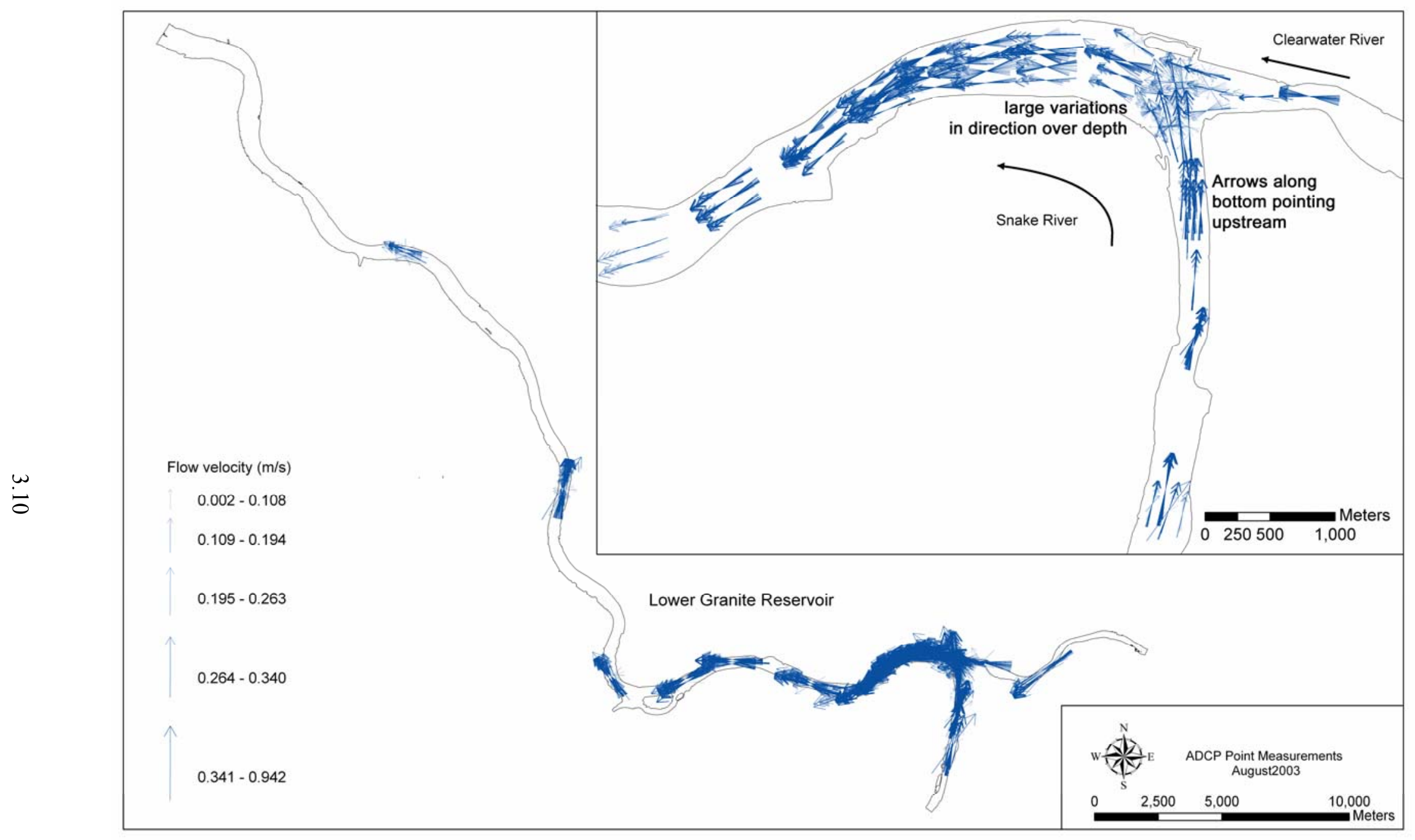

Figure 3.8. Point Velocity Measurements, August 2003 

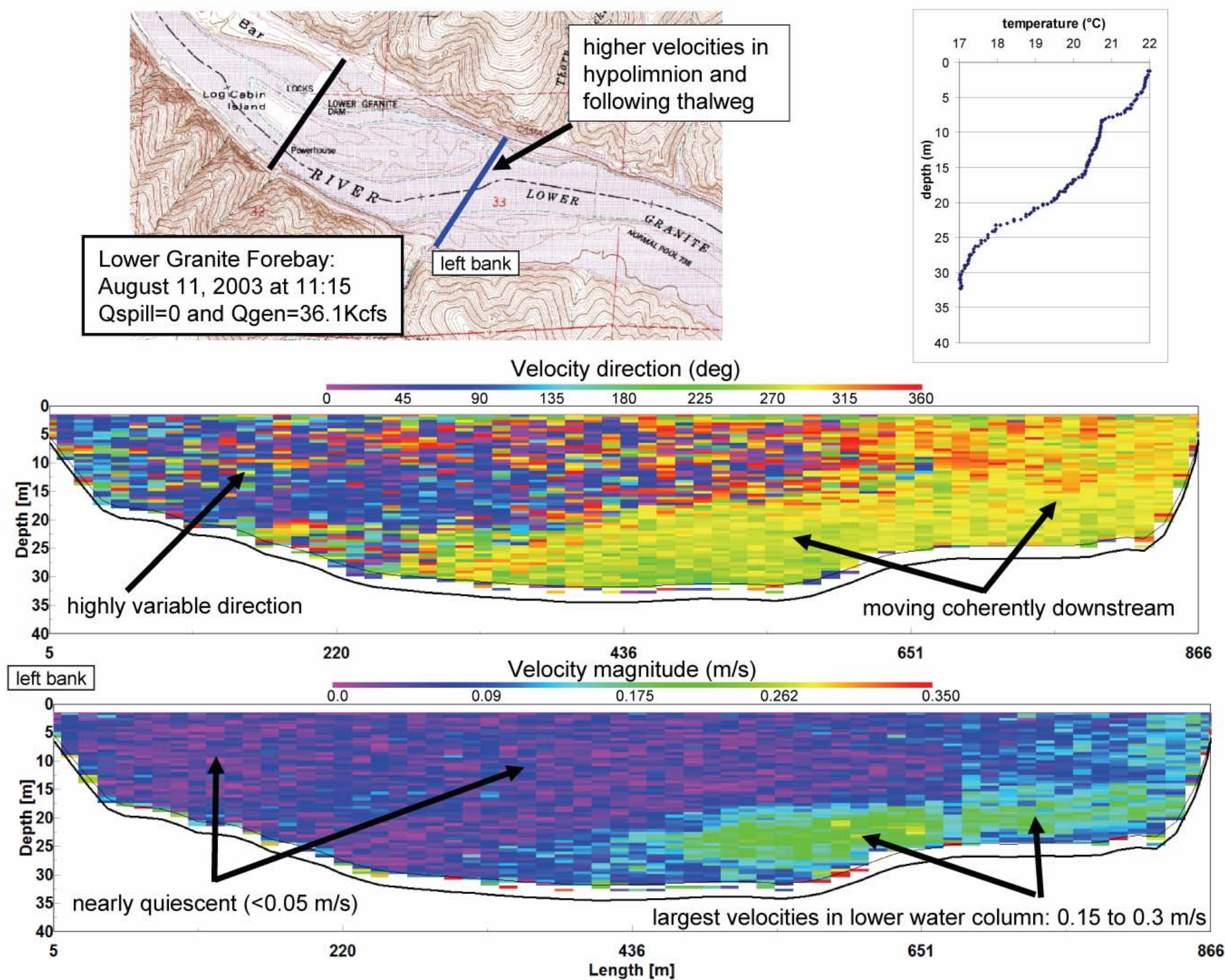

Figure 3.9. Transect of velocity measurements near the LGR forebay BRZ on August 11, 2003 
The fieldwork in LWG reservoir consisted of transects and point data collected with a boat-mounted ADCP, CTD probe, and time-series water velocity measurements using a bottom-mounted ADCP. A bottom-mounted 600-kHz ADCP was deployed for more than $24 \mathrm{~h}$ each at two locations in the confluence zone (see Figure 3.10). The ADCP was attached to a mount via a gimbal that could compensate for small bathymetric irregularities. The ADCP bottom-mount deployment was similar to the open water buoy setup (see Figure 3.1), and the mount was retrieved via a surface buoy connected to a weight placed a short distance away and outside of the beam swath of the ADCP. The goal of this deployment was to determine if significant velocity and discharge changes occurred between day and night caused by variation in inflow from the middle Snake River (i.e., the Hells Canyon Complex) or load following operations downstream at LWG dam.

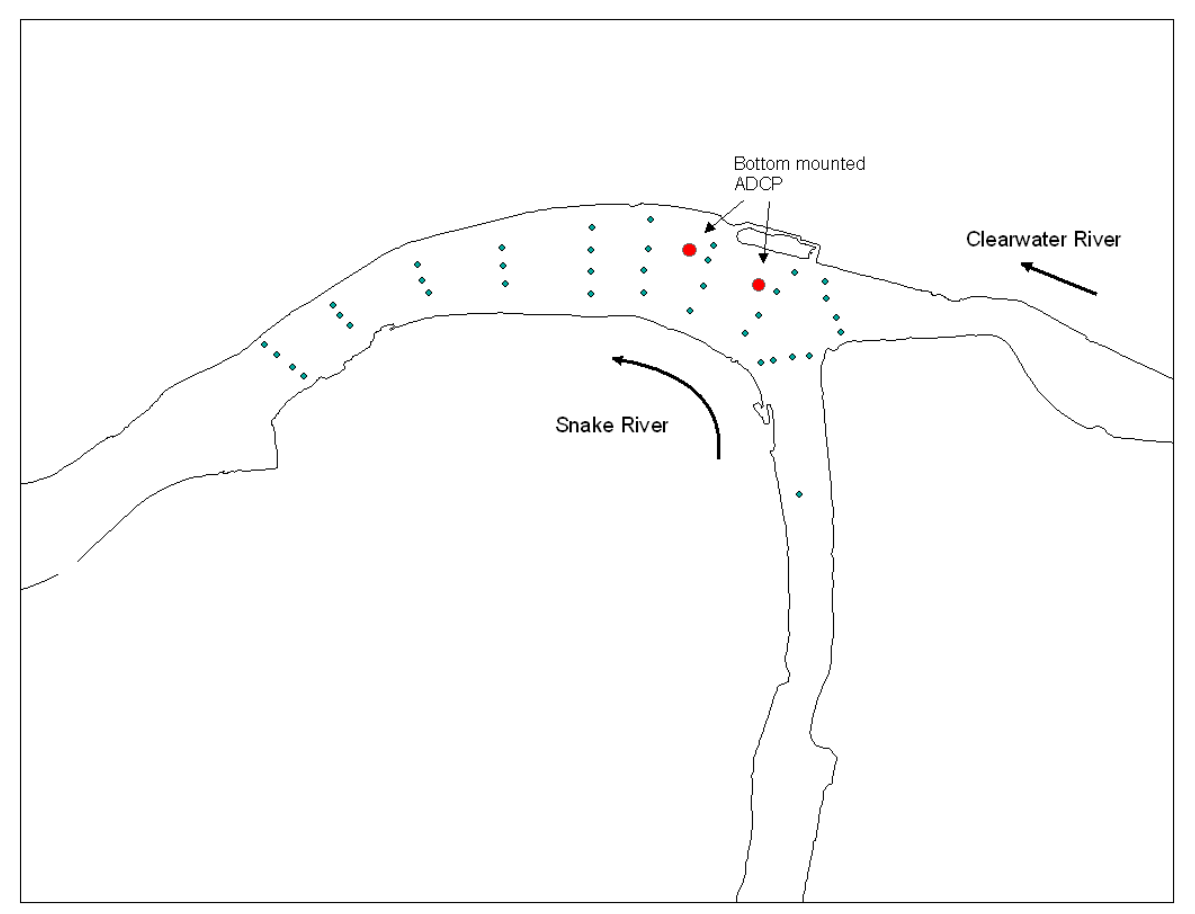

Figure 3.10. Point and bottom-mounted ADCP measurement sites: July 2005

One day of ADCP data, collected at the right red circle in Figure 3.10, is shown in Figure 3.11. Data shown in the figure were collected between 13:00 hours on July 26 and 12:10 hours on July 17. Data were collected with a vertical bin size of $0.25 \mathrm{~m}$, and each ensemble reading consisted of 40 pings, resulting in an ensemble Doppler error of $1.9 \mathrm{~cm} / \mathrm{s}$. One ensemble reading was collected every minute. Reservoir conditions were typical for this period: the water surface elevation of the reservoir varied between elevation $223.7 \mathrm{~m}(734.1 \mathrm{ft})$ and $223.9 \mathrm{~m}$ (734.6 ft); powerhouse discharge from LWG dam was approximately constant at $322.4 \mathrm{~m}^{3} / \mathrm{s}(11.4 \mathrm{kcfs})$; spillway discharge at LWG dam varied between $413.4 \mathrm{~m}^{3} / \mathrm{s}(14.6 \mathrm{kcfs})$ and $668.3 \mathrm{~m}^{3} / \mathrm{s}(23.6 \mathrm{kcfs})$; Clearwater River inflows were constant at $390.8 \mathrm{~m}^{3} / \mathrm{s}$ (13.8 kcfs); and Snake River inflows varied between $509.7 \mathrm{~m}^{3} / \mathrm{s}(18 \mathrm{kcfs})$ and $413.4 \mathrm{~m}^{3} / \mathrm{s}(14.6 \mathrm{kcfs})$.

Velocity magnitudes were fairly constant over the period, with an average value of $0.18 \mathrm{~m} / \mathrm{s}$. Maximum velocities were noted to occur near the surface of the water column. Throughout this day, no large oscillations were observed although powerhouse operations changed as normal throughout the 
period. Water velocity directions were also extremely uniform, although a 35-degree shift was noted between the top (epilimnion) and bottom (hypolimnion) of the water column. This shift is similar to those collected using point profiles (see Figure 3.12).

Point water velocity data were collected using a 1200-kHz RD Instruments ADCP. The confluence area was divided into 10 cross sections along which three or four points were measured (Figure 3.10). The ADCP was programmed to collect data in $0.5-\mathrm{m}$ vertical bins at a rate of approximately one ensemble reading every $5 \mathrm{~s}$. During this 5 -s interval, eight water pings and four bottom track pings were collected. The resulting ensemble water velocity error standard deviation was $2.13 \mathrm{~cm} / \mathrm{s}$. Ensemble velocity measurements were then collected at each point location for a minimum duration of 6-min. These points were later time-averaged to produce the observed velocity vectors shown in Figure 3.12.

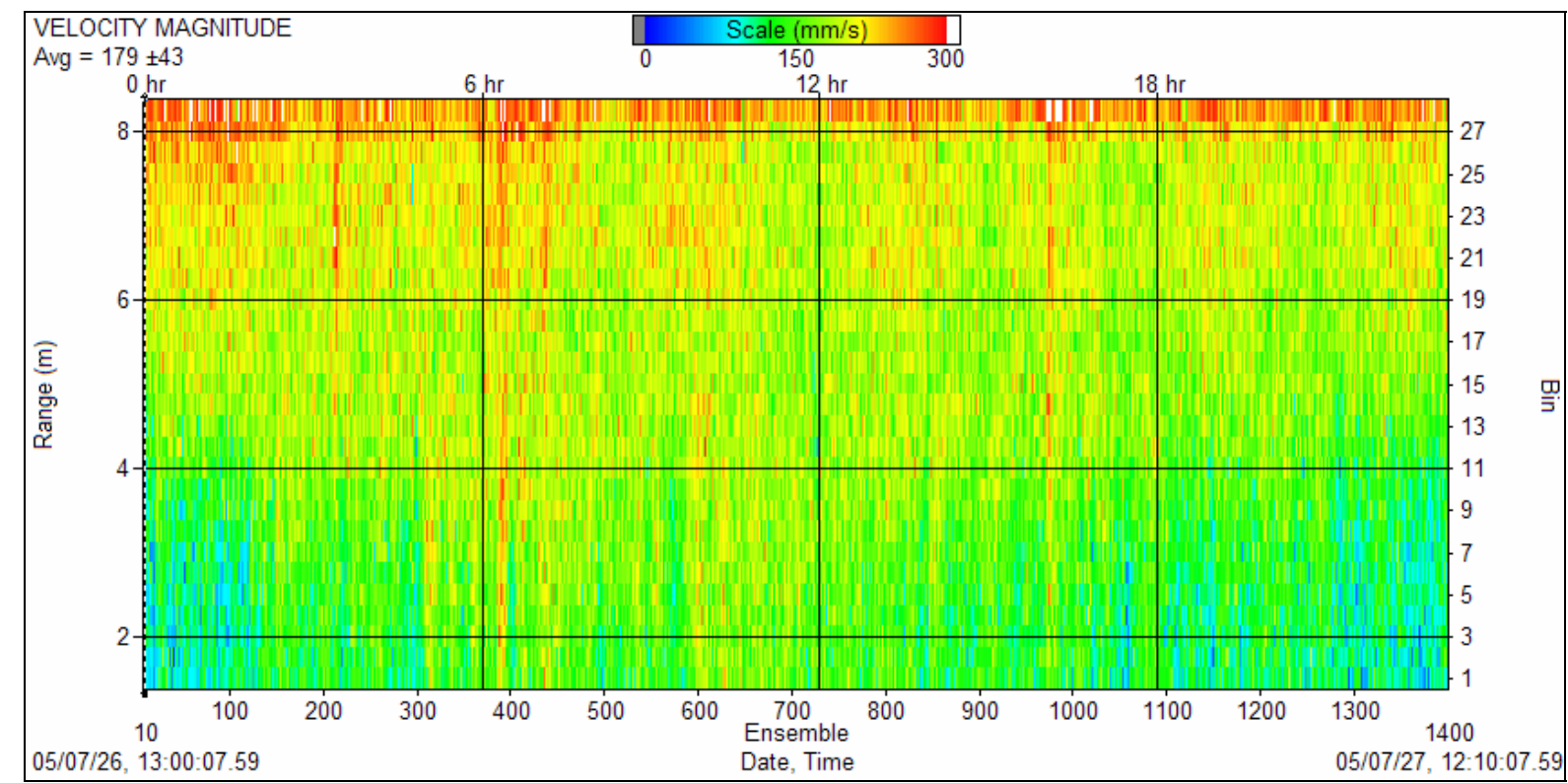

Figure 3.11. ADCP time-series data collected at the confluence (right red circle in Figure 3.10) 


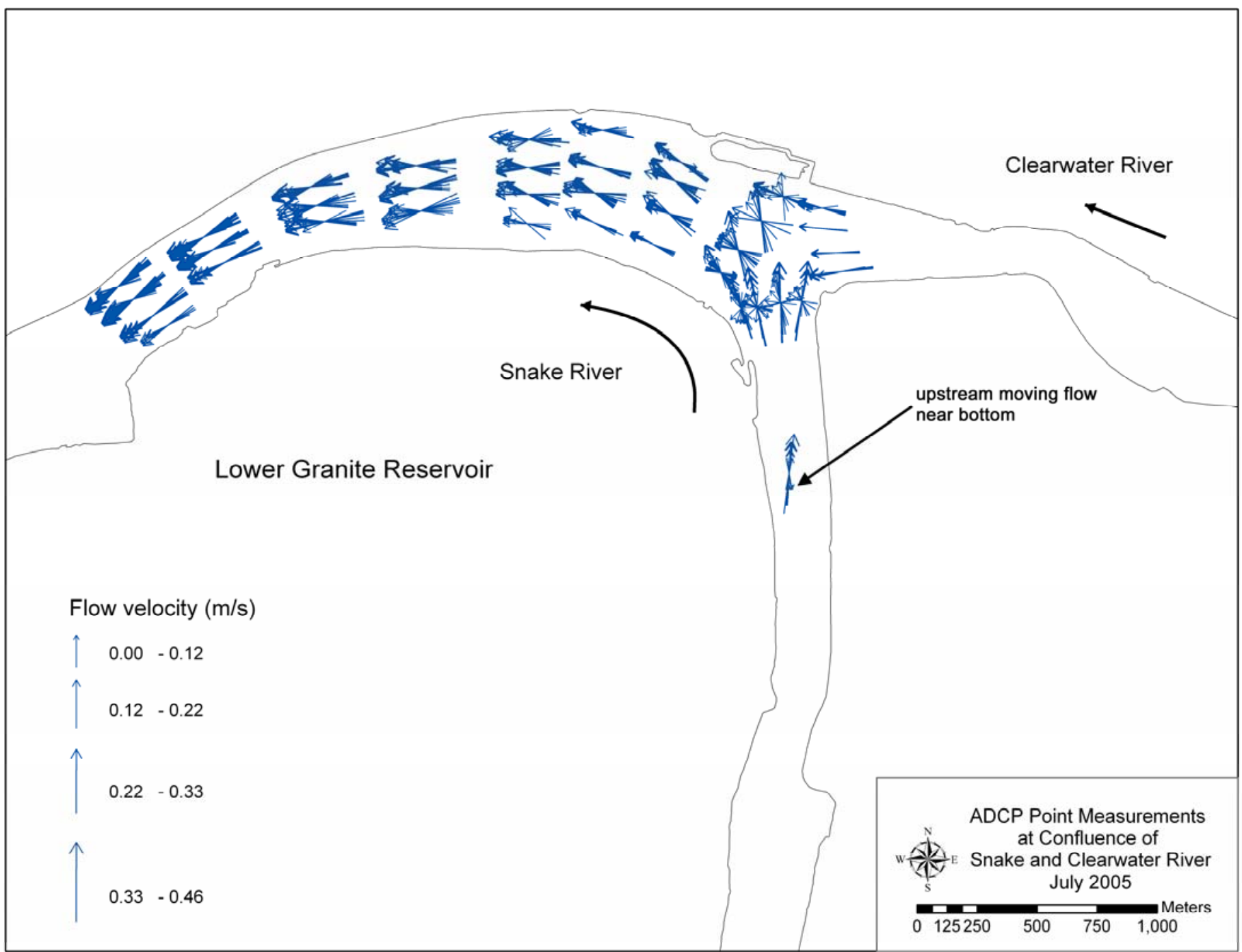

Figure 3.12. Velocity measurements, July 2005 


\subsection{Lower Granite Reservoir: Current Structure and 3D Numerical Modeling}

Lower Granite Reservoir has the potential to become thermally stratified depending upon the difference in temperature and quantity of inflow from the Clearwater and Snake rivers. Hypolimnetic releases of water far below equilibrium temperature from Dworshak Reservoir during the summer months routinely supply 283 to $566 \mathrm{~m}^{3} / \mathrm{s}(10-20 \mathrm{kcfs})$ of water between $10-14^{\circ} \mathrm{C}$ entering Lower Granite Reservoir. During the three years of long-term data collection in Lower Granite Reservoir (summers 2002 through 2004), project releases from the Hells Canyon Complex and Dworshak Dam were significantly different, providing the ability for this study to compare and contrast the effects of these inflows on vertical temperature gradients in the lower Snake River. Understanding hydraulic characteristics of these summer releases, the resulting stratification of Lower Granite Reservoir, and development of models to predict stratification for use by salmon and river managers were key objectives for this project.

\subsection{Quantity and Quality of Flow Entering Lower Granite Reservoir During Periods of Flow Augmentation}

Theoretical development and application of equilibrium temperature can be found in TVA (1972) and Edinger (1974), and equilibrium temperature is commonly used to describe the condition when zero netheat flux (daily averaged) occurs across the air-water interface. At the confluence of the Clearwater and Snake rivers, the Snake River contribution is approximately at equilibrium temperature. However, the release of 6 to $9^{\circ} \mathrm{C}$ water from the Dworshak Reservoir's hypolimnion cools the lower Clearwater River far below equilibrium temperature. For a water body far below equilibrium temperature, the rise of water temperature back to equilibrium is not linear over time (and hence distance downstream) but approximately exponential. This rapid rise of water temperature back to equilibrium is evident by considering the average travel time from Dworshak Dam to Lewiston, Idaho, which is approximately $8.5 \mathrm{hrs}$ at a river flow of $435 \mathrm{~m}^{3} / \mathrm{s}(16 \mathrm{kcfs})$ (USACE 1986). Along this river reach, observed water temperatures rose, on average, by $4.3^{\circ} \mathrm{C}(2002), 4.9^{\circ} \mathrm{C}(2003), 4.8^{\circ} \mathrm{C}(2004)$ during the flow augmentation period. As discussed in Section 2.2, the lower temperature limit for releases from Dworshak Dam passed via the powerhouse is $6^{\circ} \mathrm{C}$ due to requirements at the Dworshak National Fish Hatchery (SOR 2004). Therefore the coldest temperatures (on-average) that can be expected to reach Lower Granite Reservoir are between 10 and $11^{\circ} \mathrm{C}$.

River discharges and temperatures during the flow augmentation period between July 15 and August 31 of 2002, 2003, and 2004 are displayed in Figures 4.1 through 4.3. Discharges entering Lower Granite Reservoir from the middle Snake River (Site 9) and lower Clearwater River (Site 11) were computed by routing flows from upstream gages using MASS1 (Perkins and Richmond 2001).

The total quantity of flow entering Lower Granite Reservoir was largest in 2002, when the mean combined discharge entering the confluence was $880 \mathrm{~m}^{3} / \mathrm{s}(31.1 \mathrm{kcfs})$, and smallest in 2003 when the mean combined discharge was $813 \mathrm{~m}^{3} / \mathrm{s}(28.7 \mathrm{kcfs})$. Mean discharges for the Clearwater River were 
$396 \mathrm{~m}^{3} / \mathrm{s}$ (14.0 kcfs) (2002), $353 \mathrm{~m}^{3} / \mathrm{s}(12.5 \mathrm{kcfs})(2003)$, and $388 \mathrm{~m}^{3} / \mathrm{s}(13.7 \mathrm{kcfs})(2004)$, and for the Snake River were $481 \mathrm{~m}^{3} / \mathrm{s}$ (17.0 kcfs) (2002), $459 \mathrm{~m}^{3} / \mathrm{s}(16.2 \mathrm{kcfs})(2003)$, and $461 \mathrm{~m}^{3} / \mathrm{s}(16.3 \mathrm{kcfs})$ (2004).

Generally, lower Clearwater River discharge slowly decayed through the flow augmentation period, except in late 2004 when discharges were suddenly increased above $425 \mathrm{~m} / \mathrm{s}$ (15 kcfs) after August 26. The opposite was true during the latter part of 2003, when flows were suddenly decreased to below $283 \mathrm{~m}^{3} / \mathrm{s}$ (10 kcfs) on August 19 .

The ratio of Clearwater River to Snake River discharge is important when considering the relative impacts of hypolimnetic releases from Dworshak Reservoir on Lower Granite Reservoir. To facilitate comparison, a 24-hr center-weighted moving average ratio of the discharges was computed and shown in Figures 4.1 through 4.3. During July and August 2002, the ratio was above 1.0 (i.e., Clearwater River larger than Snake River), significantly different from 2003 and 2004 when the discharge ratio was consistently less during this period. The discharge ratio was smallest during the latter half of August 2003, when minimums of 0.4 were reached.

Differences in water temperature were computed using daily average mean temperatures. The mean temperature differences for each of the three years were $8.9^{\circ} \mathrm{C}(2002), 10.9^{\circ} \mathrm{C}(2003)$, and $10.7^{\circ} \mathrm{C}(2004)$. Interestingly, in 2002 when Clearwater River discharge contributions were the largest, the temperature difference between the Clearwater and Snake rivers at the confluence were the smallest. In both 2003 and 2004, peak differences in temperature between the two rivers were larger than $10.5^{\circ} \mathrm{C}$ during most of the augmentation period; during 2002, the temperature difference never reached this value (maximum $=$ $10.3^{\circ} \mathrm{C}$ on July 31$)$.

\subsection{Circulation Dynamics at the Confluence}

Various circulation patterns at the confluence of the Clearwater and Snake rivers were observed during late spring, summer, and early fall. To facilitate discussion, these patterns were broadly lumped into three groups depending on the temperature, and hence density, difference between the Snake and Clearwater rivers. As shown in Figure 4.4, a temperature difference was observed during the entire project sampling period, however differences were much less outside the Dworshak Dam flow augmentation period (late June/early-July through mid-September).

Satellite images of the confluence zone were collected by the U.S. Department of Energy Multispectral Thermal Imager (MTI) satellite. This satellite collected images over 15 wavebands covering the visible ( 3 bands) and near-, mid-, and long-wave infrared ranges. Images were collected at the relatively high resolution of $5 \mathrm{~m}$ in visible wavebands and moderate resolution of $20 \mathrm{~m}$ in the infrared. Research conducted at the Savannah River Technology Center (SRTC) and Los Alamos National Laboratory has produced a diverse group of algorithms for processing and analyzing these data (see Garrett et al. 1999; Villa-Aleman et al. 2000; Szymanski et al. 2001), including accurately computing surface-layer water temperatures (see Figure 4.8). Because water is worse at passing infrared wavelengths than visible wavelengths, it should be noted that surface water temperatures observed by infrared images are at a depth of less than $1 \mathrm{~mm}$ beneath the surface (i.e., only the top skin layer can be measured). 

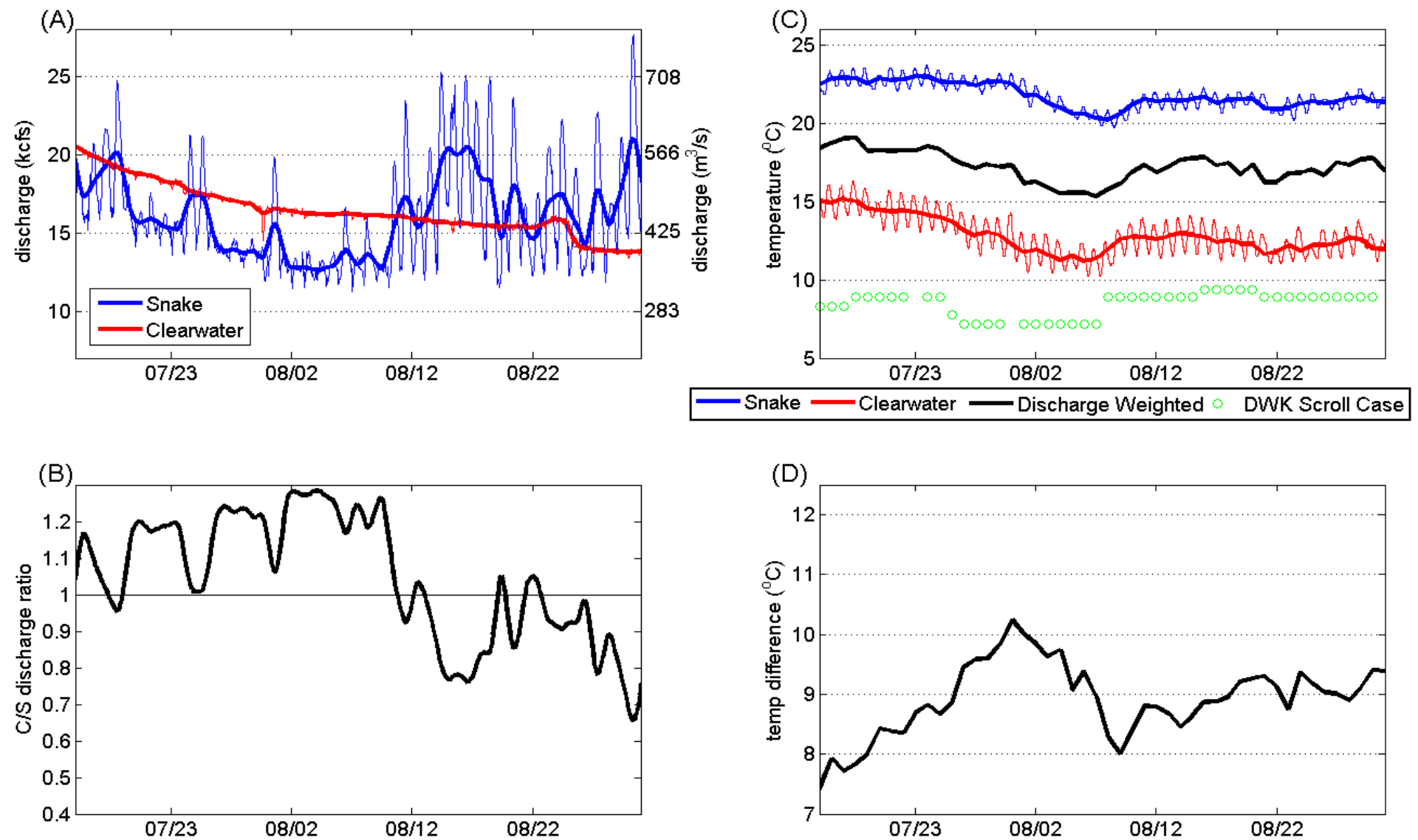

Figure 4.1. Confluence conditions for 2002. (A) Discharges just upstream of the confluence at Site 9 (Snake River) and Site 11 (Clearwater River). Thick lines are 24-hr moving averages while thin lines are hourly values. (B) Discharge ratio computed by dividing 24-hr moving average Clearwater River by Snake River discharge. (C) Thin lines are observed temperatures from loggers placed at Sites 9 and 11. Thick lines and discharge weighted temperatures were computed from daily mean values, except for DWK (Dworshak) scroll case, which are daily mean values from DART (2005). (D) Daily mean temperature difference computed by subtracting Site 9 (Snake) from Site 11 (Clearwater). 

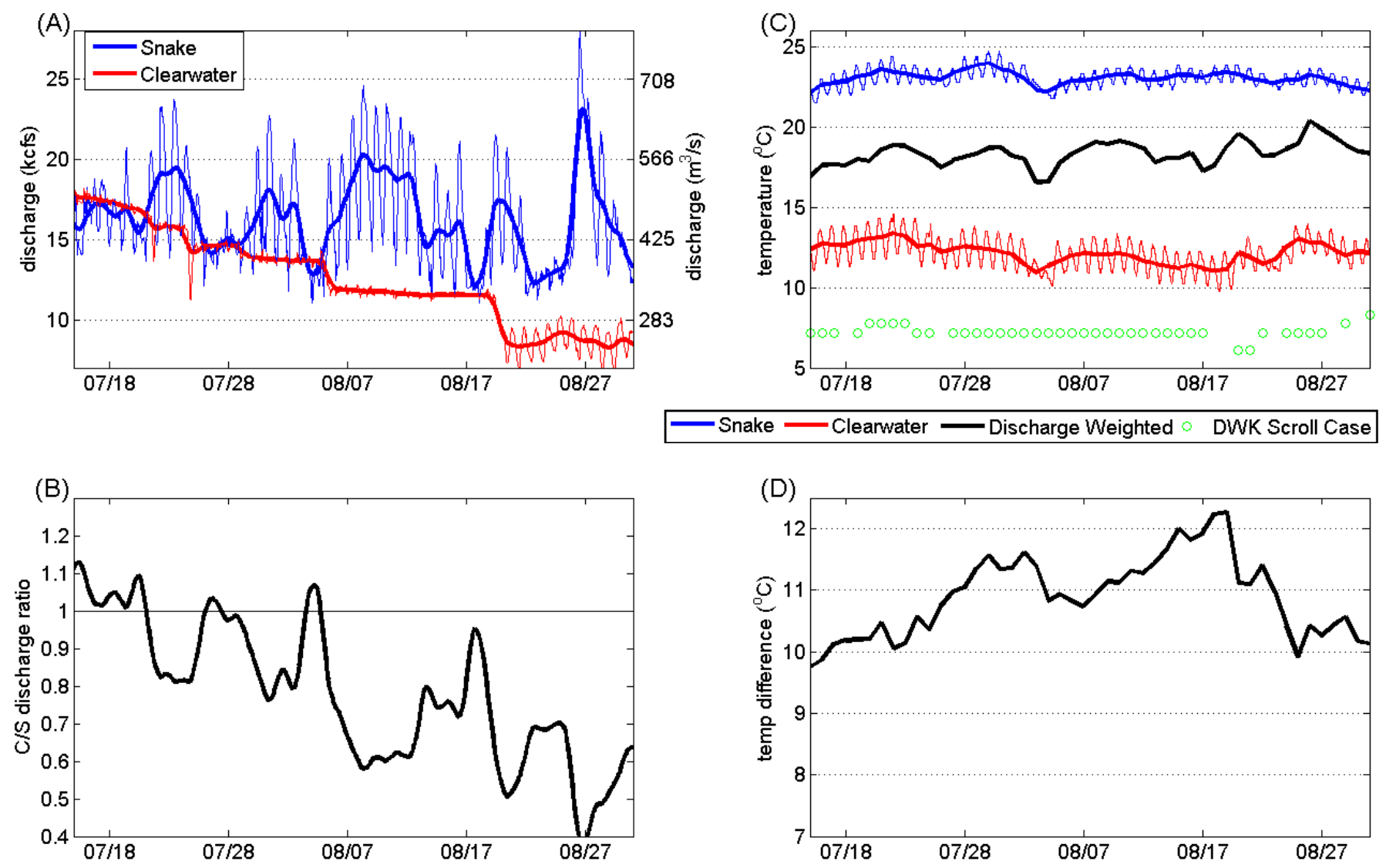

Figure 4.2. Confluence conditions for 2003. (A) Discharges just upstream of the confluence at Site 9 (Snake River) and Site 11 (Clearwater River). Thick lines are 24-hr moving averages while thin lines are hourly values. (B) Discharge ratio computed by dividing 24-hr moving average Clearwater River by Snake River discharge. (C) Thin lines are observed temperatures from loggers placed at Sites 9 and 11. Thick lines and discharge weighted temperatures were computed from daily mean values, except for DWK (Dworshak) scroll case, which are daily mean values from DART (2005). (D) Daily mean temperature difference computed by subtracting Site 9 (Snake) from Site 11 (Clearwater). 

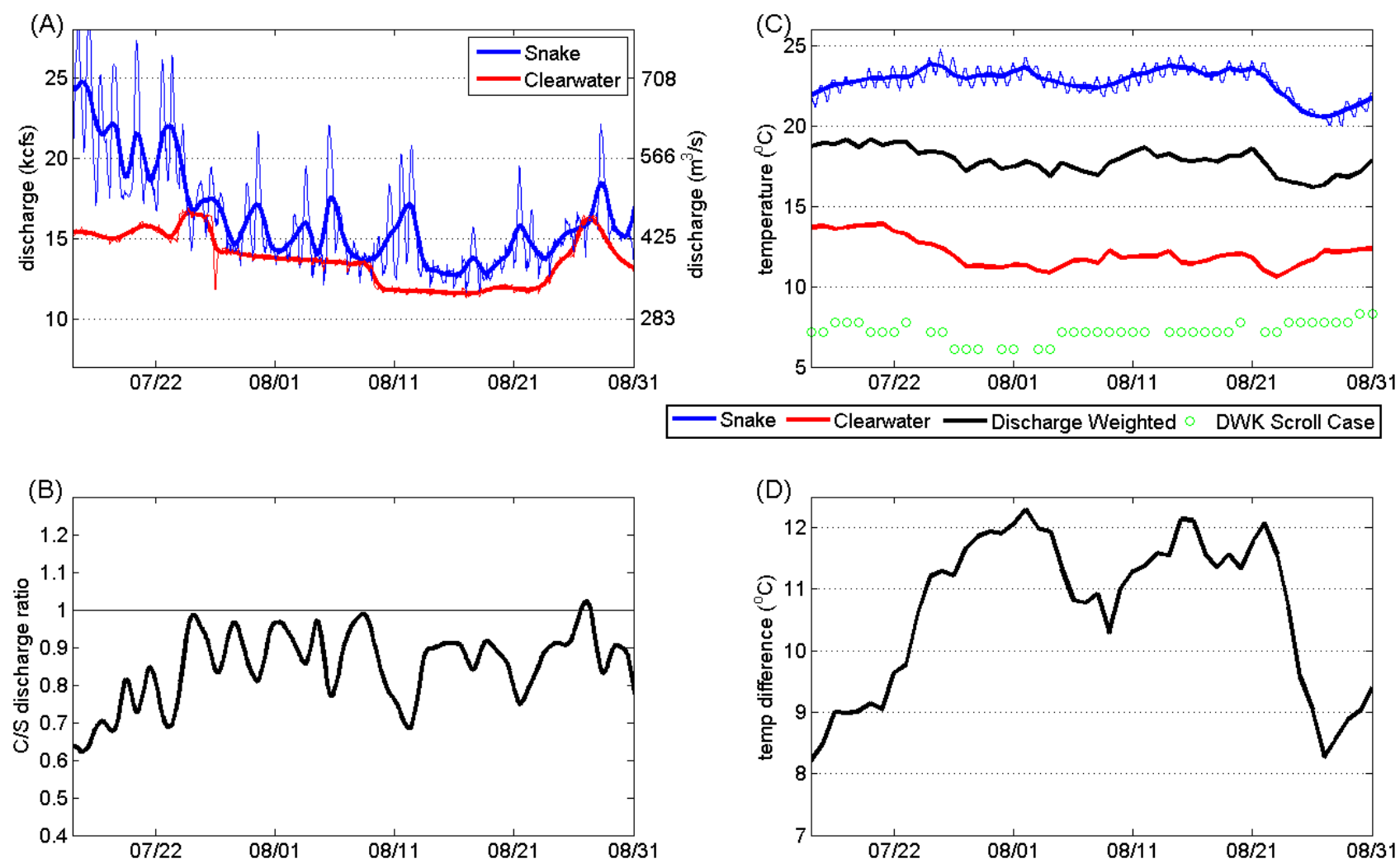

Figure 4.3. Confluence conditions for 2004. (A) Discharges just upstream of the confluence at Site 9 (Snake River) and Site 11 (Clearwater River). Thick lines are 24-hr moving averages while thin lines are hourly values. (B) Discharge ratio computed by dividing 24-hr moving average Clearwater River by Snake River discharge. (C) Thin lines are observed temperatures from loggers placed at Sites 9 and 11. Thick lines and discharge weighted temperatures were computed from daily mean values, except for DWK (Dworshak) scroll case, which are daily mean values from DART (2005). (D) Daily mean temperature difference computed by subtracting Site 9 (Snake) from Site 11 (Clearwater). 

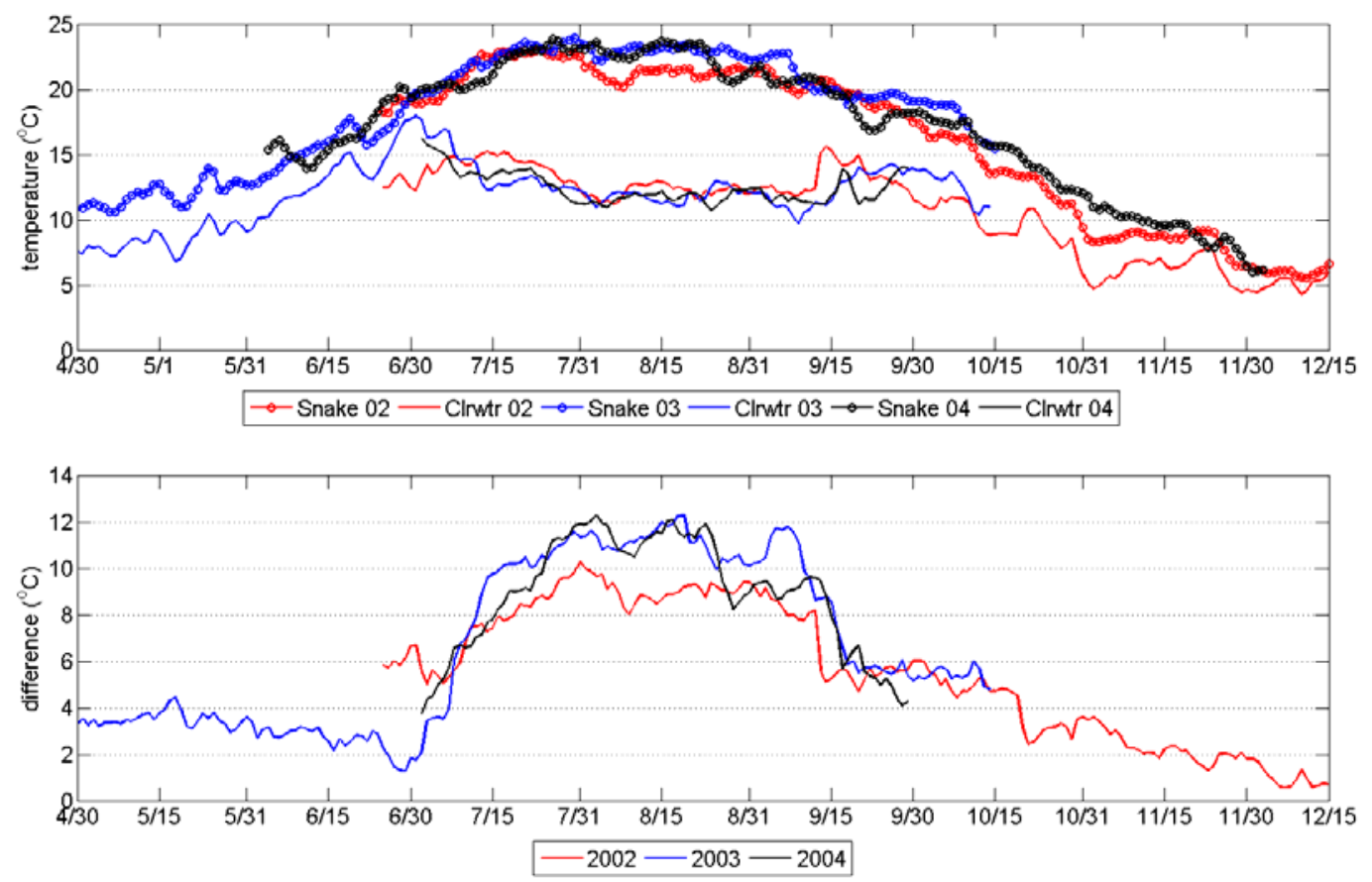

Figure 4.4. Daily-averaged observed water temperatures (upper) and differences (lower) for the Snake (Site 9) and Clearwater (Site 11) rivers during the study period

\subsubsection{Small Temperature and Small Discharge Difference Circulation}

During periods when temperature and discharge differences between the Clearwater and Snake rivers are relatively small, the two rivers flow parallel to each other downstream of the confluence. Relatively little mixing occurs between the two rivers for several miles downstream.

Figure 4.5 shows an example of this circulation pattern collected by the MTI satellite on April 4, 2002 , when temperature differences were approximately $1.6^{\circ}$ (Clearwater $=5.8^{\circ} \mathrm{C}$ and Snake $\left.=7.4^{\circ} \mathrm{C}\right)$ as observed by temperature loggers put in place at Sites 8 and 10 for the image collection (see Figure 3.3). The image shown in Figure 4.5 was collected at nighttime (00:12 PDT) and was produced using a combination of the satellite's mid- and long-wave infrared bands. Discharge in each river just upstream of the confluence at the time of the image collection was computed by routing gauged stream flows using MASS1 (Perkins and Richmond 2002), and was computed to be $680.6 \mathrm{~m}^{3} / \mathrm{s}(24,036 \mathrm{cfs})$ in the Clearwater River (Site 11) and $790.2 \mathrm{~m}^{3} / \mathrm{s}(27,907 \mathrm{cfs})$ in the Snake River (Site 9). This equates to a Clearwater/Snake discharge ratio of 0.86 .

\subsubsection{Small Temperature and Large Discharge Difference Circulation}

During periods when the temperature difference between two rivers is relatively small but large discharge differences exist, the two rivers will mix together within a short distance downstream of the confluence. Because the density difference is relatively small, nearly complete mixing occurs within a few miles of the confluence. 


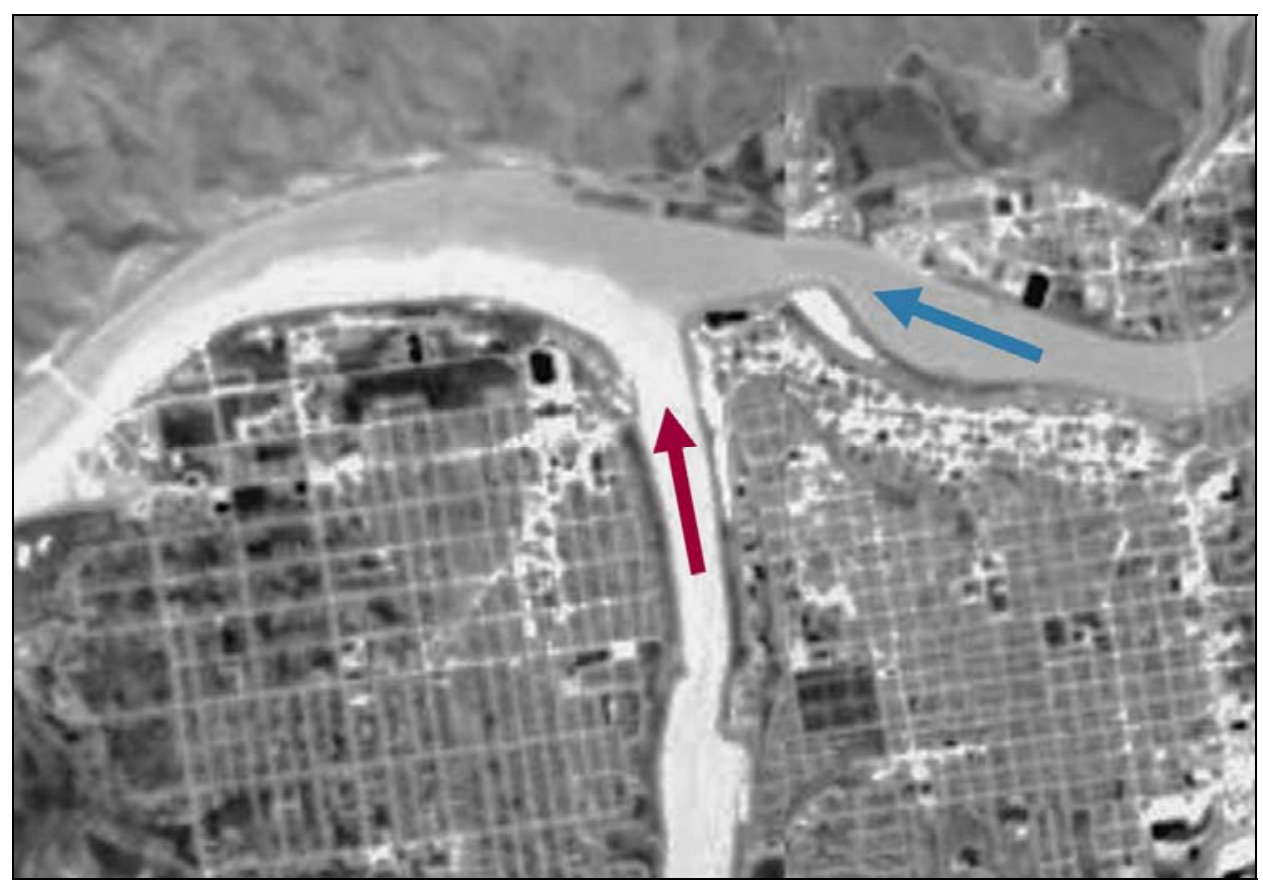

Figure 4.5. Infrared satellite image of the confluence zone taken near midnight, April 4, 2002. The red arrow indicates the direction of flow for the Snake River, while the blue arrow indicates the direction of flow for the Clearwater River.

Figure 4.6 shows an example of this circulation pattern collected by the MTI satellite on May 24, 2003 , when temperature differences were approximately $3.5^{\circ} \mathrm{C}$ (Clearwater $=10.0^{\circ} \mathrm{C}$ and Snake $=$ $13.5^{\circ} \mathrm{C}$ ) as observed by temperature loggers at Sites 9 and 11 (see Figure 3.3). The image shown in Figure 4.6 was collected in the early morning (08:21 PDT) and was produced using one the satellite's long-wave infrared bands. Discharge in each river upstream of the confluence at the time of the image collection was computed by routing gauged stream flows using MASS1 and was computed to be 1096.6 $\mathrm{m}^{3} / \mathrm{s}(38,726 \mathrm{cfs})$ in the Clearwater River (Site 11) and $1585.4 \mathrm{~m}^{3} / \mathrm{s}(55,987 \mathrm{cfs})$ in the Snake River (Site 9). This equates to a Clearwater/Snake discharge ratio of 0.65 .

Profiles of specific conductance and temperature shown in Figure 4.7 were collected on May 16, 2003, when circulation conditions at the confluence were similar to those shown in Figure 4.6 on May 24. River discharges were $781 \mathrm{~m}^{3} / \mathrm{s}(27,580 \mathrm{cfs})$ in the Clearwater River (Site 11$)$ and $1658 \mathrm{~m}^{3} / \mathrm{s}(58,560 \mathrm{cfs})$ in the Snake River (Site 9), which equates to a Clearwater/Snake discharge ratio of 0.48. Profiles of specific conductance and temperature collected upstream and downstream (Red Wolf Bridge) of the confluence indicate almost complete mixing had occurred of the colder, and hence more dense, Clearwater River water. In the upper portion of the water column, only partial mixing had occurred, and temperatures and specific conductance values were weighted toward native upstream Snake River values. Weak variations of water quality across the river were typically observed between the confluence and Silcott Island (Sites 3 and 4). 


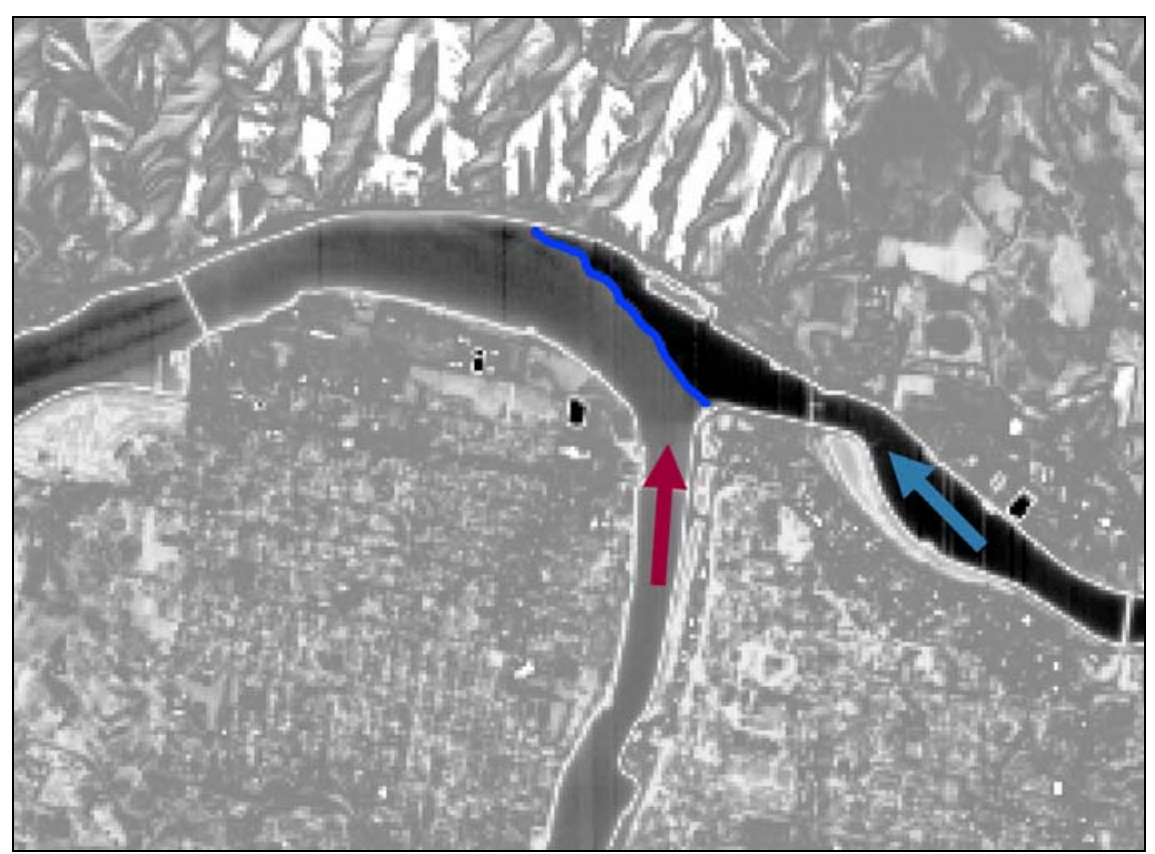

Figure 4.6. Infrared Satellite Image of the Confluence Zone Taken at 08:21 on May 24, 2003. The red arrow indicates the direction of flow for the Snake River, while the blue arrow indicates the direction of flow for the Clearwater River. Bridge on left edge of the graphic is Red Wolf Bridge.
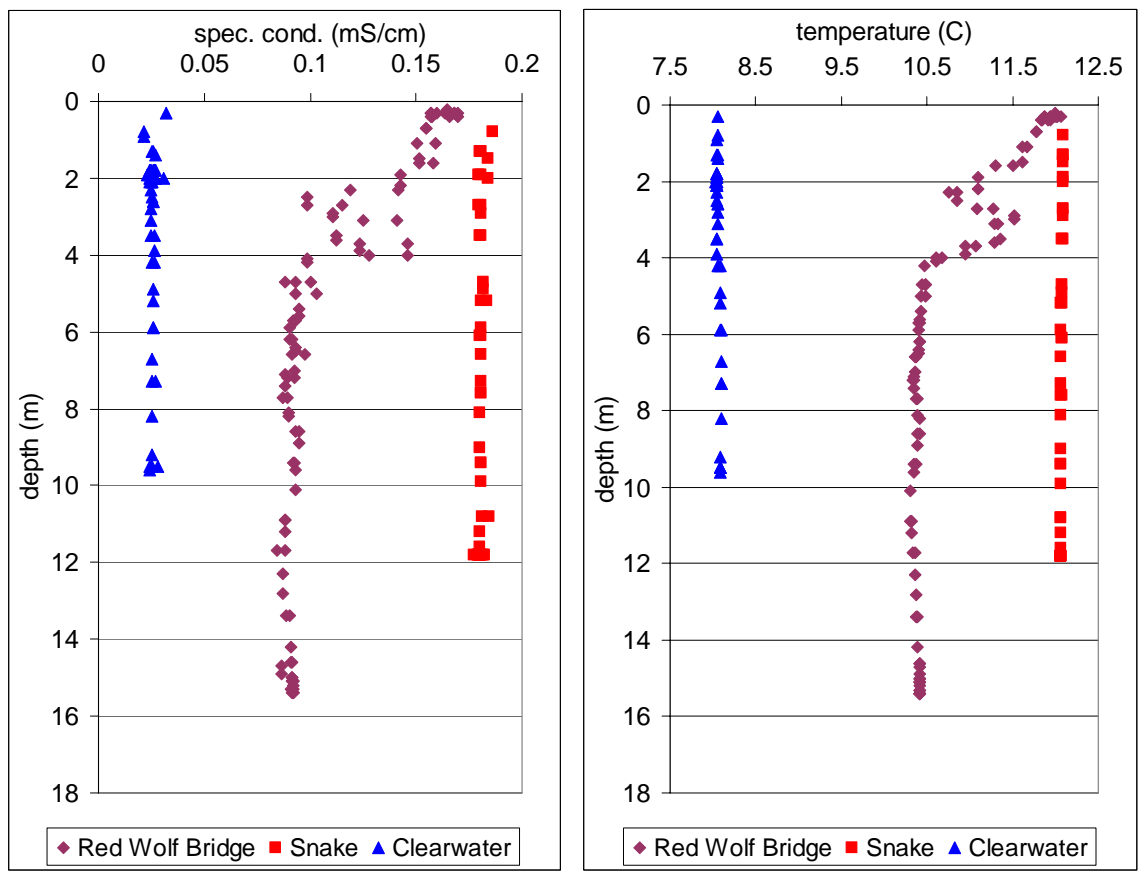

Figure 4.7. Specific Conductance and Temperature Profiles Collected on May 16, 2003. Locations 'Snake' and 'Clearwater' were collected at Sites 9 and 11, respectively. Location 'Red Wolf Bridge' was collected at the center of the river and between Sites $5 \mathrm{a}$ and $5 \mathrm{~b}$. 


\subsubsection{Large Temperature Difference Circulation}

A large difference in temperature, and hence density will result in the colder Clearwater River flow plunging beneath the warmer Snake River flow at the confluence. The plunge for the Clearwater River is typically a sharp line only a few meters thick (or less) at the water's surface and a sloping wedge shape beneath the surface that can extend upstream in the Snake River for several kilometers. Although the surface plunge line and subsurface wedge shape varies with discharge ratio, the overall phenomenon is similar across a large range of discharges.

Figure 4.8 displays a color contour of surface temperatures derived from infrared images of the confluence by the MTI satellite on July 21, 2002, at 11:03 PDT. During the same time, high-precision temperature loggers (SeaBird SBE39s) were floating within $3 \mathrm{~cm}$ of the surface to calibrate the satellite measurements. Discharge in each river upstream of the confluence at the time of image collection was computed by routing gauged stream flows using MASS1 and was computed to be $527 \mathrm{~m}^{3} / \mathrm{s}(18,605 \mathrm{cfs})$ in the Clearwater River (Site 11) and $460.5 \mathrm{~m}^{3} / \mathrm{s}$ (16,263 cfs) in the Snake River (Site 9). This equates to a Clearwater/Snake discharge ratio of 1.14 .

At the time the image was collected, the Clearwater River inflow temperature was $13.4^{\circ} \mathrm{C}$ and the Snake River inflow temperature was at $22.7^{\circ} \mathrm{C}$; resulting in a temperature difference of $9.3^{\circ} \mathrm{C}$. As discussed in Section 4.3, the immediate downstream (i.e., at Site 5a) thermal benefit of flow augmentation in the top $2.6 \mathrm{~m}$ of the water column was less than $2^{\circ} \mathrm{C}$, while water at $10 \mathrm{~m}$ beneath the surface warmed less than $2^{\circ} \mathrm{C}$.

A second MTI satellite image collected on July 30, 2003, shows how the plunge line shape can change with variation in discharge ratio between the Clearwater and Snake rivers. Unlike the straight line

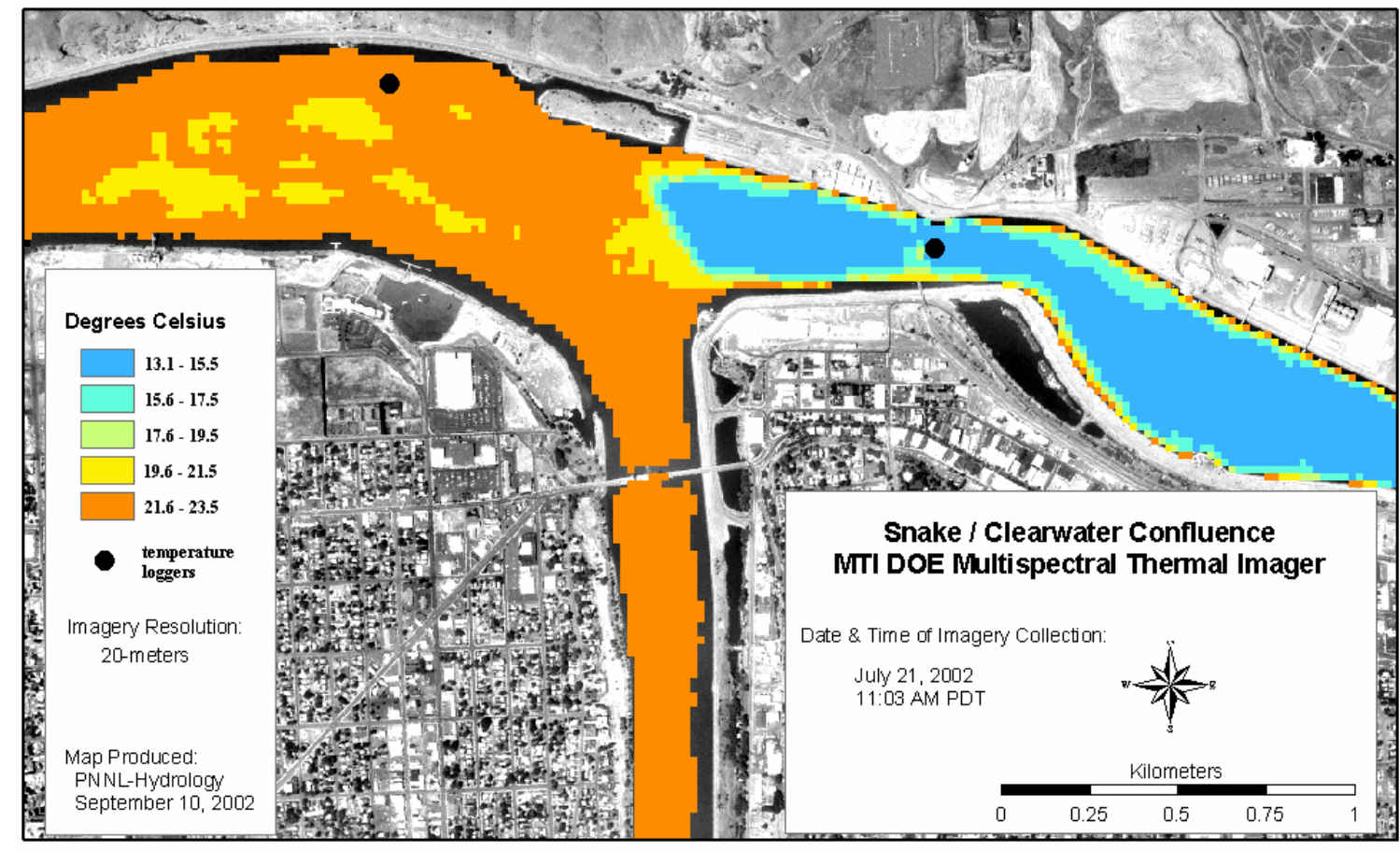

Figure 4.8. MTI Satellite Derived Surface Water Temperatures on July 21, 2002 
shown in Figure 4.8, the surface plunge becomes an arc, as shown in Figure 4.9. Discharge in each river upstream of the confluence at the time of image collection was computed by routing gauged stream flows using MASS1 and was computed to be $396 \mathrm{~m}^{3} / \mathrm{s}(13,974 \mathrm{cfs})$ in the Clearwater River (Site 11) and 586 $\mathrm{m}^{3} / \mathrm{s}(20,698 \mathrm{cfs})$ in the Snake River (Site 9). This equates to a Clearwater/Snake discharge ratio of 0.675. Upstream temperatures were $11.5^{\circ} \mathrm{C}$ and $23.1^{\circ} \mathrm{C}$ in the Clearwater and Snake rivers, respectively.

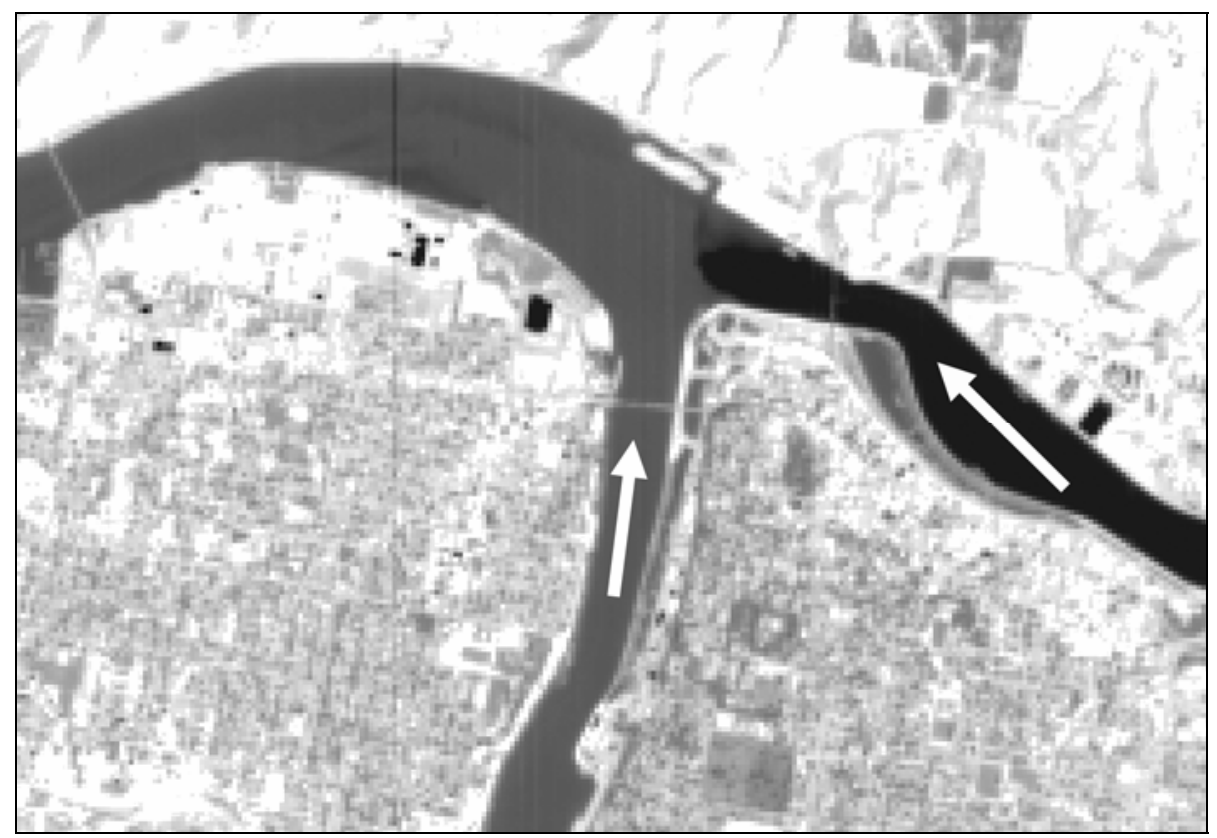

Figure 4.9. Infrared Satellite Image of the Confluence Zone Taken on May 24, 2003 at 08:21

Beneath the water surface, the plunge shape and isotherm distribution becomes highly threedimensional. Cold Clearwater River inflow, driven by gravity and density differences, has the potential to migrate upstream along the bottom of the Snake River. The extent of this cold water intrusion upstream depends upon differences in density and momentum (mass multiplied by velocity) between the two rivers. This phenomenon was observed during all study years by temperature loggers placed at Site 8 (bridge crossing the Snake River just upstream of the confluence).

The extent of upstream intrusion was mapped out between 17:30 and 18:30 hours on August 7, 2003, using the CTD probe. Upstream of the confluence effects, river conditions were: Clearwater River temperature $=12.4^{\circ} \mathrm{C}$ and discharge $=458 \mathrm{~m}^{3} / \mathrm{s}(16,202 \mathrm{cfs})$; Snake River temperature $=20.5^{\circ} \mathrm{C}$ and discharge $=359 \mathrm{~m}^{3} / \mathrm{s}(12,686 \mathrm{cfs})$. The Clearwater/Snake discharge ratio was 1.27 , and the temperature difference was $8.1^{\circ} \mathrm{C}$. Figure 4.10 graphically shows the results with red dots placed at the measurement locations. Between the confluence and $1.1 \mathrm{~km}$ upstream along the Snake River, $14^{\circ} \mathrm{C}$ and below temperatures were observed at the bottom of the water column. At $1.5 \mathrm{~km}$ upstream, bottom water temperatures were several degrees warmer; however, they were still below the native Snake River water, and both the $16^{\circ} \mathrm{C}$ and $18^{\circ} \mathrm{C}$ isotherms reached this location. At $2.4 \mathrm{~km}$ upstream, only a $0.5^{\circ} \mathrm{C}$ decrease in water temperatures near the bottom of the water column was detected. 


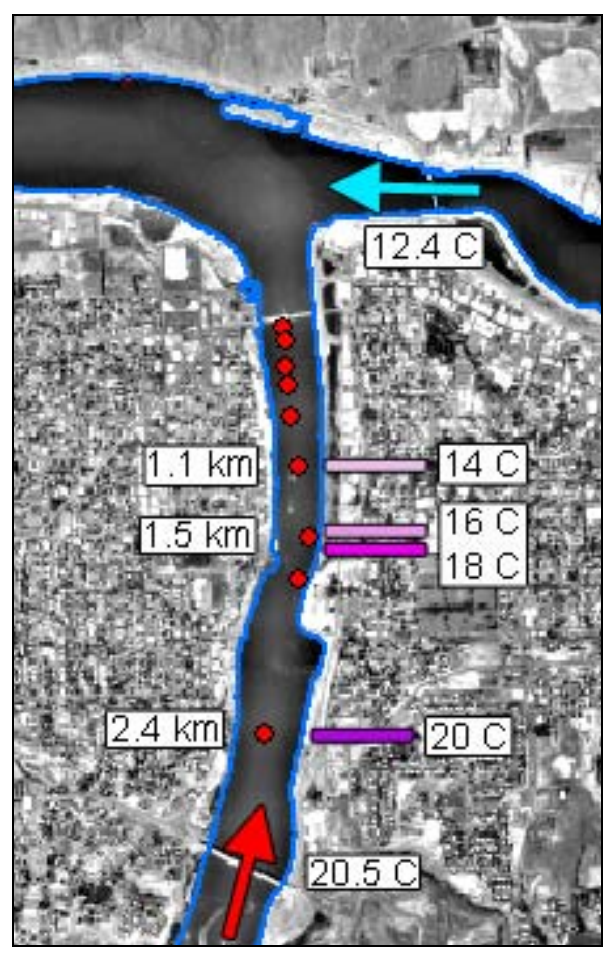

Figure 4.10. Temperature profile collection locations, August 7, 2002. Colored bars indicate last recorded location of the $14^{\circ} \mathrm{C}, 16^{\circ} \mathrm{C}, 18^{\circ} \mathrm{C}$, and $20^{\circ} \mathrm{C}$ isotherms while traveling upstream. Also shown are the approximate upstream distances from the confluence to the labeled point. Background is an MTI satellite image collected on July 21, 2002 (single infrared band).

\subsection{Thermal Benefit of Flow Augmentation near the Confluence}

Thermal augmentation benefit, as defined in this report, is the decrease in water temperature at a certain depth downstream from the confluence compared to the native Snake River temperature upstream of the confluence (Site 9). If complete mixing were to occur at the confluence, the downstream water temperature would equal the volume-weighted average temperature of the two inflowing rivers. Volumeweighted temperature is therefore a useful metric for comparing upstream operational changes in the hydrosystem and for quantifying the amount of mixing that occurred at and downstream of the confluence.

In Figure 4.11, data from temperature loggers placed upstream of the confluence (Sites 9 and 11) are averaged over the day and plotted in red. The daily volume-weighted temperatures using these data are plotted in black. All daily-averaged data used to create the remaining lines on Figure 4.11 were collected at Site 5a (RM 137.5), 1.5 miles downstream of the confluence. For all three years of the study, an immediate thermal benefit from flow augmentation was achieved at depths less than $4 \mathrm{~m}$ beneath the water's surface. These benefits, computed for the period between July 15 and August 31, were as shown in Table 4.1. 


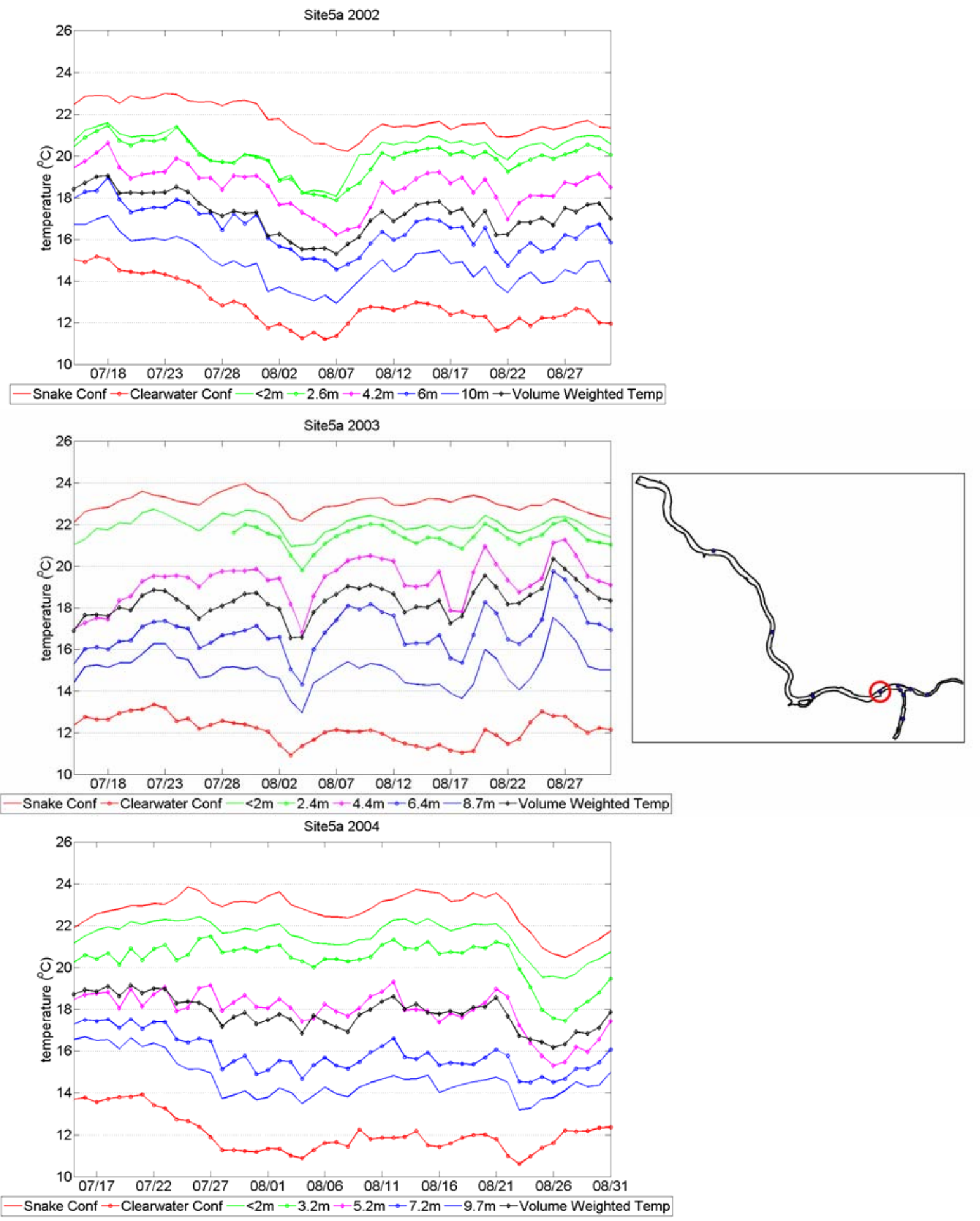

Figure 4.11. Daily-average water temperatures at Site 5a for 2002, 2003, and 2004. Data reported as 'Snake Conf' and 'Clearwater Conf' were collected at Sites 9 and 11, respectively, and 'Volume Weighted Temp' lines were computed using these values. 
Table 4.1. Thermal benefit of flow augmentation at Site 5a (logger depths in parentheses). Note the shift in depths between 2004 and the other years.

\begin{tabular}{|l|l|l|l|}
\hline 2002 & $1.4^{\circ} \mathrm{C}(<2 \mathrm{~m})$ & $1.8^{\circ} \mathrm{C}(2.6 \mathrm{~m})$ & $3.2^{\circ} \mathrm{C}(4.2 \mathrm{~m})$ \\
\hline 2003 & $1.1^{\circ} \mathrm{C}(<2 \mathrm{~m})$ & $1.6^{\circ} \mathrm{C}(2.4 \mathrm{~m})$ & $3.8^{\circ} \mathrm{C}(4.4 \mathrm{~m})$ \\
\hline 2004 & $1.2^{\circ} \mathrm{C}(<2 \mathrm{~m})$ & $2.4^{\circ} \mathrm{C}(3.2 \mathrm{~m})$ & $4.8^{\circ} \mathrm{C}(5.2 \mathrm{~m})$ \\
\hline
\end{tabular}

Seven miles downstream of the confluence at Site 3 (RM 132, Silcott Island), a several-degree reduction in surface water temperatures was observed. Figure 4.12 displays temperature data collected just upstream of the confluence (red lines) the volume-weighted temperature at the confluence (black lines with diamonds) is shown for comparison. The thermal benefit of flow augmentation in the upper layers for the period between July 15 and August 31 is shown in Table 4.2.

\subsection{Thermal Benefit of Flow Augmentation Downstream of Silcott Island}

Downstream of Silcott Island, the reservoir enters a canyon with steep side walls. The reservoir deepens considerably, with a corresponding decrease in depth-averaged water velocity. It should not be surprising then that water temperature conditions downstream of Silcott Island were considerably different from those measured at upstream sites.

Site 2 is located near RM 125, approximately 14 miles downstream of the confluence and 7 miles downstream of Site 3. The site is also approximately halfway between the confluence and Lower Granite Dam.

The thermal benefit of flow augmentation in the epilimnion varies from year to year at Site 2 (see Figure 4.13). During 2002, benefits were significant at the surface $\left(1.4^{\circ} \mathrm{C}\right)$, and at $5.7 \mathrm{~m}$ the water temperature is generally at or below $20^{\circ} \mathrm{C}$ for period. This is in contrast to 2003 , when the average thermal augmentation benefit was less than $1^{\circ} \mathrm{C}$ in the top $3 \mathrm{~m}$ of the water column. The benefit was larger at a depth of $7.5 \mathrm{~m}$, but water temperatures were consistently above $20^{\circ} \mathrm{C}$. During 2004 , the average thermal benefit from flow augmentation in the upper water column ( $>3 \mathrm{~m}$ depth) was large (similar to 2002) except for a one-week period around August 1. The thermal benefit data from Site 2 are displayed in Table 4.3.

The thermocline at Site 2 was at a depth between 7 and $15 \mathrm{~m}$ during all three years. Hypolimnetic water below the thermocline was warmer than at Site 3, and temperatures in this zone were approximately equal to the volume-weighted average temperatures computed at the confluence (black line). It was also noted that time-series patterns in the volume-weighted temperature were mimicked in the hypolimnetic temperatures but with a lag of approximately one day earlier in the season and up to two days toward the end of August.

Site 1 is located near RM 116, approximately 23 river miles downstream of the confluence. Travel time to this site can be several days (note the visible lag between hypolimnetic and volume-weighted time series). During 2003 and 2004, surface heating warmed the upper $3 \mathrm{~m}$ to values at or above those measured in the Snake River upstream of the confluence (see Figure 4.14). The thermal benefit of flow augmentation in the upper layers for the period between July 15 and August 31 is shown in Table 4.4. In 


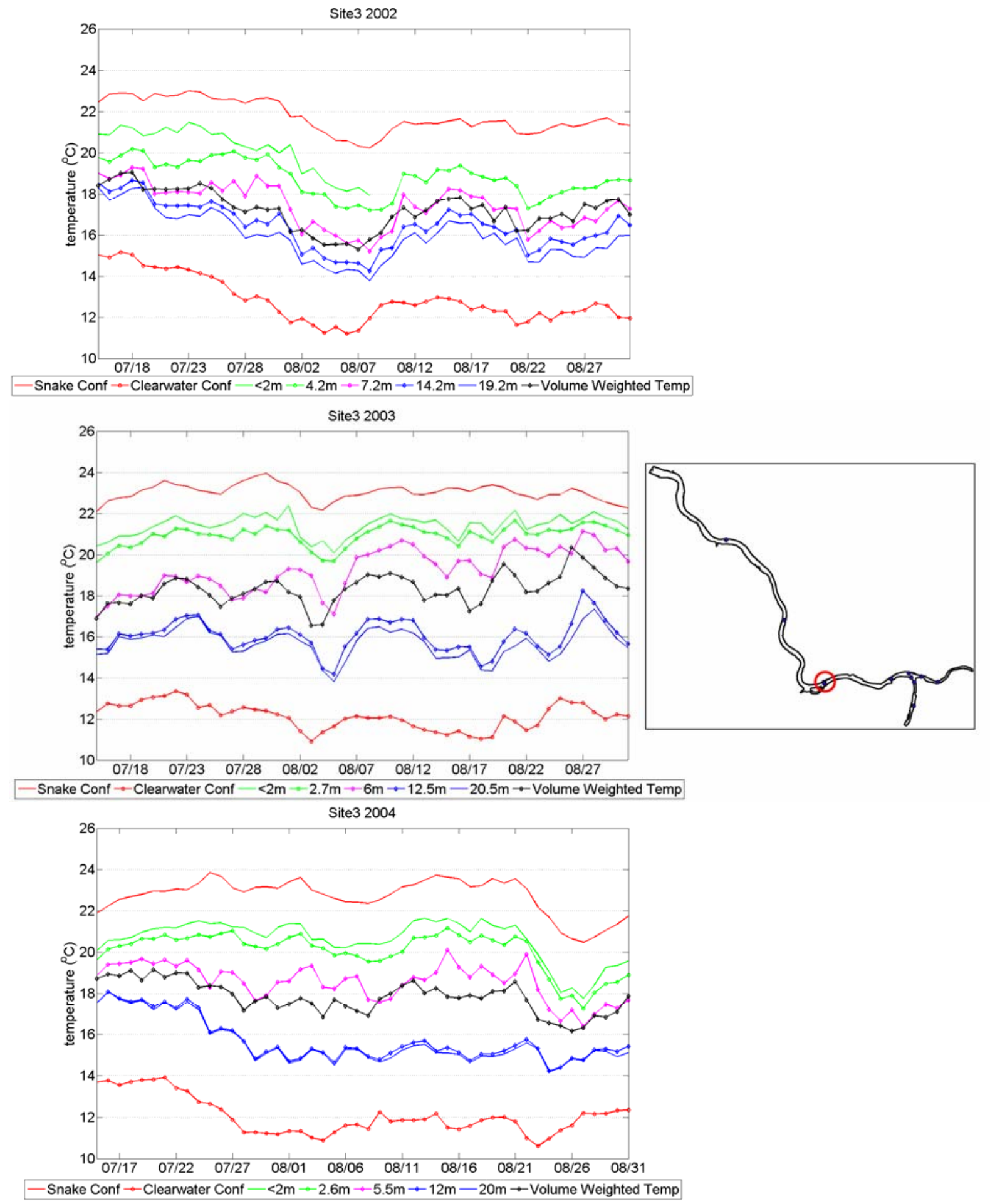

Figure 4.12. Daily-average water temperatures at Site 3 for 2002, 2003, and 2004. Data reported as 'Snake Conf' and 'Clearwater Conf' were collected at Sites 9 and 11, respectively, and 'Volume Weighted Temp' lines were computed using these values. 
Table 4.2. Thermal benefit of flow augmentation at Site 3 (logger depths in parentheses)

\begin{tabular}{|l|l|c|c|}
\hline 2002 & $1.9^{\circ} \mathrm{C}(<2 \mathrm{~m})$ & $\mathrm{n} / \mathrm{a}$ & $3.0^{\circ} \mathrm{C}(4.2 \mathrm{~m})$ \\
\hline 2003 & $1.6^{\circ} \mathrm{C}(<2 \mathrm{~m})$ & $2.1^{\circ} \mathrm{C}(2.7 \mathrm{~m})$ & n/a \\
\hline 2004 & $2.1^{\circ} \mathrm{C}(<2 \mathrm{~m})$ & $2.7^{\circ} \mathrm{C}(2.6 \mathrm{~m})$ & n/a \\
\hline
\end{tabular}

Table 4.3. Thermal benefit of flow augmentation at Site 2 (logger depths in parentheses)

\begin{tabular}{|l|l|l|l|}
\hline 2002 & $1.4^{\circ} \mathrm{C}(<2 \mathrm{~m})$ & $2.5^{\circ} \mathrm{C}(3.7 \mathrm{~m})$ & $3.2^{\circ} \mathrm{C}(7.7 \mathrm{~m})$ \\
\hline 2003 & $0.6^{\circ} \mathrm{C}(<2 \mathrm{~m})$ & $0.9^{\circ} \mathrm{C}(2.8 \mathrm{~m})$ & $2.2^{\circ} \mathrm{C}(7.5 \mathrm{~m})$ \\
\hline 2004 & $1.5^{\circ} \mathrm{C}(<2 \mathrm{~m})$ & $1.8^{\circ} \mathrm{C}(2.8 \mathrm{~m})$ & $3.2^{\circ} \mathrm{C}(8.5 \mathrm{~m})$ \\
\hline
\end{tabular}

Table 4.4. Thermal benefit of flow augmentation at Site 1 (logger depths in parentheses)

\begin{tabular}{|c|c|c|c|c|}
\hline 2002 & $\mathrm{n} / \mathrm{a}$ & $1.2^{\circ} \mathrm{C}(3.5 \mathrm{~m})$ & $1.5^{\circ} \mathrm{C}(5.4 \mathrm{~m})$ & $1.8^{\circ} \mathrm{C}(7.5 \mathrm{~m})$ \\
\hline 2003 & $-0.3^{\circ} \mathrm{C}(<2 \mathrm{~m})$ & $0.2^{\circ} \mathrm{C}(2.8 \mathrm{~m})$ & $1.0^{\circ} \mathrm{C}(6.0 \mathrm{~m})$ & $1.6^{\circ} \mathrm{C}(9.0 \mathrm{~m})$ \\
\hline 2004 & $0.2^{\circ} \mathrm{C}(<2 \mathrm{~m})$ & $0.5^{\circ} \mathrm{C}(2.6 \mathrm{~m})$ & $1.3^{\circ} \mathrm{C}(6.0 \mathrm{~m})$ & $2.0^{\circ} \mathrm{C}(9.0 \mathrm{~m})$ \\
\hline
\end{tabular}

the lower part of the water column, water temperatures at the site rose slightly as warmer water was entrained across the thermocline. At depths greater than $17 \mathrm{~m}$, temperatures were consistently warmer than the volume-weighted temperature.

Data were also collected just inside the forebay BRZ at LWG dam (Carroll and Barko 2005; see Figure 4.15). This site is located at RM 109 and approximately 31 river miles downstream of the confluence. Surface warming of the upper water column between Site 1 and this location is evident within the upper $10 \mathrm{~m}$. However, only slight warming occurred in the hypolimnetic zone at depths of $20 \mathrm{~m}$ or more. This indicates a suppression of mixing across the thermocline, which is expected because water velocities in this part of the reservoir are the lowest. Sequestered hypolimnetic water is therefore efficiently transported downstream with little additional increase in temperature. The response lag between the confluence and BRZ site time-series temperatures is indicative of the travel time between the two locations. The thermal benefit of flow augmentation in the upper layers for the period between July 15 and August 31 is summarized in Table 4.5.

Table 4.5. Thermal benefit of flow augmentation at the forebay BRZ (logger depths in parenthesis)

\begin{tabular}{|l|l|l|l|l|}
\hline 2002 & $0.8^{\circ} \mathrm{C}(1.5 \mathrm{~m})$ & $1.1^{\circ} \mathrm{C}(3 \mathrm{~m})$ & $1.3^{\circ} \mathrm{C}(5 \mathrm{~m})$ & $2.0^{\circ} \mathrm{C}(10 \mathrm{~m})$ \\
\hline 2003 & $0.1^{\circ} \mathrm{C}(1.5 \mathrm{~m})$ & $0.5^{\circ} \mathrm{C}(3 \mathrm{~m})$ & $0.8^{\circ} \mathrm{C}(5 \mathrm{~m})$ & $1.9^{\circ} \mathrm{C}(10 \mathrm{~m})$ \\
\hline 2004 & $-0.4^{\circ} \mathrm{C}(1.5 \mathrm{~m})$ & $0.1^{\circ} \mathrm{C}(3 \mathrm{~m})$ & $0.7^{\circ} \mathrm{C}(5 \mathrm{~m})$ & $1.8^{\circ} \mathrm{C}(10 \mathrm{~m})$ \\
\hline
\end{tabular}




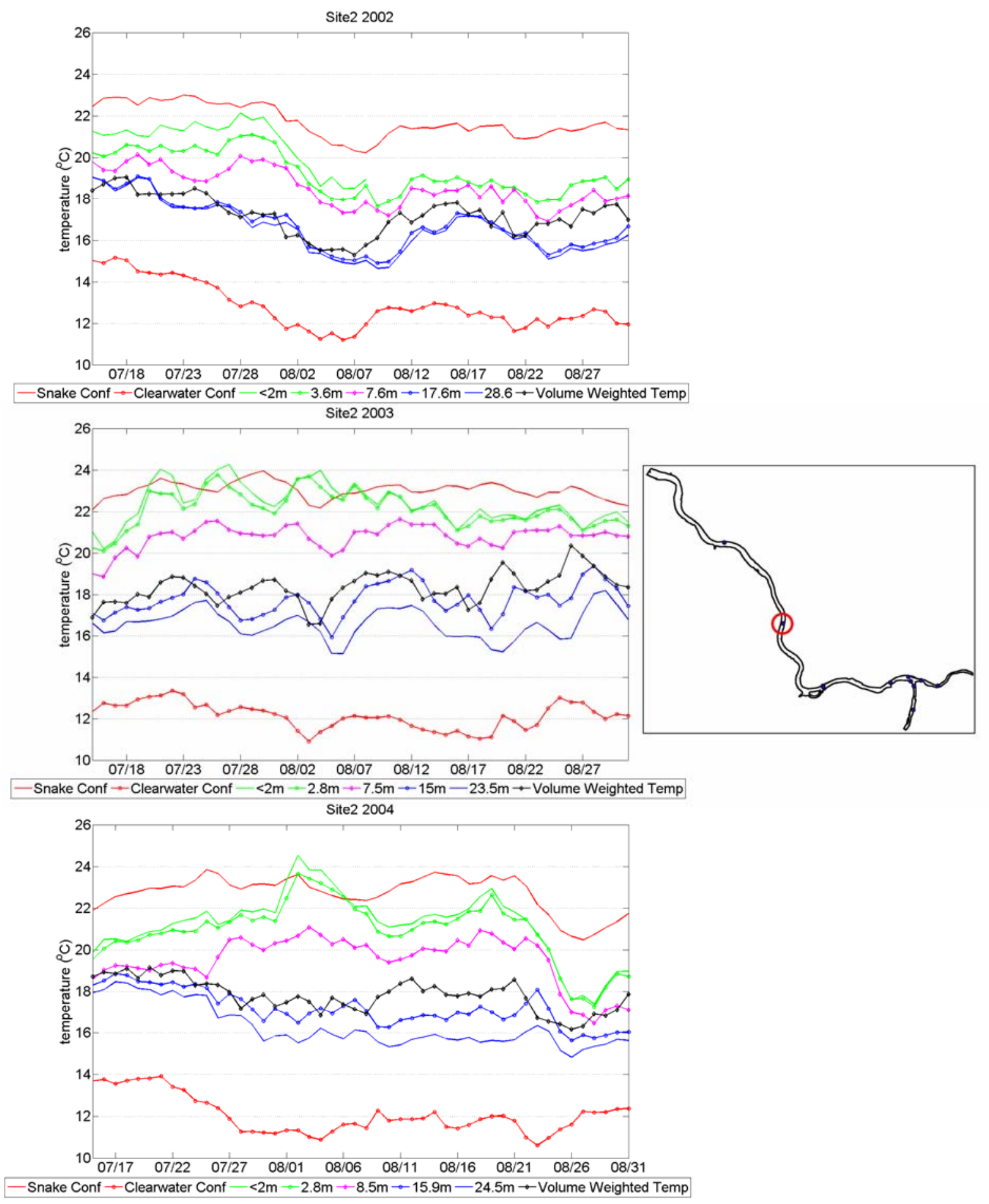

Figure 4.13. Daily-average water temperatures at Site 2 for 2002, 2003, and 2004. Data reported as 'Snake Conf' and 'Clearwater Conf' were collected at Sites 9 and 11, respectively, and 'Volume Weighted Temp' lines were computed using these values. 

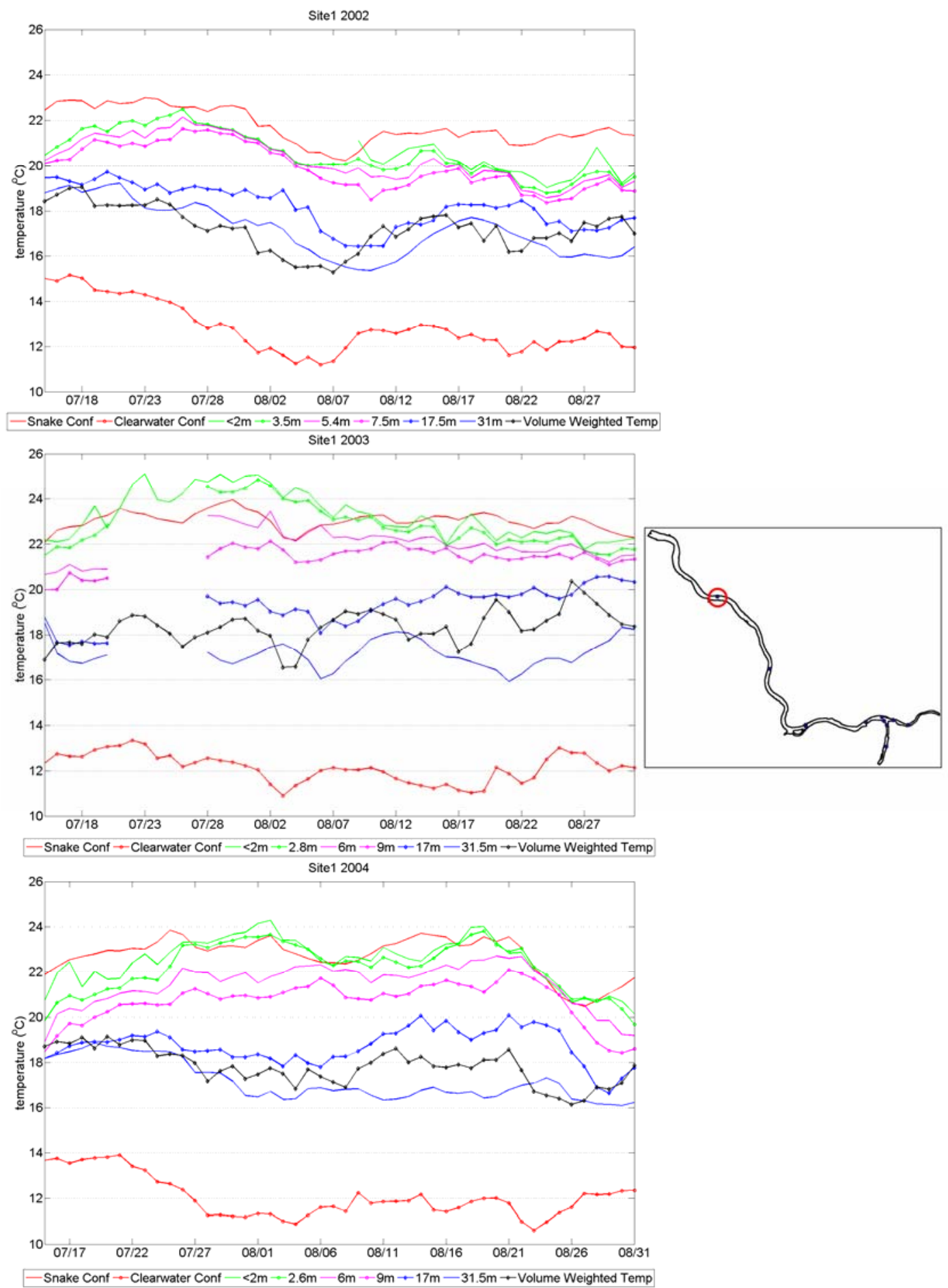

Figure 4.14. Daily-average water temperatures at Site 1 for 2002, 2003, and 2004. Data reported as 'Snake Conf' and 'Clearwater Conf' were collected at Sites 9 and 11, respectively, and 'Volume Weighted Temp' lines were computed using these values. 

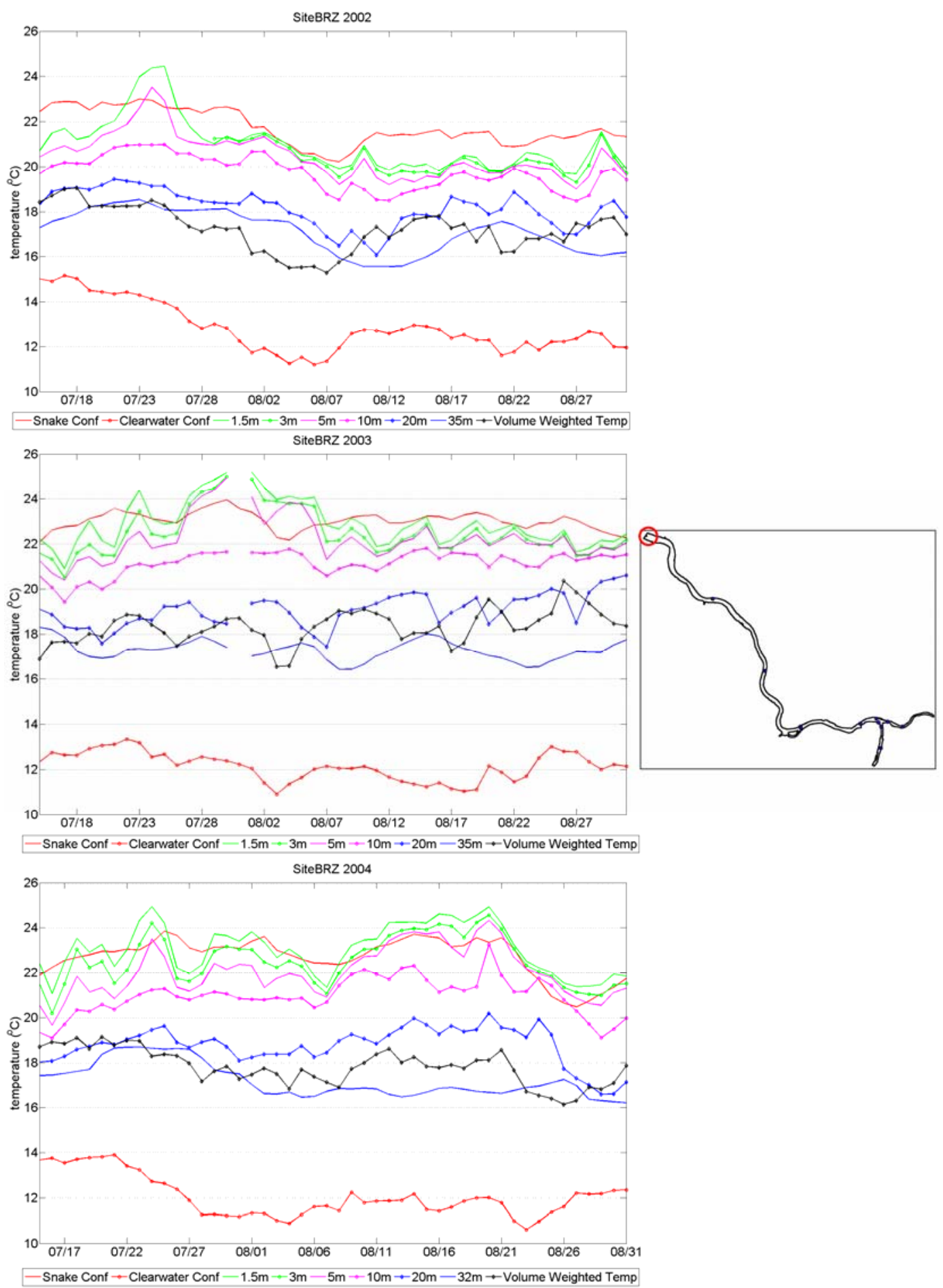

Figure 4.15. Daily-average water temperatures in LWG forebay BRZ for 2002, 2003, and 2004. Loggers 'Snake Conf' and 'Clearwater Conf' were collected at Sites 9 and 11, respectively, and 'Volume Weighted Temp' lines were computed using these values. 


\subsection{Three-Dimensional Numerical Modeling of the Confluence}

A three-dimensional (3D) numerical model of the confluence zone was developed to further refine understanding of mixing and entrainment (Cook and Richmond 2004). The hydraulic conditions in this zone vary rapidly over depth, laterally across the river, and with distance downstream; necessitating use of a 3D non-hydrostatic model.

\subsubsection{Model Selection}

Hydrodynamic and water quality (i.e., temperature) modeling of the confluence zone was accomplished using Flow-3D, a commercial software package supported through Flow Science, Inc. The model has a large user base and has been previously tested under a wide range of applications by multiple researchers including Bradford (2000), Bombardelli et al. (2001), and Savage and Johnson (2001). In addition to applying Flow-3D to the confluence, PNNL has previously simulated the entire reservoir using both the 2D model CE-QUAL-W2 (see Chapter 6) and MASS2 (Richmond et al. 2000), and the 3D model Environmental Fluid Dynamic Code (EFDC) (Cook et al. 2003; Rakowski et al. 2003). Flow-3D was chosen for this application because it is fully three-dimensional and does not employ the hydrostatic pressure assumption or a stretched vertical transformation.

Flow-3D uses the finite volume method to solve the three-dimensional Reynolds-averaged NavierStokes (RANS) equations. The physical domain to be simulated was outlined and then decomposed into hexahedral (brick) cells. These cells were filled with either fluid (water at variable density) or solid (ground) in this 'rigid-lid' model application. Definition of the solid bathymetry was based on the bathymetry dataset collected by this project and documented in Cook et al. (2003).

For each model application in this study, two separate domains were used. The first was with coarse grid used to 'warm-up' the simulated domain to conditions appropriate for the scenario. The simulated domain was decomposed into approximately 1.4 million cells that were $15 \mathrm{~m}$ by $15 \mathrm{~m}$ in the horizontal direction and $1.5 \mathrm{~m}$ high in the vertical direction. The second domain was smaller in horizontal extent; however, grid refinement was higher. The finer domain totaled approximately 2.5 million cells that were $5 \mathrm{~m}$ by $5 \mathrm{~m}$ in the horizontal direction and $0.75 \mathrm{~m}$ high in the vertical direction.
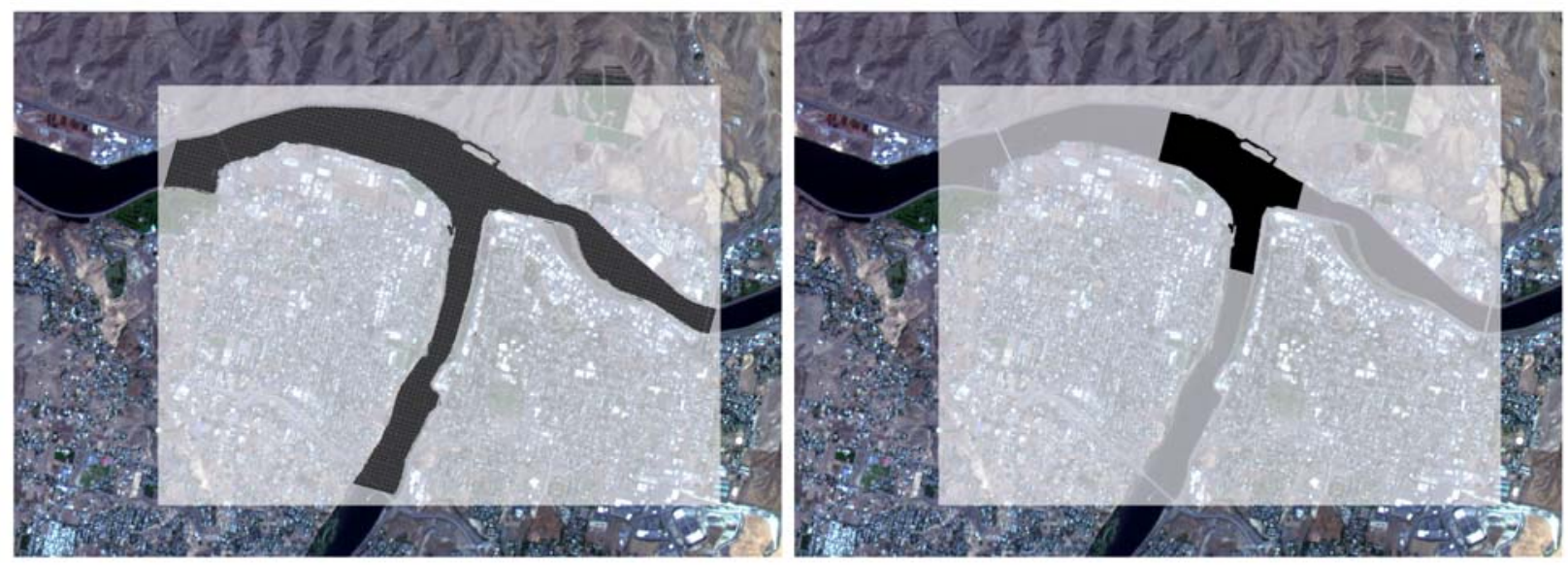

Figure 4.16. Extent of the coarse (left) and fine (right) domain 3D confluence zone model 
The upstream Snake and Clearwater river model boundary conditions for the model were specified inflow density and discharge for the simulated period at Sites 9 and 11, respectively. Density specified at these upstream boundaries was derived from observed temperature loggers and United Nations Educational, Scientific, and Cultural Organization (UNESCO 1983). Discharges were obtained by routing the nearest U.S. Geological Survey (USGS) stream gage downstream to the Flow-3D boundary using MASS1 (Perkins and Richmond 2001). For the fine domain model, the computed coarse domain solution was held fixed along the upstream boundary. The Flow-3D downstream boundary for both the coarse and fine models was an outflow, or Summerfeld radiation, condition which allows downstream traveling waves to continue past the boundary with a minimum of reflection.

\subsubsection{Simulated Hydraulic Conditions for the Small Temperature and Small Discharge Difference Circulation Pattern}

A computational fluid dynamics (CFD) model of this circulation pattern (see Section 4.2.1) was developed by simulating conditions on April 4, 2002, at approximately midnight. This corresponds to the time when the MTI satellite image shown in Figure 4.5 was collected. The water surface elevation at the confluence was $224 \mathrm{~m}(734.9 \mathrm{ft})$, and the inflowing temperatures were $5.8^{\circ} \mathrm{C}\left(\right.$ density $\left.=999.949 \mathrm{~kg} / \mathrm{m}^{3}\right)$ and $7.4^{\circ} \mathrm{C}\left(\right.$ density $\left.=999.885 \mathrm{~kg} / \mathrm{m}^{3}\right)$ for the Clearwater and Snake rivers, respectively. Based on MASS1 routed discharges, the upstream velocity boundary conditions specified in the model were $0.89 \mathrm{~m} / \mathrm{s}$ and $0.32 \mathrm{~m} / \mathrm{s}$ for the Clearwater and Snake rivers, respectively.

CFD model results shown in Figure 4.17 display a pattern similar to those captured in the MTI satellite image shown in Figure 4.5, in which the two rivers are shown flowing parallel to each other downstream of the confluence at the surface. Beneath the surface at elevation $219.4 \mathrm{~m}(719.8 \mathrm{ft})$, some mixing is predicted by the model. The model is fully transient and, although upstream boundary
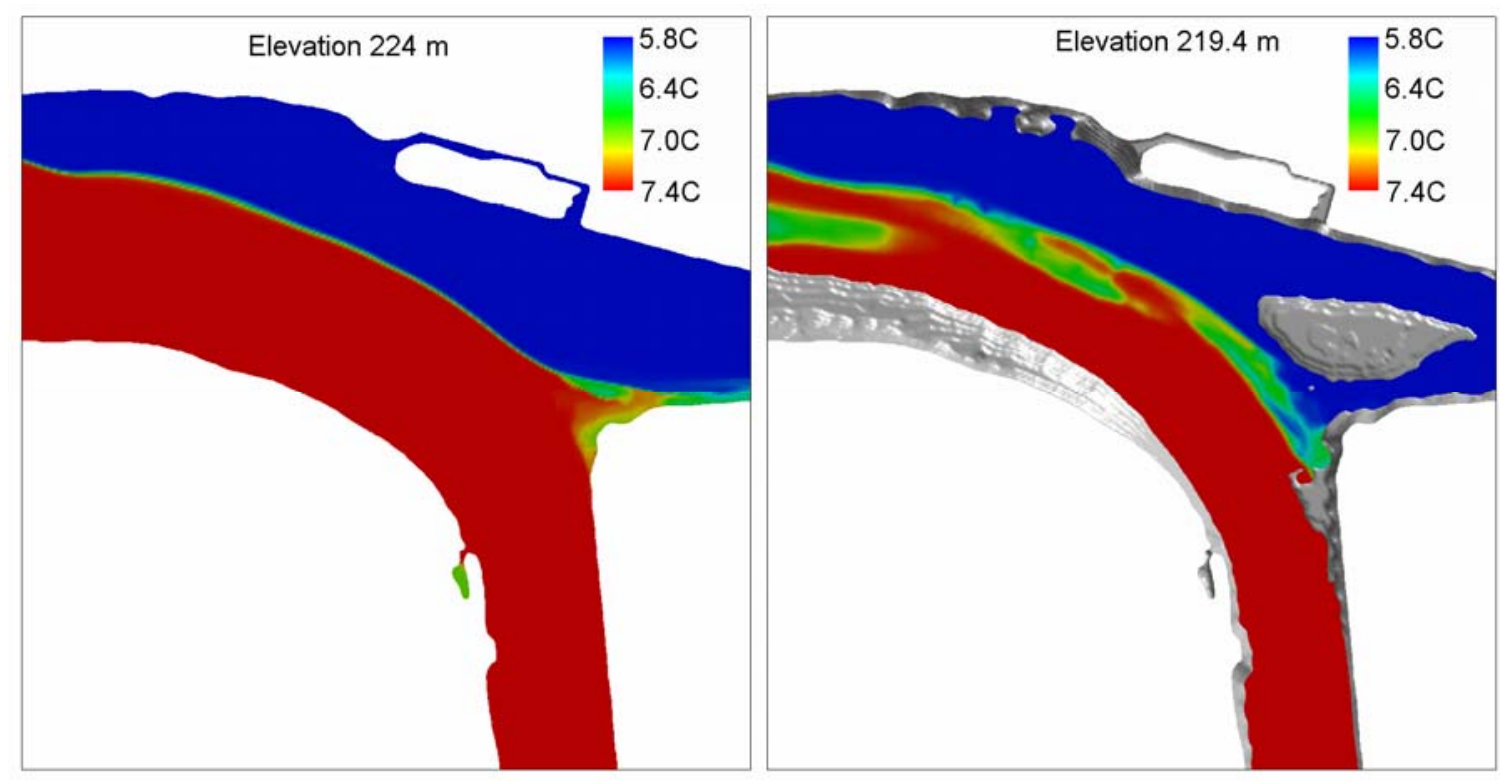

Figure 4.17. Temperature simulation results for April 4, 2002, at two elevations. Vertical dimension has been exaggerated by 10 to show variations in bathymetry for the left graphic. 
conditions were held steady, the exact location of the interface moved (waved) slightly over time, both at the surface and below. The pattern shown at elevation $219.4 \mathrm{~m}$ is for a single snapshot in time, and variations in location of the $6^{\circ} \mathrm{C}$ (green) mixed water evolved and moved downstream as time progressed forward in the simulation.

CFD results shown in the upper portion of Figure 4.18 display slices of temperature throughout the modeled domain at one time step. Native Clearwater and Snake river water are colored blue and red, respectively. Intermediate colors indicate mixing and entrainment as the rivers meet and then follow the river bend downstream. The bottom portion of Figure 4.18 displays streamline tracks for particles seeded at the downstream end of the domain in areas that consisted of unmixed Snake and Clearwater river water. Streamline tracks were then tracked backward in time (upstream) to determine particle origins at the upstream end of the domain.

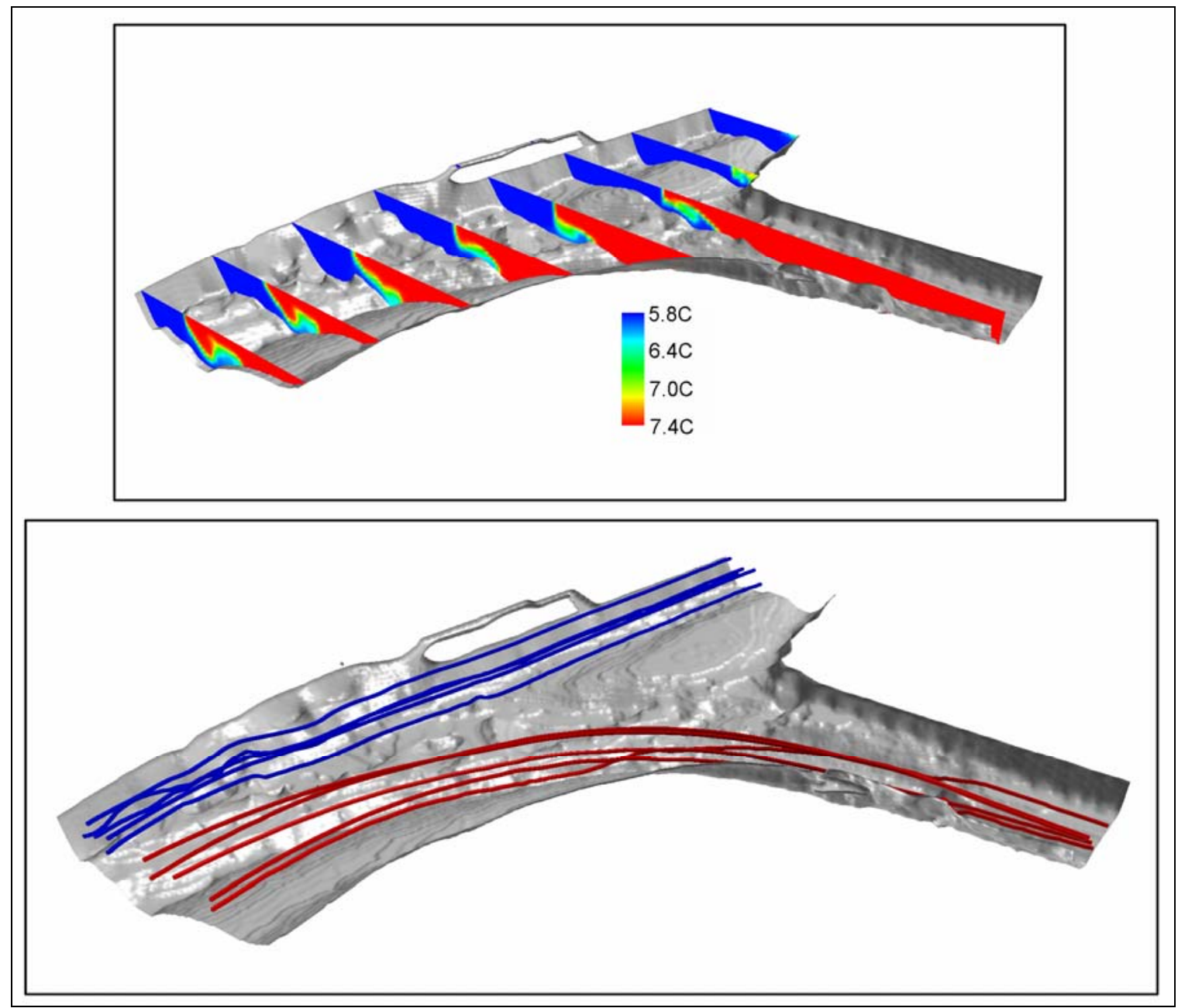

Figure 4.18. Contours of temperature (upper) and streamline tracks (lower) colored by temperature for the April 4, 2002, CFD simulation. Vertical dimension has been exaggerated by 10 to show variation. 


\subsubsection{Simulated Hydraulic Conditions for the Large Temperature Difference Circulation Pattern}

A CFD model of this circulation pattern (see Section 4.2.3) was developed by simulating conditions on July 21, 2002, at approximately 11:00 hours. This circulation corresponds to the time when the MTI satellite image shown in Figure 4.8 was collected. The water surface elevation at the confluence was $223.9 \mathrm{~m}(734.7 \mathrm{ft})$, and the inflowing temperatures were $13.5^{\circ} \mathrm{C}\left(\right.$ density $\left.=999.314 \mathrm{~kg} / \mathrm{m}^{3}\right)$ and $22.4^{\circ} \mathrm{C}$ $\left(\right.$ density $\left.=997.681 \mathrm{~kg} / \mathrm{m}^{3}\right)$ for the Clearwater and Snake rivers, respectively. Based on MASS1 routed discharges, the upstream velocity boundary conditions specified in the model were $0.68 \mathrm{~m} / \mathrm{s}$ and $0.22 \mathrm{~m} / \mathrm{s}$ for the Clearwater and Snake rivers, respectively.

CFD model results shown in Figure 4.19 display a pattern similar to those captured in the MTI satellite image shown in Figure 4.8, which shows the Clearwater River subducting beneath the Snake River at the confluence. Beneath the water surface at elevation $219.4 \mathrm{~m}$ (719.8 ft), a slice through the CFD results at the thermocline is also shown. The CFD model is fully transient and, although upstream boundary conditions were held steady, the pattern shown at elevation $219.4 \mathrm{~m}$ varied over time as water mixed and moved downstream.

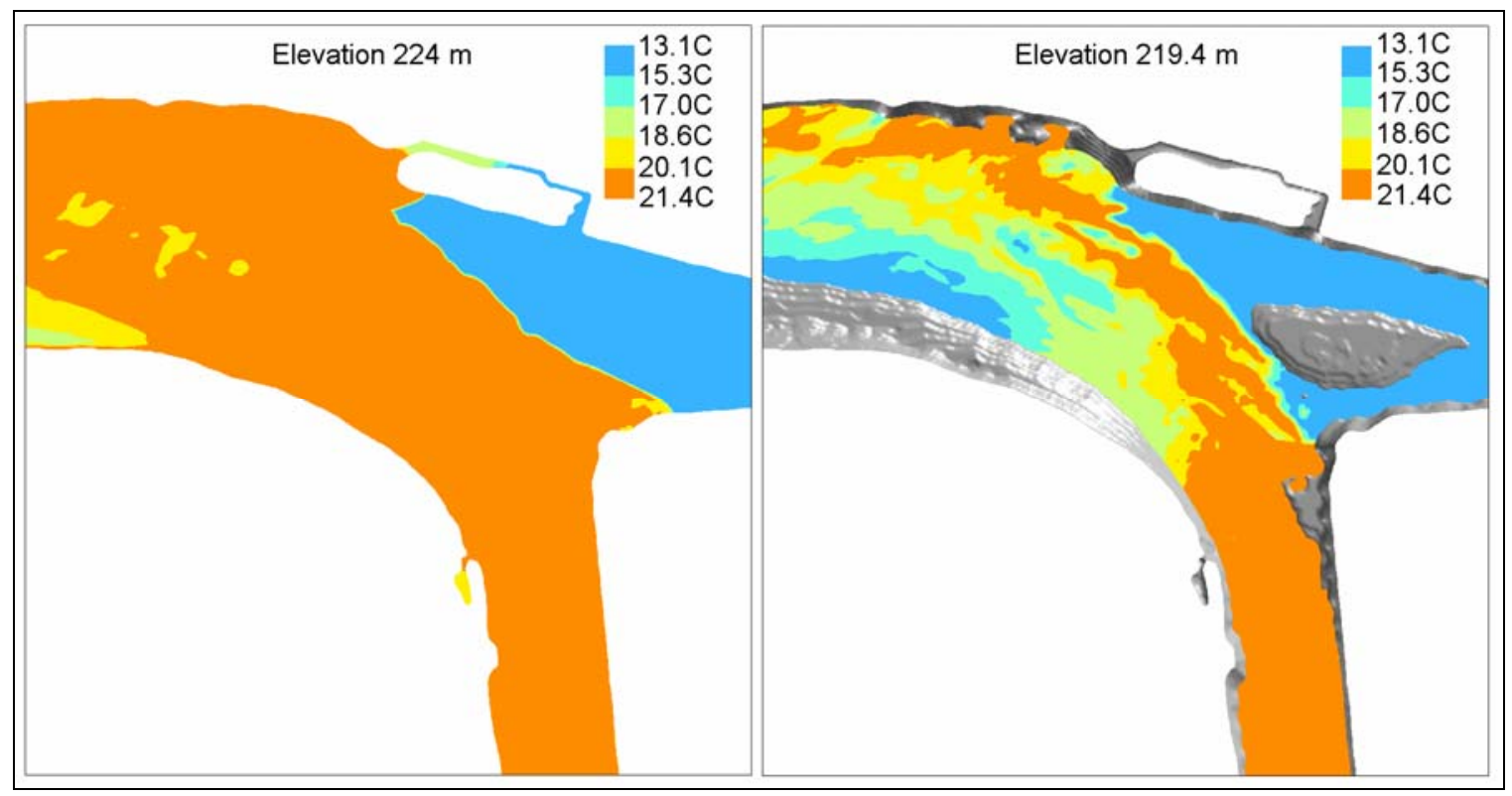

Figure 4.19. Temperature simulation results for July 21, 2002, at two elevations. Color contours are similar to those shown in Figure 4.8.

CFD results shown in the upper portion of Figure 4.20 display slices of temperature through the modeled domain at one time step. Native Clearwater and Snake river water are colored blue and red, respectively. Intermediate colors indicate mixing and entrainment as the rivers meet and follow the river bend downstream. For comparison, the bottom portion of Figure 4.18 displays streamline tracks for particles seeded at the downstream end of the domain as in Figure 4.18. Streamline tracks were again tracked backward in time (upstream) to determine particle origins at the upstream end of the domain. Tracks were then colored by temperature, as in the upper portion of Figure 4.20. 


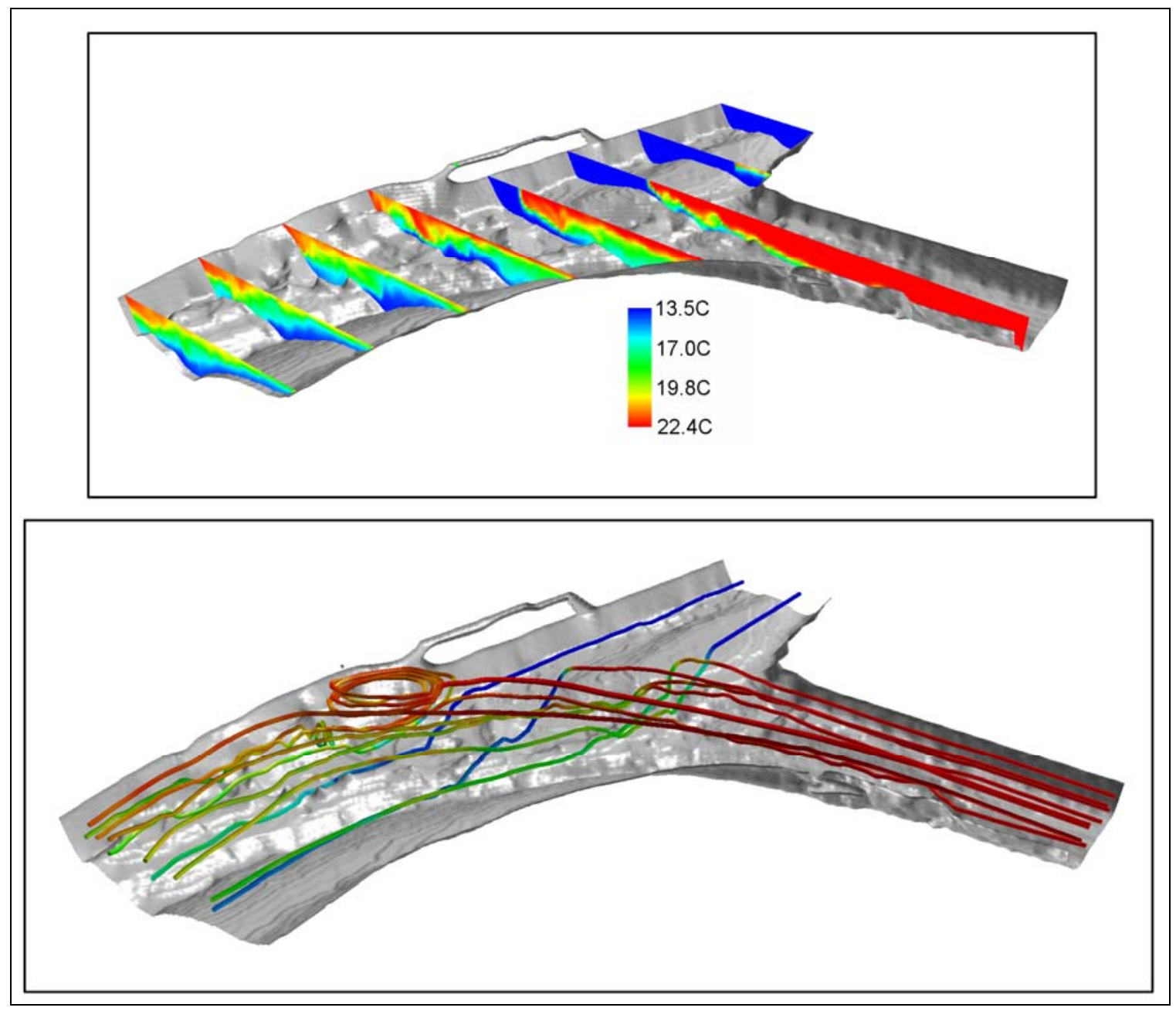

Figure 4.20. Contours of temperature (upper) and streamline tracks (lower) colored by temperature for the July 31, 2002, CFD simulation. Vertical dimension has been exaggerated by 10 to show variation.

Figure 4.21 was created by seeding the hypolimnetic zone of the vertical computational plane with streamline particles. Particles were then tracked backward in time to their upstream origins in the Clearwater River. Tracks have been colored by temperature. The predominant location of Clearwater River flow that, when reaching the opposite bank of the Snake River, turned right and slowly progressed upstream the Snake River, originated from the right bank of the Clearwater River. This pattern of flow was confirmed in the field by both ADCP and temperature/conductivity profiles. 


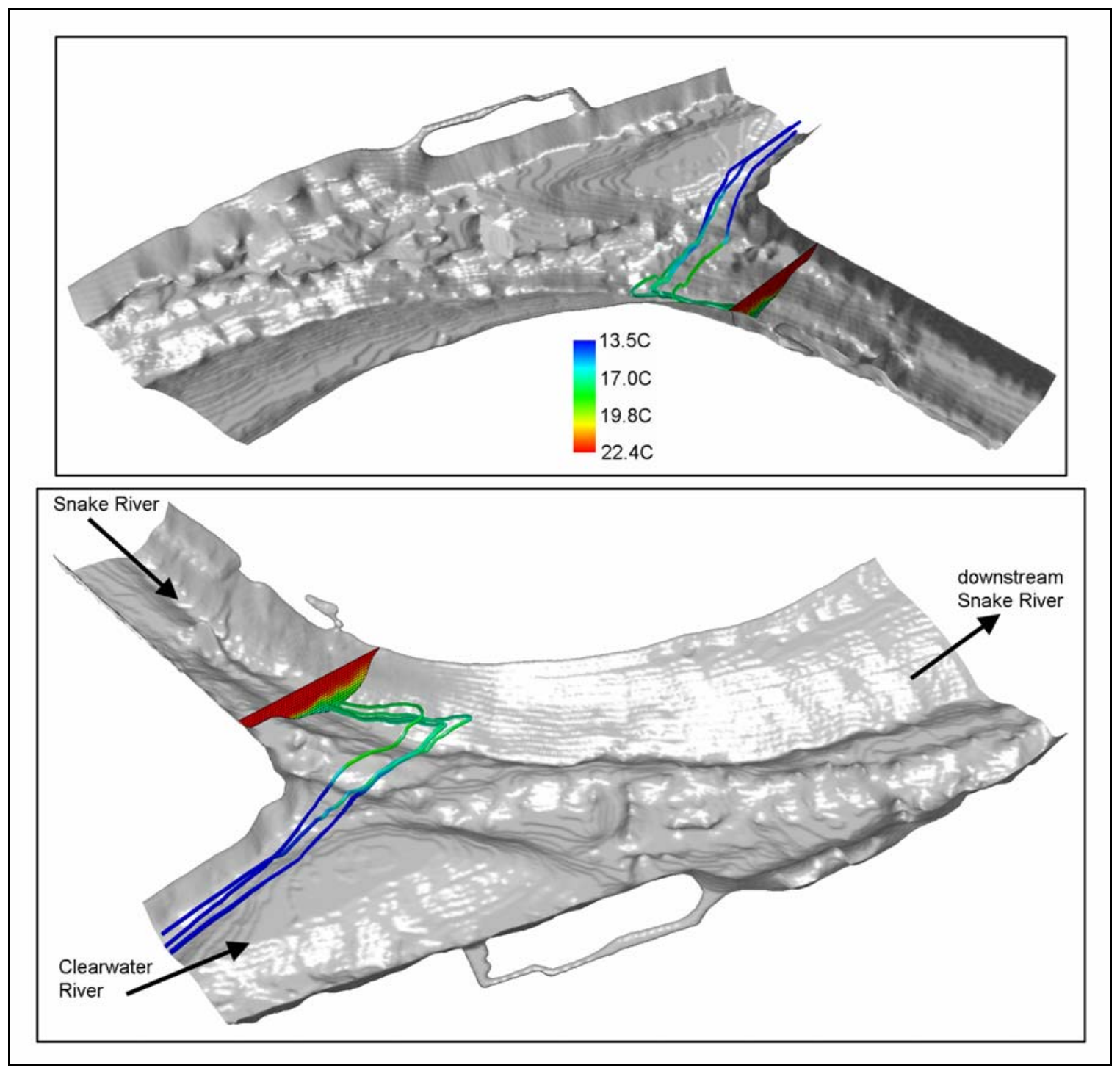

Figure 4.21. Two views of streamline tracks that migrate downstream the Clearwater River and then upstream along the bottom of the Snake River. Tracks were colored by temperature and are from the July 31, 2002, CFD simulation. Vertical dimension has been exaggerated by 10 to show variation. 


\subsection{Lower Snake River: General Current Structure}

At the start of this study, little information had been published regarding stratification of the lower Snake River during the late summer months while cold releases from Dworshak Reservoir were occurring. This project found that during these months, each of the four lower Snake reservoirs stratify to various intensities depending on the quantity of cold water released, difference in temperature between the Clearwater and Snake rivers at the confluence in Lower Granite Reservoir, and meteorological conditions. This chapter describes general reservoir-wide circulation patterns that developed during the summer months of 2002 through 2004. In particular, the reservoirs were found to develop into two layers, with the upper layer being particularly sensitive to wind blowing across the water surface. In addition, a latter section quantifies temperature differences in the four reservoirs by comparing a similar period (July 15 through August 15) for 2002 through 2004. Maximum, mean, and minimum temperature differences between the upper and lower water column were compared and contrasted over the three study years.

\subsection{Wind Setup and Mid-Pool Warming}

During this project, we noted that there were multi-day-long periods when mid-pool temperatures in the upper part of the water column (top 5 to $10 \mathrm{~m}$ ) were warmer than at similar depths downstream near the dam. In fact, the upper water column mid-pool loggers were sometimes warmer than downstream loggers at a shallower depth (even the surface). This was initially counter-intuitive because water entering at the upstream end of the reservoir was below equilibrium temperature and was thought to continuously warm while traveling downstream. This assumption was shown to be incorrect by these field data, and we now propose that wind setup may be the cause of this phenomenon.

Observed upstream, mid-pool, and downstream time-series of water temperatures collected in Little Goose Reservoir (see Figure 5.1) during 2003 and 2004 are shown in Figures 5.2 and 5.3. These data were collected by Carroll and Barko (2005), and data were reported at depths of 0.5, 1.5, 3.0, 5.0, 10.0, 15.0 , and $20 \mathrm{~m}$.

Little Goose mid-pool water temperatures during periods of flow augmentation were warmer for several three- to four-day periods during both 2003 and 2004 and can be identified in the figures anytime the red line is above the blue line. During these periods, the $10 \mathrm{~m}$ depth mid-pool logger was also warmer than $5 \mathrm{~m}$ depth BRZ logger (red line above green line).

Based on these data, a hypothesis was developed that the stratified reservoirs were responding to wind blowing across the water surface. Figure 5.4 shows a schematic representation of the wind driven phenomenon. Typical wind magnitudes recorded at the AgriMet Rice Bar meteorological station during flow augmentation were largest in the afternoon with magnitudes of $3 \mathrm{~m} / \mathrm{s}$ and oriented in an upstream direction. We hypothesized that wind holds the upper layer of the stratified reservoir in place or moves the layer slightly upstream, therefore providing additional time for this upper layer to be exposed to surface heating processes. Near the dam (boat restricted zone boundary) mixing processes appear to entrain cooler hypolimnetic water into the epilimnion, thereby causing the observed cooling in the upper 


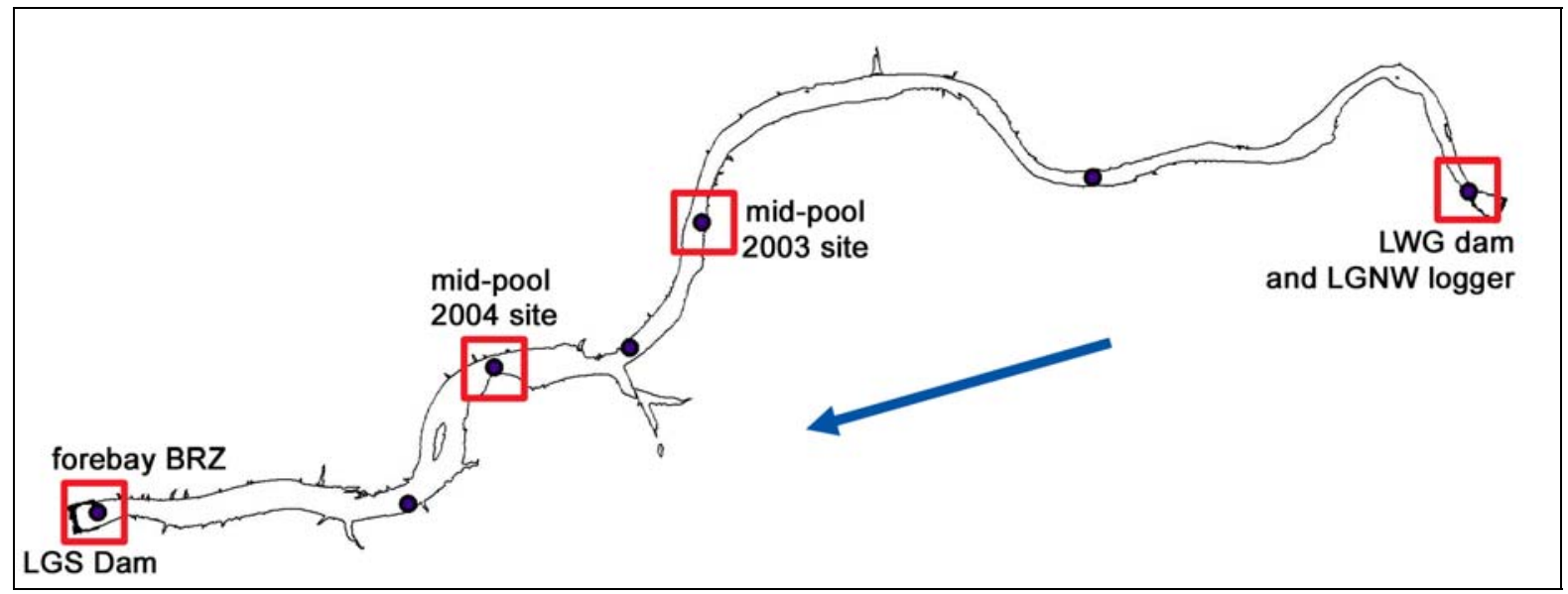

Figure 5.1. Little Goose Reservoir map showing location of temperature loggers. Blue arrow represents the general direction of flow from Lower Granite Dam to Little Goose Dam.

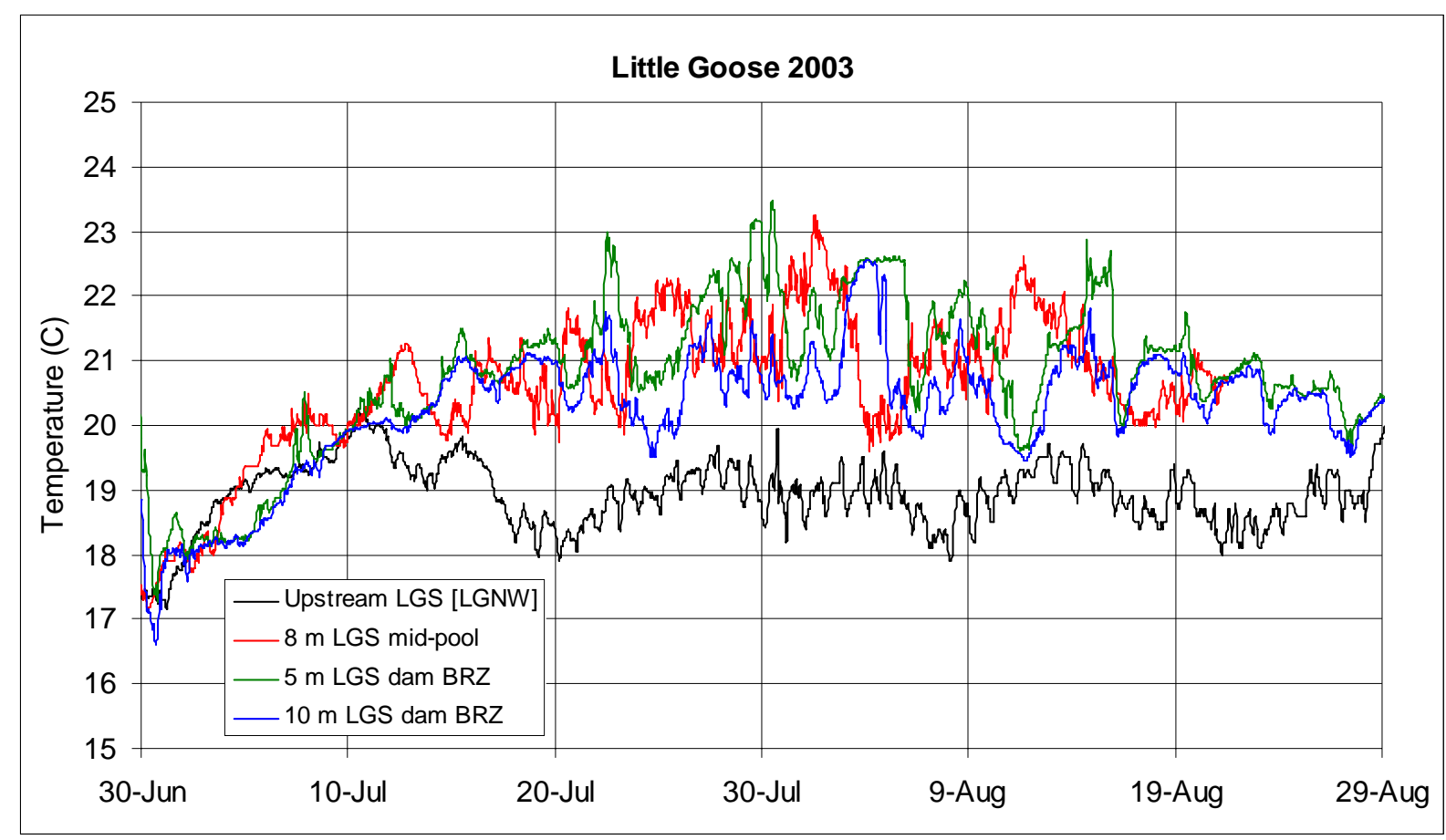

Figure 5.2. $\quad$ Little Goose Reservoir water temperature time-series data during 2003

layer of the reservoir. Phenomena occurring near the dam are not well understood and require further investigation into the physical processes causing decreases in surface water temperatures near the dam.

To test the wind setup hypothesis (Figure 5.4), ADCP data were collected on July 24, 2005. A single transect near the 2004 mid-pool logger string is shown in Figure 5.5 although other transects can be viewed in Appendix B. The water column on this day in 2005 was strongly stratified, with upper water column ( $>5 \mathrm{~m}$ depth) approximately $3^{\circ} \mathrm{C}$ above hypolimnetic temperatures. A sharp break in both velocity magnitude and direction is evident at a depth of approximately $7 \mathrm{~m}$. In the upper $5 \mathrm{~m}$ of the water column, the upper layer is moving between 0 (i.e., still) to $10 \mathrm{~cm} / \mathrm{s}$ upstream, while in the lower 


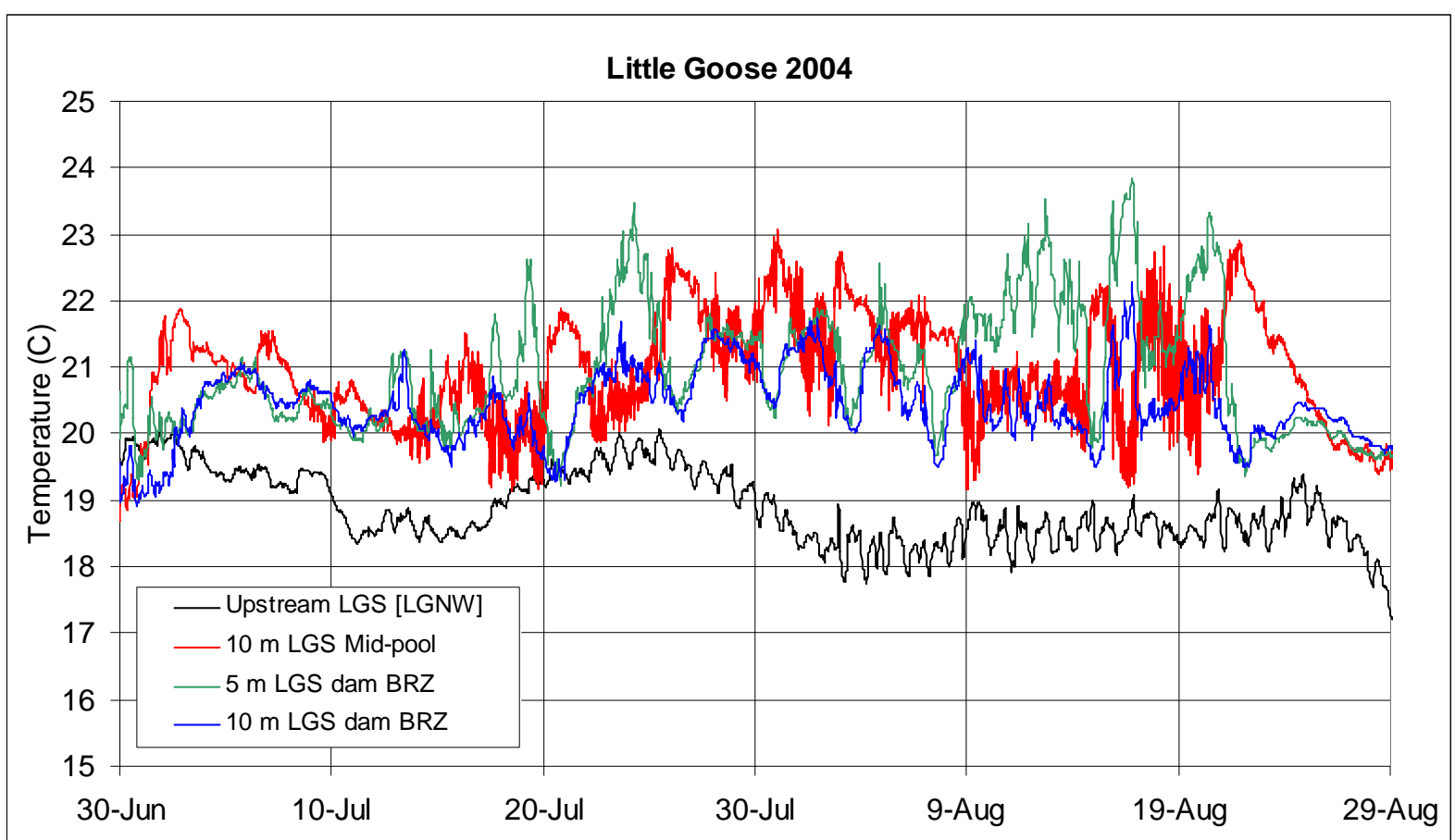

Figure 5.3. L Little Goose Reservoir water temperature time-series data during 2004

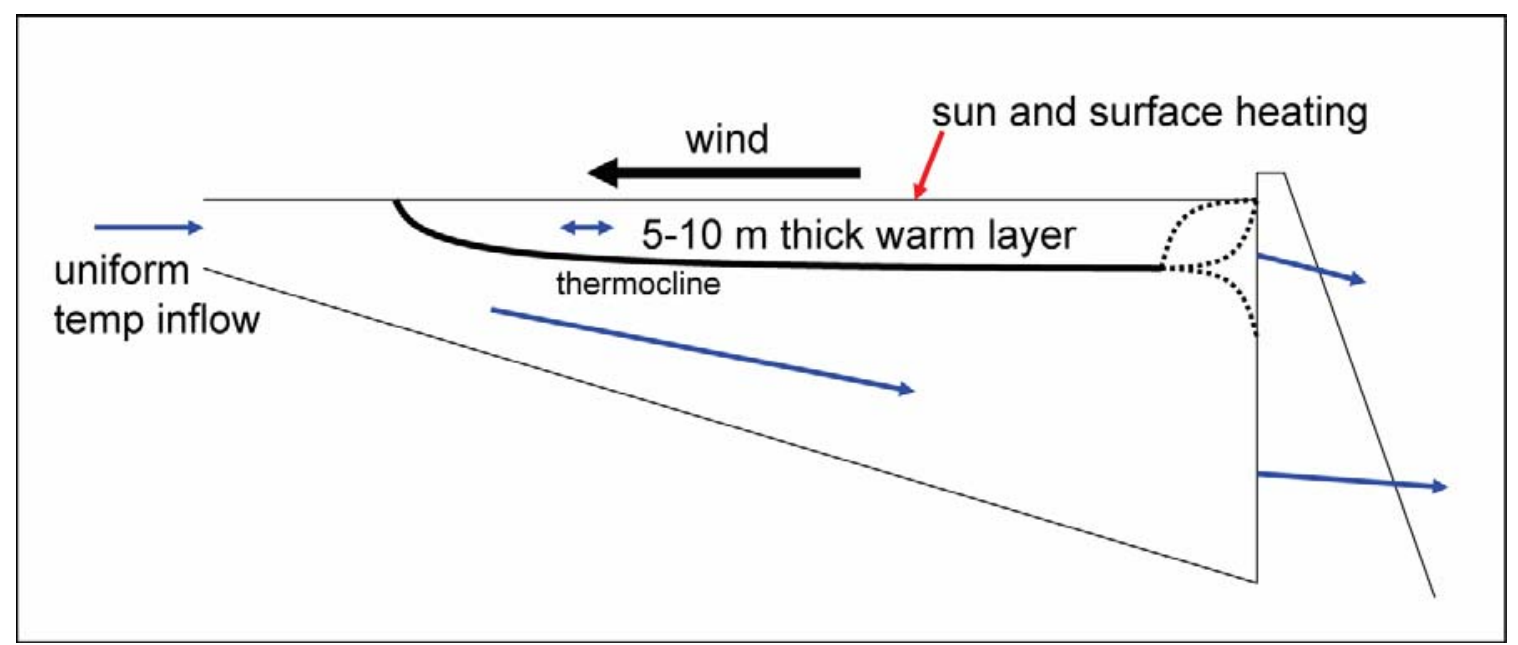

Figure 5.4. Schematic of wind-driven circulation pattern hypothesized to occur in the lower Snake River reservoirs

water column, the water is moving downstream between 15 and $25 \mathrm{~cm} / \mathrm{s}$. A shear layer of approximately $0 \mathrm{~m} / \mathrm{s}$ velocity magnitude is evident at a depth of approximately $7 \mathrm{~m}$. At the time of data collection, the wind was blowing upstream at approximately $1.9 \mathrm{~m} / \mathrm{s}$ at the Rice Bar Meteorological Station (approximately halfway between the 2003 mid-pool site and LWG dam).

Similar mid-pool temperature phenomena were observed in Lower Monumental pool during both 2003 and 2004. Occurrence of the phenomena can be seen by comparing red lines to green lines in Figures 5.6 and 5.7. Downstream in Ice Harbor pool and upstream in Lower Granite Reservoir, the phenomena were not strongly observed during either 2003 or 2004 . For comparison to the other 

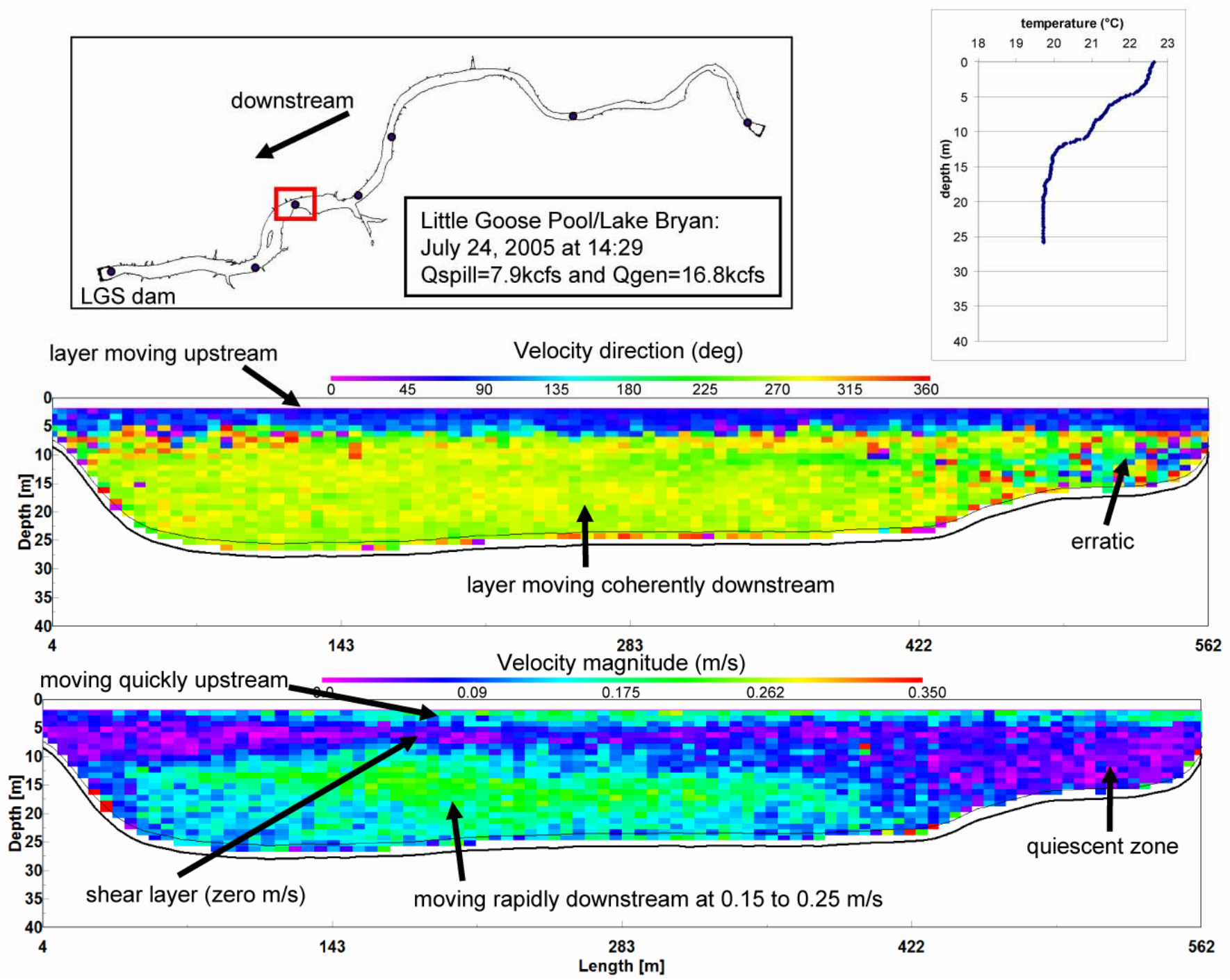

Figure 5.5. $\quad$ ADCP transect collected in Little Goose Pool on July 24, 2005. At the time of the data collection wind was blowing upstream at approximately $1.9 \mathrm{~m} / \mathrm{s}$. Top 5 to $7 \mathrm{~m}$ of the water column moving upstream. 


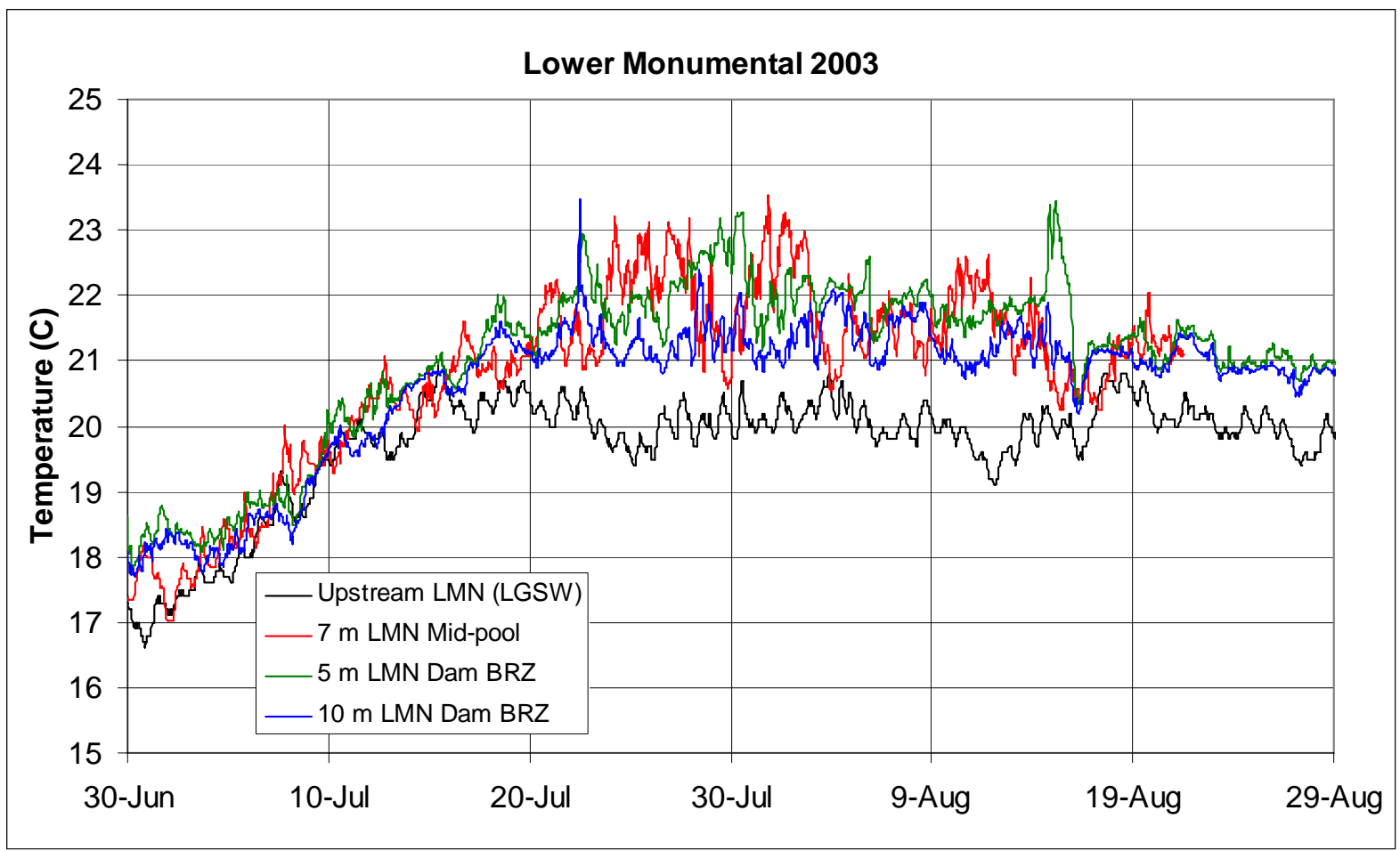

Figure 5.6. Lower Monumental Reservoir water temperature time-series data during 2003

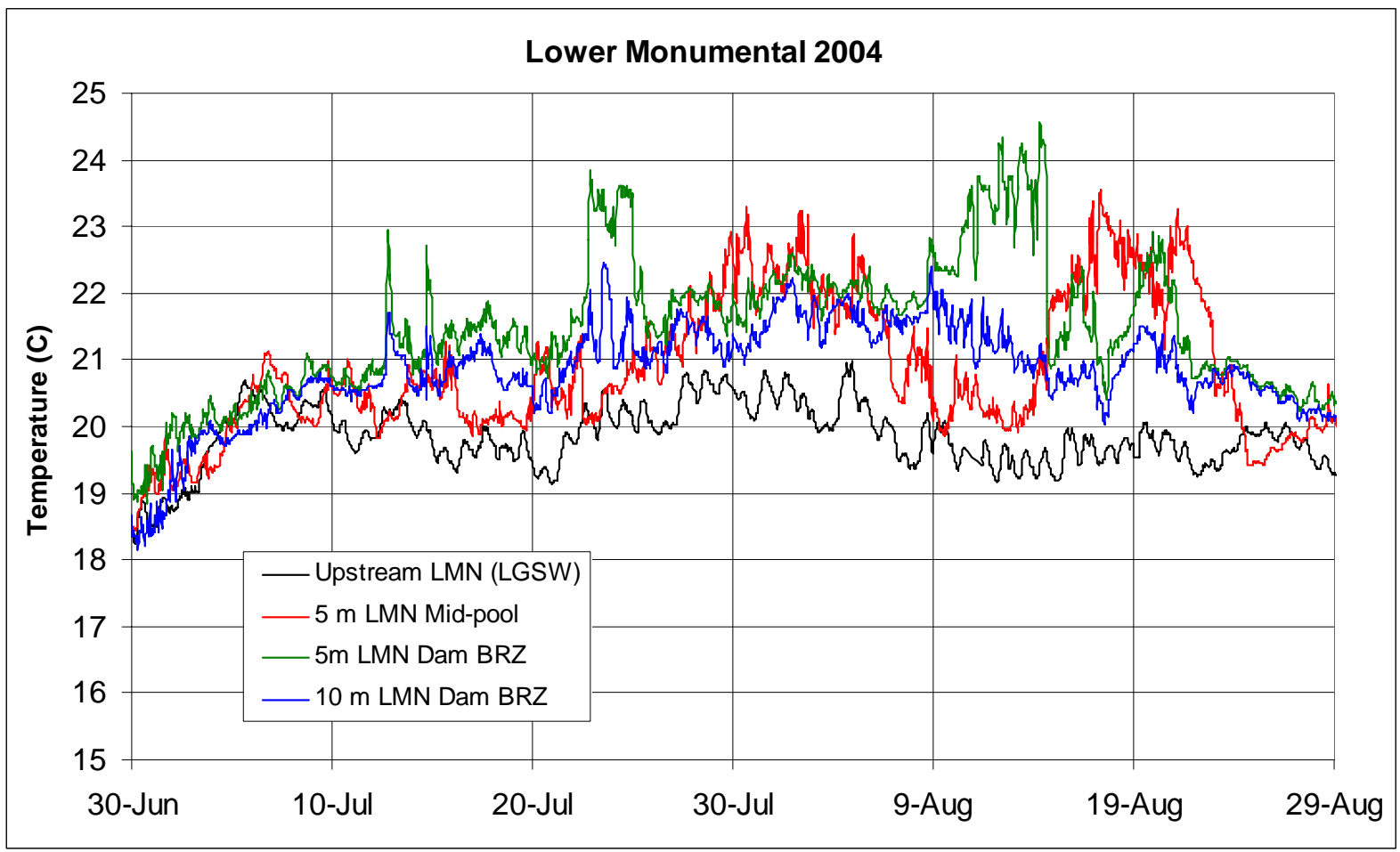

Figure 5.7. Lower Monumental Reservoir water temperature time-series data during 2004 
reservoirs, Ice Harbor data are shown in Figure 5.8. Lower Granite Reservoir data can be seen by comparing upper water column values in Figures 4.14 and 4.15.

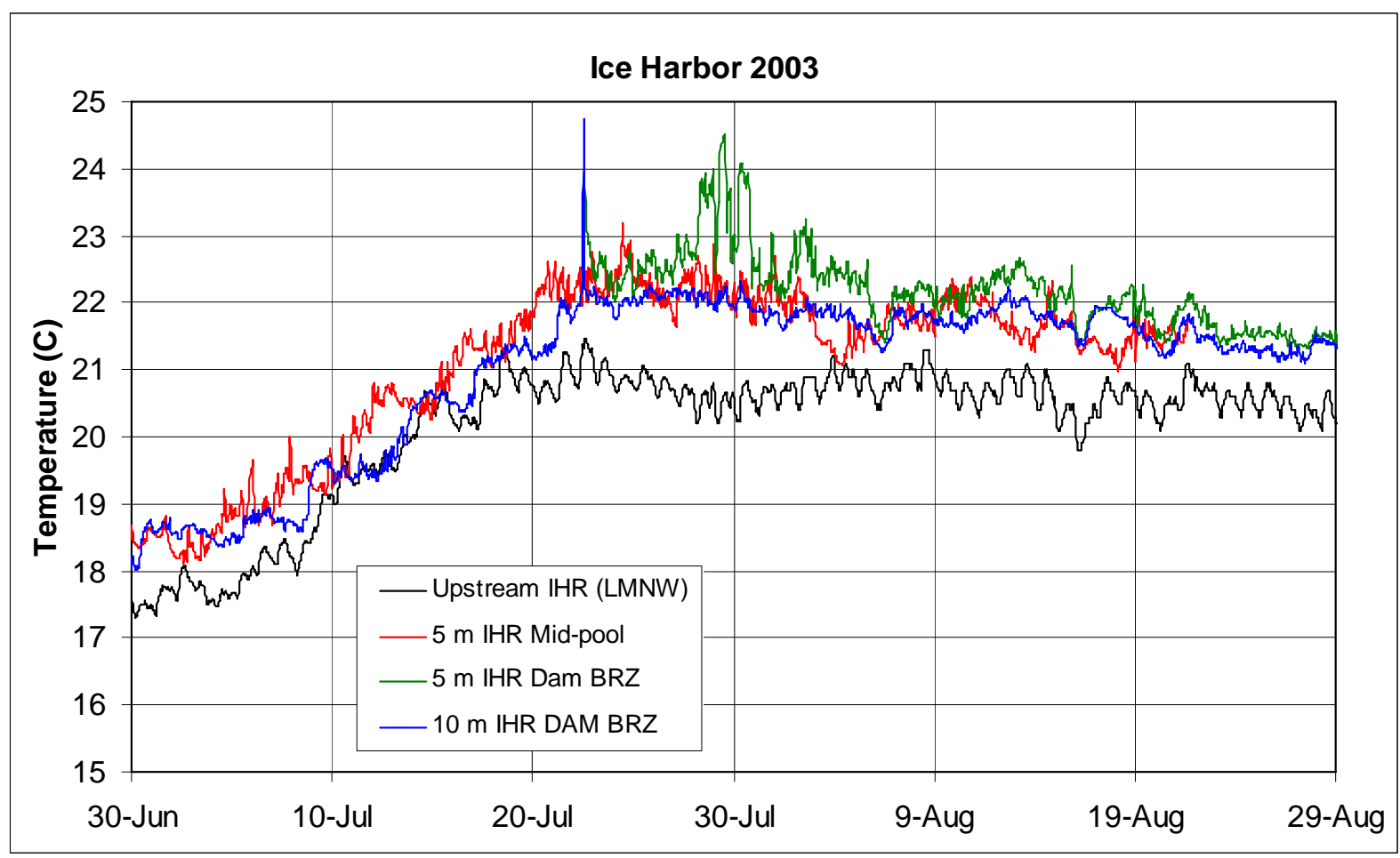

Figure 5.8. Ice Harbor Reservoir water temperature time-series data during 2003

\subsection{Stratification Intensity Throughout the Snake River System}

Large volumes of cold water released from the Dworshak Reservoir hypolimnion during summer will produce stratification in the lower Snake River system. Temperature differences are greatest at the confluence when the Clearwater and Snake rivers meet. Depending upon the discharge ratio and temperature differences (see Section 4.2), various levels of mixing are achieved in Lower Granite Reservoir.

Releases from Lower Granite Dam under current system-wide operation rules (see Section 2.2; Dworshak Reservoir SOR (2005)) typically produce uniform temperatures in the tailrace just below $20^{\circ} \mathrm{C}$ during the flow augmentation period. Because this temperature is below equilibrium, the reservoir downstream will again stratify. The strength of stratification is dependent upon river discharge, pool depth, and meteorological conditions. Releases from dams downstream of Lower Granite Dam are also below equilibrium temperature. As in Little Goose Reservoir, stratification will again develop in the reservoir, the strength of which depends upon discharge, reservoir depth, and meteorological conditions.

During all three years, near-dam epilimnetic water temperatures decreased by approximately $1^{\circ} \mathrm{C}$ between Lower Granite and Little Goose pools. Downstream of Little Goose Dam, epilimnetic temperatures again rose, and during most years, epilimnetic values in Ice Harbor Reservoir matched epilimnetic values in Lower Granite Reservoir. In contrast, temperatures in the hypolimnion progressively increase when traveling downstream across all 4 reservoirs and all 3 years. 
The left side of Figure 5.9 displays July 15 through August 15 averaged mean temperatures recorded at temperature loggers placed in the forebay BRZ upstream of each lower Snake River dam. Data were collected by Carroll and Barko (2005), and their loggers were placed at depths of $0.5 \mathrm{~m}, 1.5 \mathrm{~m}, 3.0 \mathrm{~m}, 5.0$ $\mathrm{m}$, and then in $5 \mathrm{~m}$ increments to the reservoir bottom. To compute a measure of stratification intensity, the second logger at a depth of $1.5 \mathrm{~m}$ was selected to not unduly bias results since the $0.5 \mathrm{~m}$ depth was highly influenced by diurnal variations in solar radiation. Likewise, the second-to-deepest logger was selected to represent the hypolimnion. Data from these loggers were subtracted from each other to produce the results shown in the right side of Figure 5.9. Because mid-pool water temperatures were noted to be higher than downstream at the forebay BRZ, temperature difference values shown in the right side of the figure are conservative for the reservoir.

The mean temperature difference (i.e., stratification intensity) at Lower Granite Dam ranges between 4 and $6^{\circ} \mathrm{C}$ across the three years. Differences were highest at Lower Granite Dam, and values are approximately twice those measured at the next dam downstream. Downstream of Little Goose Dam, the stratification intensity consistently declined, however the overall change was less.

Tables 5.1 through 5.3 quantify stratification at each of the reservoirs. The 'mean $1.5 \mathrm{~m}$ ' and 'mean deep' values are those values displayed in the left side of Figure 5.9. The 'difference 1.5-deep' values are those values displayed in the right side of Figure 5.9.

Maximum temperature values at 1.5 and 'deep' were computed by averaging the daily maximum temperatures over the entire period. Values were typically 1 to $2^{\circ} \mathrm{C}$ higher in at $1.5 \mathrm{~m}$ and just under $1{ }^{\circ} \mathrm{C}$ in the hypolimnion.

The 'forebay weighted mean' temperature was computed using the cross-sectional area of the river near the dam to area-weighted each temperature logger value. These weights were then used to produce a depth-averaged mean temperature that took into account the irregular depth spacing of the BRZ temperature loggers. The 'forebay weighted mean' BRZ temperatures were compared to observed values collected in the tailrace at the fixed monitoring station 'Tailrace FMS MEAN'. Although the values are not identical, the weighted-averaged forebay values are similar to those observed in the tailrace and indicate that releases from each dam are (approximately) equal to the depth-averaged forebay temperatures. An exception to this is Lower Granite Reservoir, which followed the rule in 2002, but did not in 2003 and 2004.

Table 5.1. Stratification intensity for lower Snake River reservoirs, 2002, as computed using forebay BRZ and FMS loggers. See figures above for depth of 'deep logger'.

\begin{tabular}{|l|c|c|c|c|}
\hline July 15 through August 15, 2002 & LWG & LGS & LMM & IHR \\
\hline mean $1.5 \mathrm{~m}$ & 21.33 & 20.78 & 21.26 & 21.93 \\
\hline max daily $1.5 \mathrm{~m}$ & 24.44 & 23.30 & 23.50 & 22.82 \\
\hline mean deep & 17.56 & 18.98 & 19.71 & 20.66 \\
\hline max daily deep & 19.05 & 20.27 & 20.66 & 21.48 \\
\hline mean of (1.5 - deep) & 3.77 & 1.80 & 1.56 & 1.27 \\
\hline forebay weighted mean & 18.29 & 19.85 & 20.50 & 21.02 \\
\hline mean tailrace FMS & 18.59 & 19.75 & 20.22 & 20.86 \\
\hline max tailrace FMS & 19.92 & 20.86 & 21.17 & 21.61 \\
\hline
\end{tabular}


Table 5.2. Stratification intensity for lower Snake River reservoirs, 2003, as computed using forebay BRZ and FMS loggers. See figures above for depth of 'deep logger'.

\begin{tabular}{|l|c|c|c|c|}
\hline July 15 through August 15,2003 & LWG & LGS & LMM & IHR \\
\hline mean $1.5 \mathrm{~m}$ & 23.28 & 22.31 & 22.52 & 23.23 \\
\hline max daily $1.5 \mathrm{~m}$ & 25.24 & 23.89 & 23.76 & 25.09 \\
\hline mean deep & 17.52 & 19.57 & 20.40 & 21.07 \\
\hline max daily deep & 18.72 & 20.48 & 20.76 & 21.69 \\
\hline mean of $(1.5-$ deep) & 5.76 & 2.73 & 2.12 & 2.16 \\
\hline forebay weighted mean & 20.59 & 20.47 & 21.25 & 21.82 \\
\hline mean tailrace FMS & 18.89 & 20.08 & 20.52 & 21.65 \\
\hline max tailrace FMS & 19.66 & 20.70 & 21.13 & 22.19 \\
\hline
\end{tabular}

Table 5.3. Stratification Intensity for lower Snake River reservoirs, 2004, as computed using forebay BRZ and FMS loggers. See figures above for depth of 'deep logger'.

\begin{tabular}{|l|c|c|c|c|}
\hline July 15 through August 15, 2003 & LWG & LGS & LMM & IHR \\
\hline mean $1.5 \mathrm{~m}$ & 23.28 & 22.31 & 22.52 & 23.23 \\
\hline max daily $1.5 \mathrm{~m}$ & 25.24 & 23.89 & 23.76 & 25.09 \\
\hline mean deep & 17.52 & 19.57 & 20.40 & 21.07 \\
\hline max daily deep & 18.72 & 20.48 & 20.76 & 21.69 \\
\hline mean of (1.5 - deep) & 5.76 & 2.73 & 2.12 & 2.16 \\
\hline forebay weighted mean & 20.59 & 20.47 & 21.25 & 21.82 \\
\hline mean tailrace FMS & 18.89 & 20.08 & 20.52 & 21.65 \\
\hline max tailrace FMS & 19.66 & 20.70 & 21.13 & 22.19 \\
\hline
\end{tabular}



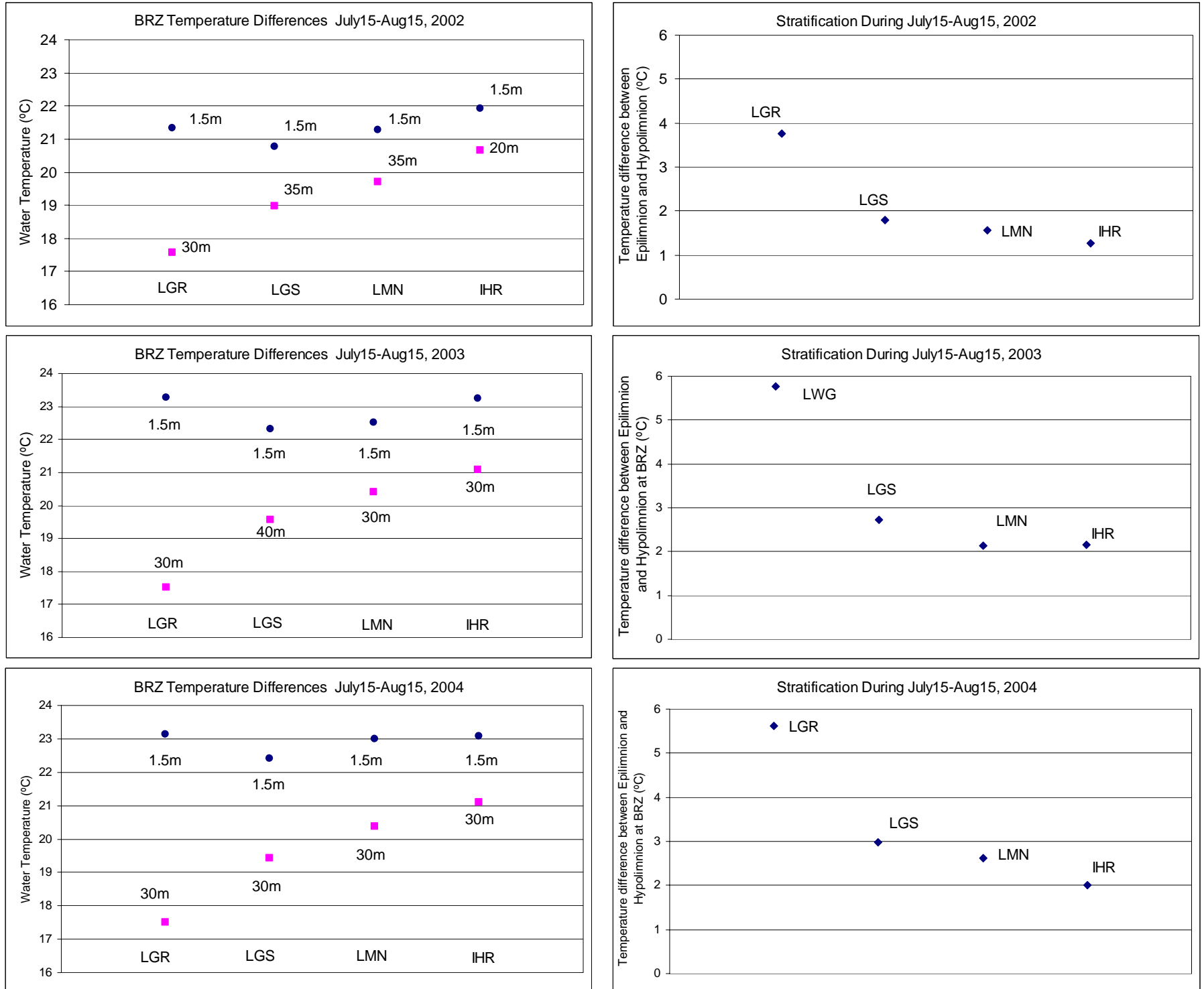

Figure 5.9. Stratification intensity for lower Snake River reservoirs, 2002-2004 


\subsection{Two-Dimensional Hydrodynamic and Water Quality Modeling of the Lower Snake River}

\subsection{Two-Dimensional Model Selection}

A two-dimensional (2D) laterally-averaged hydrodynamic and water quality model was applied to the reservoirs upstream of Lower Granite, Little Goose, Lower Monumental, and Ice Harbor dams. Although several numerical models previously have been applied to these reservoirs (e.g. Richmond et al., 2000; Perkins and Richmond 2001), CE-QUAL-W2 was selected for use in this project due to outcomes decided by the RPA 143 working group (see Chapter 1).

CE-QUAL-W2 assumes complete lateral homogeneity and is best suited for water bodies with negligible lateral gradients. The model solves the conservative form of the Navier-Stokes equations, and the hydrostatic pressure assumption has been applied to simplify the vertical momentum equation. Turbulence terms have been approximated using an eddy viscosity approach, although several methods are available for use. Complete details on the numerical scheme and water quality options can be found in the model documentation (Cole and Wells 2002; Wells 2005).

\subsection{Numerical Representation of Bathymetry and Topography}

\subsubsection{Bathymetry}

As with the three dimensional model, a numerical grid was developed to approximate the bathymetry of the Snake River. A large dataset of bathymetric data was collected in LWG reservoir (see Cook et al. 2003) and from previous PNNL modeling of the reservoirs (Richmond et al. 2000). This information was used to construct the CE-QUAL-W2 (W2) model geometry file. The orientation of each individual segment was determined relative to true north.

Geometric data used to describe the reservoirs were checked by comparing the elevation versus volume ratios computed by W2 to those from the Water Control Manual (Emmert 2003). Storage curves were not compared for Lower Granite Reservoir because similar volume ratios were not available. The normal operating range at each dam is much less than the elevation range shown in the storage curves in Figures 6.1 through 6.3. Storage differences between the Water Control Manual and CE-QUAL-W2 at the normal operating elevation are as follows:

- $\quad$ LGS at elevation $193 \mathrm{~m}(633 \mathrm{ft})=4.6 \%$

- $\quad$ LMN at elevation $164 \mathrm{~m}(538 \mathrm{ft})=9.4 \%$

- $\quad$ IHR at elevation $134 \mathrm{~m}(440 \mathrm{ft})=4.7 \%$.

\subsubsection{Shading}

Local topography can influence the amount of solar radiation reaching the water surface. CE-QUALW2 has numerical algorithms to determine the location of the sun relative to the water surface and local terrain. To use these algorithms, the user must determine inclination angles between the water surface and local terrain crests in 20-degree increments (i.e., 18 values) at every computational node. 


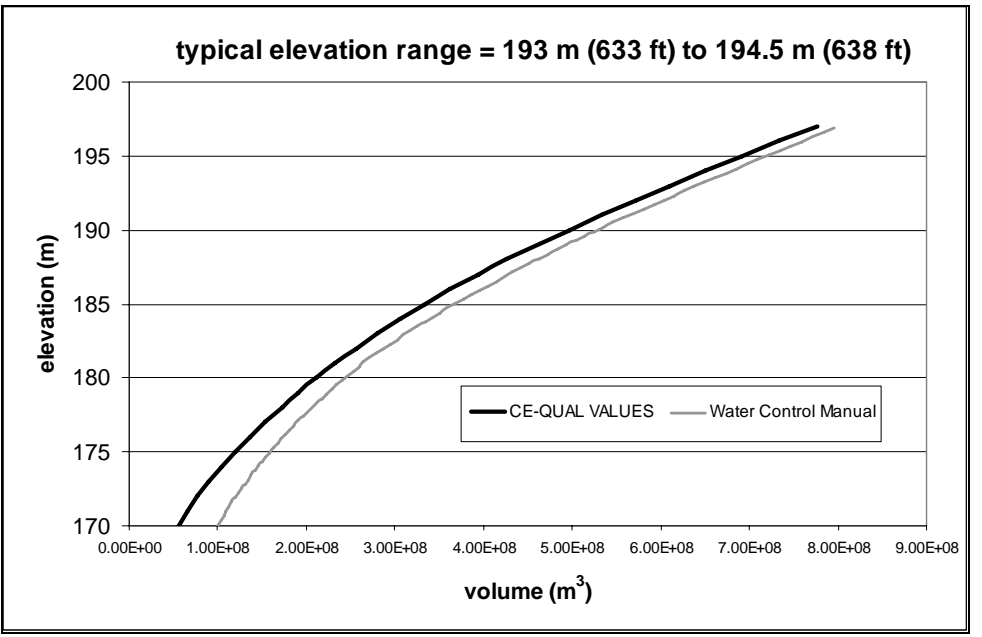

Figure 6.1. LGS Reservoir Storage-Elevation Curves

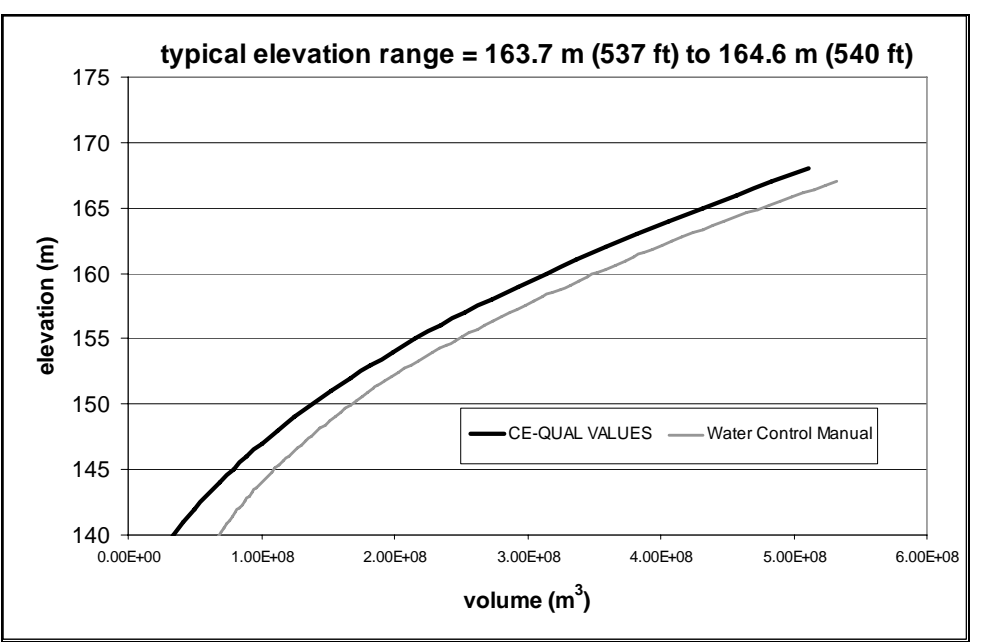

Figure 6.2. $\quad$ LMN Reservoir Storage-Elevation Curves

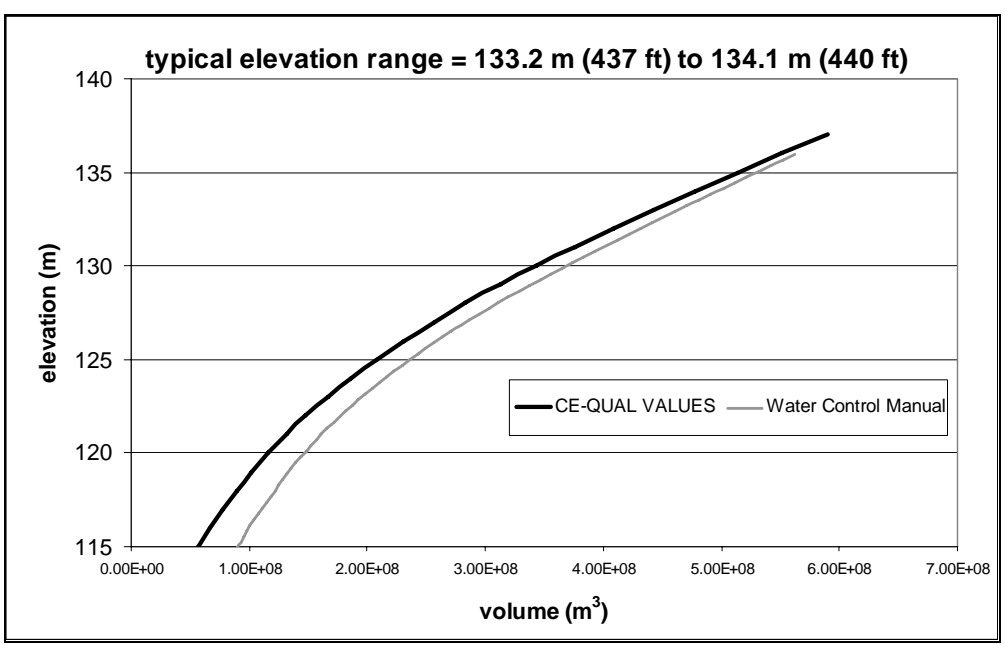

Figure 6.3. IHR Reservoir Storage-Elevation Curves 
This task was accomplished by using a GIS and a 10-m-resolution digital elevation map (DEM) from the U.S. Geological Survey. Sample results from this procedure are shown in Figure 6.4 for Central Ferry (river mile 82 [river kilometer 132)) in Little Goose Reservoir. At the center of the Figure 6.4 is the W2 computation node, and subsequent computational nodes have been displayed along the river centerline at $804 \mathrm{~m}$ (half-mile) spacing. At the node of interest, the field of view 'seen' by the node at the water surface has been shaded in blue and the 18 lines at 20-degree increments are displayed as radiating black lines. The incidence angle for each black line was computed and written into the W2 geometry file. This process was then repeated for each computational node and for all reservoirs.

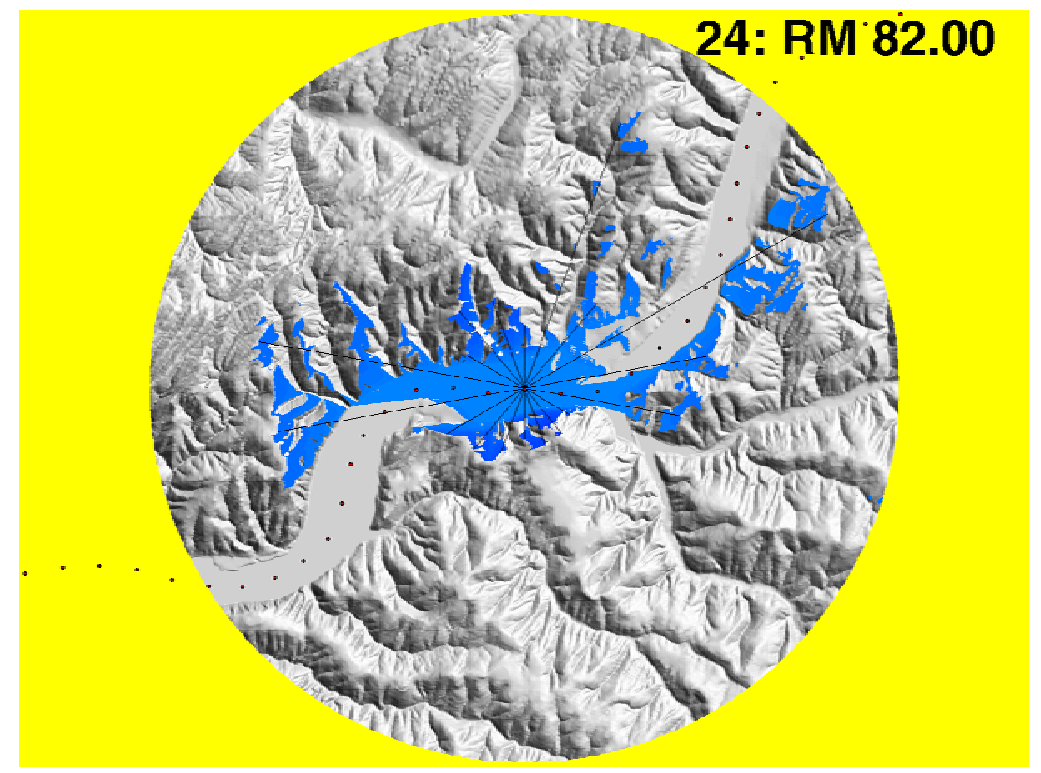

Figure 6.4. Area (in blue) which can be 'seen' by the computational node at center of the figure for Segment 24 (Central Ferry) in Little Goose Reservoir

\subsection{D Model Boundary Conditions}

\subsubsection{Inflow}

Inflow data were obtained from the Columbia River Operation Hydromet Management System (CHROMS) database, as reported by the USACE through its website (USACE 2005). For Lower Granite Reservoir, the Memorial Bridge (Site 11) at the Clearwater River and the Southway Bridge (Site 9) at the Snake River act as upper boundaries, and discharges were routed from upstream gauges to these locations. This was done using the one-dimensional model MASS1, an unsteady hydrodynamic and water quality model for river systems developed by PNNL (Perkins and Richmond 2001).

To compute discharge entering from the Clearwater River, MASS1 uses the upstream USGS surface water flow gage at Orofino, ID and the USACE fixed monitoring station below Dworshak Dam. Because a USGS surface water flow gage exists at Spalding, the numerical model results were checked at this location to verify calibration of the model. Figure 6.5 shows an example of MASS1 simulated and observed Spalding gage data for the 2004 study period. 


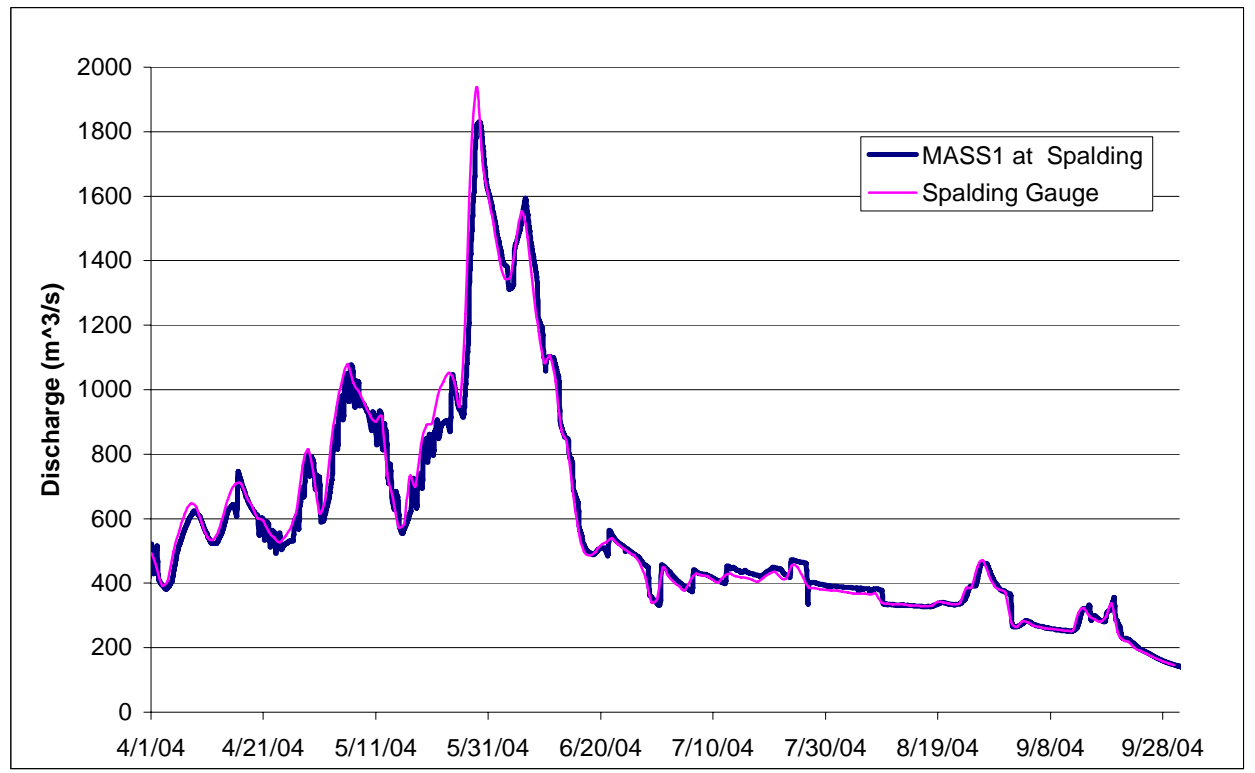

Figure 6.5. Verification of MASS1 Simulation Accuracy

\subsubsection{Outflow}

Outflow data were obtained from the CHROMS database, as reported by USACE through its website (USACE 2005). These data were separated into spill and powerhouse discharge for use in the numerical model. Because of small imbalances due to unaccounted fish ladder or other flows, spill discharge was computed as the total reported dam outflow minus the reported powerhouse outflow.

\subsubsection{Inflow Water Temperatures}

Temperature data collected in the tailrace of each dam were obtained from the CHROMS database (USACE 2005). These data were used as the upper boundary conditions for the LGS, LMN, and IHR reservoir models. These monitors measure the temperature at a single depth, normally between 3 and $7 \mathrm{~m}$ beneath the water surface. It was assumed that flow below each dam was sufficiently turbulent that any vertical gradients in temperature could be ignored. Field data collected in 2005 supports that assumption.

The upstream inflow water temperature boundaries for the Lower Granite Reservoir model were observed data collected at Sites 9 (Snake River) and Site 11 (Clearwater River). Each temperature string consisted of two loggers, one near the surface and the other near the bottom in order to detect the presence of stratification. During the entire four-year sampling period, the water column at these sites were thermally homogeneous (see Appendix A, Sites 9 and 11).

Observed water temperature data were used to calibrate the numerical models. The LWG reservoir model was calibrated using the PNNL dataset (see Figures 2.3 and 2.4). The LMN, LGS, and IHR reservoir models used forebay BRZ and mid-pool temperature data at all depths. These data were collected for the USACE by Carrol and Barko (2005). At each dam, several temperature strings were deployed to detect the presence of lateral temperature gradients. Although weak lateral gradients were noted close to the surface, thermal gradients deeper in the water column were negligible. These data justify application of CE-QUAL-W2, a 2D laterally-averaged model. When several temperature logger 
strings were available along a cross-section, the dataset with the greatest water column depth or the most complete dataset was used for model calibration.

Inflow temperatures for $\mathrm{LMN}$ reservoir tributaries Palouse and Tucannon rivers were also provided by Carrol and Barko (2005) for the 2002 and 2004 field seasons; no data were collected in 2003.

Comparison of observed data collected in 2002 and 2004 indicates that tributary inflow temperatures do not vary significantly from one year to the next. In addition, these tributary flows are small compared to Snake River flows. For the 2003 LMN model, the tributary water temperature data collected in 2002 were applied.

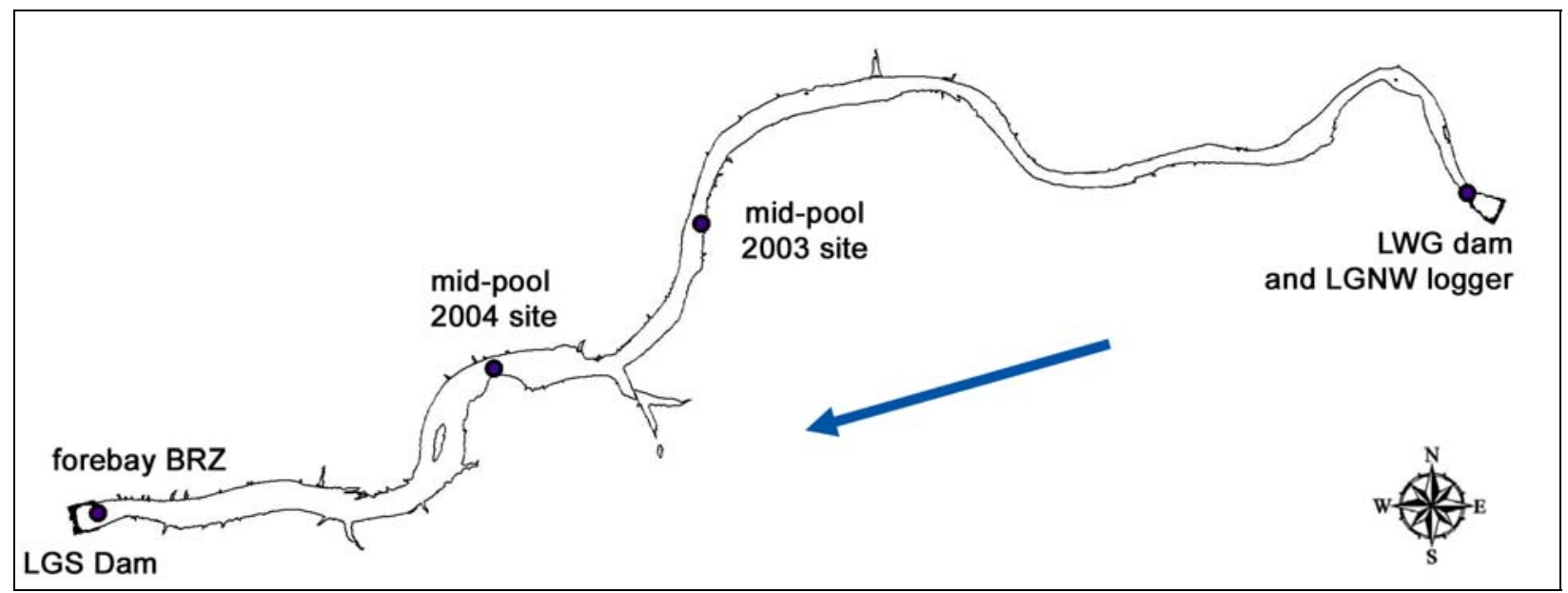

Figure 6.6. Temperature logger monitoring sites in the reservoir upstream of Little Goose Dam. Blue arrow indicates general downstream flow direction.

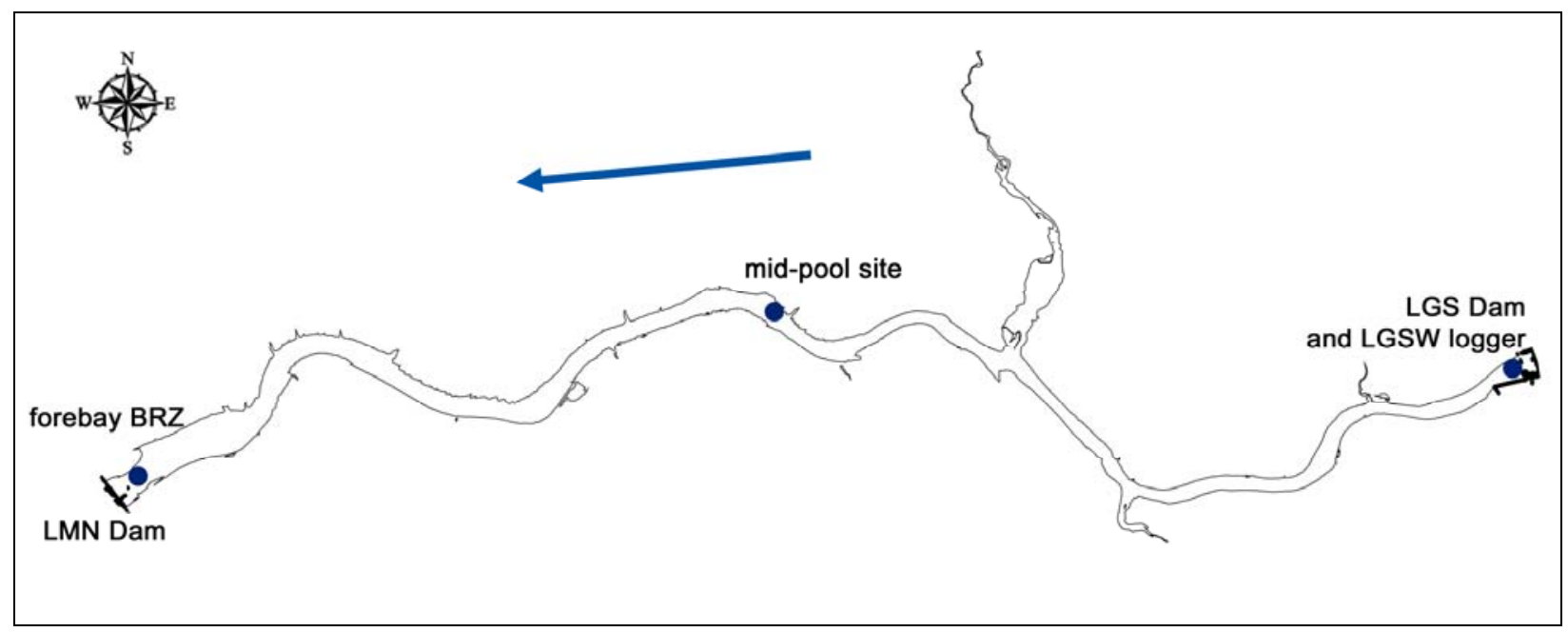

Figure 6.7. Temperature logger monitoring sites in the reservoir upstream of Lower Monumental Dam. Blue arrow indicates general downstream flow direction. 


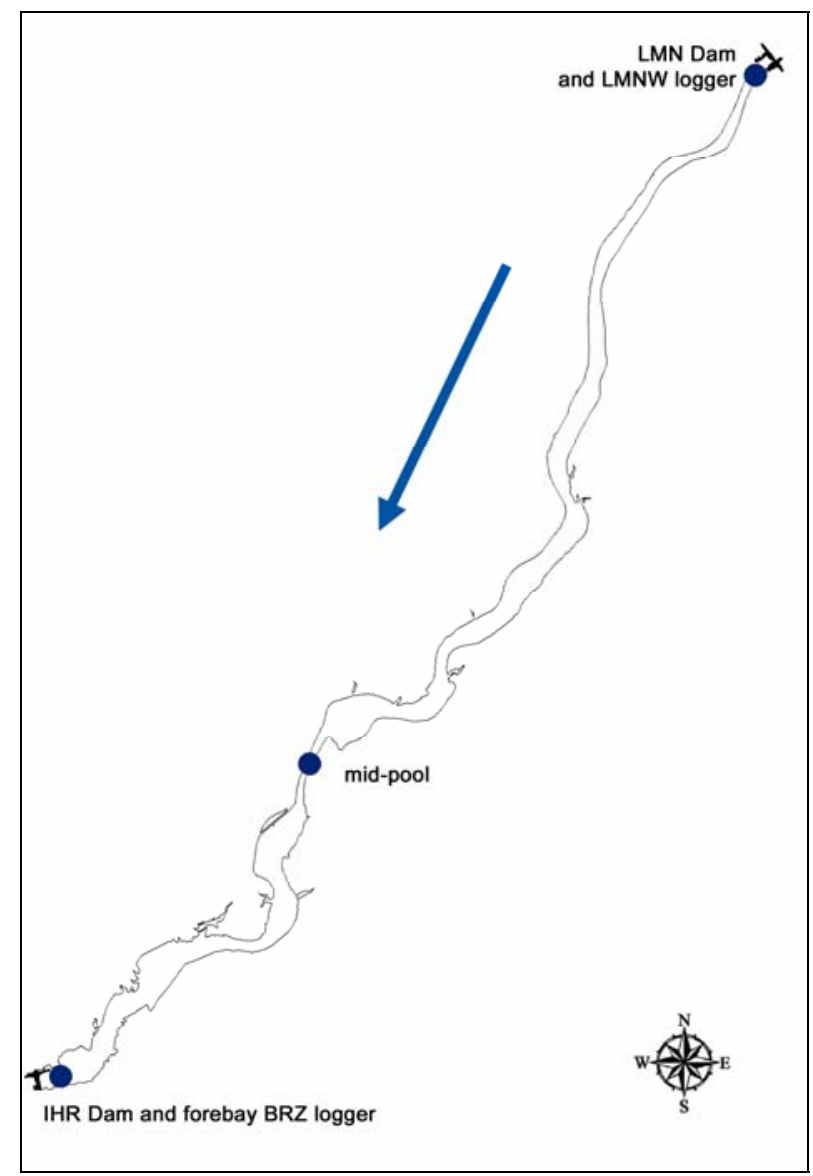

Figure 6.8. Temperature logger monitoring sites in the reservoir upstream of Ice Harbor Dam. Blue arrow indicates general downstream flow direction.

\subsubsection{Meteorology}

Meteorological data applied when modeling all four reservoirs were collected at either AgriMet Station SILW (Silcott Island) or LBRW (Lake Bryan). These stations were installed by the U.S. Bureau of Reclamation and are calibrated annually. They have been in continual operation since April 19, 2002 (Rice Bar), and July 17, 2002 (Silcott Island). The Silcott Island station was initially funded and installed as part of this project. The Rice Bar station is located at latitude N46 $41^{\prime} 51^{\prime \prime}$ and longitude W117 $39^{\prime}$ 15". The Silcott Island station is located at latitude N46 $25^{\prime}$ '07" and longitude W117 $11^{\circ}$ ' $05^{\prime \prime}$. A maps showing location of these stations is shown in Figure 6.9.

The stations record wind speed and direction, air temperature, relative humidity (and derivatives), atmospheric pressure, solar radiation, and precipitation. A full listing of the types of sensors used on the AgriMet station can be found in Agrimet (2005). Data from the station are uploaded to the AgriMet website at close to real time.

Nighttime cloud cover is not monitored at the AgriMet stations (daytime can be inferred from solar radiation values, although not done for this project), however it can influence heat budget calculations. Hourly cloud cover information was obtained at the Tri-Cities Airport ( $1 \quad$ o, Washington) from the National Climatic Data Center, NOAA. 


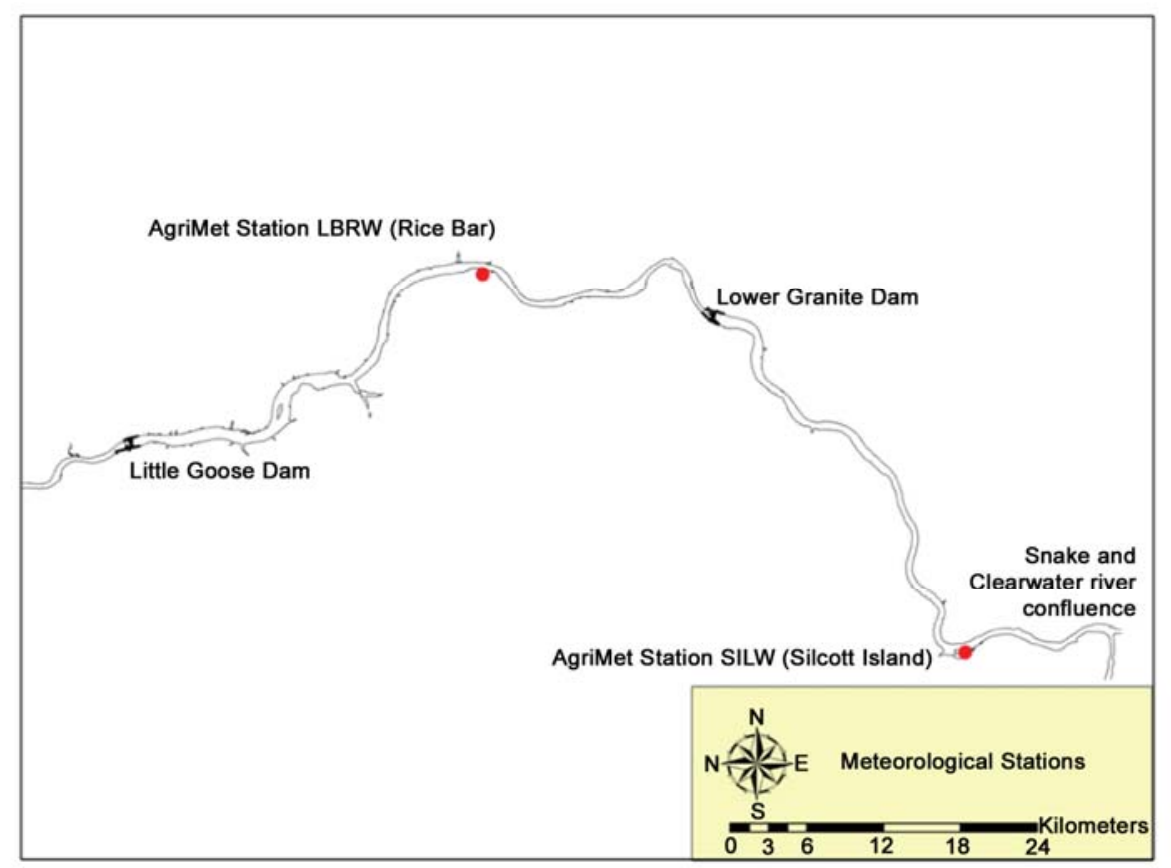

Figure 6.9. Location of AgriMet meteorological stations used in during the study

A summary of data frequency, and interpolation methods for each data type used by the numerical models are as follows:

\section{Air Temperature}

Air temperature data, which were recorded in 15-min increments in degrees Celsius at the weather station, was converted into an hourly dataset. Data gaps were linearly interpolated.

Dew Point Temperature

Dew point temperature data were recorded in 15 min increments in degrees Fahrenheit and converted into degrees Celsius on an hourly basis. Data gaps were linearly interpolated.

Wind Speed

Wind speed data were recorded on an hourly basis in miles per hour and converted into meters per second. Data gaps were linearly interpolated.

Cloud Cover

Cloud cover data were recorded approximately once every hour while sky cover was divided in 8 parts. These data was converted to tenths as required for W2. Data gaps were linearly interpolated.

Solar Radiation

Solar radiation data were available hourly in cumulative Langley units which were converted to watt per square meter. Data gaps were linearly interpolated.

Wind direction

Reported directions are the direction from which the wind originates (standard meteorological convention). The directions are in terms of degrees from true north ( 0 degrees), and the angle increases in a clockwise direction. For example, if the wind direction is 45 degrees, the wind is coming from the northeast. 
A sample of meteorological conditions recorded from weather station Rice Bar for 2003 is shown in Figures 6.10 through 6.15. These data indicate the general range of these parameters at the study site.

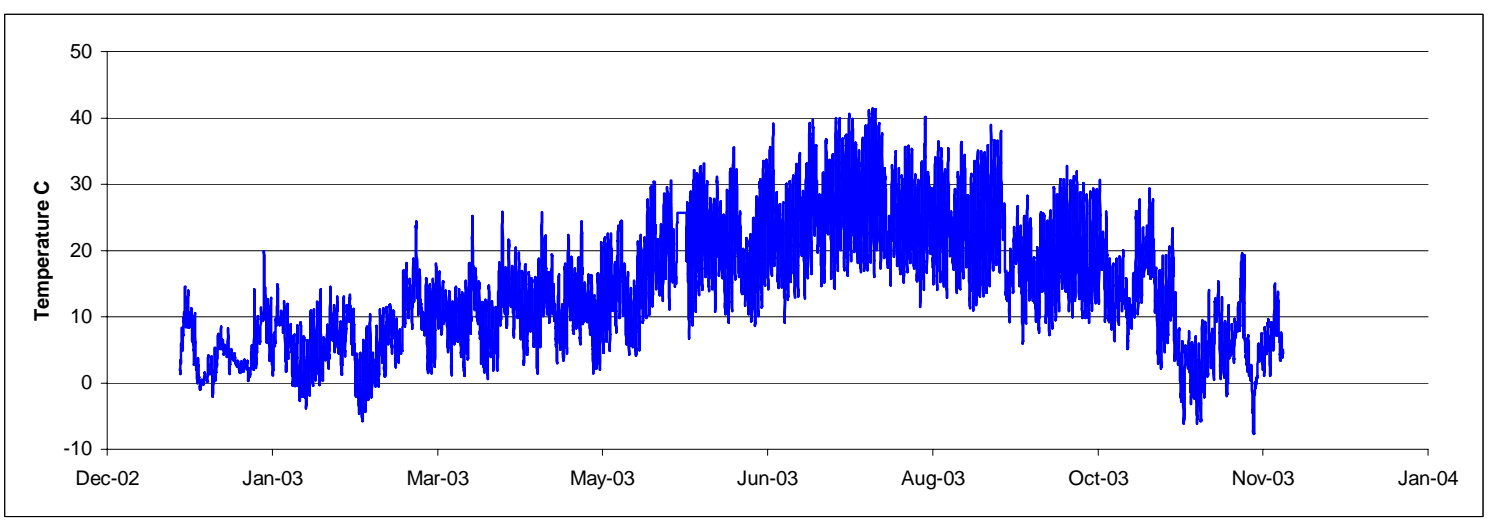

Figure 6.10. Observed air temperature from AgirMet Station LBRW (Rice Bar)

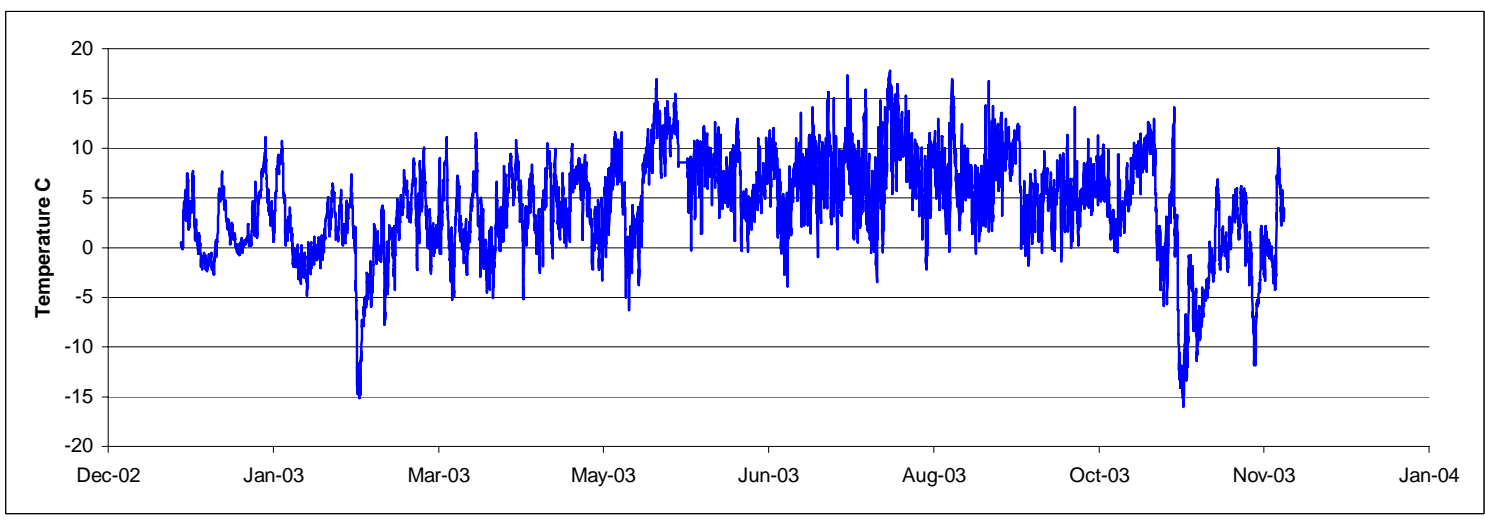

Figure 6.11. Observed dew point temperature from AgirMet Station LBRW (Rice Bar)

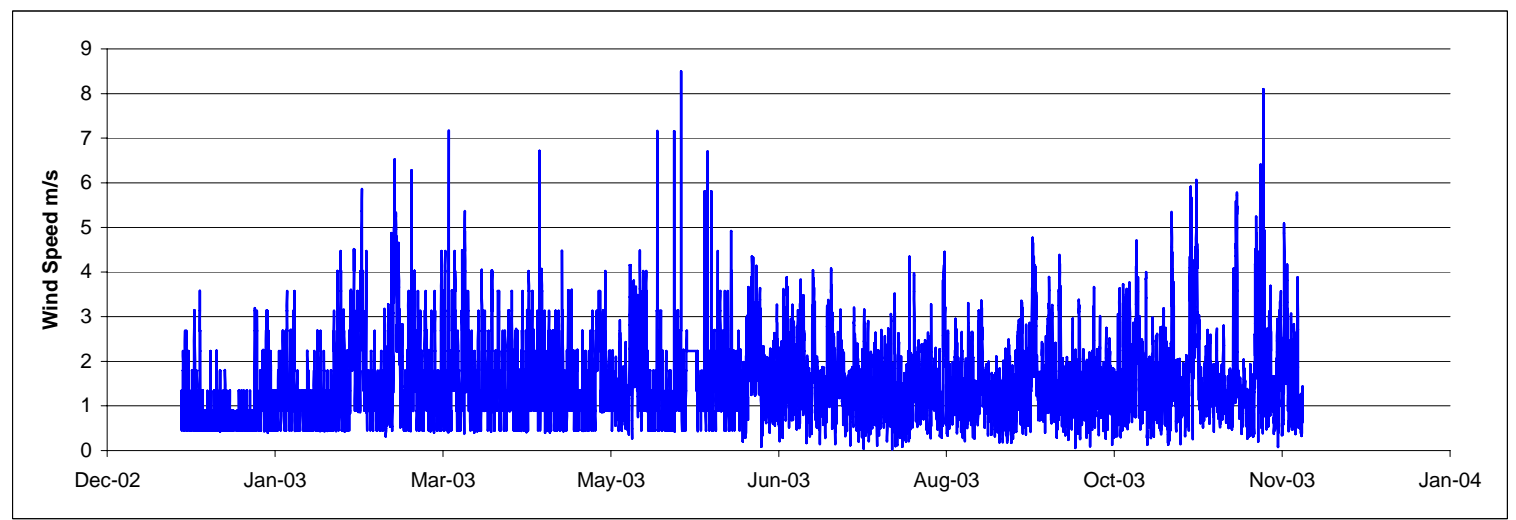

Figure 6.12. Observed wind speed from AgirMet Station LBRW (Rice Bar) 


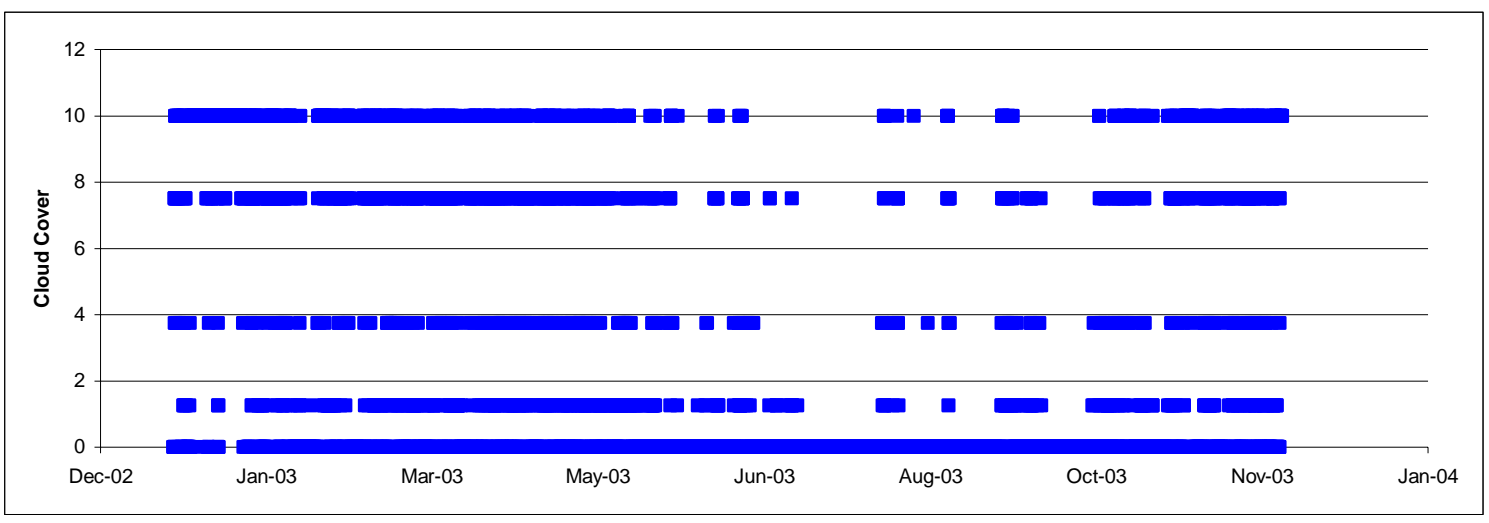

Figure 6.13. Observed cloud cover from AgirMet Station LBRW (Rice Bar)

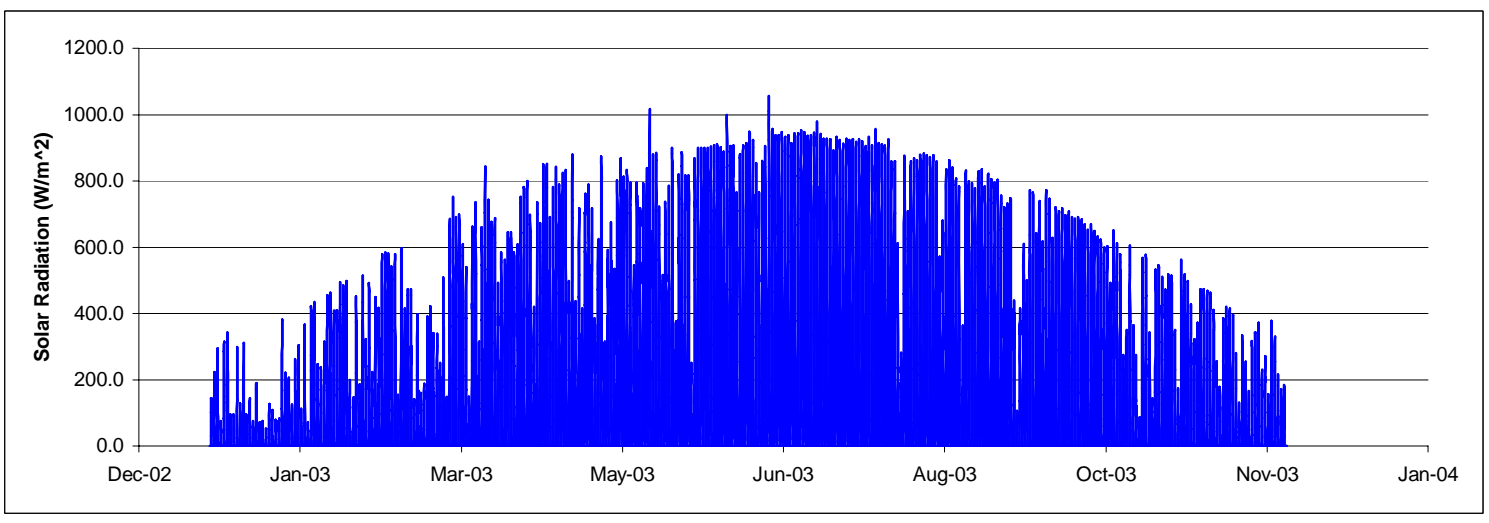

Figure 6.14. Observed solar radiation from AgirMet Station LBRW (Rice Bar)

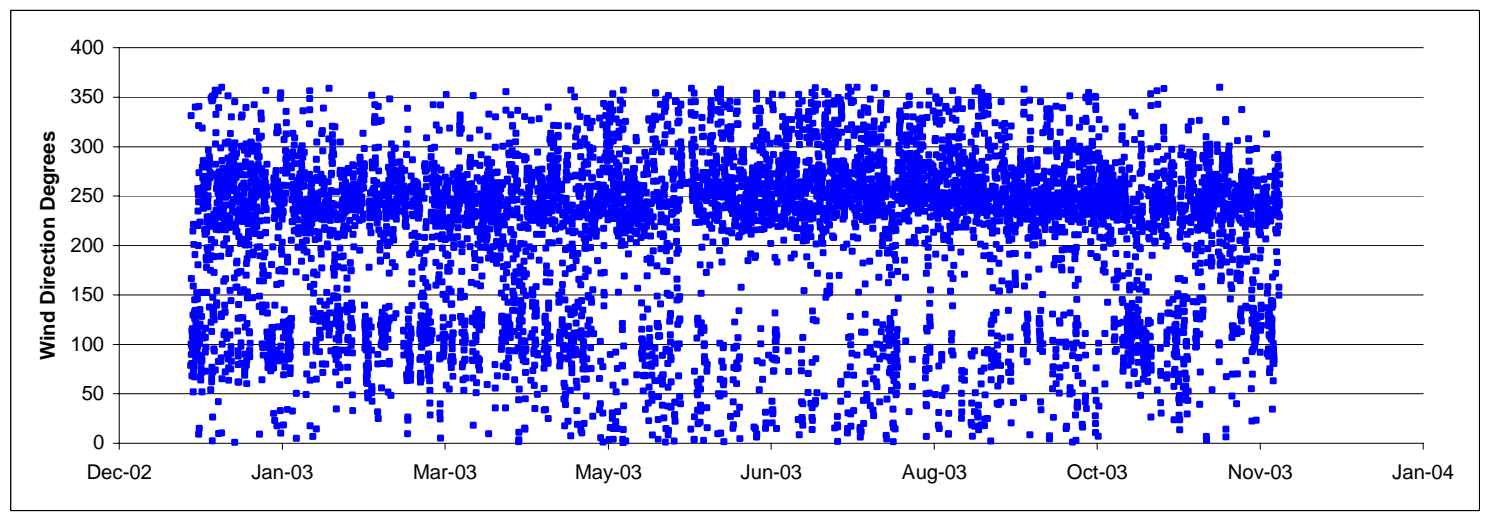

Figure 6.15. Observed wind direction from AgirMet Station LBRW (Rice Bar). Predominant wind direction $\left(\sim 250^{\circ}\right)$ is upstream to the primary flow direction of the river. 


\subsection{Two-Dimensional Model Development}

\subsubsection{Water Balance}

Differences in mass conservation between upstream inflow and downstream outflow caused water surface elevations in the reservoir to deviate from observed values. This imbalance is normally caused by incorrect discharge gage measurements or groundwater accretions/depletions. To correct for this mass flow imbalance, the software "waterbalance.exe" (Wells 2005) was used to adjust the inflow or outflow discharge. Water balance flows were specified at daily intervals and were small compared to the total river discharge. It was found that for Lower Granite and Little Goose reservoirs an outflow adjustment was necessary, while for Lower Monumental and Ice Harbor reservoir an inflow adjustment was necessary. The average discharge adjustment for each reservoir averaged $\pm 23 \mathrm{~m}^{3} / \mathrm{s}$ (for comparison, late summer discharges are typically $>400 \mathrm{~m}^{3} / \mathrm{s}$; see Figures 4.1 through 4.3). After the adjustment was performed, close agreement was achieved between observed and simulated water surface elevations at the forebay of each dam. Figure 6.16 shows an example of computed versus observed water surface elevations at the Lower Granite Dam forebay.

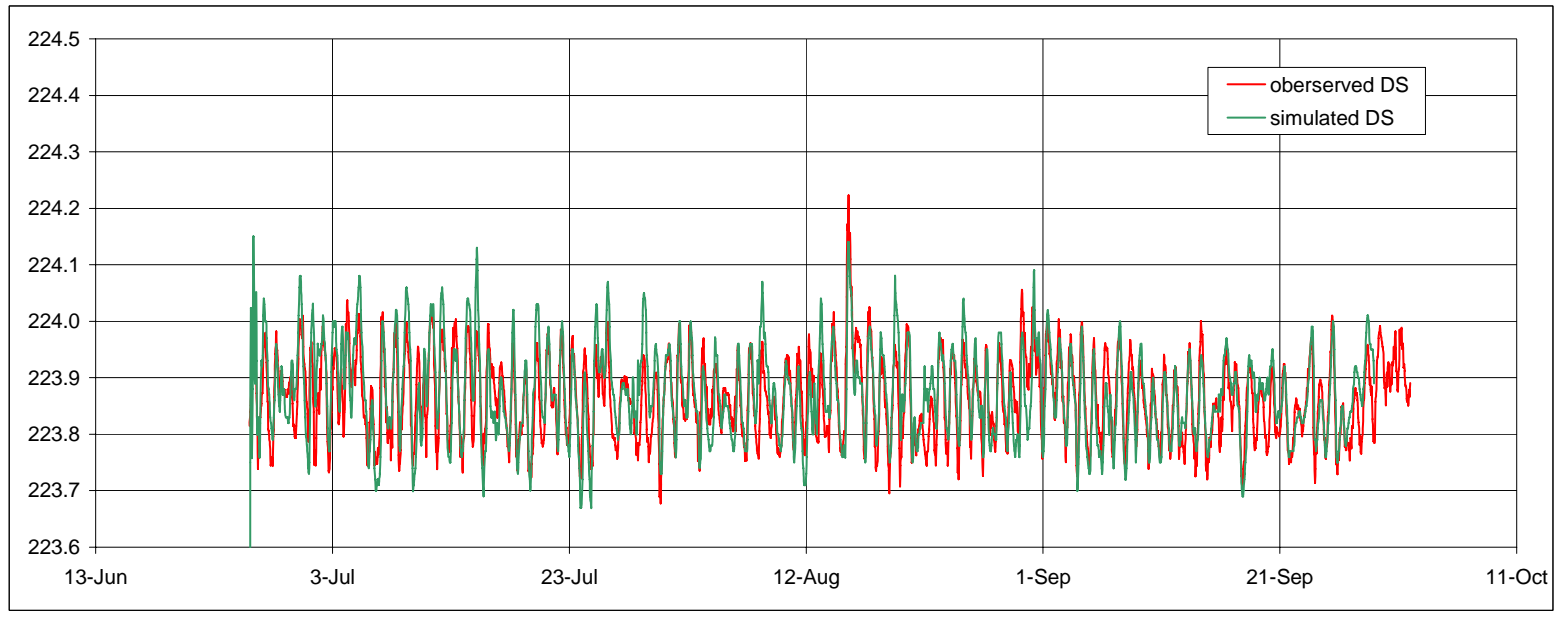

Figure 6.16. Observed and simulated water surface elevations during part of 2002 at the Lower Granite Dam forebay after applying the water balance adjustment. Graph ordinate units are meters.

\subsubsection{Velocity Calibration}

In August 2003, ADCP measurements were collected in Lower Granite Reservoir (Figure 6.17). Observed water velocities were averaged over the collection time (typically 10 minutes) and then compared to numerical model results at the same time/location.

The primary water velocity calibration parameter in the model was bottom friction (Manning's n), and, as described Section 6.4.3, a sensitivity analysis of this parameter was performed. Final calibrated Manning's n values ranged between 0.015 and 0.03. Simulation results comparing observed ADCP velocities to simulated values at identical times/locations are displayed in the Figures 6.18 through 6.26. Simulated values are generally deeper because the ADCP measurement was not collected at the deepest 


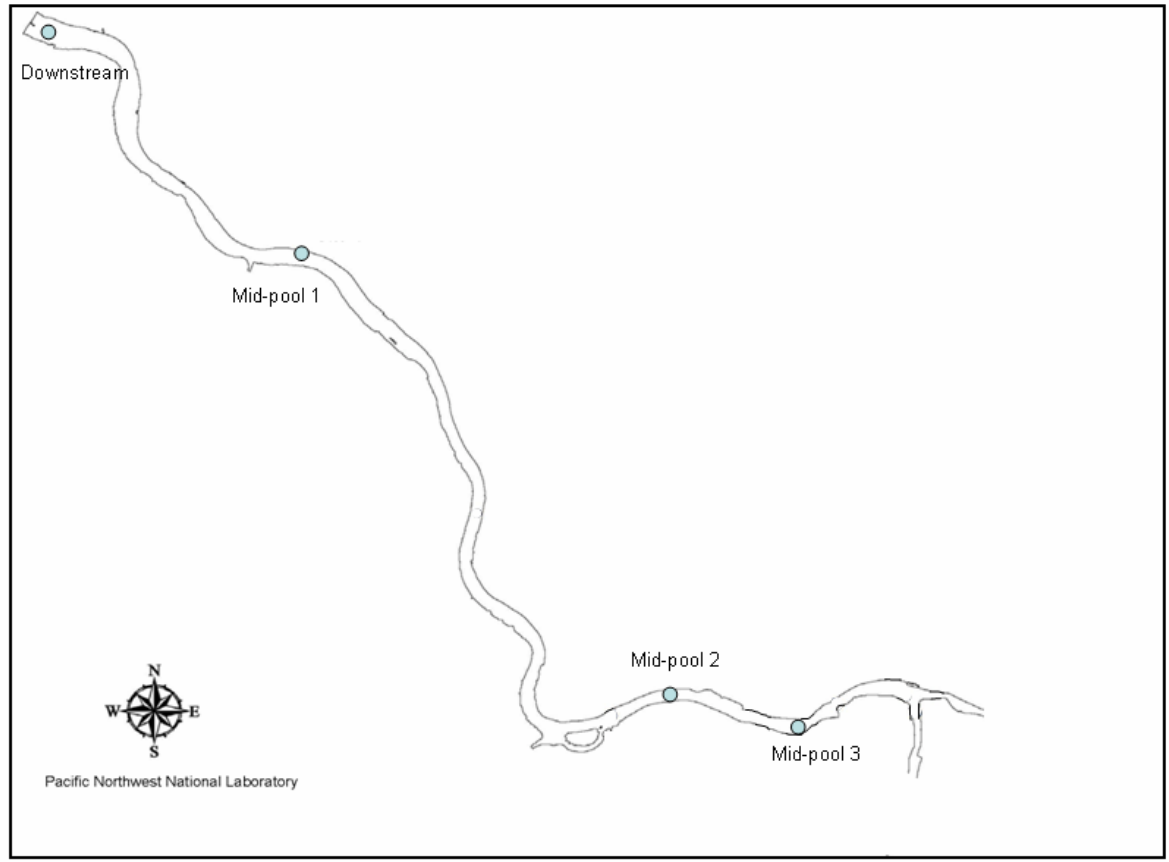

Figure 6.17. Locations of ADCP Measurements in Lower Granite Reservoir

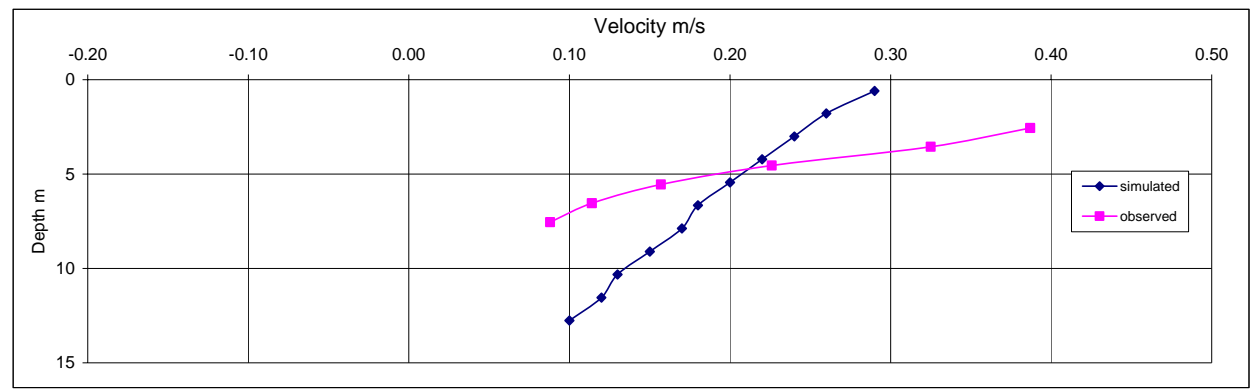

Figure 6.18. Velocities at Mid-pool 3 in Lower Granite Reservoir. Downstream (+)/upstream (-).

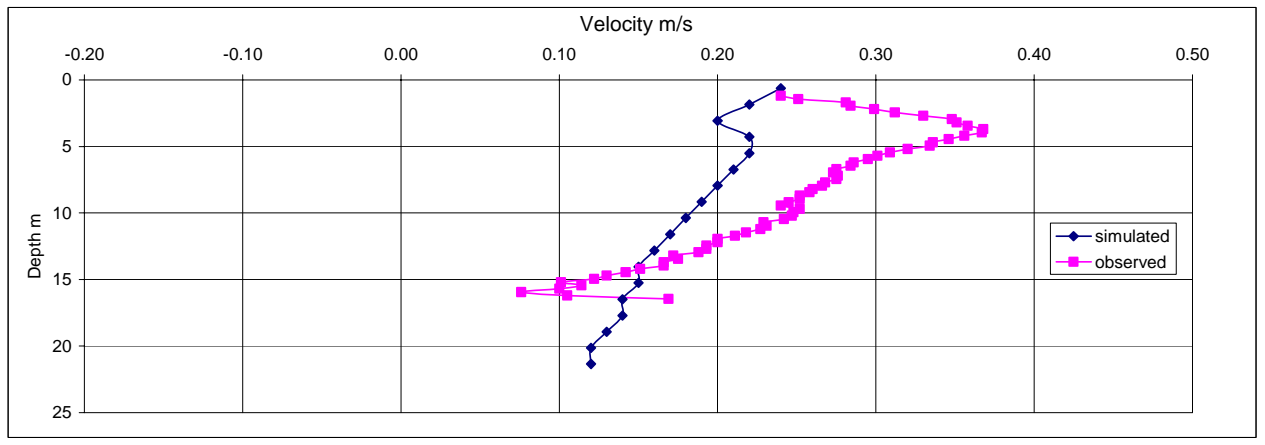

Figure 6.19. Velocities at Mid-pool 2 in Lower Granite Reservoir. Downstream (+)/upstream (-). 


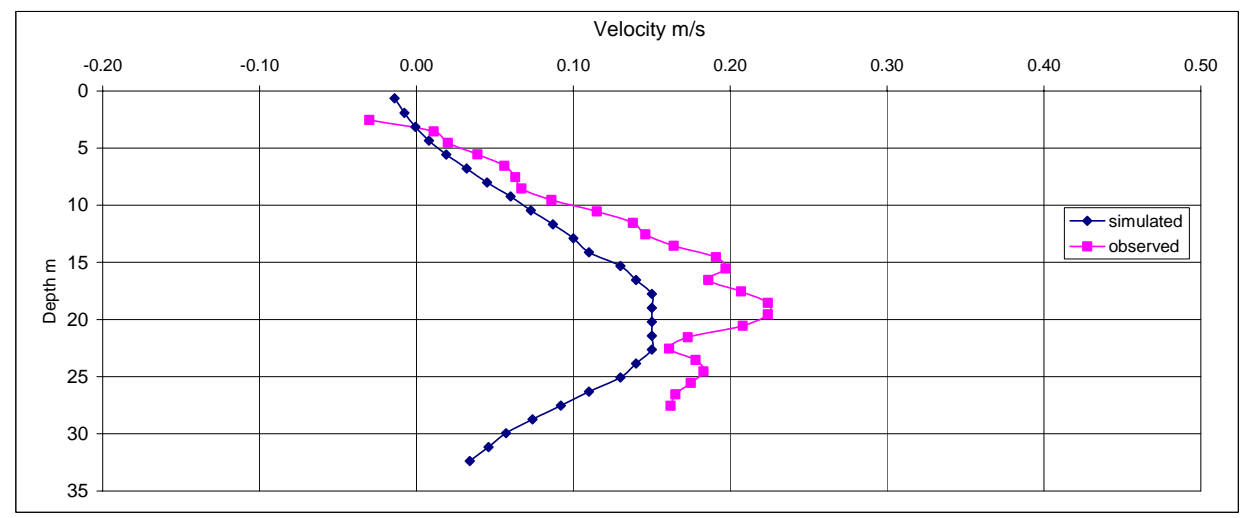

Figure 6.20. Velocities at Mid-pool 1 in Lower Granite Reservoir. Downstream (+)/upstream (-).

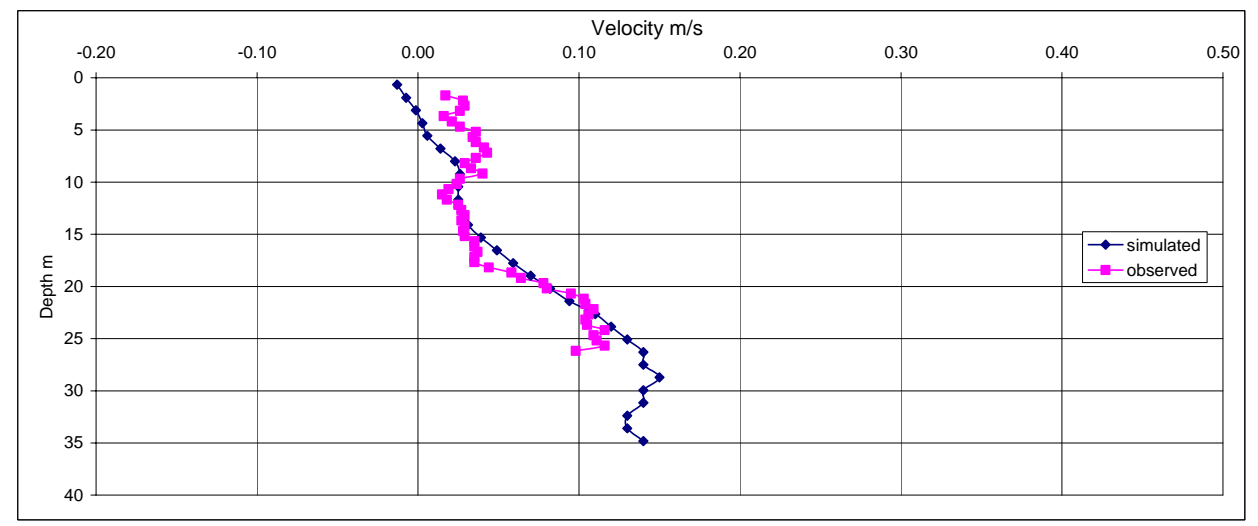

Figure 6.21. Velocities at BRZ in Lower Granite Reservoir. Downstream (+)/upstream (-).

point in the cross-section. Since the numerical model is laterally-averaged, the profiles results always extend to the deepest point in the cross-section. The simulated flow velocities were generally within the range of the measured values.

Observed data collected at Mid-pool 1 and downstream near the forebay BRZ were collected during a period of slight upstream epilimnetic movement (negative velocity magnitude indicates movement upstream). Although the simulated magnitudes in the epilimnion are slightly smaller than observed, the same general water column pattern was matched. This pattern is consistent with the wind setup schematic shown in Figure 6.4.

In July 2005, ADCP measurements were collected in Little Goose and Lower Monumental reservoirs to investigate the mid-pool anomaly (Section 5.1) and to verify model results. Observed data collected on July 24, 2005 in Little Goose Reservoir are shown in Figures 6.23 through 6.26. Flow at mid-pool site A was directed uniformly downstream, however data collected at the other mid-pool sites was directed upstream in the upper part of the water column and downstream in the lower portion of the water column.

Simulation results at these same times/locations contain the same general velocity pattern throughout the water column, however it was noted that some differences do exist. Since the numerical model is laterally-averaged, profiles results extend to the deepest point in the cross-section, which is not where the 


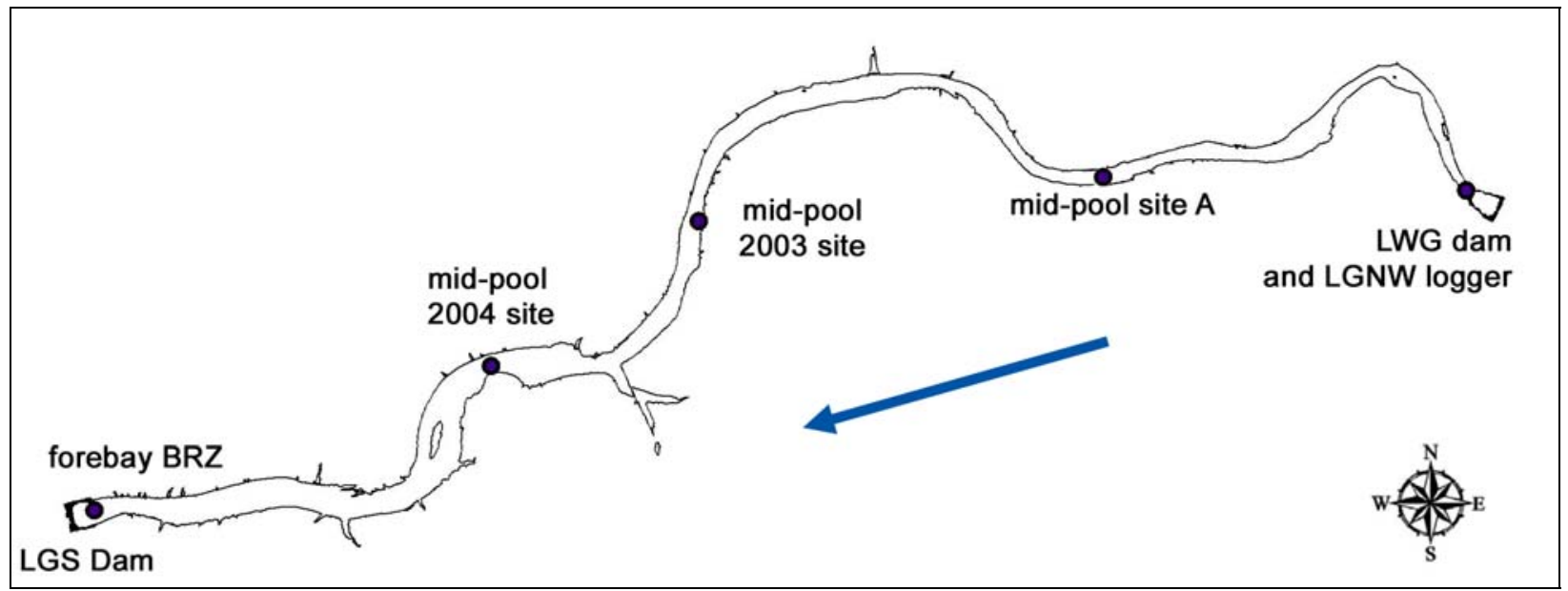

Figure 6.22. Locations of ADCP Measurements in Little Goose Reservoir. Blue arrow indicates the downstream (positive velocity magnitude) direction of flow.

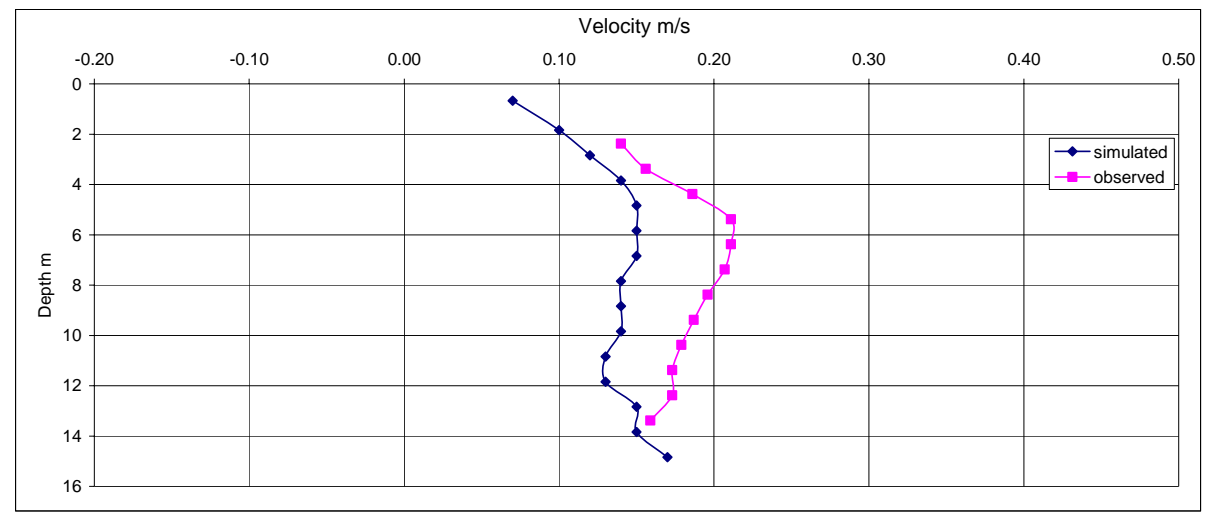

Figure 6.23. Velocities at mid-pool site A in Little Goose Reservoir. Downstream (+)/upstream (-)

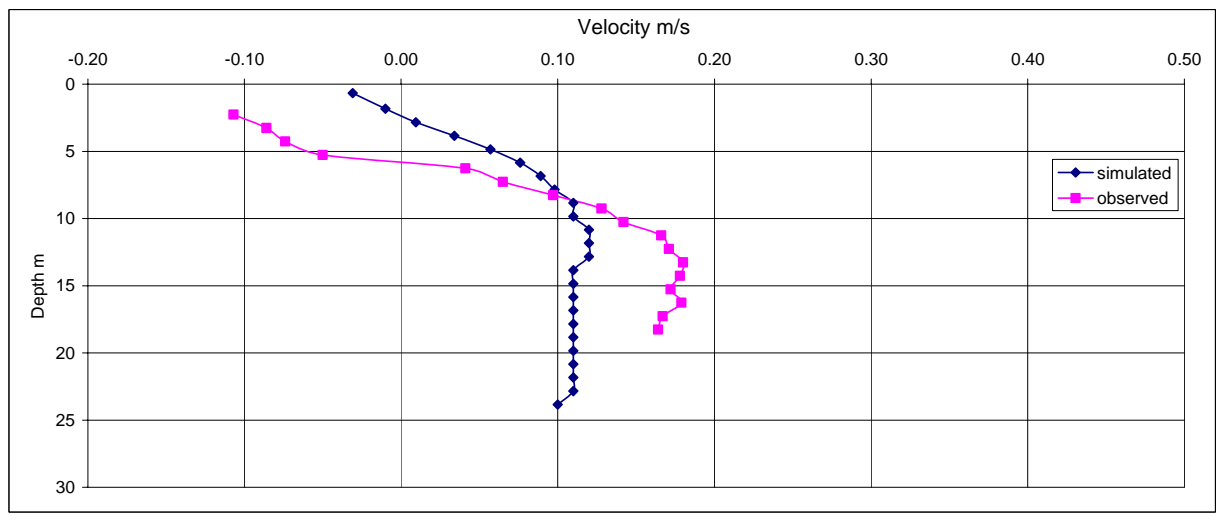

Figure 6.24. Velocities at mid-pool 2003 site in Little Goose Reservoir. Downstream (+)/upstream (-) 


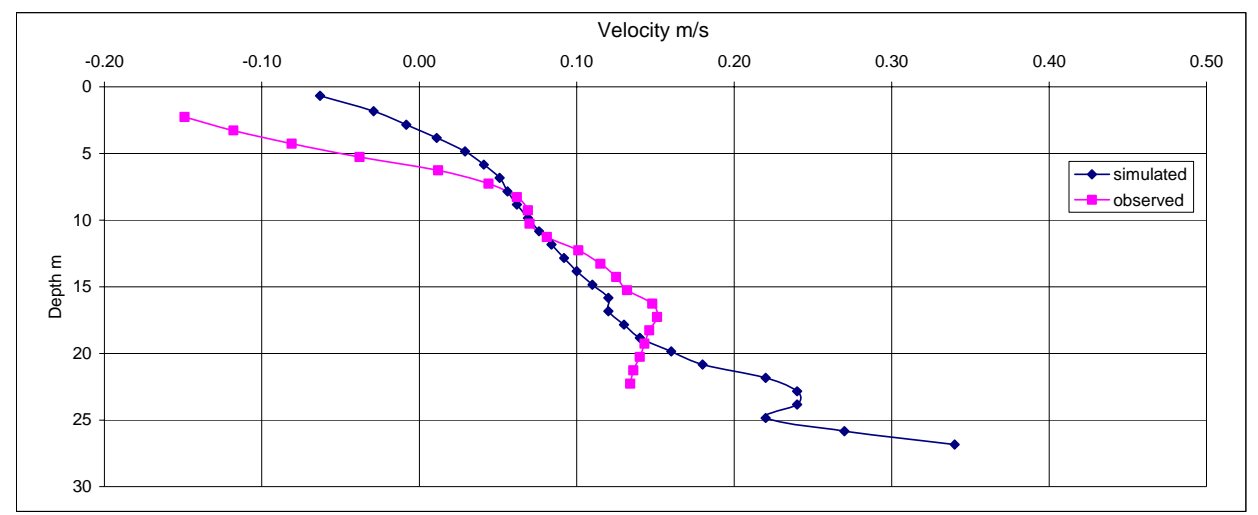

Figure 6.25. Velocities at mid-pool 2004 site in Little Goose Reservoir. Downstream (+)/upstream (-)

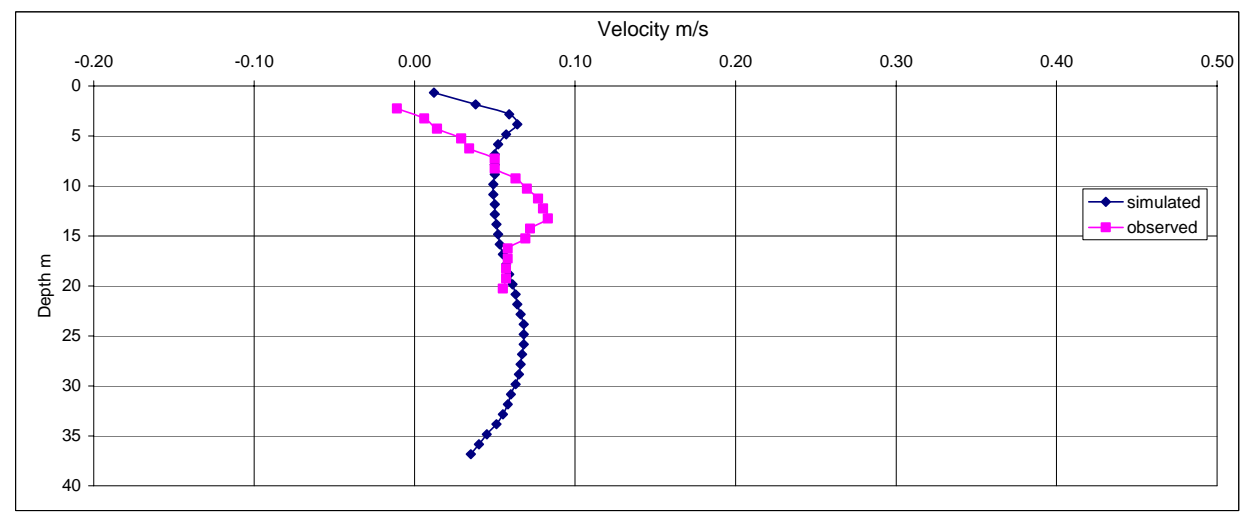

Figure 6.26. Velocities at the forebay BRZ site in Little Goose Reservoir. Downstream (+)/upstream (-)

ADCP measurements were collected. Overall, however, model result trends compare well with observed ADCP data and the model does capture general upstream-driven flow phenomenon observed in the upper water column.

\subsubsection{Sensitivity Analysis}

A sensitivity analysis was conducted by changing various parameters in a systematic fashion to determine which parameters had the greatest overall impact on solution results. This included, but was not limited to, the following model parameters in various combinations.

Segment length and height:

The final calibrated model used segment (i.e., computational cell) lengths of $804 \mathrm{~m}$ (half-mile) and heights of $1 \mathrm{~m}$. The sensitivity test was carried out with the Little Goose model, and the lengths were halved $(400 \mathrm{~m})$ and then halved again $(200 \mathrm{~m})$. Cell heights were also reduced to $0.5 \mathrm{~m}$ for both grids. Simulation results produced by all grids were approximately equal. We therefore concluded that use of a coarser grid did not degrade results, and produced similar results with a significantly shortened amount of computational effort.

Wind-sheltering coefficient:

The wind-sheltering coefficient had a significant impact on model results. Because the four reservoirs are mostly surrounded by steep hillsides, it is hypothesized that a wind funneling effect 
may occur, along with topographic steering of the wind. Final calibrated results used parameter values between 1.0 and 1.2.

Vertical eddy viscosity:

The vertical turbulence algorithm used to generate the final simulations results was the W2N method (W2 with mixing length of Nickuradse). The RNG (renormalization group) and TKE (turbulent kinetic energy) methods were also tested during the sensitivity analysis. Slightly better results (i.e., minimum errors compared to observed) were achieved with the W2N method, and this method was used for all four reservoirs.

Light extinction coefficients

The fraction of incident solar radiation absorbed at the water surface, BETA, was varied between 0.3 and 0.45 . The extinction for pure water, $\mathrm{EXH} 2 \mathrm{O}$, was varied in correspondence with the BETA value between 0.2 and $0.45 \mathrm{~m}^{-1}$.

Bottom roughness

A change to the model's bottom friction parameter impacted water levels, flow velocities and temperature, the latter especially near the river bed. Once the water balance was completed, the simulated water temperatures were slightly adjusted by varying the bottom friction. Observed velocity data were available for Lower Granite, Little Goose, and Lower Monumental reservoirs, and were used to generate the final calibrated results.

Heat exchange and evaporation

Several parameters affect surface heat exchange and evaporation. The 'term-by-term' method was specified in the computation of the surface heat exchange. The variables AFW, BFW and $\mathrm{CFW}$, which are the coefficients for wind, and hence latent heat exchange. These coefficients, in connection with evaporation, have a large impact on short-term water temperature variations. In addition, raising the height of meteorological station to $10 \mathrm{~m}$, which is reasonable since the station is located on a bank above the water surface, improved results.

Water balance flow location

The location (either inflow or outflow) of the water balance flow adjustment was tested. Shading

The simulations used the dynamic shading factors based on actual topography and sun position, and hence were not calibrated.

Meteorological Stations

Meteorological station Rice Bar on the shores of Little Goose Reservoir was used for all simulations. Meteorological station Silcott Island in Lower Granite Reservoir was tested, however after the model was calibrated for 2003, the 2004 validation using weather station Silcott Island was not successful. Simulated temperatures deviated from observed with increasing differences toward Lower Granite Dam. A further analysis of meteorological parameters for the month of August revealed inconsistent characteristics. While average air temperature at Rice Bar changed little between 2003 and 2004, Silcott Island temperatures dropped by more than $4^{\circ} \mathrm{C}$ (see Figure 6.27). Meteorological station Silcott Island is at the upper portion of Lower Granite pool (see Figure 6.10), and is just upstream of where the reservoir enters a canyon with steep slopes. AgriMet Station LBRW (Rice Bar), however, is located within a canyon section. Simulation results for all four reservoirs were improved by using Rice Bar over Silcott Island meteorological data. 

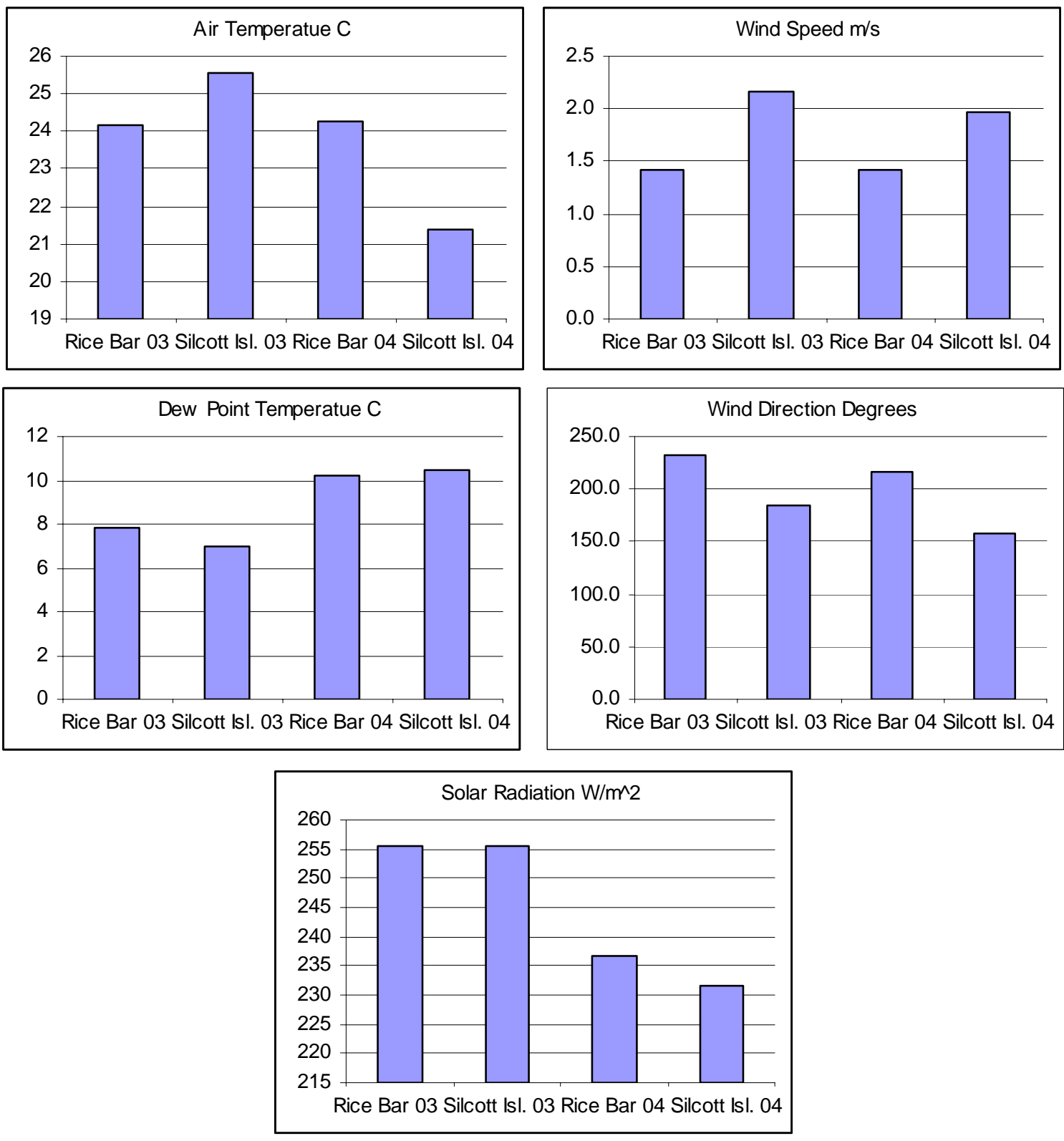

Figure 6.27. Comparison of average meteorological parameters collected at AgriMet Stations Rice Bar (LBRW) and Silcott Island (SILW) for August 2003 and 2004. Note the large difference in air temperature between the two stations for 2004.

\subsubsection{Temperature Calibration}

The reservoir upstream of Little Goose Dam was the first to be simulated because1) it contains a relatively large vertical temperature gradient, unlike IHR; 2) it has a simple upstream boundary, unlike like LWG reservoir; and 3) it does not have any significant tributaries, unlike the LMN reservoir. Once the LGS model was calibrated, the other three reservoirs were then developed based upon the LGS model setup, and model parameters were adjusted slightly to best match observed data. The year 2003 was selected for calibration for LGS, LMN, and IHR reservoirs because this was the first year when mid-pool 
temperatures were available. LWG reservoir was first calibrated for the year 2002 because PNNL started its mid-pool measurements in this year.

The initial LGS model calibration was challenging due to discovery of the mid-pool temperature anomaly described in Section 5.1. Only after the confirmatory data had been collected during July 2005 were we able to be confident in model results. These results showed that the epilimnion tended to be held in place for long periods of time due to wind setup (see Figure 5.4). This produces mid-pool epilimnetic temperatures that are warmer than similar epilimnetic depth water downstream at the BRZ forebay.

Figures 6.28 and 6.29 compare simulated results versus observed data at both the mid-pool and forebay BRZ sites in the reservoir upstream of Little Goose Dam. These graphics illustrate the ability of the model to capture the wide range of conditions that occur in the lower Snake reservoir system. Computed versus simulated results for all reservoirs, all sites, and all years can be found in Appendix B.
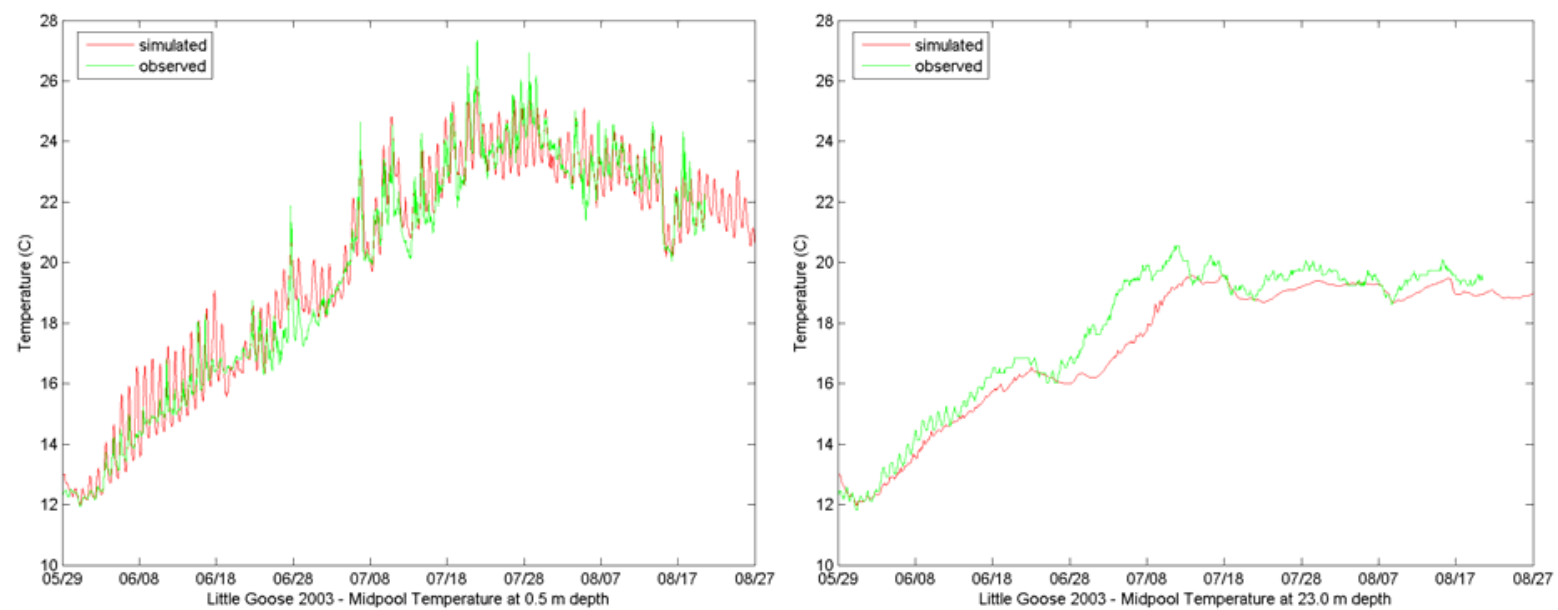

Figure 6.28. Example comparison of observed and simulated data at mid-pool near the surface (left) and near bottom (right) for Little Goose Reservoir, 2003
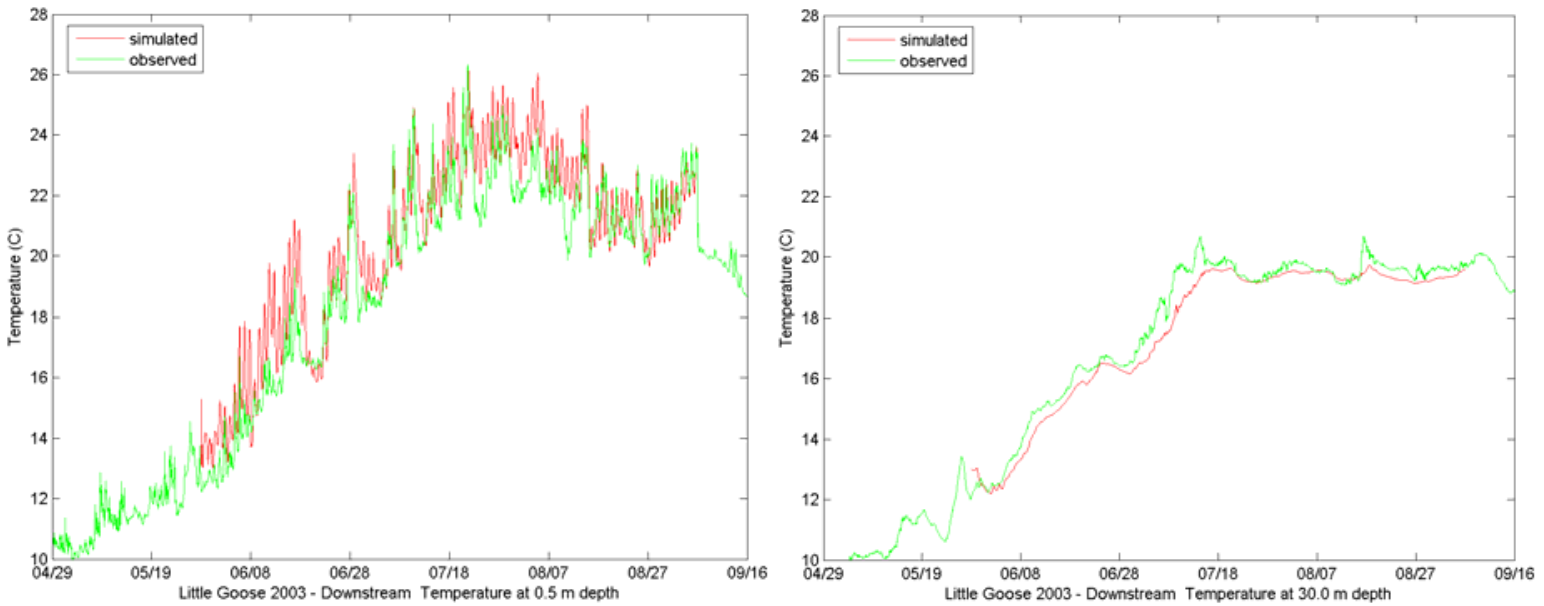

Figure 6.29. Example comparison of observed and simulated data at the forebay BRZ near the surface (left) and near bottom (right) for Little Goose Reservoir, 2003 


\subsection{Model Validation and Results Summary}

The purpose of a model validation process is to ensure that calibrated parameters which produced reasonable results for one study period produce nearly equal (from an error standpoint) results for different years with different boundary conditions. The LGS, LMN and IHR reservoirs were calibrated for 2003 and validated for 2002 and 2004; LWG reservoir was calibrated for 2002 and validated for 2003 and 2004. Inflow and boundary temperature changed between these years, as shown in Figures 4.1 through 4.3. Discharge ratio between the middle Snake and Clearwater river changed, as did the temperature differences between the two rivers. While inflows in 2002 were similar in magnitude, in 2003 and 2004 Snake River flows dominated.

Several statistics were computed to evaluate model performance. These statistics are used to compare hydraulic (i.e., forebay water surface elevation) and water temperature goodness-of-fit between observed data and simulated results. These statistics are defined as follows:

$$
\begin{aligned}
& \text { bias }=\frac{1}{n} \sum_{n}^{1}\left(y_{i}-y_{o b s}\right)^{2} \\
& M A E=\frac{1}{n} \sum_{n}^{1}\left|y_{i}-y_{o b s}\right| \\
& R M S=\sqrt{\frac{1}{n} \sum_{n}^{1}\left(y_{i}-y_{o b s}\right)^{2}}
\end{aligned}
$$

where MAE is mean absolute error, RMS is root mean square, $\mathrm{y}_{\mathrm{i}}$ are computed model values (either forebay elevation or water temperature), and $\mathrm{y}_{\mathrm{obs}}$ are observed values.

\subsubsection{Hydraulic Results}

Bias between observed and predicted water surface elevations at each forebay ranged between -2 and $+3 \mathrm{~cm}$ (Table 6.2). Values of RMS and MAE were slightly higher because negative and positive difference values did not eliminate each other. Overall, the model captured most of the water surface variations and all goodness-of-fit values are reasonably small.

\subsubsection{Temperature Results}

Model generated temperature data were compared with observed data. For each depth where a temperature logger was available, model temperature output was compared to observations. Statistical goodness-of-fit statistics were generated for bias, MAE and RMS. The model evaluation period consisted of times both with and without stratification, and model results were computed to observed data for as long a period as possible. Table 6.2 shows the earliest and latest time for the statistical analysis for all reservoirs and years. Loggers at some sites were in operation for a shorter time than other nearby loggers. 
Table 6.1. Comparison of model simulated results to observed data for each of the lower Snake River reservoirs

\begin{tabular}{|l|c|c|c|}
\hline Reservoir - Year & Bias (m) & MAE (m) & RMS (m) \\
\hline Lower Granite 2002 & 0.01 & 0.04 & 0.05 \\
\hline Lower Granite 2003 & 0.01 & 0.04 & 0.07 \\
\hline Lower Granite 2004 & 0.00 & 0.09 & 0.11 \\
\hline Little Goose 2002 & 0.01 & 0.05 & 0.06 \\
\hline Little Goose 2003 & -0.01 & 0.04 & 0.06 \\
\hline Little Goose 2004 & 0.02 & 0.06 & 0.08 \\
\hline Lower Monumental 2002 & 0.01 & 0.06 & 0.08 \\
\hline Lower Monumental 2003 & -0.02 & 0.06 & 0.08 \\
\hline Lower Monumental 2004 & 0.01 & 0.05 & 0.07 \\
\hline Ice Harbor 2002 & 0.01 & 0.04 & 0.05 \\
\hline Ice Harbor 2003 & 0.00 & 0.05 & 0.07 \\
\hline Ice Harbor 2004 & 0.03 & 0.06 & 0.07 \\
\hline
\end{tabular}

Table 6.2. $\quad$ Starting and Ending Dates of the Calibration/Validation Comparisons

\begin{tabular}{|c|c|c|c|}
\hline & Year & Start Date & End Date \\
\hline \multirow{3}{*}{$\begin{array}{c}\text { Lower Granite } \\
\text { Reservoir }\end{array}$} & 2002 & June 28 & September 26 \\
\hline & 2003 & June 8 & October 7 \\
\hline & 2004 & June 3 & October 6 \\
\hline \multirow{3}{*}{$\begin{array}{c}\text { Little Goose } \\
\text { Reservoir }\end{array}$} & 2002 & June 11 & September 27 \\
\hline & 2003 & May 30 & September 6 \\
\hline & 2004 & May 29 & October 6 \\
\hline \multirow{3}{*}{$\begin{array}{c}\text { Lower } \\
\text { Monumental } \\
\text { Reservoir }\end{array}$} & 2002 & May 30 & September 27 \\
\hline & 2003 & May 30 & September 22 \\
\hline & 2004 & May 29 & September 16 \\
\hline \multirow{3}{*}{$\begin{array}{l}\text { Ice Harbor } \\
\text { Reservoir }\end{array}$} & 2002 & June 10 & September 29 \\
\hline & 2003 & May 30 & September 21 \\
\hline & 2004 & May 29 & September 15 \\
\hline
\end{tabular}

Goodness-of-fit values at any particular site were computed by using all loggers throughout the water column. These values are displayed in Tables 6.4 through 6.6. The calibration periods are highlighted in bold, while other years were used as validation periods. Graphical results showing observed versus simulated data for each depth and at each site can be viewed in Appendix C.

Table 6.4 summarizes results for Lower Granite Reservoir. A map showing the locations of these sites can be found at Figure 3.3. The temperature loggers placed in the forebay BRZ are named 'DS' for downstream site. Simulation results for the calibration year (2002) result in a maximum bias of $-0.27^{\circ} \mathrm{C}$ at Site 1. MAE and RMS are slightly larger, however all values are less than $1.0^{\circ} \mathrm{C}$. These values increase slightly for validation years 2003 and 2004 and have a maximum bias of $-0.63^{\circ} \mathrm{C}$ (Table 6.4). In 2004, temperature data were not collected at Site 4. 
Table 6.3. Lower Granite Reservoir simulation results summary

\begin{tabular}{|c|c|c|c|}
\hline Year - Site & Bias $\left({ }^{\circ} \mathrm{C}\right)$ & MAE $\left({ }^{\circ} \mathrm{C}\right)$ & RMS $\left({ }^{\circ} \mathrm{C}\right)$ \\
\hline 2002 LWG Site 4 & $\mathbf{- 0 . 0 4}$ & $\mathbf{0 . 7 0}$ & $\mathbf{0 . 9 2}$ \\
\hline 2002 LWG Site 3 & $\mathbf{0 . 1 0}$ & $\mathbf{0 . 5 4}$ & $\mathbf{0 . 7 0}$ \\
\hline 2002 LWG Site 2 & $\mathbf{- 0 . 1 3}$ & $\mathbf{0 . 4 3}$ & $\mathbf{0 . 5 9}$ \\
\hline 2002 LWG Site 1 & $\mathbf{- 0 . 2 7}$ & $\mathbf{0 . 4 3}$ & $\mathbf{0 . 5 7}$ \\
\hline 2002 LWG DS & $\mathbf{0 . 1 1}$ & $\mathbf{0 . 5 2}$ & $\mathbf{0 . 6 7}$ \\
\hline & & & \\
\hline 2003 LWG Site 4 & 0.02 & 0.80 & 1.11 \\
\hline 2003 LWG Site 3 & -0.08 & 0.63 & 0.85 \\
\hline 2003 LWG Site 2 & -0.63 & 0.76 & 1.07 \\
\hline 2003 LWG Site 1 & -0.59 & 0.67 & 0.90 \\
\hline 2003 LWG DS & -0.06 & 0.59 & 0.78 \\
\hline & & & \\
\hline 2004 LWG Site 3 & 0.11 & 0.55 & 0.77 \\
\hline 2004 LWG Site 2 & -0.29 & 0.49 & 0.73 \\
\hline 2004 LWG Site 1 & -0.54 & 0.63 & 0.87 \\
\hline 2004 LWG DS & -0.21 & 0.64 & 0.84 \\
\hline
\end{tabular}

Little Goose Reservoir was calibrated for year 2003 (bold font) and validated for years 2002 and 2004. In 2002, observed temperatures data were available only at the forebay BRZ for LGS, LMN and IHR reservoirs and no data was collected at the mid-pool locations. MAE and RMS validation results for LGS Reservoir are slightly worse than for the calibration year. Bias however is slightly reduced for validation years 2004 (Table 6.5).

Table 6.4. Little Goose Reservoir simulation results summary

\begin{tabular}{|c|c|c|c|}
\hline Reservoir - Year - Site & $\operatorname{Bias}\left({ }^{\circ} \mathrm{C}\right)$ & $\operatorname{MAE}\left({ }^{\circ} \mathrm{C}\right)$ & RMS $\left({ }^{\circ} \mathrm{C}\right)$ \\
\hline 2002 LGS DS & 0.10 & 0.57 & 0.88 \\
\hline 2003 LGS MP & $\mathbf{- 0 . 3 3}$ & $\mathbf{0 . 5 7}$ & $\mathbf{0 . 7 3}$ \\
\hline 2003 LGS DS & $\mathbf{0 . 0 3}$ & $\mathbf{0 . 4 7}$ & $\mathbf{0 . 6 8}$ \\
\hline 2004 LGS MP & 0.04 & 0.61 & 0.86 \\
\hline 2004 LGS DS & 0.02 & 0.61 & 0.97 \\
\hline
\end{tabular}

Table 6.5. Lower Monumental Reservoir simulation results summary

\begin{tabular}{|c|c|c|c|}
\hline Reservoir - Year - Site & $\operatorname{Bias~}\left({ }^{\circ} \mathrm{C}\right)$ & $\operatorname{MAE}\left({ }^{\circ} \mathrm{C}\right)$ & RMS $\left({ }^{\circ} \mathrm{C}\right)$ \\
\hline 2002 LMN DS & 0.21 & 0.70 & 1.03 \\
\hline 2003 LMN MP & $\mathbf{0 . 0 1}$ & $\mathbf{0 . 4 9}$ & $\mathbf{0 . 6 8}$ \\
\hline 2003 LMN DS & $\mathbf{- 0 . 1 5}$ & $\mathbf{0 . 5 9}$ & $\mathbf{0 . 7 5}$ \\
\hline 2004 LMN MP & 0.17 & 0.48 & 0.77 \\
\hline 2004 LMN DS & -0.24 & 0.78 & 1.03 \\
\hline
\end{tabular}


Lower Monumental Reservoir was calibrated for 2003 (bold font) and validated for 2002 and 2004. A summary of goodness-of-fit values are shown in Table 6.6. Predicted temperatures fit within $-0.15{ }^{\circ} \mathrm{C}$ (bias), $0.59^{\circ} \mathrm{C}(\mathrm{MAE})$, and $0.75^{\circ} \mathrm{C}(\mathrm{RMS})$ during calibration. Validation results produce similar values for the mid-pool location, the downstream location is slightly worse.

Table 6.6. Ice Harbor Reservoir simulation results summary

\begin{tabular}{|c|c|c|c|}
\hline Reservoir - Year - Site & Bias $\left({ }^{\circ} \mathrm{C}\right)$ & $\operatorname{MAE}\left({ }^{\circ} \mathrm{C}\right)$ & RMS $\left({ }^{\circ} \mathrm{C}\right)$ \\
\hline 2002 IHR DS & 0.13 & 0.41 & 0.62 \\
\hline 2003 IHR MP & $\mathbf{0 . 0 5}$ & $\mathbf{0 . 2 4}$ & $\mathbf{0 . 3 3}$ \\
\hline 2003 IHR DS & $\mathbf{0 . 0 6}$ & $\mathbf{0 . 3 5}$ & $\mathbf{0 . 4 9}$ \\
\hline 2004 IHR MP & 0.15 & 0.38 & 0.53 \\
\hline 2004 IHR DS & 0.07 & 0.40 & 0.59 \\
\hline
\end{tabular}

Vertical temperature gradients in the reservoir upstream of Ice Harbor Dam are much less than in the other three reservoirs upstream. This may be why results from the goodness-of-fit statistic (Table 6.7) indicate the model is more accurate for this reservoir than for the other three reservoirs. 


\subsection{Management Scenarios and Reservoir-Integrated Metrics Computed Using FINS}

Once confidence in the CE-QUAL-W2 models had been obtained by validating results against observed field data, the models were used to examine how water temperatures would change if alternate reservoir operation rules were implemented. The scenarios discussed in this section are for illustrative purposes and are neither proposed nor being considered by the Action Agencies.

In the first management scenario, inflows to Lower Granite Reservoir were modified. The scenario was designed to answer questions about how alteration of Clearwater or Snake river inflows might change vertical temperature profiles in Lower Granite Reservoir.

In the second scenario, the water surface elevation of Little Goose pool was lowered to elevation $190.2 \mathrm{~m}(624 \mathrm{ft})$, or approximately $2.75 \mathrm{~m}(9 \mathrm{ft})$ below the normal minimum operating pool elevation. This elevation equates to a forebay head of $25.9 \mathrm{~m}(85 \mathrm{ft})$ on the powerhouse turbines and is the minimum elevation developed under the $1 \%$ turbine operating range guidelines (FPP 2005). This scenario was designed to answer questions about how velocity patterns in the reservoir might change if pool elevation was lowered, and specifically investigated whether or not wind setup in the pool could be minimized.

The third section of this chapter examines results generated from linking CE-QUAL-W2 output with the Fish Individual Numerical Simulator (FINS) model. Results generated by the FINS model provide reservoir-integrated metrics that allow comparison of hydrodynamic and water temperature conditions experienced by particles moving through the reservoir had different hydrosystem operations taken place.

\subsection{Alteration of Inflows to Lower Granite Reservoir: Managing Vertical Temperature Gradients}

Vertical temperature gradients within Lower Granite Reservoir are highly dependent upon the quantity and quality of flow entering the reservoir from the lower Clearwater and middle Snake rivers. Section 4.1 described inflow conditions to the reservoir during the summers of 2002, 2003, and 2004. Insets $\mathrm{C}$ and $\mathrm{D}$ of Figures 4.1 through 4.3 display the Clearwater/Snake $(\mathrm{C} / \mathrm{S})$ river discharge ratio and the relative temperature difference of these inflows, which are the key parameters adjusted during these management scenarios.

Between July 1 and August 9, 2002, the C/S ratios were above 1.0, and values exceeding 1.2 were not uncommon for the early part of August. These values are much higher than those that occurred during most of 2003 and 2004, when C/S ratios were rarely above 1.0. Because discharge ratios during July 1 through August 9, 2002, were significantly different from those of the later 21 days of 2002, most of 2003 , and all of 2004, this part of 2002 was analyzed separately.

\subsubsection{Raising Clearwater Discharge or Lowering Snake Discharge to Achieve a Discharge Ratio of 1.0}

During the last 21 days in August 2002, most of 2003, and all of 2004, the Clearwater/Snake river discharge ratio was generally less than 1.0 (i.e., Snake River discharge larger). This group of 
management scenarios investigates vertical changes in water temperature when the discharge ratio was altered to achieve a perfect match of 1.0 for the entire simulation period. Results were then compared to the actual historical period at Sites 1, 2, 3, and the forebay BRZ (see Figure 7.1). Three-dimensional effects between the confluence and Site 3 made comparison at these upstream sites impractical using the 2D laterally-averaged model CE-QUAL-W2. In the future, if results in this upstream reach are desired, the 3D model (see Section 4.5) is suitable for generating those values.

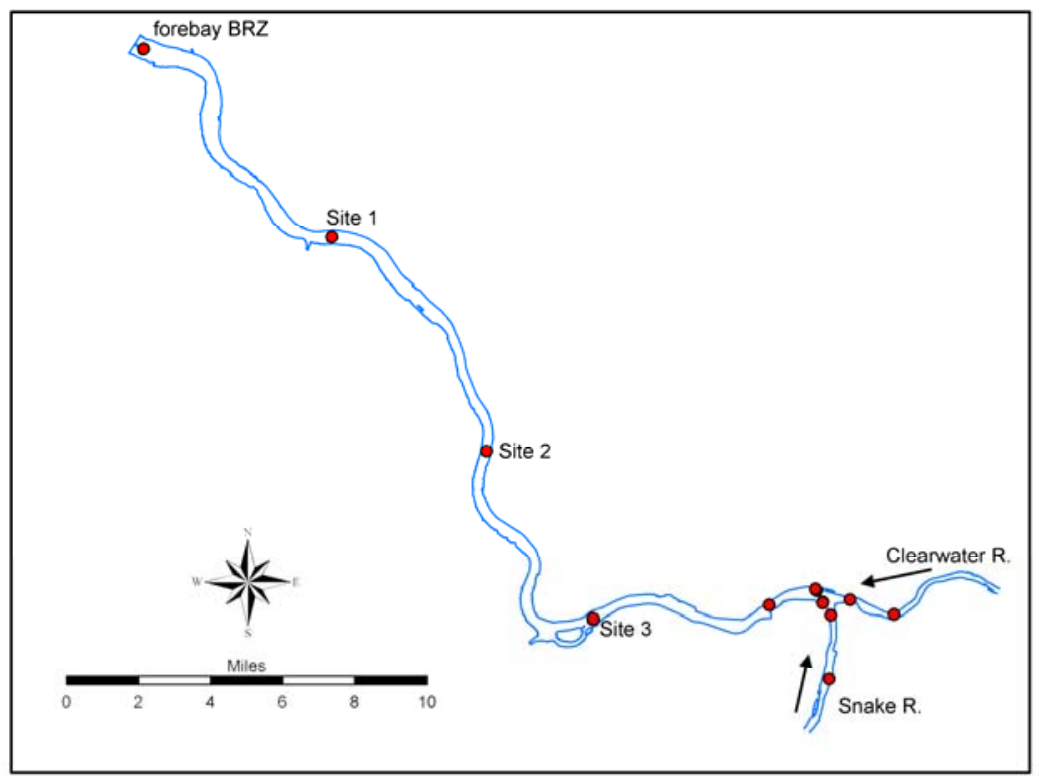

Figure 7.1. Lower Granite Reservoir and temperature monitoring sites

To achieve a discharge ratio of 1.0, either the Clearwater River discharge (symbol Q in Figure 7.2) was altered (left side of Figure 7.2) or the Snake River discharge was altered (right side of Figure 7.2) to match discharge in the other river. Generally, this meant either increasing the Clearwater River discharge or decreasing the Snake River discharge entering Lower Granite Reservoir throughout the simulation period.

Inflow water temperatures during the management scenario were identical to the historical period. Discharge-weighted temperatures, similar to those shown in Figures 3.1 through 3.3, were also computed for each management scenario. The simulation-average difference in discharge-weighted temperature between the management scenario and the historical period (management minus historical) are shown as vertical aqua colored lines in Figure 7.2. Negative values indicate the weighted-average temperature is cooler under the management scenario. Because the averaging weights for the management scenario are exactly 1.0, the discharge-weighted temperature is equal to the mean inflow temperature between the Clearwater and Snake rivers. Therefore, temperature differences between management scenarios and the historical period (light blue lines) do not change from one scenario to the other for an identical simulation period. However, temperature differences do occur from year to year. During the 2002 period, discharge-weighted water temperatures were colder by $0.43^{\circ} \mathrm{C}$ over the historical period. Likewise, during 2003 and 2004, the discharge-weighed water temperatures are also colder than the historical period by $0.73^{\circ} \mathrm{C}$ and $0.38^{\circ} \mathrm{C}$, respectively. 

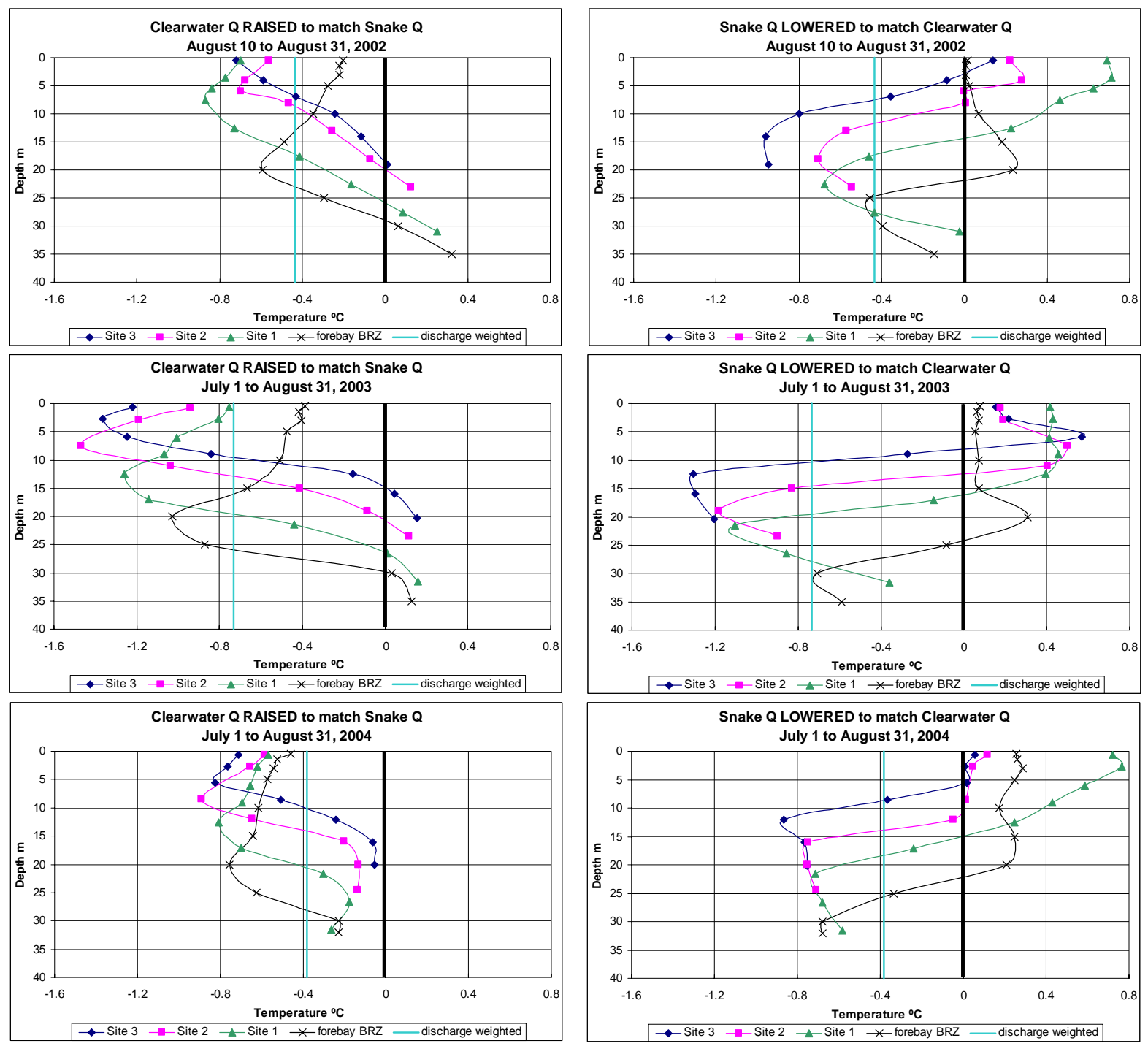

Figure 7.2. Simulation-Average Temperature Differences Between Historic and Management Scenario Results for Lower Granite Reservoir. Zero temperature difference line (i.e., no change line) is marked in bold.

Vertical changes in water temperature were computed at Sites 1,2,3, and the forebay BRZ by subtracting management scenario results from the historical period results at depths corresponding to where temperature loggers were placed in the water column. Vertical profiles of simulation-average differences are displayed in Figure 7.2. As before, negative values indicate a decrease in the average water temperature during the management scenario.

When the Clearwater River discharge was raised to match the entering Snake River discharge (left side of Figure 7.2), a decrease in epilimnetic water temperatures was noted for all years. Temperature decreases were largest at Sites 1, 2, and 3, with some values being (on average) larger than $1.2^{\circ} \mathrm{C}$. Decreases were generally less at the forebay BRZ site, with epilimnetic differences being less than $0.5^{\circ} \mathrm{C}$. In the hypolimnion, simulation-average water temperature differences were small, although a slight $\left(<0.5^{\circ} \mathrm{C}\right)$ warming was noted for 2002 and 2003 . 
When the Snake River discharge was lowered to match the Clearwater River discharge (right side of Figure 7.2), upper water column temperatures were noted to warm slightly at most sites. Differences downstream at the forebay BRZ were close to zero. Hypolimnetic temperatures cooled significantly, with the largest differences occurring closest to the confluence (Site 3). Vertical mixing occurred as the water traveled through the reservoir, decreasing vertical temperature gradients and decreasing the overall hypolimnetic thermal benefit. Hypolimnetic temperatures at the forebay BRZ were cooler than the historical period by 0.4 to $0.8^{\circ} \mathrm{C}$ over the entire simulation period.

In summary, for the management scenarios when the Clearwater River discharge was raised, the total river discharge in the Lower Snake River was increased. This increased mixing at the confluence, with a subsequent decrease of epilimnetic temperatures. Because these temperatures are generally very warm (see Figures 4.12 through 4.15), an average decrease of even $1{ }^{\circ} \mathrm{C}$ over the entire period may have a beneficial impact on migrating juvenile salmon in the upper water column. The negative aspect of this scenario is that additional releases of cold water from Dworshak Dam were assumed to be released. Although this cold water probably existed in Dworshak Reservoir, the arbitrated reservoir elevation minimum of $463.3 \mathrm{~m}(1,520 \mathrm{ft})$ may have been violated (see Section 2.2$)$ if this scenario been implemented.

For the management scenarios when Snake River discharge was lowered, the total river discharge in the Lower Snake River was decreased. This decreased mixing at the confluence, with a subsequent increase in stratification throughout Lower Granite Reservoir. Less Clearwater River water was entrained in the epilimnion, and temperatures in the upper water column were warmer than the historical period. However, the hypolimnion did realize a significant thermal benefit and was cooled by up to $1{ }^{\circ} \mathrm{C}$ at some sites. The net result was that a larger volume of cold hypolimnetic water reached Lower Granite Dam. The net benefit from this scenario is that a larger volume of cold water may exist for use downstream of Lower Granite Dam for the same Dworshak Dam release. The negative aspect of this scenario is that less water was released from the Hells Canyon Complex, potentially resulting in lost revenue from hydroelectric power generation.

\subsubsection{Flow Augmentation Period: Discharge Ratio of 1.0 Plus Holding Clearwater River Inflow Temperatures Constant}

During the July 1 through August 31, 2004 period, lower Clearwater River inflow temperatures at Site 11 (most upstream red circle in Figure 7.1) ranged from 10.6 to $15.5^{\circ} \mathrm{C}$. This resulted in temperature differences during early July and late August of only 8 to $10^{\circ} \mathrm{C}$ (see Figure 4.3, inset D). Because colder release temperatures from Dworshak Reservoir would have been possible during early July and late August, this management scenario investigated impacts of altering the discharge ratio and holding the lower Clearwater River inflow temperature constant at $11.5^{\circ} \mathrm{C}$. This also implies that during part of the scenario (late July and early August), Clearwater River inflow temperatures were also raised by approximately $1{ }^{\circ} \mathrm{C}$.

The discharge-weighted temperature difference between the two scenarios was small and decreased from $-0.38^{\circ} \mathrm{C}$ to $-0.54{ }^{\circ} \mathrm{C}$. Effects in the water column downstream, however, were more significant. When the Clearwater River discharge was raised, upper water column temperatures decreased almost 

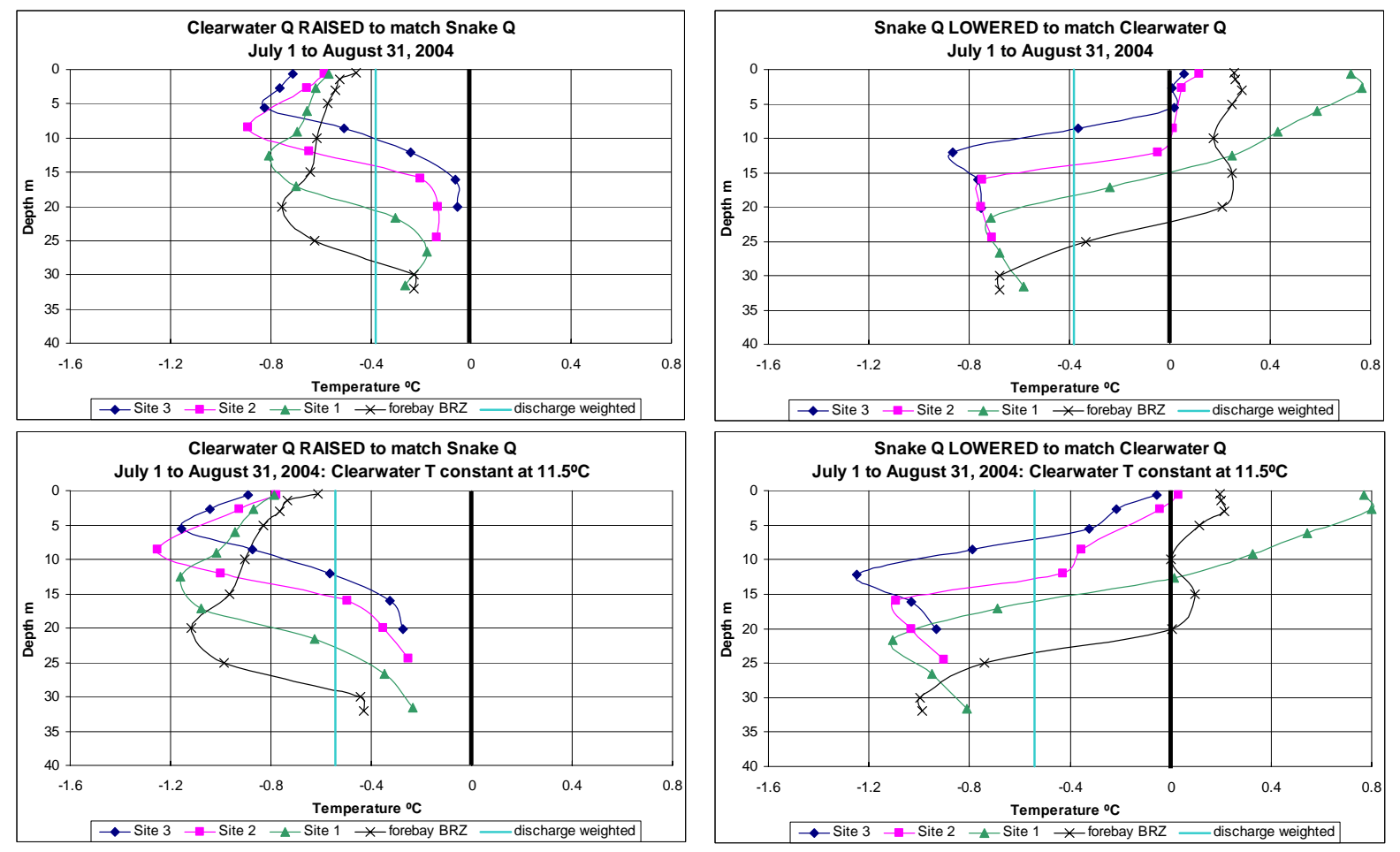

Figure 7.3. Simulation-Average Temperature Differences Between Historic and Management Scenario Results for the 2004 Period. Upper graphics (inflow discharge altered but inflow temperatures held equal to historic), repeated from Figure 7.3, are included here to facilitate comparison.

$0.4^{\circ} \mathrm{C}$. Likewise, when the Snake River discharge was lowered, the hypolimnetic benefit at the dam was also increased, and temperatures dropped by $0.4^{\circ} \mathrm{C}$ with a slight benefit in the upper water column as well.

In summary, these results indicate that thermal benefits may be obtained in Lower Granite Reservoir if current operational rules were changed (see Section 2.2). Results indicate that colder period-average releases would have increased the thermal benefit in Lower Granite Reservoir. Because during part of the period Clearwater River temperatures were raised up to $11.5^{\circ} \mathrm{C}$, negative aspects associated with extremely cold releases from Dworshak Dam also may have been minimized.

\subsubsection{July 2002 Flow Augmentation Period: Discharge Ratio of 1.0}

The July 1 through August 9, 2002, period was unique because Clearwater River discharges were, on average, larger than those of the Snake River. Impacts on vertical temperature profiles in Lower Granite Reservoir with the discharge ratio held constant at 1.0 during this period were investigated. To achieve this discharge ratio, the Clearwater River flows were decreased or the Snake River discharges were increased. This is opposite to the increases/decreases simulated under management scenarios discussed in Section 7.1.1.

Simulation results displayed in Figure 7.4 indicate that the overall impacts of this management scenario were minimal. The discharge-weighted averaged temperature increased by $0.05^{\circ} \mathrm{C}$ (negligible). 

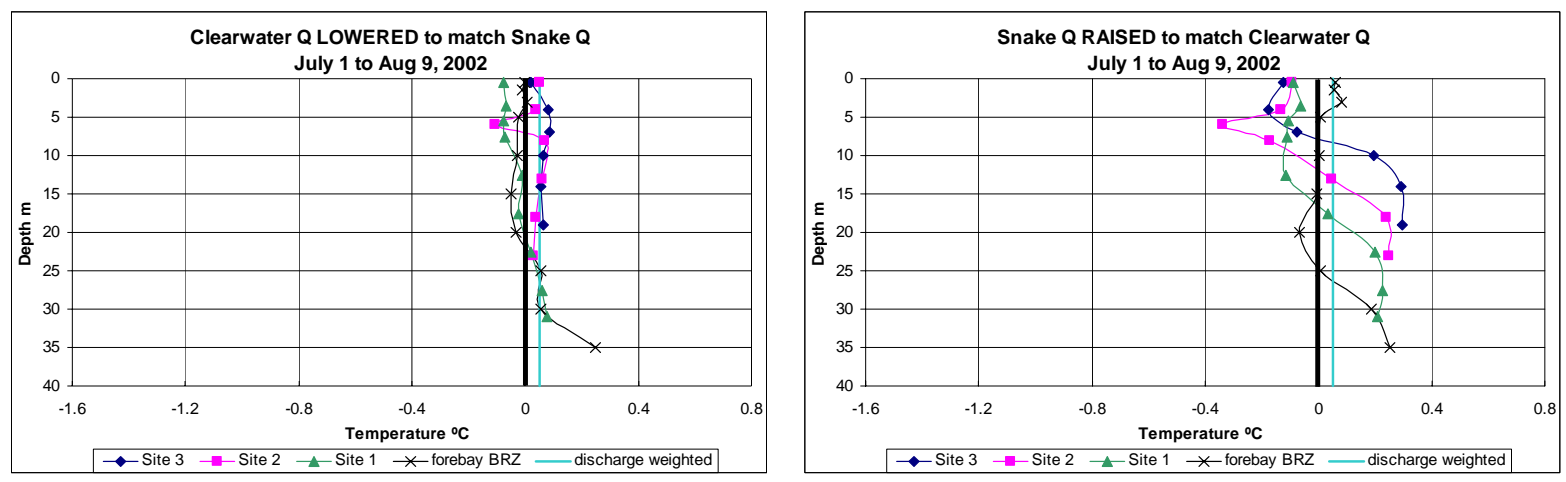

Figure 7.4. Simulation-Average Temperature Differences Between Historic and Management Scenario Results for Lower Granite Reservoir

A small increase in hypolimnetic temperatures was noted when the Snake River discharge was increased; however, differences were generally less than $0.3^{\circ} \mathrm{C}$. Differences when the Clearwater River was lowered were also minimal, suggesting that water could have been stored in the reservoir with minimal impact on Lower Granite Reservoir temperatures.

\subsection{Impacts of Lowering the Water Surface Elevation of Little Goose Pool}

The water surface elevation of the Little Goose pool is maintained during the flow augmentation period within $0.30 \mathrm{~m}$ (1 ft) of the MOP. During July 1 and August 31 of 2002, 2003, and 2004, there were only six days when the daily-average water surface elevation was more than $0.15 \mathrm{~m}(0.5 \mathrm{ft})$ away from elevation $193.4 \mathrm{~m}$ (634.5 ft) (DART 2005). This scenario investigated impacts on water temperatures and water velocities in the reservoir had Little Goose Dam been operated differently and instead maintained a constant water surface elevation of $190.2 \mathrm{~m}(624.5 \mathrm{ft})$. This represents an average decrease in water surface elevation of $3.2 \mathrm{~m}(10.5 \mathrm{ft})$. Assuming that the immediate Little Goose tailrace elevation was $164.3 \mathrm{~m}(539.0 \mathrm{ft})$, the operating head on the powerhouse turbines would be $25.9 \mathrm{~m}(85.0$ $\mathrm{ft}$ ), which is the lowest value developed under the $1 \%$ turbine operating range guidelines (FPP 2005).

Simulation results are displayed in Figure 7.5. Profiles of water temperature differences at mid-pool and downstream at the forebay BRZ were computed by averaging differences in simulation results (management scenario minus historic) over the simulation period. Results for both 2002 and 2004 indicate little change in profiles of temperature between historic and management scenario results, although a net cooling of approximately $0.5^{\circ} \mathrm{C}$ in the top $5 \mathrm{~m}$ was noted during 2003 .

Vertical profiles of water velocity increased as expected under this management scenario. However, because the reservoir is relatively deep compared to the elevation change, the velocity changes were relatively small. One zone that was noted to change was the upper $4 \mathrm{~m}$ of the water column during 2003. Simulated averaged velocities changed from being slightly negative (upstream) to slightly positive (downstream), indicating absence of wind setup at mid-pool during the management scenario. However, during 2004 when wind setup also occurred, simulation results indicate that increased velocities induced by this management scenario were not sufficient to overcome wind setup. 
In summary, simulation results show that velocities increase only slightly if the water surface of the reservoir is lowered $3.2 \mathrm{~m}$. During 2003, the velocity increase appears to be sufficient to remove wind setup effects. However, during 2004, the velocity increase was not sufficient, and wind setup developed similar to the historical period. It is hypothesized that at some, even lower, water surface elevation, wind setup effects that developed during the 2004 period could be removed. However, it is unknown at this time what that elevation would be.
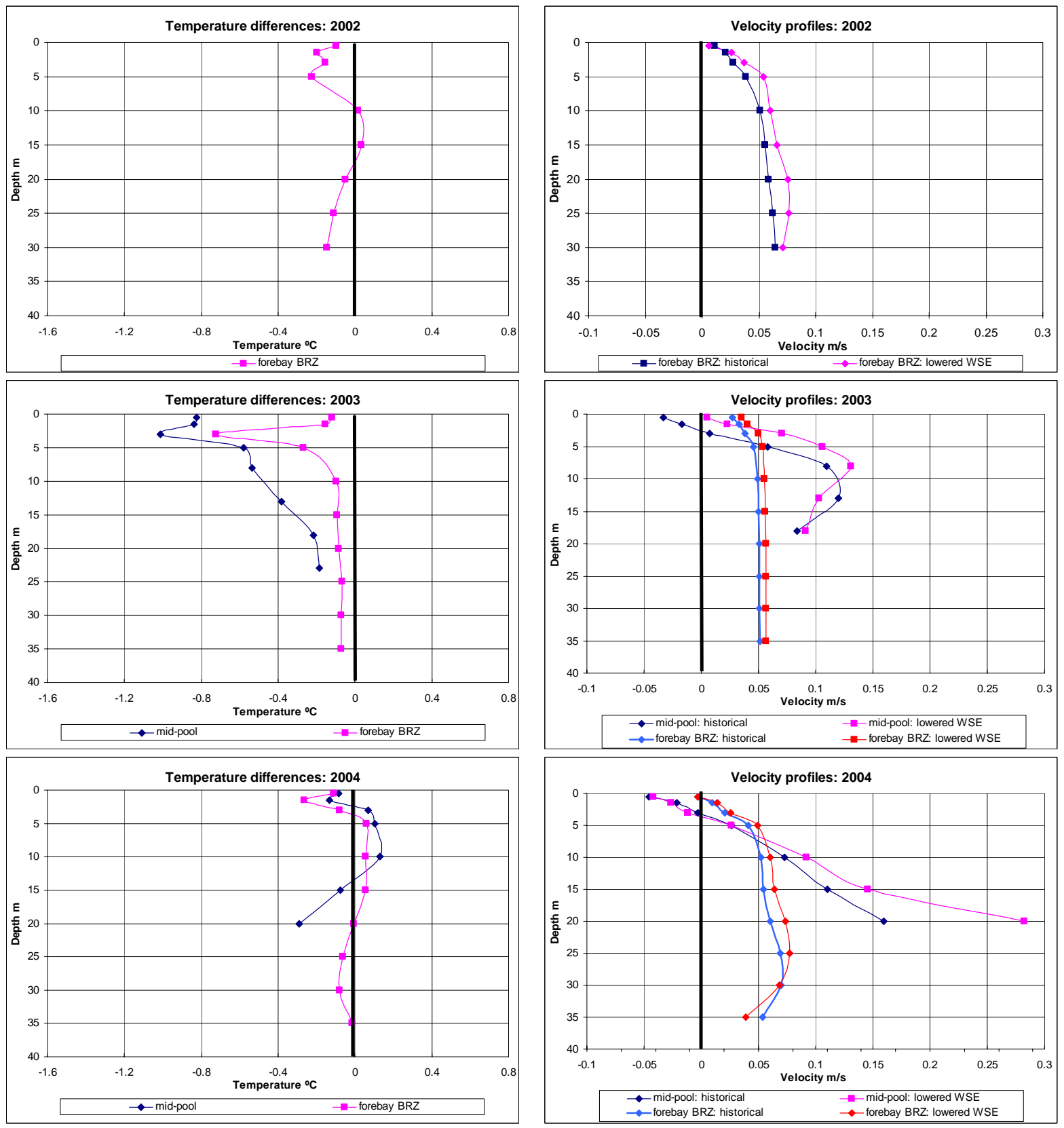

Figure 7.5. Computed Temperature Differences (left) and Velocity Profiles (right) for Little Goose Pool. Negative velocities imply water flowing upstream. Line indicating zero temperature difference (i.e., no change) and velocity magnitude is marked in bold. 


\subsection{Reservoir-Integrated Metrics Computed via FINS}

The Fish Individual Numerical Simulator (FINS) model is a discrete, individual-based numerical model (Scheibe and Richmond 2002). "Individual-based" refers to the simulation of individual particles within the water body. The FINS model was developed originally for evaluating the biological effects of supersaturated dissolved gas exposure on juvenile salmonids. The FINS model is also applicable to a number of other problems related to the survival of fish during out-migration, such water temperatures exposure.

Like any numerical model, the FINS model must be calibrated against observed field data. Basic biological data on juvenile fall Chinook salmon swimming depth, intra-reservoir speed of travel, and sensitivity to hydraulic phenomena such as wind setup is lacking in the technical literature. The best data available at the time of this study are from the passive integrated transponder (PIT) tag system. Unfortunately these data provide only times when a juvenile salmon passes through one of the PIT-tag monitoring facilities located at one of the lower Snake River dams, and hence only provide reservoirintegrated information (e.g., average travel time and speed from an upstream point to the downstream PIT-tag monitoring facility).

\subsubsection{Application of the FINS Model}

The FINS model was used in this study as a tool for comparing reservoir-integrated metrics, such as travel time and average temperature exposure, not fish behavior. To compute these metrics, particles were introduced into the FINS model, which relied on the previously computed CE-QUAL-W2 hydrodynamics and water temperature values. Particles were then routed through the reservoir using the FINS model. FINS model results were generated for all four reservoirs and all three simulation years.

The CE-QUAL-W2 output file snapshot contained all necessary hydrodynamic and water quality data for the FINS model. Values used by the FINS model include longitudinal and vertical velocity, vertical turbulent eddy viscosity, and water temperature for each computational cell in the CE-QUAL-W2 model. To be used by the FINS model, the snapshot file was first converted into CFD General Notation System (CGNS) format, which could then be read directly by the FINS model.

Two different types of particles were used during the study. The first particle was neutrally buoyant and without any preferred swimming depth. These particles followed flow streamlines from the upstream cell to the downstream boundary cell of the model. The second particle type was provided with a preferred swimming depth. This model input parameter persuaded the particles to stay around a given depth value, although vertical hydraulic forces could move them temporarily either upward or downward in the water column. After the vertical force was reduced, the particles would migrate back to the preferred swimming depth.

FINS model results were compared to data obtained via the PIT-tag system. PIT-tag data were obtained from several sources, including published literature and DART (2005). These data, and the sources used, are described more fully in Appendix D. Representative data spanning several years for juvenile fall Chinook passing through Little Goose Reservoir are displayed in Table 7.1. 
Table 7.1. Migration rates for Little Goose Reservoir (Source: Connor et al. 2003b)

\begin{tabular}{|c|c|c|c|}
\hline Year & $\begin{array}{c}\text { Migration } \\
\text { rate } \\
\text { (km/day) }\end{array}$ & $\begin{array}{c}\text { Fish } \\
\text { Count }\end{array}$ & $\begin{array}{c}\text { Range } \\
\text { (days) }\end{array}$ \\
\hline 1996 & 13.5 & 44 & $1.4-30$ \\
\hline 1997 & 8.4 & 49 & $0.8-30$ \\
\hline 1998 & 17.7 & 289 & $1.2-60$ \\
\hline 1999 & 12.4 & 187 & $1.3-60$ \\
\hline 2000 & 10.7 & 153 & $0.9-30$ \\
\hline 2001 & 8.3 & 91 & $0.6-30$ \\
\hline
\end{tabular}

Data presented in Table 7.1 were collected from PIT-tagged fish that were first monitored at Lower Granite Dam and then monitored again as they passed through Little Goose Dam. Unfortunately, no information can be obtained between the two dams, and migration rates shown in the table were computed by dividing the total distance between the dams by the elapsed time. The range of migration rates for any specific individual fish is large, as can be seen by noting the range in the number of days necessary to pass through the reservoir in Table 7.1.

A second example of PIT-tag data is shown in Figure 7.6, which displays the typical distribution of traveling speed for hatchery-raised juvenile fall Chinook salmon passing through Little Goose pool. These data were obtained from DART (2005). Data are a summary of all juvenile fall Chinook salmon passing through both Lower Granite and Little Goose dams between July 1 and September 30 for the years 2002, 2003, and 2004. As can be seen in the figure, migration rates vary from less than 1 to more than $35 \mathrm{~km} /$ day.

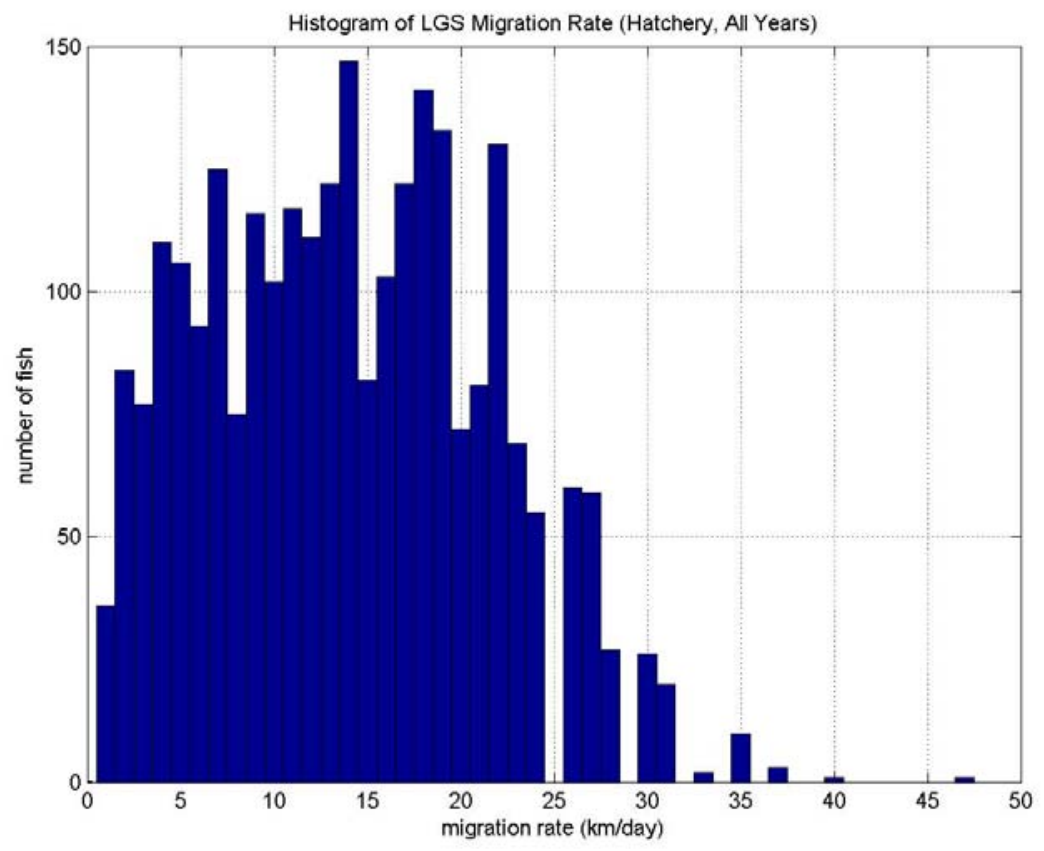

Figure 7.6. Computed histogram of migration rate for hatchery-raised juvenile fall Chinook salmon passing through Little Goose Pool: 2002 through 2004. Source: DART (2005). 


\subsubsection{Reservoir-Integrated Metrics}

FINS particles were introduced at the upstream end of the computational domain for each reservoir. The FINS model would then compute the travel path for each particle based on the CE-QUAL-W2 results and any user specified particle depth preference. Because the reservoirs were stratified, the epilimnion and hypolimnion velocities were significantly different. In fact, because of wind setup (see Section 5.1), epilimnetic velocities were often not moving (zero velocity) or traveling slowly upstream.

Particle migration rates $(\mathrm{km} /$ day) and elapsed time to pass each reservoir were highly dependent upon depth preference. If particles were not provided with a depth preference, they would generally move into the hypolimnion and be translated out of the reservoir relatively quickly. Likewise, particles given a shallow depth preference would remain in the epilimnion and, if wind setup was present, would not move downstream for long periods. Unfortunately, because biological data were not available regarding observed swimming depth for juvenile fall Chinook salmon in the lower Snake River during these periods, only limited conclusions can be derived from the FINS analysis.

Figure 7.7 displays time-histories results for two particles that were introduced into the Little Goose Reservoir (Lower Granite Dam tailrace) on August 1, 2003. The first particle introduced at a depth of 5 $m$ but was not supplied with a preferred swimming depth. The second particle was introduced at the same location but supplied with a preferred swimming depth of $5 \mathrm{~m}$. Because the tailrace conditions were isothermal, both particles experienced the same conditions during the first 1.5 days. On approximately August 3, the particle had moved far enough downstream to encounter the onset of vertical stratification and the circulation pattern described in Figure 5.4. The no-depth preference particle dove downward in the water column, following the streamlines, because the parcel of water associated with the particle was colder and hence denser than the warmer epilimnetic water. The 5-m-depth preference particle was forced to remain at approximately the same depth and crossed the isotherms to enter the epilimnion, as shown in the temperature-time history graphic. The epilimnion was not moving rapidly downstream and, for part of the simulation, the 5-m particle did not make downstream progress. Time history results shown in Figure 7.7 terminate when the particles left the reservoir, which occurred on August 8 for the no-depth preference particle and August 17 for the 5-m-depth preference particle. It should be noted that these results are for two particles only. Typically 280 particles (140 no-depth preference/140 with depth preference) were released over 7 days to generate the ensemble-averaged results shown in Figure 7.7.

Table 7.2 displays ensemble FINS model results generated for Little Goose Reservoir. Particle velocities are expressed in ensemble median migration rate $(\mathrm{km} /$ day) and elapsed time to pass through the reservoir. Particles were seeded at the upstream end of each reservoir and were released in groups of 10 starting August 1. A total of 14 groups were released, and each group was released 12 hours apart (i.e., a total of 140 particles were released in equal groups over a one week period).

Simulated particle migration rates and elapsed times for particles without any depth preference correspond well with median migration rates of juvenile fall Chinook salmon (see Table 7.1 and Appendix D). Migration rates for particles with a depth preference, however, reflect the stratified nature of the reservoir. Particles enter the epilimnion and experience much longer travel times due to wind setup and upstream moving water. These hydraulic phenomena lead to migration rates that are small; however, they still are plausible considering the histogram shown in Figure 7.6. 

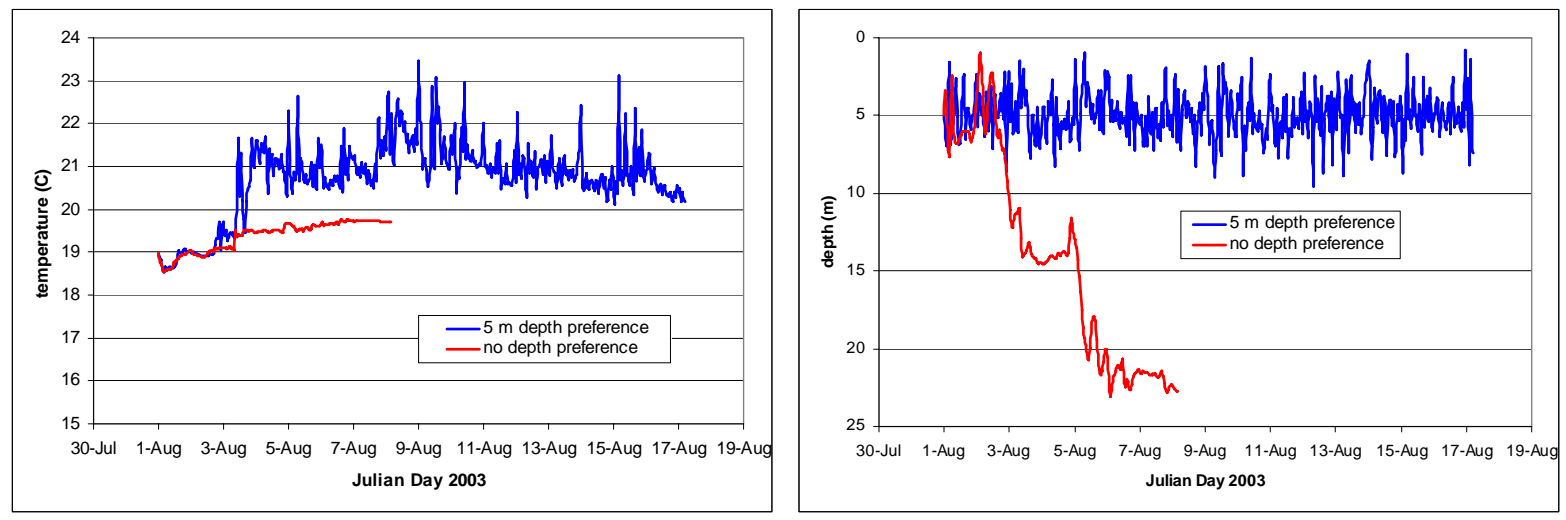

Figure 7.7. Computed time-series results for two FINS particles introduced into the upstream end of Little Goose Reservoir (Lower Granite tailrace) on August 1, 2003

Table 7.2. FINS-computed ensemble median particle information for all groups

\begin{tabular}{|c|c|c|c|c|c|c|c|}
\cline { 3 - 8 } \multicolumn{2}{c|}{} & \multicolumn{2}{c|}{$\mathbf{2 0 0 2}$} & \multicolumn{2}{c|}{2003} & \multicolumn{2}{c|}{2004} \\
\cline { 2 - 8 } \multicolumn{2}{c|}{} & $\begin{array}{c}\text { Migration } \\
\text { rate } \\
\text { (km/day) }\end{array}$ & $\begin{array}{c}\text { Travel } \\
\text { time } \\
\text { (days) }\end{array}$ & $\begin{array}{c}\text { Migration } \\
\text { rate } \\
\text { (km/day) }\end{array}$ & $\begin{array}{c}\text { Travel } \\
\text { time } \\
\text { (days) }\end{array}$ & $\begin{array}{c}\text { Travel } \\
\text { rate } \\
\text { (km/day) }\end{array}$ & $\begin{array}{c}\text { Travel } \\
\text { time } \\
\text { (days) }\end{array}$ \\
\hline \multirow{3}{*}{ LGS } & $\begin{array}{c}\text { No depth } \\
\text { preference }\end{array}$ & 11.4 & 5.2 & 9.2 & 6.5 & 12.6 & 4.7 \\
\cline { 2 - 8 } & $\begin{array}{c}\text { With 5m depth } \\
\text { preference }\end{array}$ & $\begin{array}{c}\text { Less than } \\
2.7\end{array}$ & $\begin{array}{c}\text { More } \\
\text { than 22 }\end{array}$ & 4.9 & 12.3 & 4.0 & 14.9 \\
\hline
\end{tabular}

FINS model results were generated for the Little Goose Reservoir management scenario where the reservoir elevation was lowered by $3.2 \mathrm{~m}$ (see Section 7.2). These results show the response of FINS particles, especially those without a depth preference, to increased water velocities due to the lowered pool elevation. Results shown in Table 7.3 should be compared to those shown in Table 7.2. The particles with no depth preference, on average, passed the reservoir in 4.2 days instead of 6.5 days for the historical period scenario. This equates to a $35 \%$ reduction in median elapsed time and a net increase in migration rate of $5 \mathrm{~km} /$ day. Migration rates and reservoir travel time for FINS particles with a depth preference of $5 \mathrm{~m}$ were changed only slightly by the reduction in reservoir elevation.

Table 7.3. FINS-Computed Median Particle Information: Little Goose Management Scenario

\begin{tabular}{|c|c|c|c|}
\cline { 3 - 3 } \multicolumn{2}{c|}{} & \multicolumn{2}{|c|}{2003} \\
\cline { 3 - 4 } \multicolumn{2}{c|}{} & $\begin{array}{c}\text { Migration rate } \\
(\mathrm{km} / \text { day })\end{array}$ & $\begin{array}{c}\text { Elapsed time } \\
\text { (days) }\end{array}$ \\
\hline \multirow{2}{*}{ LGS with lowered pool elevation } & No depth preference & 14.2 & 4.2 \\
\cline { 2 - 4 } & With 5 m depth preference & 5.0 & 11.9 \\
\hline
\end{tabular}

In summary, the FINS model is a useful tool for quantifying reservoir-integrated statistics regarding various scenarios generated by the CE-QUAL-W2 model. Both migration rate and travel time to pass through the reservoir were highly influenced by particle depth preference. This dependency was expected, because large differences in velocity magnitude and direction exist between the epilimnion and 
hypolimnion in the lower Snake River reservoirs during July and August. This study showed that impacts of various management scenarios (e.g., lowering the elevation of Little Goose pool) can be examined using the FINS model to better quantify CE-QUAL-W2 results and various reservoir-wide metrics (e.g., average temperature exposure, time to pass the reservoir). Additional research and input from biological experts are necessary, however, to further refine results, primarily the selection of actual swimming depth preference of juvenile fall Chinook salmon passing through the reservoir during periods when the reservoirs are stratified. 


\subsection{Conclusions and Recommendations}

For the past several years, circulation dynamics in the lower Snake River reservoir system have been studied during periods when large releases of cold water from Dworshak Reservoir have occurred. These releases combine with warmer water originating from the middle Snake River at the confluence of the Clearwater and Snake rivers to produce a stratified environment in Lower Granite Reservoir downstream. In addition to Lower Granite Reservoir, the three other downstream reservoirs also stratify because the water released from each upstream dam in the series is also below equilibrium temperature.

Migrating juvenile fall Chinook salmon must pass through this cascade of four reservoirs in order to reach the lower Columbia River and finally the Pacific Ocean. Water quality conditions in the lower Snake River are known to directly impact health, survival, and passage timing of these fish, although exact temperature thresholds are debated in the technical literature as is common for biological phenomena. What are generally agreed upon is that health is improved and total survival is increased with lower water temperatures and, for the lower Snake River, higher flow rates.

\subsection{Conclusions}

We conclude that cold water released from the Dworshak Reservoir hypolimnion during the summer months has a profound impact on the lower Clearwater River and lower Snake River systems. Water released from Dworshak Dam during July and August under flow augmentation operations were generally between 6 to $9^{\circ} \mathrm{C}$. Because this water is far below equilibrium temperature, it warms rapidly and is typically $4.5^{\circ} \mathrm{C}$ warmer when the Clearwater River meets the Snake River at the upstream end of Lower Granite Reservoir. The temperature difference between the Clearwater and Snake rivers at the confluence was between 9 and $11^{\circ} \mathrm{C}$ during the three years this study performed long-term data collection in Lower Granite Reservoir. Average stratification intensity (difference in mean temperature between $1.5 \mathrm{~m}$ and 30 $m$ depth temperature loggers) over the three years in the Lower Granite Reservoir Dam forebay between July 15 and August 15 was $5^{\circ} \mathrm{C}$. Downstream of Lower Granite Dam, the cascade of reservoirs also stratified although temperature differences between epilimnetic and hypolimnetic layers were less. Average downstream stratification over the same period were: Little Goose $B R Z=2.5^{\circ} \mathrm{C}$; Lower Monumental $B R Z=2.1{ }^{\circ} \mathrm{C}$; and Ice Harbor $B R Z=1.8^{\circ} \mathrm{C}$. Therefore, although the intensity of stratification at the forebay BRZ zones decreased with distance downstream from the confluence, all four lower Snake River reservoirs stratified as a result of cold water released from Dworshak Reservoir's hypolimnion.

Within each lower Snake River reservoir, the most upstream portion of the reservoir was not stratified. For Lower Granite Reservoir, the onset of stratification was at the confluence of the Clearwater and Snake rivers. Cold water was found to migrate upstream of the confluence along the bottom of the Snake River during periods of intense stratification however stratification was limited to a river reach less than $3 \mathrm{~km}$ long. For Little Goose, Lower Monumental, and Ice Harbor reservoirs, the most upstream reach was the tailrace of the upstream dam. Data collected in these upstream zones showed the river to be thermally homogenous. The location of initial stratification within these three reservoirs is not as well defined as Lower Granite Reservoir, however onset of stratification did occur in the upper half of the reservoir (i.e., upstream of the mid-pool temperature loggers). 
Temperature loggers placed within the top $7 \mathrm{~m}$ of the water column near mid-pool of Lower Monumental and Little Goose reservoirs were found to be 1 to $3^{\circ} \mathrm{C}$ warmer than similar depth loggers placed downstream near the dam. As described in Section 5.1, this phenomenon is thought to be caused by wind 'holding' the upper water column in place. Increased exposure to surface heating caused this section of the water column to heat up. This phenomenon was found to be strongest at Lower Monumental and Little Goose reservoirs during the summer of 2003 and 2004. During a two-day period in July 2005, this phenomenon was measured with ADCP transects and CTD probe profiles in Little Goose Reservoir. Similar wind-setup phenomena, although weaker in magnitude, were observed in temperature records at Lower Granite and Ice Harbor reservoirs.

The immediate thermal benefit of cold water releases from Dworshak Reservoir at various depths within Lower Granite Reservoir was computed based on a three-year data measurement campaign. To facilitate comparison between sites, thermal benefit is defined in this report as the average decrease in water temperature at a certain depth as compared to the Snake River temperature just upstream of the confluence between July 15 and August 31. Close to the confluence, a thermal benefit of 1 to $2^{\circ} \mathrm{C}$ was observed in the top $2 \mathrm{~m}$ of the water column during all years. Farther downstream from the confluence, the thermal benefit in the upper water column decreased markedly, and varied from year to year. For example, at a distance of $11 \mathrm{~km}$ upstream of the dam (Site 1), the thermal augmentation benefit in the top $2.8 \mathrm{~m}$ was negligible $\left(-0.3^{\circ} \mathrm{C}\right)$ in 2003 , while in 2002 was $1.2^{\circ} \mathrm{C}$ at $3.5 \mathrm{~m}$ and larger at shallower depths.

Although cold water was present during all three years at deep depths within Lower Granite Reservoir, flow augmentation did not necessarily benefit the upper water column throughout the entire reservoir. Although conditions specified in SOR (2005) for Lower Granite Dam tailrace temperatures were met, temperatures in the upper $3 \mathrm{~m}$ of Lower Granite Reservoir were above $20^{\circ} \mathrm{C}$ for all of 2003 and most of 2004 (see Section 4.3 and 3.4). Also, at Site 1 and the forebay BRZ, temperatures for most at 2003 in the top $6 \mathrm{~m}$ of the water column were above $22^{\circ} \mathrm{C}$, with peak daily mean temperatures above $24^{\circ} \mathrm{C}$ in the top $2 \mathrm{~m}$.

A 3D model of the Snake and Clearwater river confluence developed during the study successfully captured hydraulic and water quality patterns observed in the field. This model now is suitable for use in determining transient entrainment and mixing near the confluence, and is useful as a pre-migration forecast planning tool.

Numerical models of the four Lower Snake River reservoirs were developed using CE-QUAL-W2. A separate model for each reservoir was developed so that individual reservoirs could be tested independently of the remainder of the system. The models were calibrated and validated using threeyears of observed water temperature and elevation data. Typical bias and mean absolute errors were less than $0.5^{\circ} \mathrm{C}$ (see Section 6.5.2). The models also accurately represented the wind setup (see Section 5.1) and system-wide stratification patterns (see Section 5.2) observed with field data. These models are suitable also for both pre-migration forecast planning and for real-time within-season management.

Once the 2D model was calibrated and validated against field data, two management scenarios were developed to illustrate the capability of the model to investigate alternative operations scenarios. Two scenarios were selected: (1) alter Dworshak Dam or Hells Canyon Complex releases so that at the 
confluence the two river meet with the same river flow, and (2) lower the water surface elevation of Little Goose Reservoir to increase water velocities and minimize the influence of wind setup.

Impacts of the first alternative (altering Clearwater or Snake River inflows to the confluence) on downstream results significantly changed vertical profiles of water temperature. For example, when Dworshak Dam releases were hypothetically increased for 2003, epilimnetic temperatures decreased by more than $1{ }^{\circ} \mathrm{C}$, however there was little change in hypolimnetic temperatures (i.e., hypolimnetic temperatures remained at approximately the volume-weighted average temperature of the Clearwater and Snake rivers at the confluence). Likewise, when Hells Canyon Complex releases were hypothetically decreased, the epilimnion warmed only slightly due to increased travel times through the reservoir. The hypolimnion however decreased by more than $1^{\circ} \mathrm{C}$ due to a suppression of mixing at the confluence. Therefore two potential management trade-offs resulting from these scenarios are: (a) release more cold (Dworshak Dam) water, which can cool the upper water column, or (b) release the same quantity of cold water but less hot water (curtail Hells Canyon Complex releases), therefore suppressing mixing at the confluence and transporting colder water to the dam. Although power, recreation, and upstream river impacts must also be included in the decision process, these results illustrate the ability of the numerical model to investigate various management scenarios.

An aid to understanding numerical model results is the FINS model, which can produce reservoirintegrated metrics, such as travel time or average velocity, along an entire reservoir. For example, for the management scenario where LGS pool was lowered, the net change in water temperatures were approximately negligible. Using FINS however, the net change in velocity can be fully realized. Particles without any depth preference (i.e., acting like streamlines) passed through the reservoir in 4.2 days instead of 6.5 days, or 35\% faster. Although these particles are not representative of fish, FINS results were shown to produce useful reservoir-integrated metrics to compare various management alternatives.

\subsection{Recommendations}

Based on the results of this study, we recommend a continued effort to further substantiate our findings and to clarify the hydraulic phenomena, primarily wind setup and intensity of stratification due to cold hypolimnetic releases from Dworshak Dam in the lower Snake River. Because a general lack of information was found to exist regarding behavior and survival of juvenile fall Chinook salmon in the lower Snake River, we recommend continued paired research that links fish behavior, health, and survival with various hydraulic phenomena observed and numerically modeled during this study.

Specific recommendations for continued research efforts include the following:

- a paired hydraulic and fish behavior study - Wind setup and upstream movement of epilimnetic water was observed in all reservoirs (Section 5.1). In addition, upstream movement of cold water along the bottom of the Snake River at the confluence of the Clearwater and Snake rivers was observed each summer (Section 4.2.3). The impacts of these complex hydrodynamic motions on migrating juvenile fall Chinook salmon are currently unknown. Migrating juveniles should be tagged with either radio or acoustic tags so that intra-reservoir movement, behavior, and survival can be observed. In addition, water motion and atmospheric boundary layer conditions should be concurrently measured using ADCPs (both bottom- and boat-mounted), 
vertical strings of water temperature loggers, and meteorological stations (primarily anemometers).

- continued dialogue with the Action Agencies and biological experts to discuss implications of numerical model results -- The Lower Granite Dam tailrace temperature criterion used to regulate cold water releases from Dworshak Dam does not guarantee cold water in the upper layers of Lower Granite Reservoir (Section 4.4). In addition, numerical model results show that alternative release patterns from either Dworshak Dam or the Hells Canyon Complex can change thermal conditions in the Lower Granite Reservoir (Section 7.1 and 6.3) and the rest of the lower Snake River. Models developed during this project should be used by the Action Agencies to further examine implications of current hydrosystem operations on the river. These models should also be used to test impacts of alternative hydrosystem operations that seek to optimize environmental conditions for migrating salmon, recreational and barging demands on the reservoirs, and hydroelectric power generation. 


\subsection{References}

Agrimet. 2005. The Pacific Northwest Cooperative Agricultural Weather Network. Data obtained from http://www.usbr.gov/pn/agrimet. Last accessed November 2005.

Bombardelli, FA, CW Hirt, and MH Garcia. 2001. "Discussion on Computations of Curved Free Surface Water Flow on Spiral Concentrators." Journal of Hydraulic Engineering 127(7).

Branford, SF. 2000. "Numerical Simulation of Surf Zone Dynamics." Journal of Waterway, Port, Coastal, and Ocean Engineering 126(1).

Brett, JR. 1952. “Temperature Tolerance in Young Pacific Salmon, Genus Orcorhynchus.” Journal of the Fisheries Research Board of Canada 9:265-322.

Carroll, J, and K Barko. 2005. Personal communication and data transfer, OA Systems, Inc. under contract with the USACE Walla Walla District

Cole, TM, and SA Wells. 2002. CE-QUAL-W2: A Two-Dimensional, Laterally Averaged, Hydrodynamic and Water Quality Model, Version 3.2. Instruction Draft Report EL-2003-1, U.S. Army Engineering Research and Development Center, Vicksburg, Mississippi .

Connor, WP, HL Burge, JR Yearsley, and TC Bjornn. .2003a. "Influence of Flow and Temperature on Survival of Wild Subyearling Fall Chinook Salmon in the Snake River." North American Journal of Fisheries Management 23:362-375.

Connor, WP, RK Steinhorst, and HL Burge. 2003b. "Migrational Behavior and Seaward Movement of Wild Subyearling Chinook Salmon in the Snake River." North American Journal of Fisheries Management 23:414-430.

Connor, WP, HL Burge, and R Waitt. 2002. "Juvenile Life History of Wild Fall Chinook Salmon in the Snake and Clearwater Rivers.” North American Journal of Fisheries Management 22:703-712.

Cook, CB, CL Rakowski, MC Richmond, SP Titzler, AM Coleman, and MD. Bleich. 2003. Numerically Simulating the Hydrodynamic and Water Quality Environment for Migrating Salmon in the Lower Snake River. PNNL-14297, Pacific Northwest National Laboratory, Richland, Washington.

Cook, CB, and MC Richmond. 2004. Monitoring and Simulating 3D Density Currents at the Confluence of the Snake and Clearwater Rivers, in Critical Transitions in Water and Environmental Resources Management, edited by G Sehike, D Hayes and D Stevens, American Society of Civil Engineering Press.

Coutant, CC. 1973. "Effect of Thermal Shock on Vulnerability of Juvenile Salmonids to Predation." Journal of the Fisheries Research Board of Canada 30:965-973.

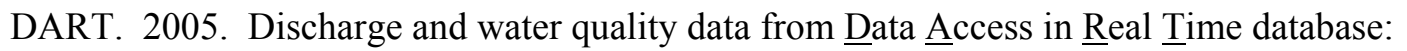
http:/www.cbr.washington.edu/dart/dart.html. Columbia River DART, Columbia Basin Research, School of Aquatic and Fishery Sciences, University of Washington. Last accessed November, 2005. 
Edinger, JE, DK Brady, and JC Geyer. 1974. "Heat Exchange and Transport in the Environment." Cooling Water Discharge Research Project (RP-49), Electric Power Research Institute, Palo Alto, California.

Emmert, R. 2003. Personal communication and data transfer of information from Water Control Manual, USACE Walla Walla District

FCRPS. 2000. Federal Columbia River Power System Biological Opinion: Reinitiating of the Consultation on Operation of the Federal Columbia River Power System, Including the Juvenile Fish Transport System, and 19 Bureau of Reclamation Projects in the Columbia Basin. U.S. Army Corps of Engineers, Bonneville Power Administration, Bureau of Reclamation, National Marine Fisheries Service.

FPP. 2005. "Fish Passage Plan: Corps of Engineers Projects." Northwestern Division, U.S. Army Corps of Engineers, CENWD-PDW-R, Chapter 8.

Garrett, AJ, RJ Kurzeja, BL O'Steen, MJ Parker, MM Pendergast, and E Villa-Aleman. 1999. PostLaunch Validation of Multispectral Thermal Imager (MTI) Data and Algorithms. WSRC-MS-9900423, Westinghouse Savannah River Company, Aiken, South Carolina.

Groves, PA, and JA Chandler. 1999. "Spawning habitat used by fall Chinook salmon in the Snake River.” North American Journal of Fisheries Management 19:912-922.

Hicks, M. 2002: "Evaluating Standards for Protecting Aquatic Life in Washington's Surface Water Quality Standards - Temperature Criteria." Draft Discussion Paper and Literature Summary. Washington State Department of Ecology, Water Quality Program.

Mains, EM. and JM Smith. 1964. 'The distribution, size, time, and current preferences of seaward migrant chinook salmon in the Columbia and Snake rivers. 'Washington Department of Fisheries, Fisheries Research Papers 2(3):5-43.

McMicheal, GA, AL Fritts, TN Pearsons, and, JL Dunnigan. 1999. Lower Yakima River predatory fish monitoring: progress report 1998. Management implications of co-occurring native and introduced fishes: Proceedings of the workshop. Portland, Oregon. Pages 93-124

National Marine Fisheries Service (NMFS). 1992. Threatened status for Snake River spring/summer/fall chinook salmon. Federal Register 47:78 (22. April 1992): 14653-14663

NOAA Fisheries (2000). White Paper: Salmonid travel time and survival related to flow in the Columbia River Basin, National Marine Fisheries Service, NOAA.

National Marine Fisheries Service (NMFS). 2004. Biennial Report to Congress on the Recovery Program for Threatened and Endangered Species.

Perkins, WA, and MC Richmond. 2001. Long-term one-dimensional simulation of Lower Snake River temperatures for current and unimpounded conditions. PNNL-13443, Pacific Northwest National Laboratory, Richland, Washington. 
Rakowski, CL, MC Richmond, and WA Perkins. 2003. Characterizing the Physical Environment Encountered by Mobile-Tracked Salmon in the Columbia and Snake Rivers. PNWD-3354, BattellePacific Northwest Division, Richland, Washington.

Richmond, MC, WA Perkins, and Y Chien. 2000. Numerical model analysis of system-wide dissolved gas abatement alterations. PNWD-3245, Battelle-Pacific Northwest Division, Richland, Washington.

Savage, BM, and MC Johnson. 2001. "Flow over Ogee Spillway: physical and Numerical Model Case Study." Journal of Hydraulic Engineering 127(8).

Scheibe, TD, and MC Richmond. 2002. "Fish individual-based numerical simulator (FINS): a particlebased model of juvenile salmonid movement and dissolved gas exposure history in the Columbia River basin.” Ecological Modeling 147 :233-252.

Smith, SG, WD Muir, EE Hockersmith, RW Zabel, RJ Graves, CV Ross, WP Connor, and BD Arnsberng. 2003. "Influence of River conditions on Survival and Travel Time of Snake River Subyearling Fall Chinook Salmon." North American Journal of Fisheries Management 23:939-961.

SOR. 2005. "System Operational Request: \#2005-17”, obtained from: http://www.nwdwc.usace.army.mil/tmt/sor/2005/. Last accessed November 2005.

Szymanski, JJ, W Atkins, WL, L Balick, C Borel, WB Clodius, W Christensen, AB Davis, JC Echohawk, A Galbraith, K Hirsch, JB Krone, C Little, P Maclachlan, A Morrison, K Pollock, P Pope, C Novak, K Ramsey, E Riddle, C Rohde, D Roussel-Dupre, BW Smith, K Starkovich, J Theiler, PG Weber. 2001. Multispectral Thermal Imager Science, Data Product and Ground Data Processing Overview. LA-UR-01-1941, Los Alamos National Laboratory, Los Alamos, New Mexico.

TVA. 1972. Heat and Mass Transfer between a Water Surface and the Atmosphere, Water Resources Research Laboratory Report No 14 prepared for the Tennessee Valley Authority, Division of Water Control Planning, Engineering Laboratory, Report No. 0-6803, Norris, Tennessee.

UNESCO. 1983. In "Algorithms for the computation of fundamental properties of seawater " by Fofonoff, N.P., and R.C. Millard Jr., UNESCO (United Nations Educational, Scientific, and Cultural Organization) Technical Papers in Marine Sciences, No. 44, 1-52, 1983.

USACE 1986. Water Control Manual for Dworshak Dam and Reservoir, North Ford, Clearwater River, Idaho. U.S. Army Corps of Engineers, Walla Walla District, Walla Walla, Washington.

USACE. 2005. Profiles of water temperature from Dworshak Reservoir from web site: http://www.nwd-wc.usace.army.mil/. Last accessed November, 2005.

USGS. 2002. Real-time monitoring of the Earth's magnetic field Data for research and practical application: http://geomag.usgs.gov/models/models/. Last accessed June 2005.

Villa-Aleman, E, AJ Garrett, RJ Kurzeja, and MM Pendergast. 2000. Aerial Thermography Studies of Power Plant Heated Lakes. WSRC-MS-99-00903, Westinghouse Savannah River Company, Aiken, South Carolina. 
Washington Administrative Code. (WAC) 1997. Water quality standards for surface waters of the State of Washington. Chapter 173-201A. Olympia, Washington

Wells, SA. 2005: CE-QUAL-W2 model. Available at http://www.ce.pdx.edu/w2/. 


\section{Appendix A}

\section{Observed Water Temperatures in Lower Granite Reservoir}




\section{Appendix A}

\section{Observed Water Temperatures in Lower Granite Reservoir}

Water temperature data collected by PNNL are displayed in the following figures. Water temperature data collected in 2002 can be found in Cook at al. 2003. Data displayed here were collected in 2003 or 2004. Figure A.1 shows the location of sites monitored in 2003. In 2004, only Sites 1, 2, 3, 5a, 9 and 11 were monitored.

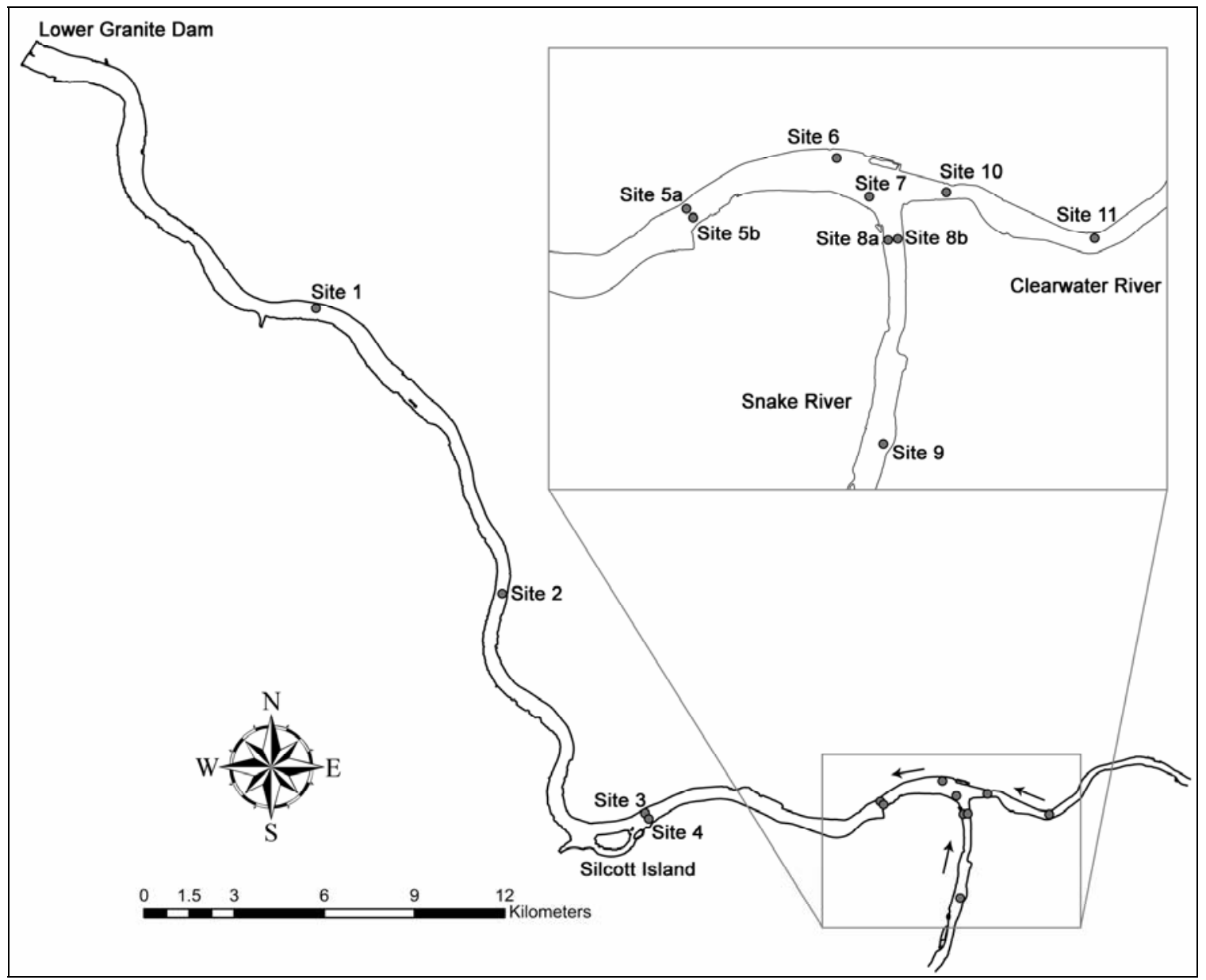

Figure A.1. Lower Granite Reservoir temperature monitoring sites 


\section{A.1 Lower Granite Reservoir 2003}

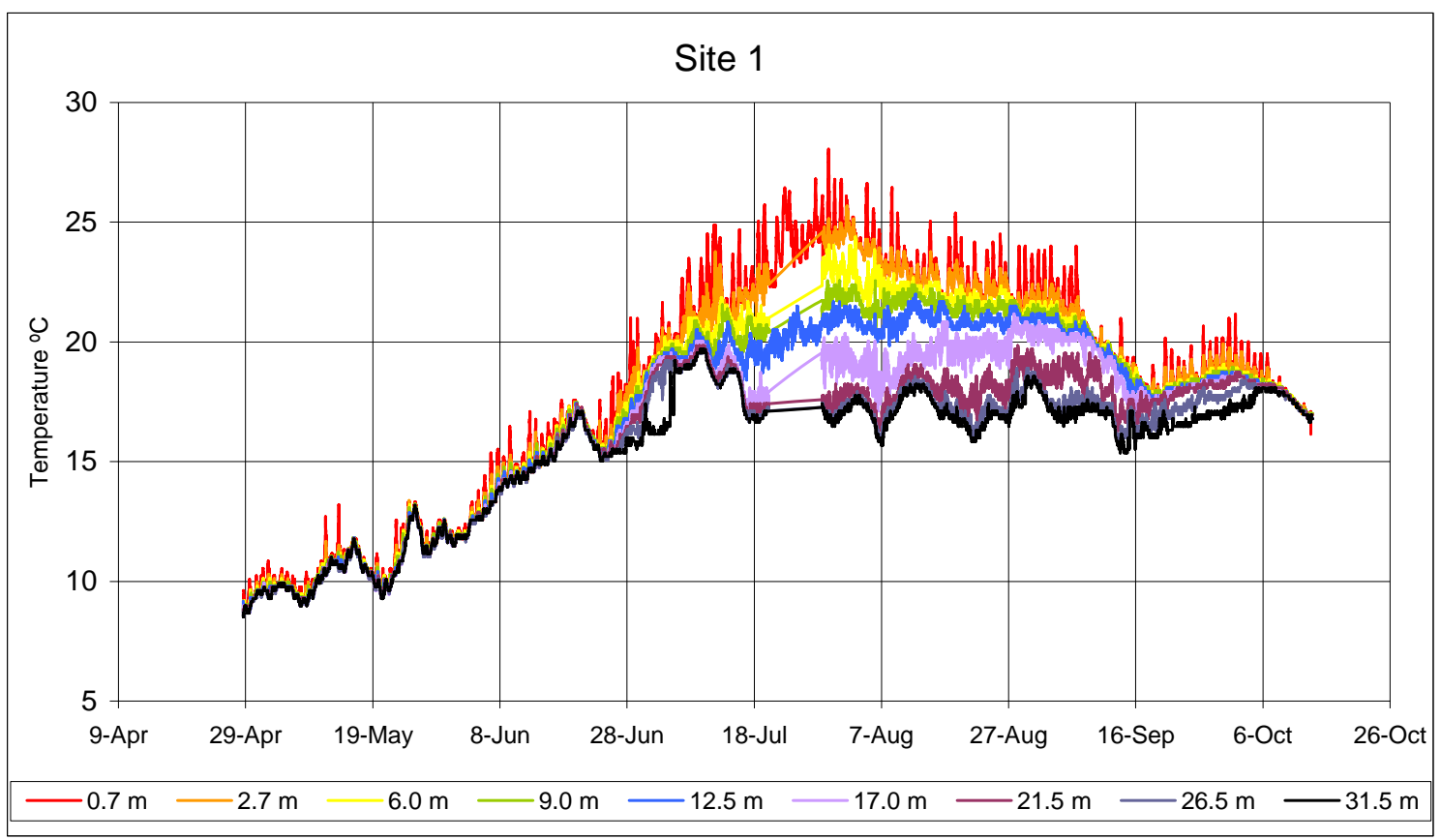

Figure A.1.2. Observed temperature at Site 1 in Lower Granite Reservoir 2003

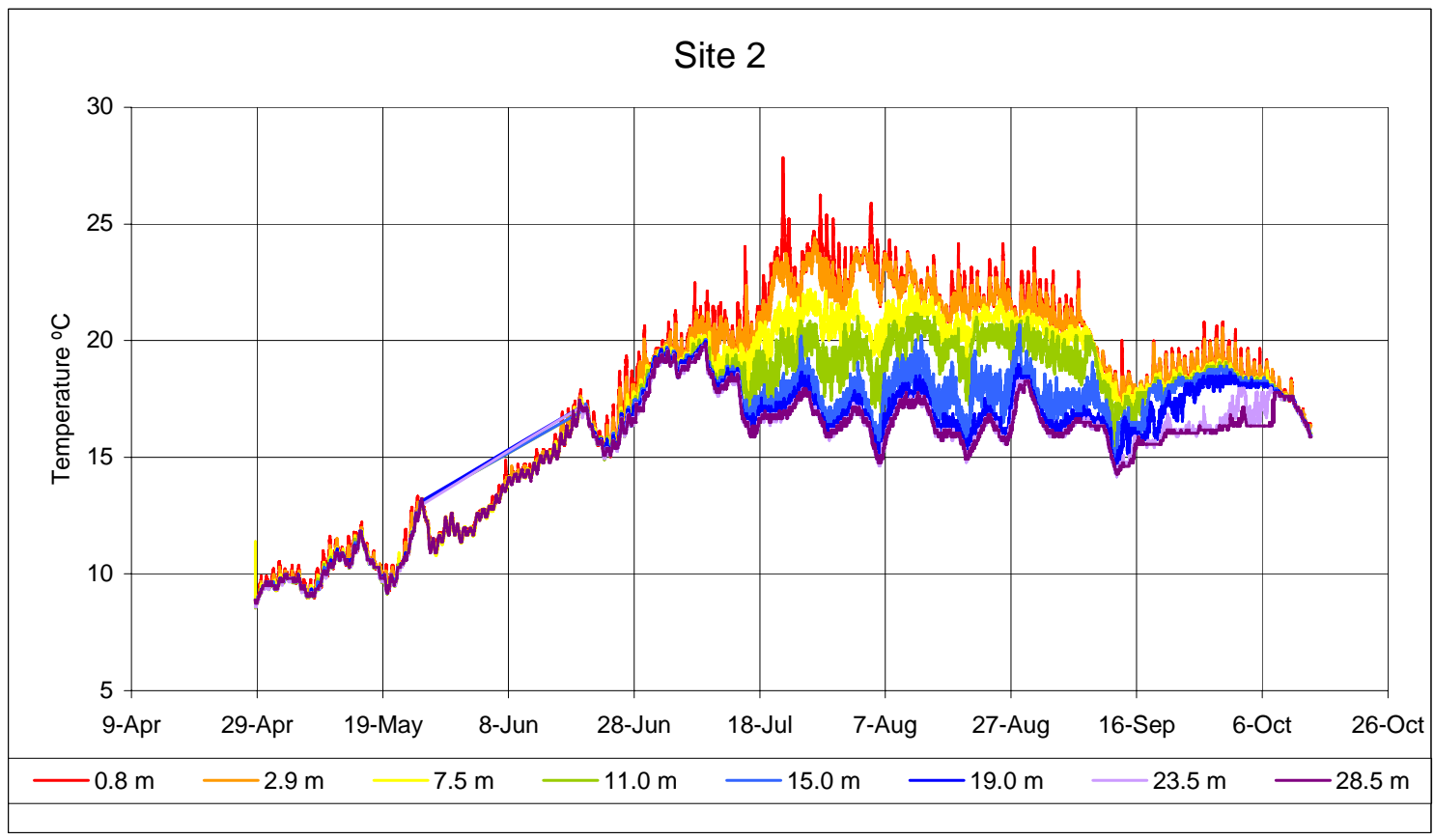

Figure A.1.3. Observed temperature at Site 2 in Lower Granite Reservoir 2003 


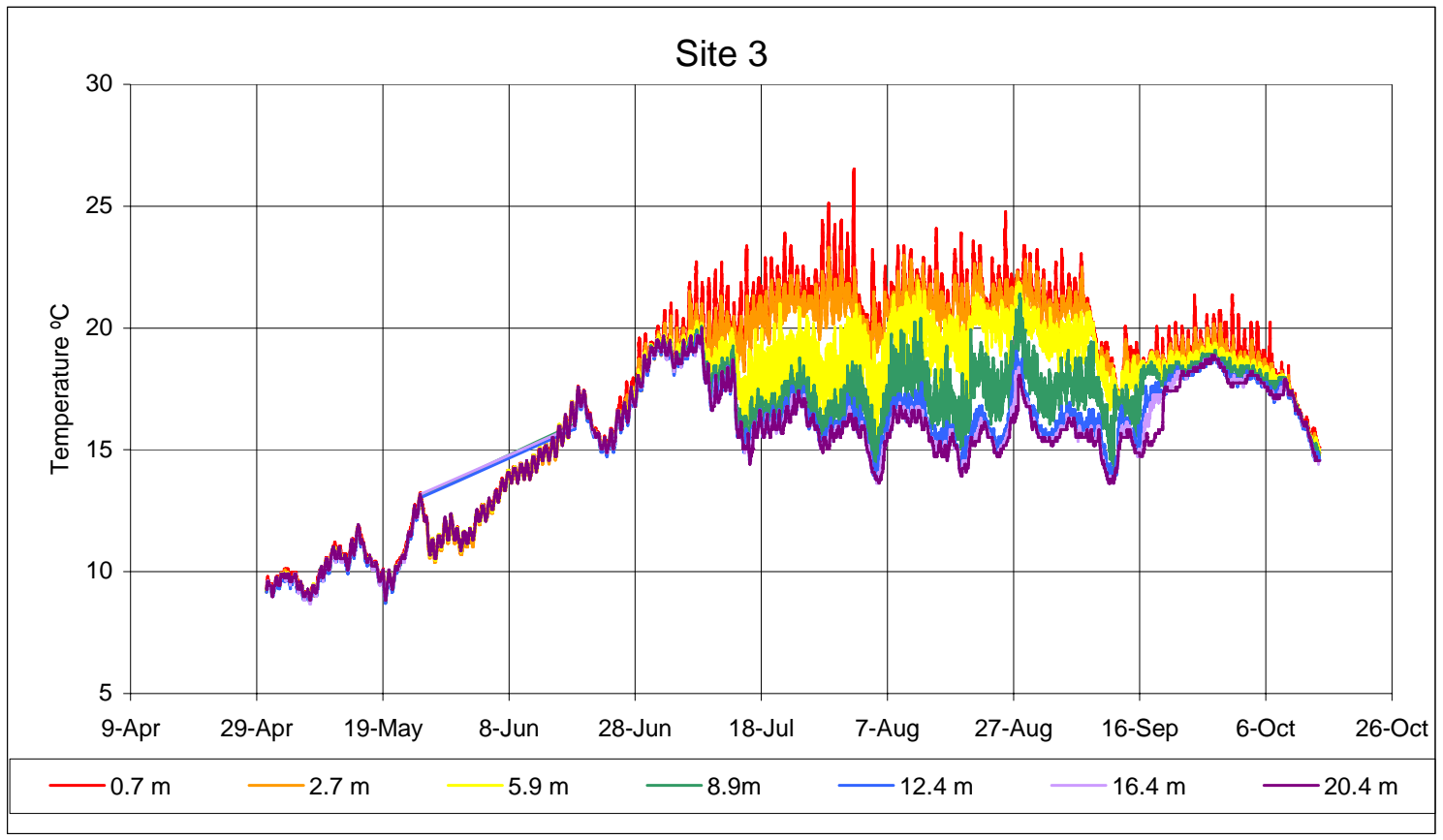

Figure A.1.4. Observed temperature at Site 3 in Lower Granite Reservoir 2003

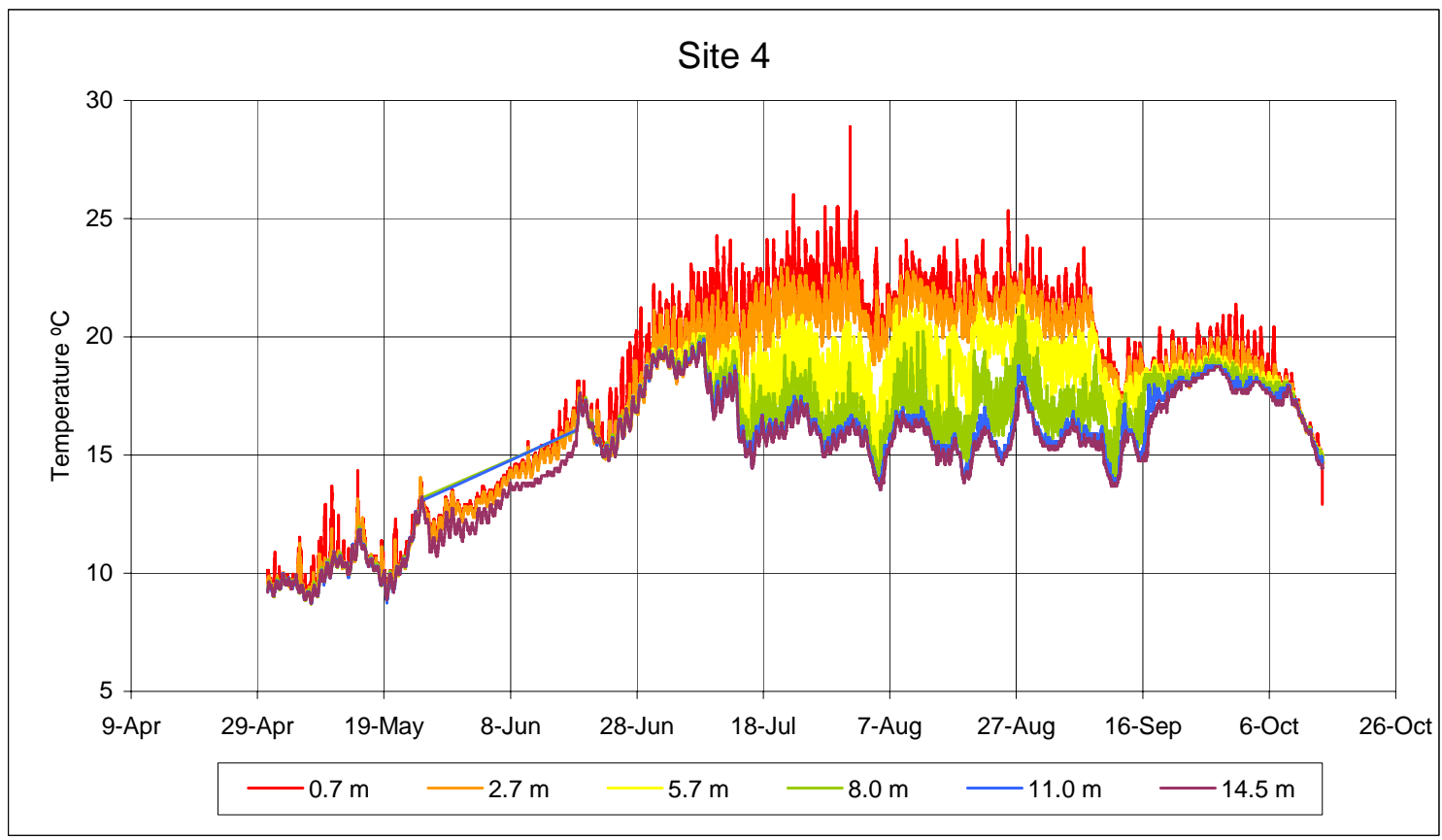

Figure A.1.5. Observed temperature at Site 4 in Lower Granite Reservoir 2003 


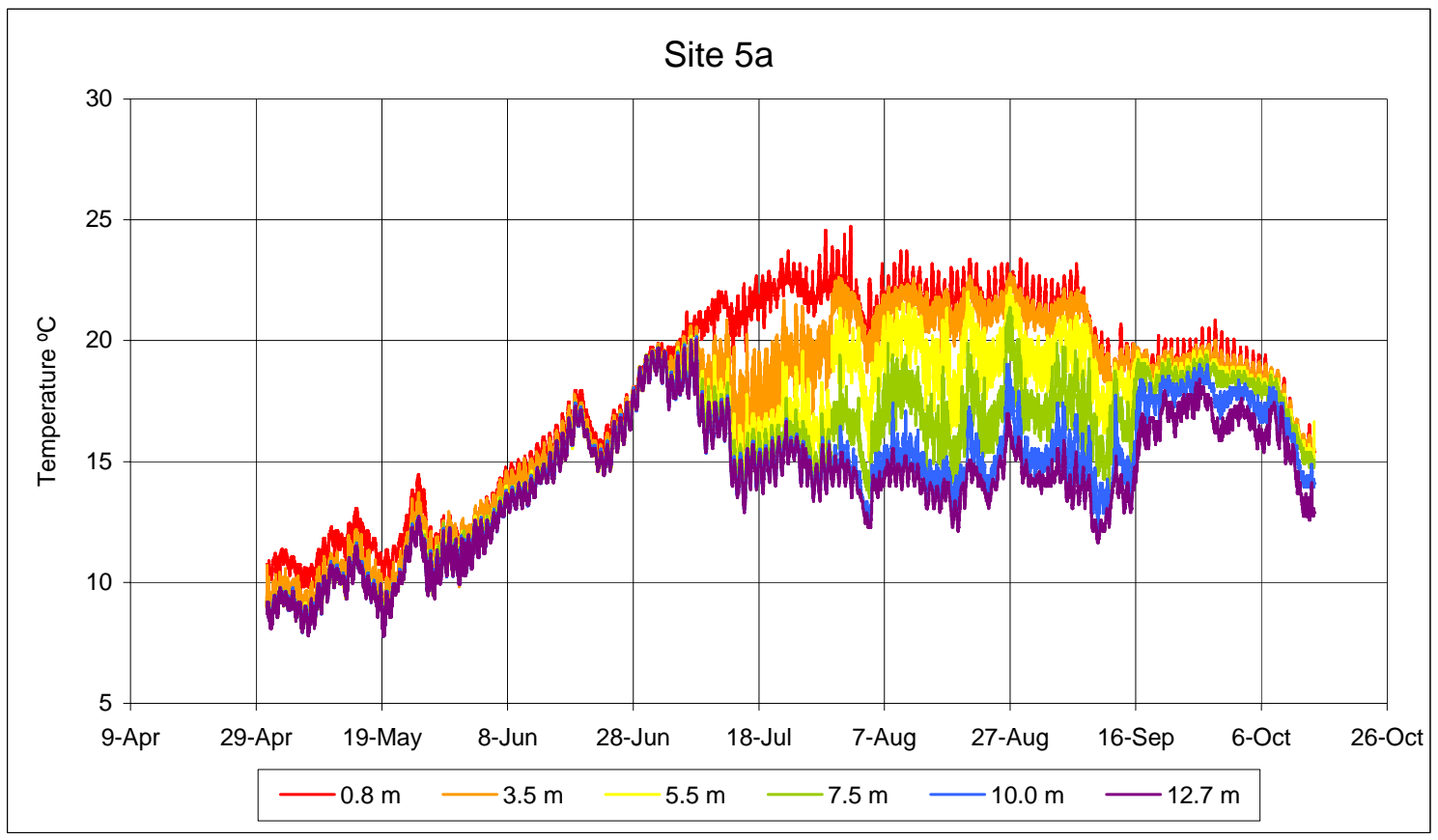

Figure A.1.5. Observed temperature at Site 5a in Lower Granite Reservoir 2003

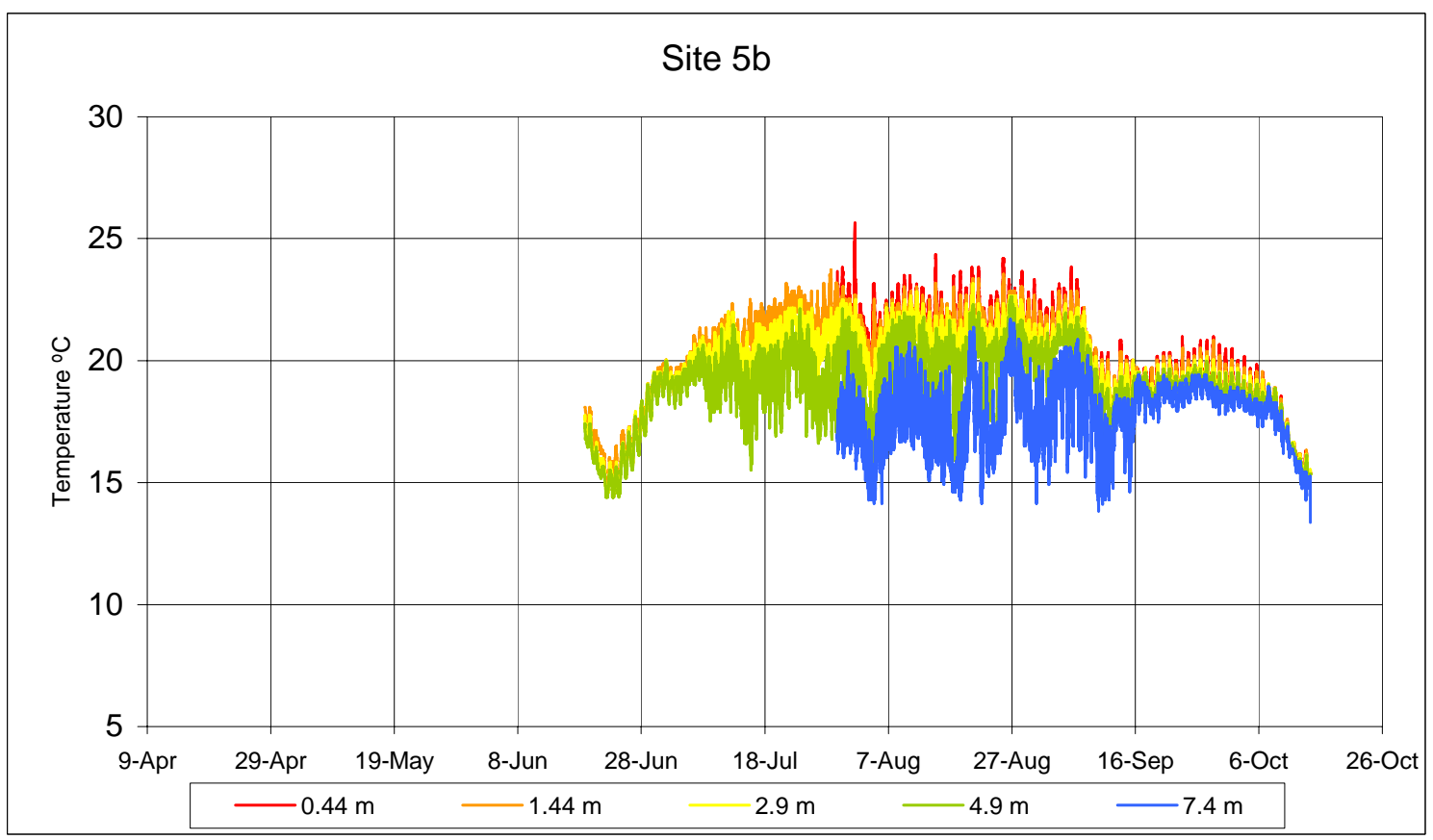

Figure A.1.6. Observed temperature at Site 5b in Lower Granite Reservoir 2003 


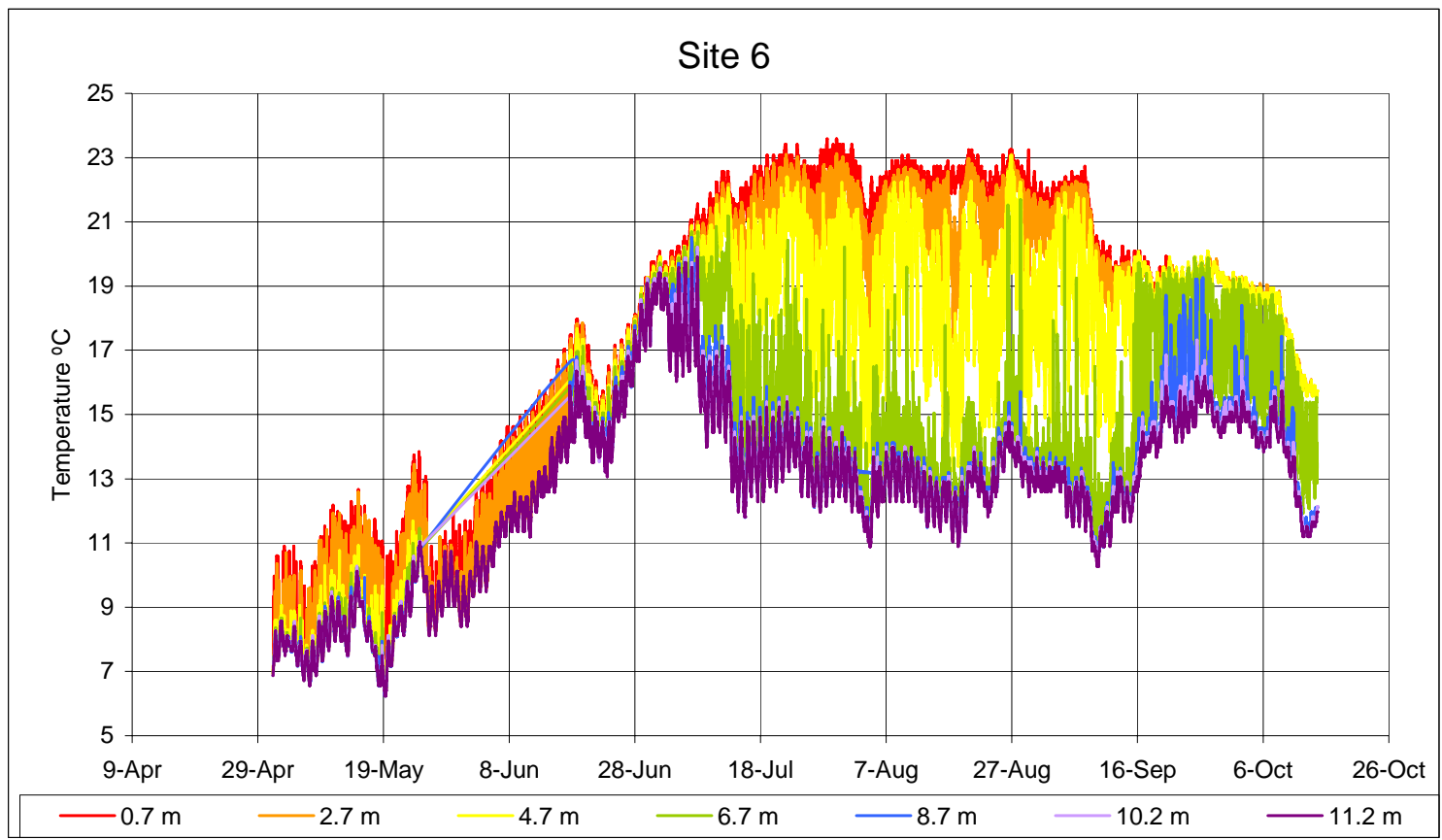

Figure A.1.7. Observed temperature at Site 6 in Lower Granite Reservoir 2003

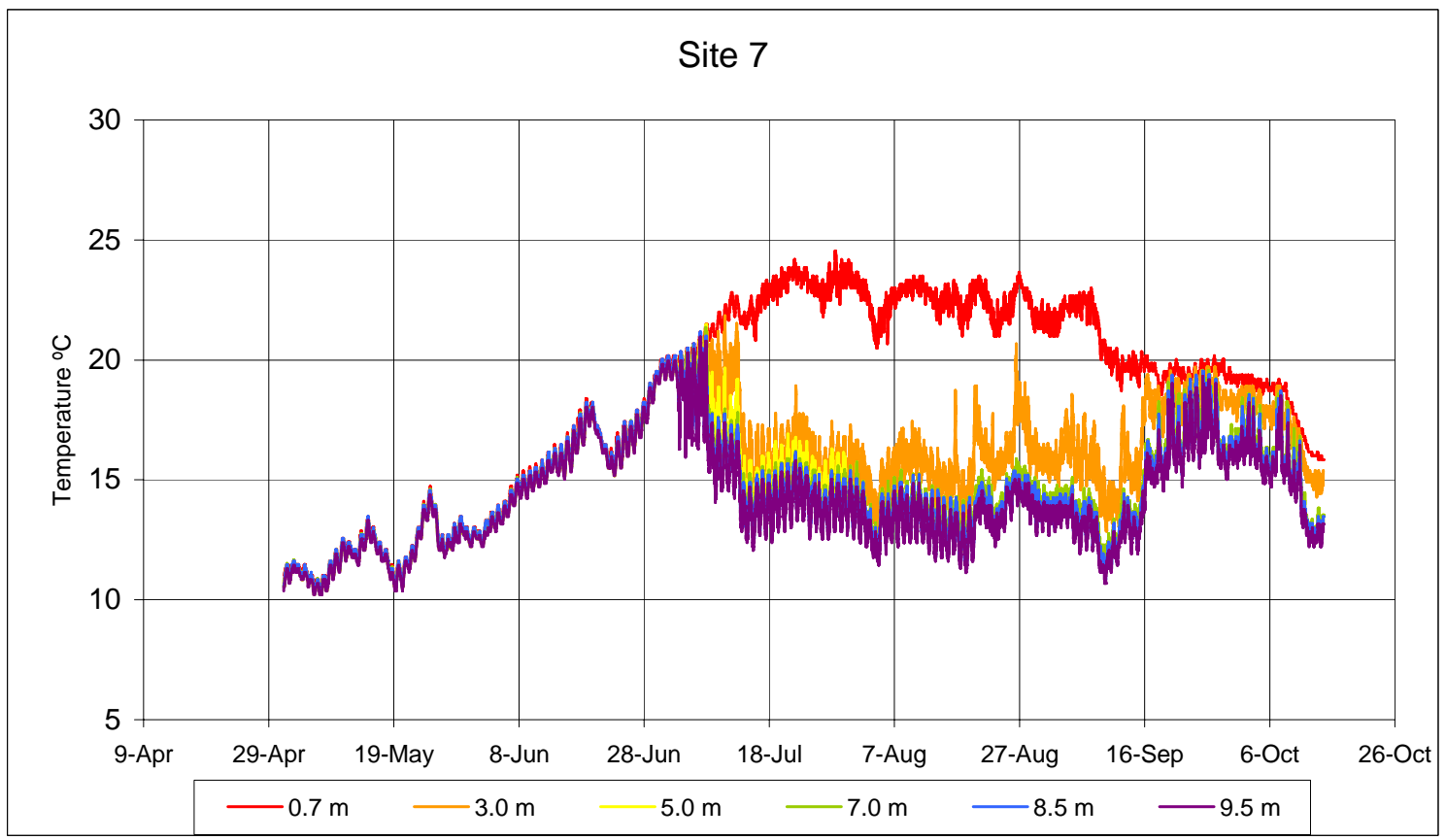

Figure A.1.8. Observed temperature at Site 7 in Lower Granite Reservoir 2003 


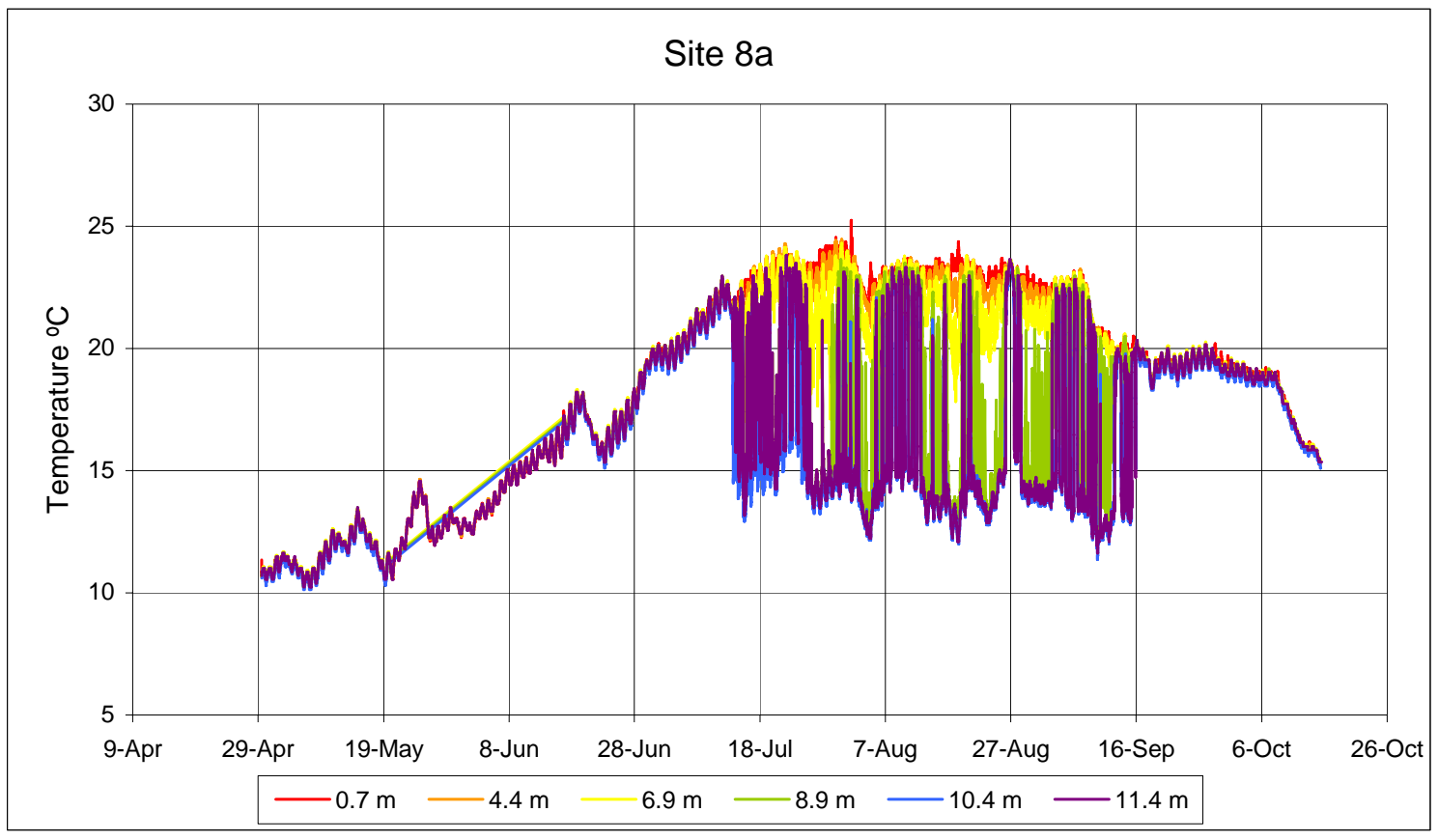

Figure A.1.9. Observed temperature at Site 8a in Lower Granite Reservoir 2003

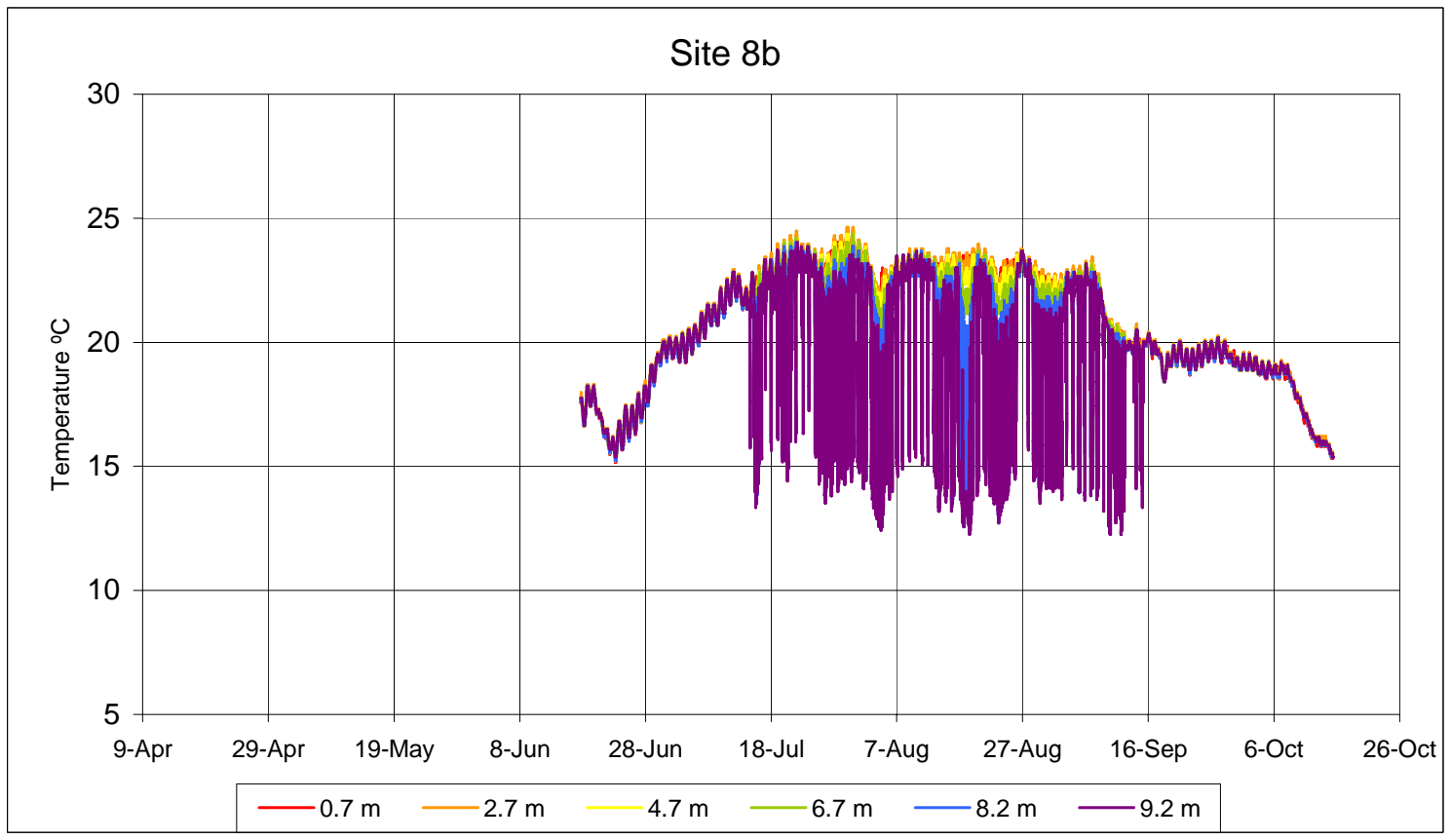

Figure A.1.10 . . Observed temperature at Site 8b in Lower Granite Reservoir 2003 


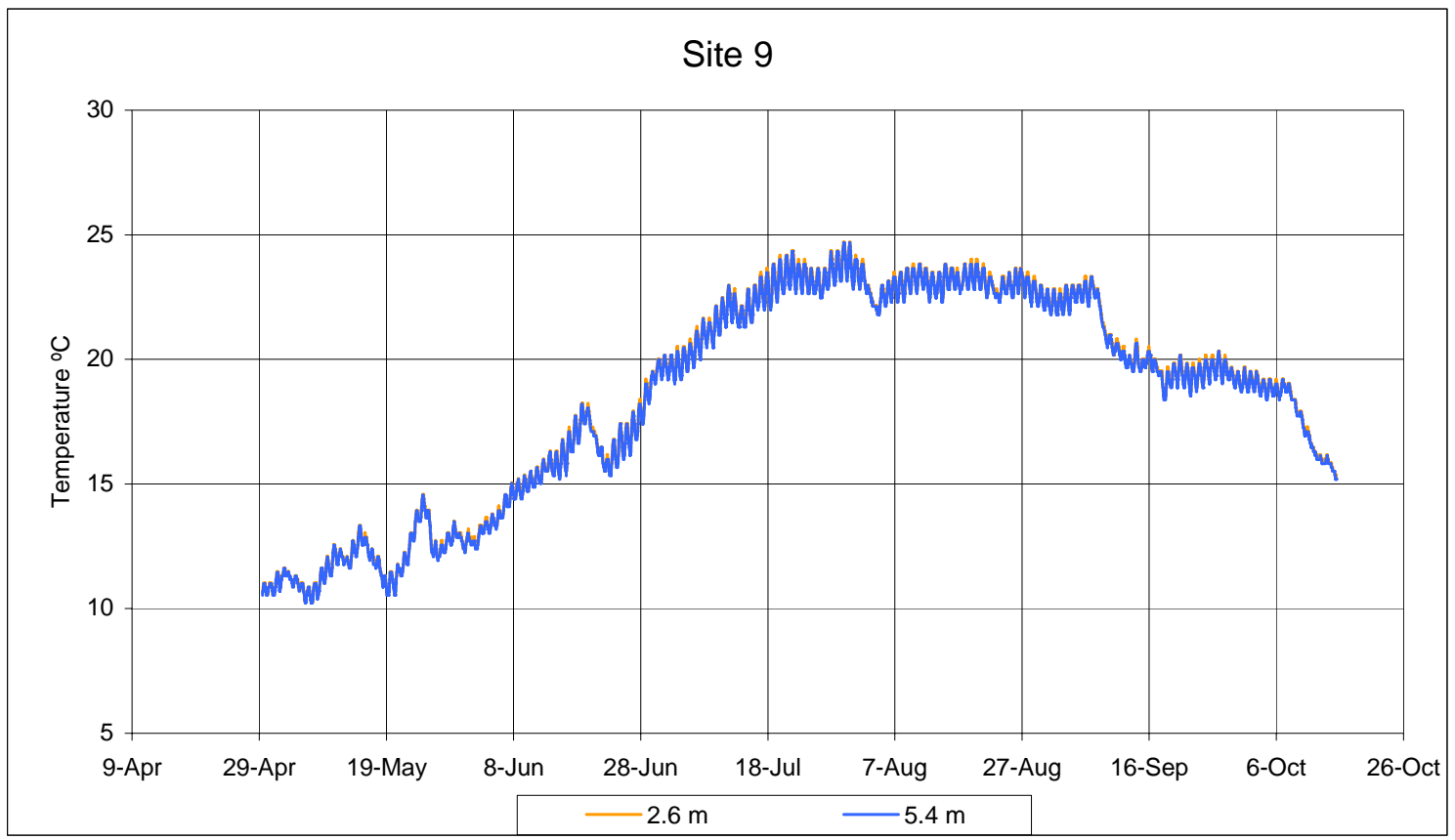

Figure A.1.11. Observed temperature at Site 9 in Lower Granite Reservoir 2003

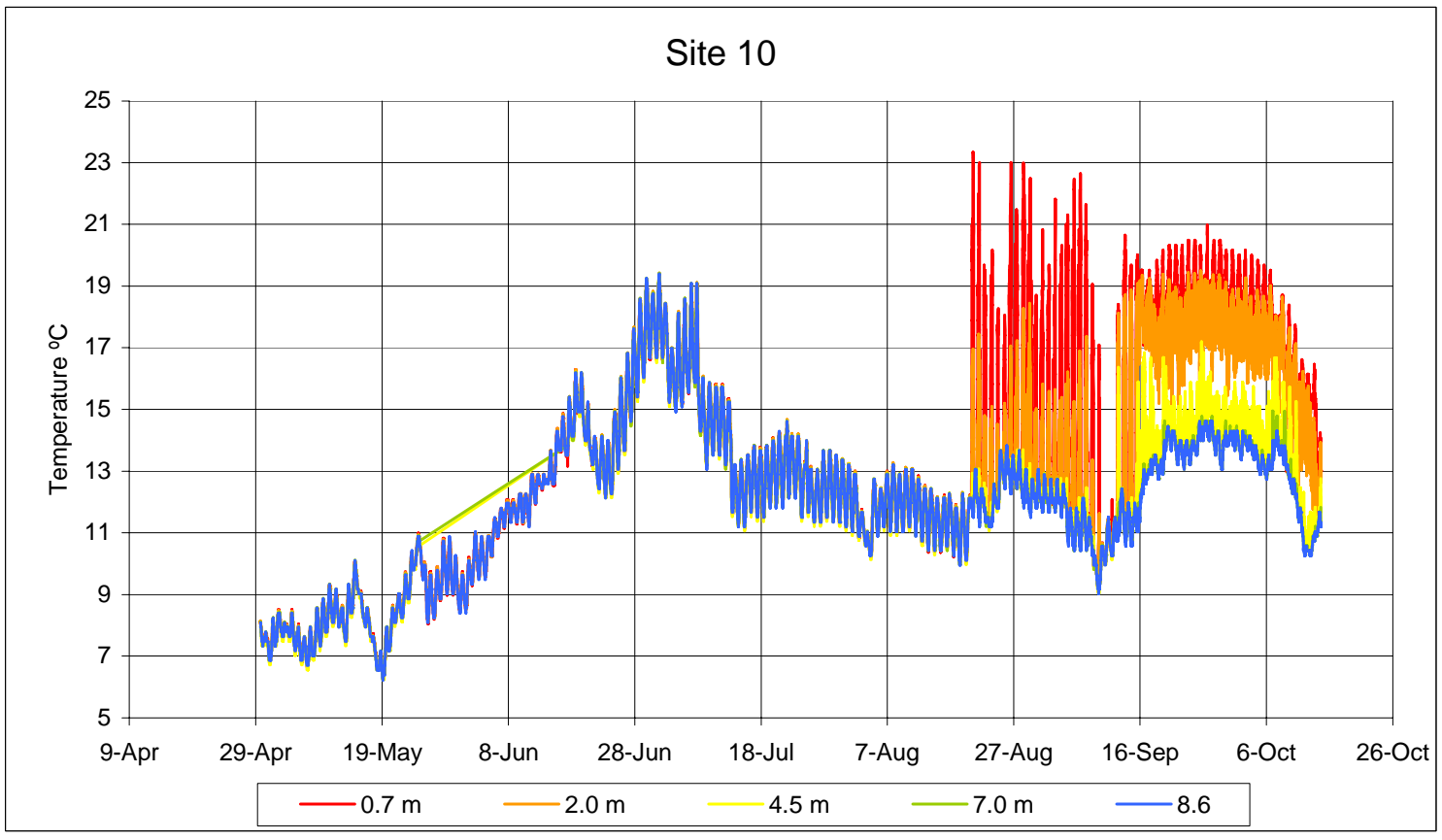

Figure A.1.12. Observed temperature at Site 10 in Lower Granite Reservoir 2003 


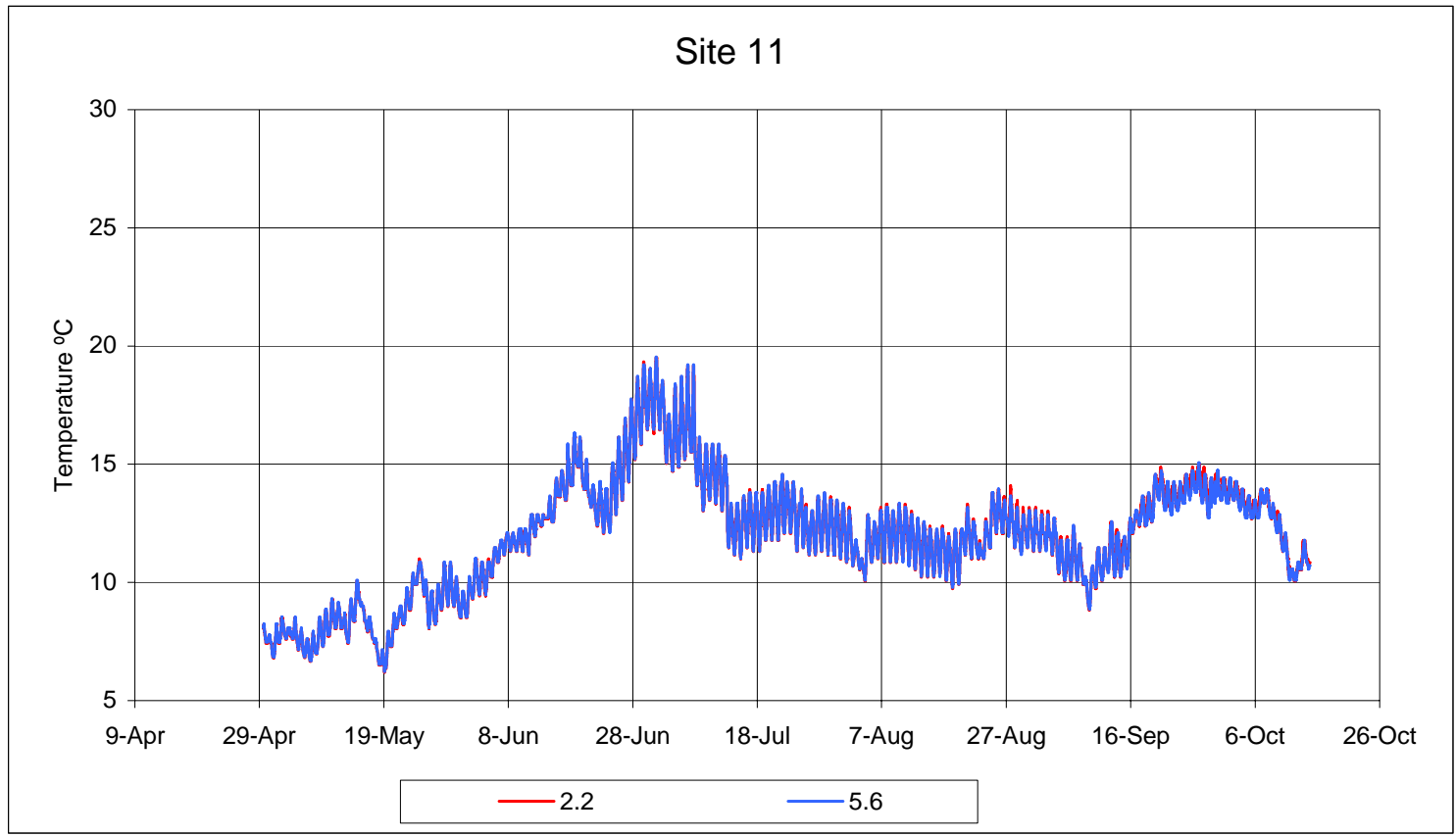

Figure A.1.13. Observed temperature at Site 11 in Lower Granite Reservoir 2003

\section{A.2 Lower Granite Reservoir 2004}

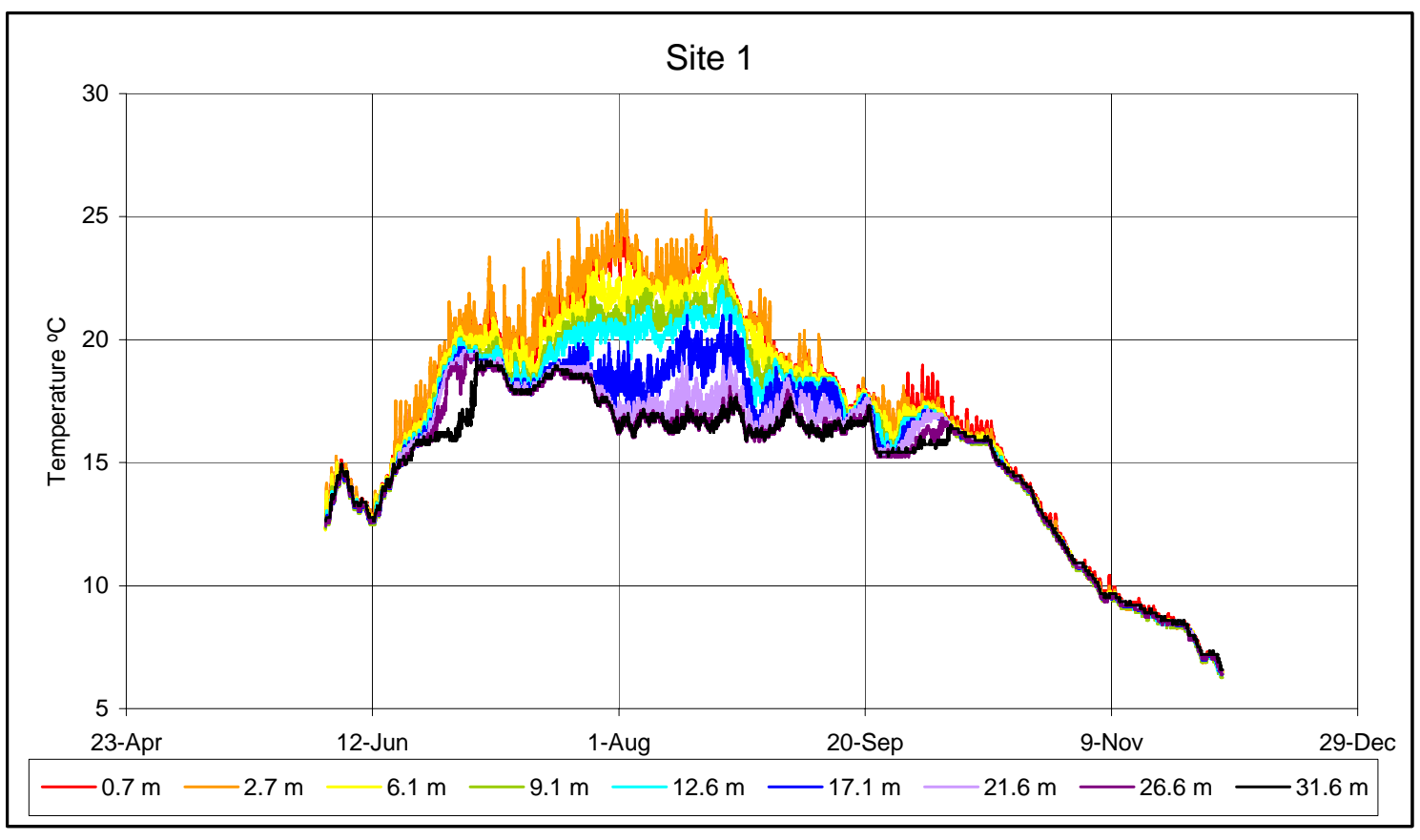

Figure A.2.1. Observed temperature at Site 1 in Lower Granite Reservoir 2004 


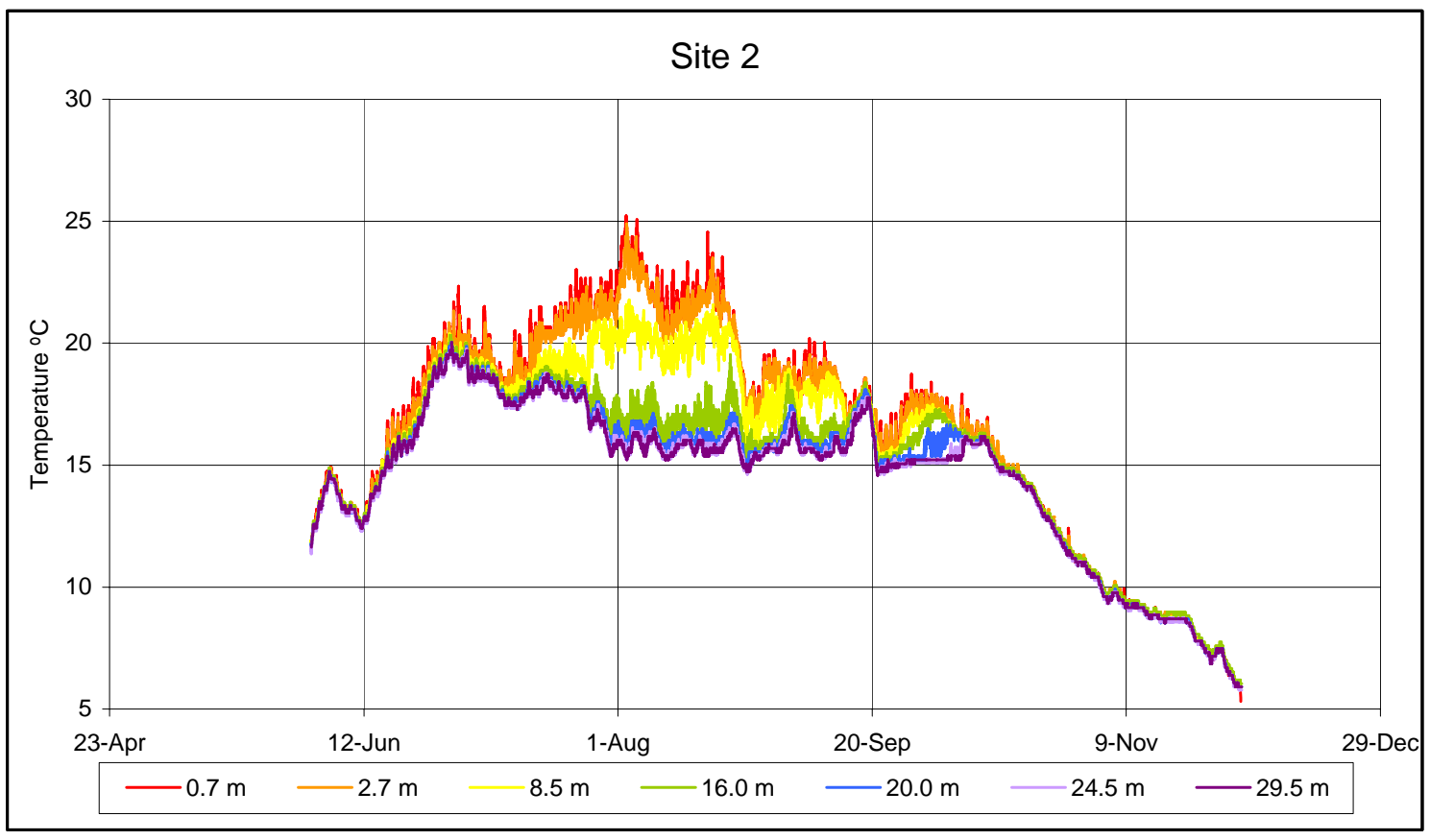

Figure A.2.2. Observed temperature at Site 2 in Lower Granite Reservoir 2004

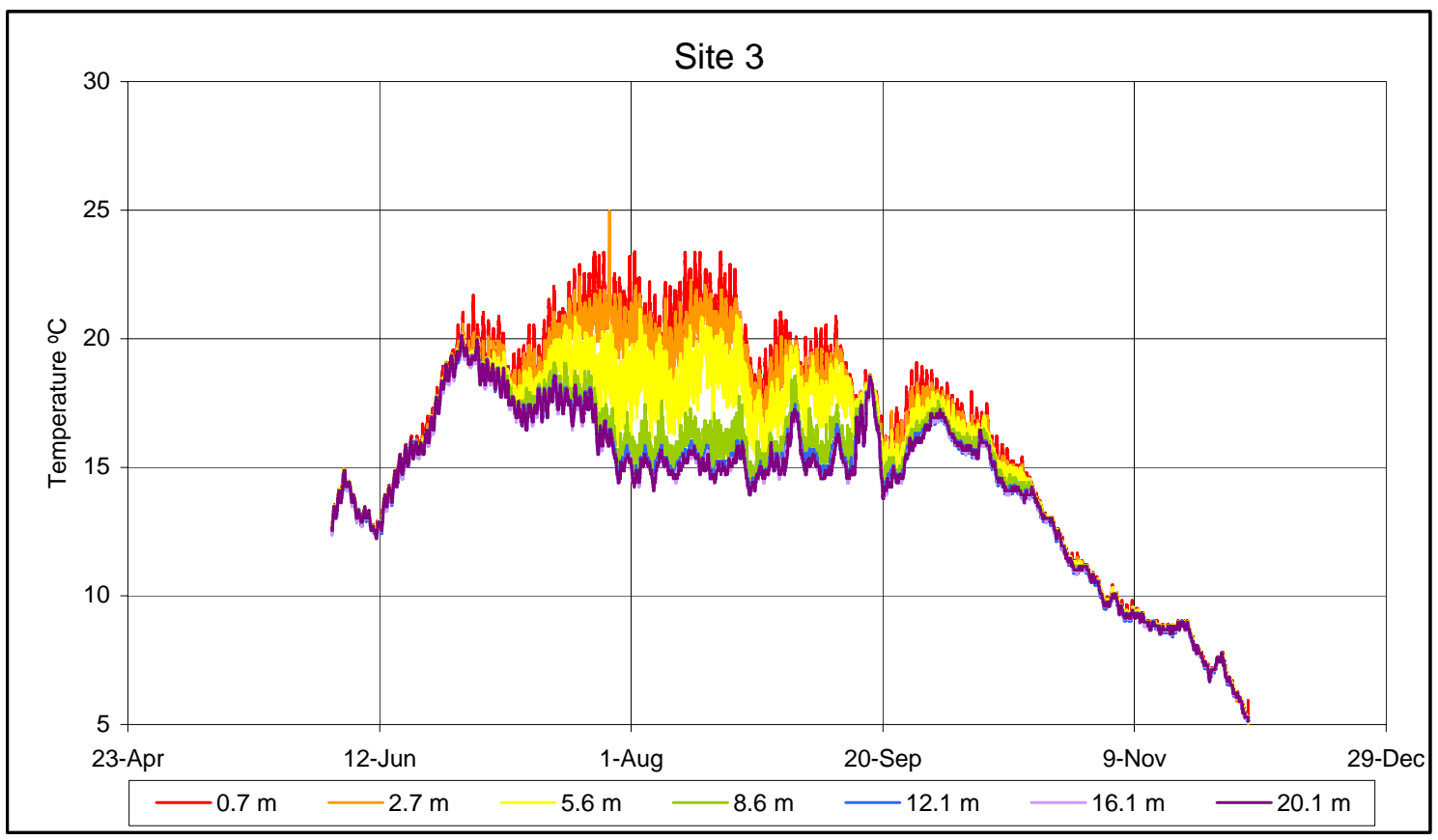

Figure A.2.3. Observed temperature at Site 3 in Lower Granite Reservoir 2004 


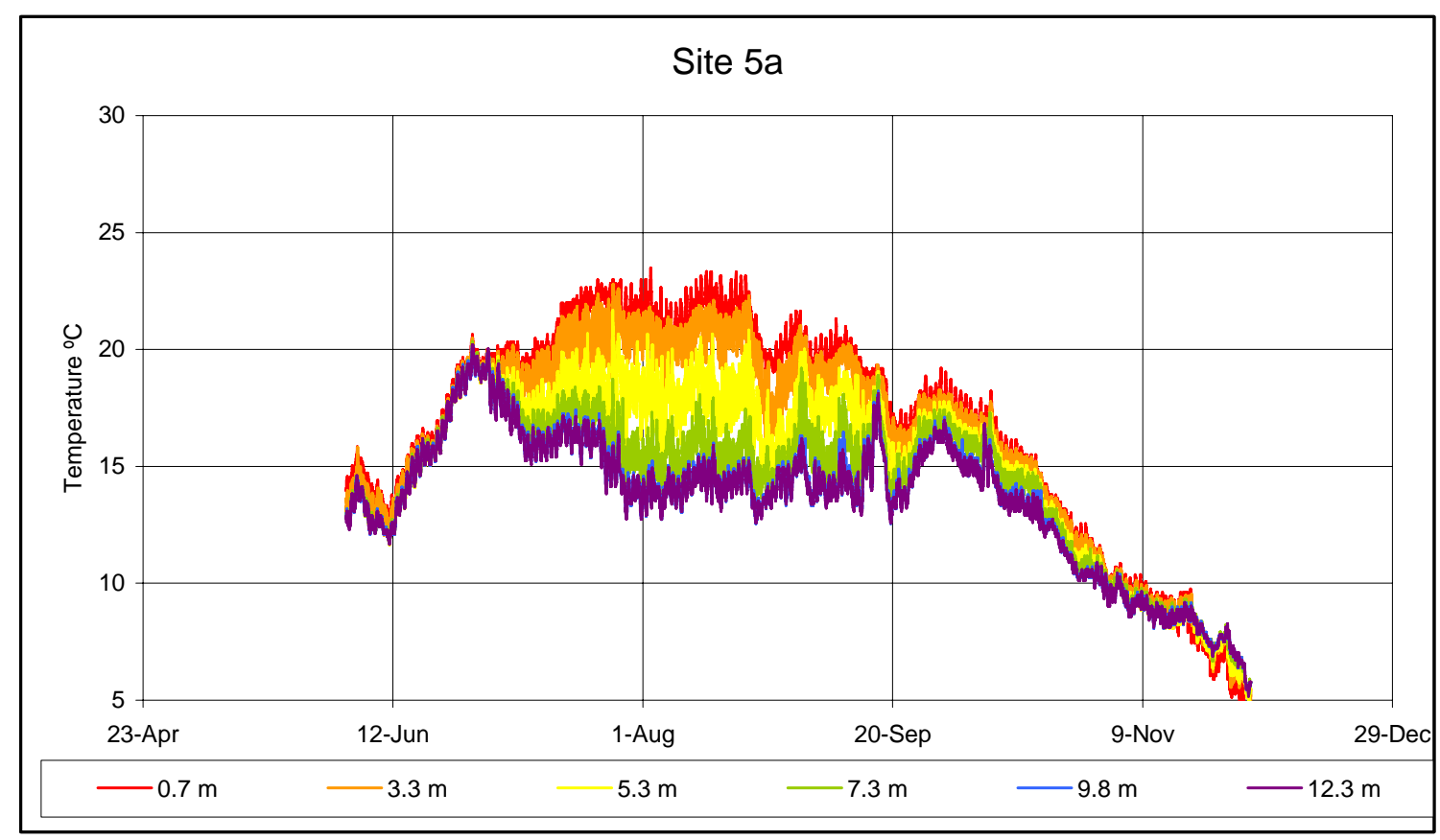

Figure A.2.4. Observed temperature at Site 5a in Lower Granite Reservoir 2004

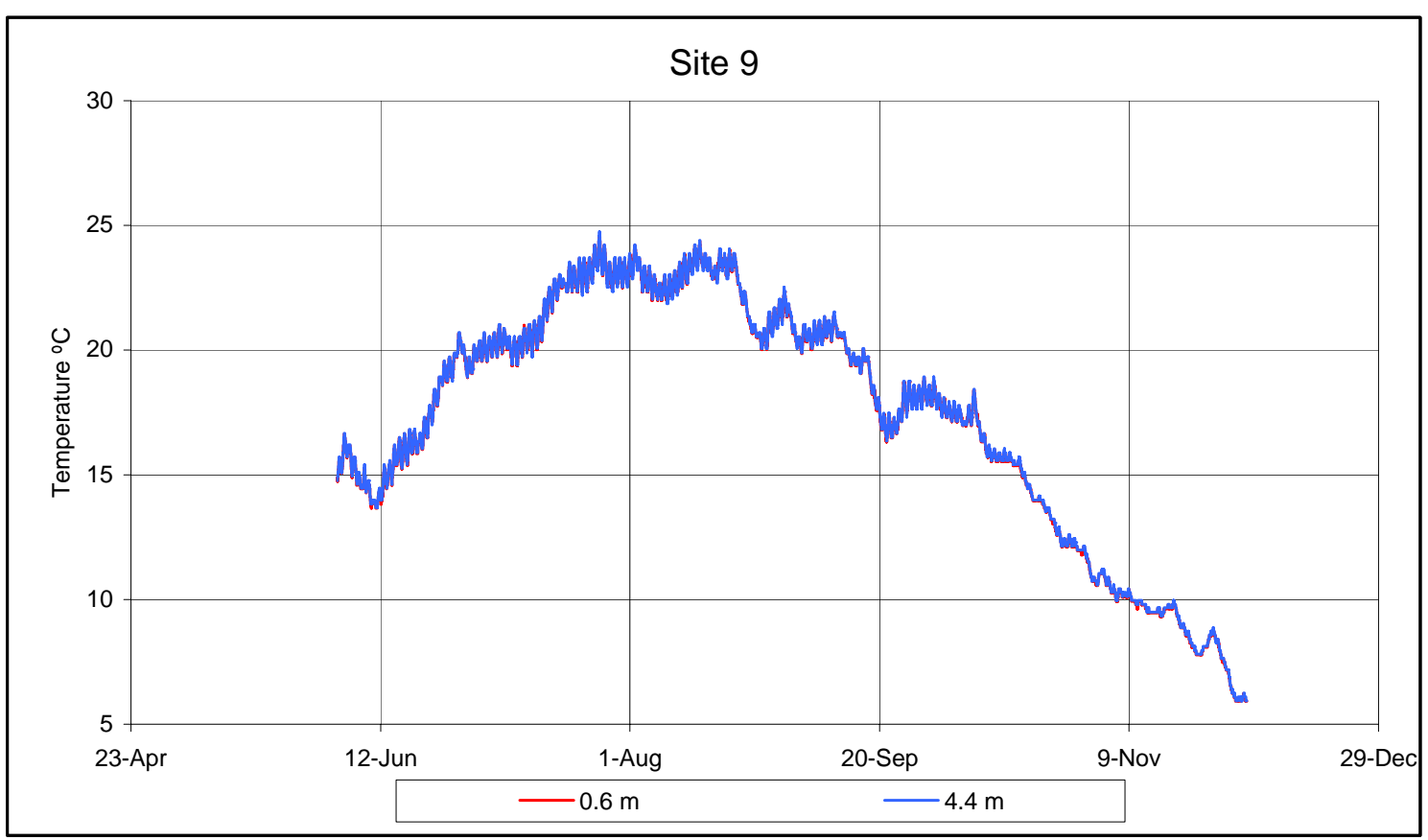

Figure A.2.5. Observed temperature at Site 9 in Lower Granite Reservoir 2004 


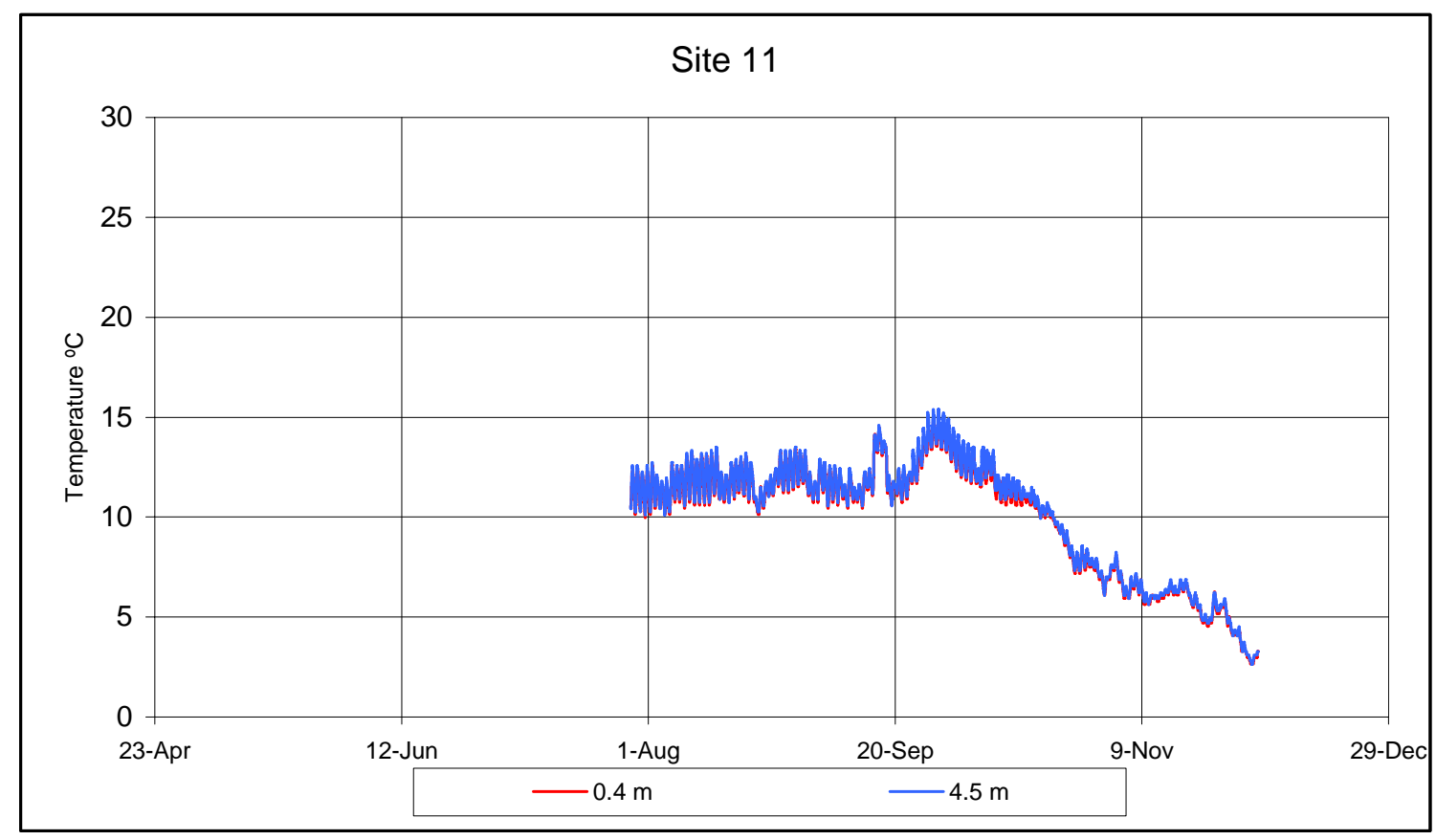

Figure A.2.6. Observed temperature at Site 11 in Lower Granite Reservoir 2004 


\section{Appendix B}

\section{Transects of Water during the 2005 Study}




\section{Appendix B}

\section{Transects of Water Velocities during the 2005 Study}

During the intensive July 2005 field study transects of water velocity were collected in the reservoirs upstream of Little Goose and Lower Monumental Dams. These data were collected to confirm the windsetp hypothesis (see Section 4.1) that occurs when these reservoirs are stratified. Data collected in the reservoir upstream of Little Goose Dam (Figures B.2 and B.3) show the existence of a 5 to $7 \mathrm{~m}$ thick surface layer moving in an upstream direction. The sequence of figures in Figures B.1 through B.5 support the wind-setup hypothesis shown in Figure 4.4.

The reservoir upstream of Lower Monumental Dam was not stratified except within close proximity of the dam. Although the reservoir is stratified near the dam (see Figure B.6), the epilimnetic and hypolimnetic layers are moving in the same downstream direction, however there is a difference in velocity magnitude above and below the thermocline. Farther upstream, including at mid-pool, the reservoir was not stratified on the sampling day. When the reservoir is not stratified, hydraulic behavior is, as expected, relatively homogenous vertically and water is moving uniformly downstream. Sampled water velocities at the mouth of the Palouse River show that conditions in this area are quiescent. 


\section{B.1 Little Goose Reservoir 2005}
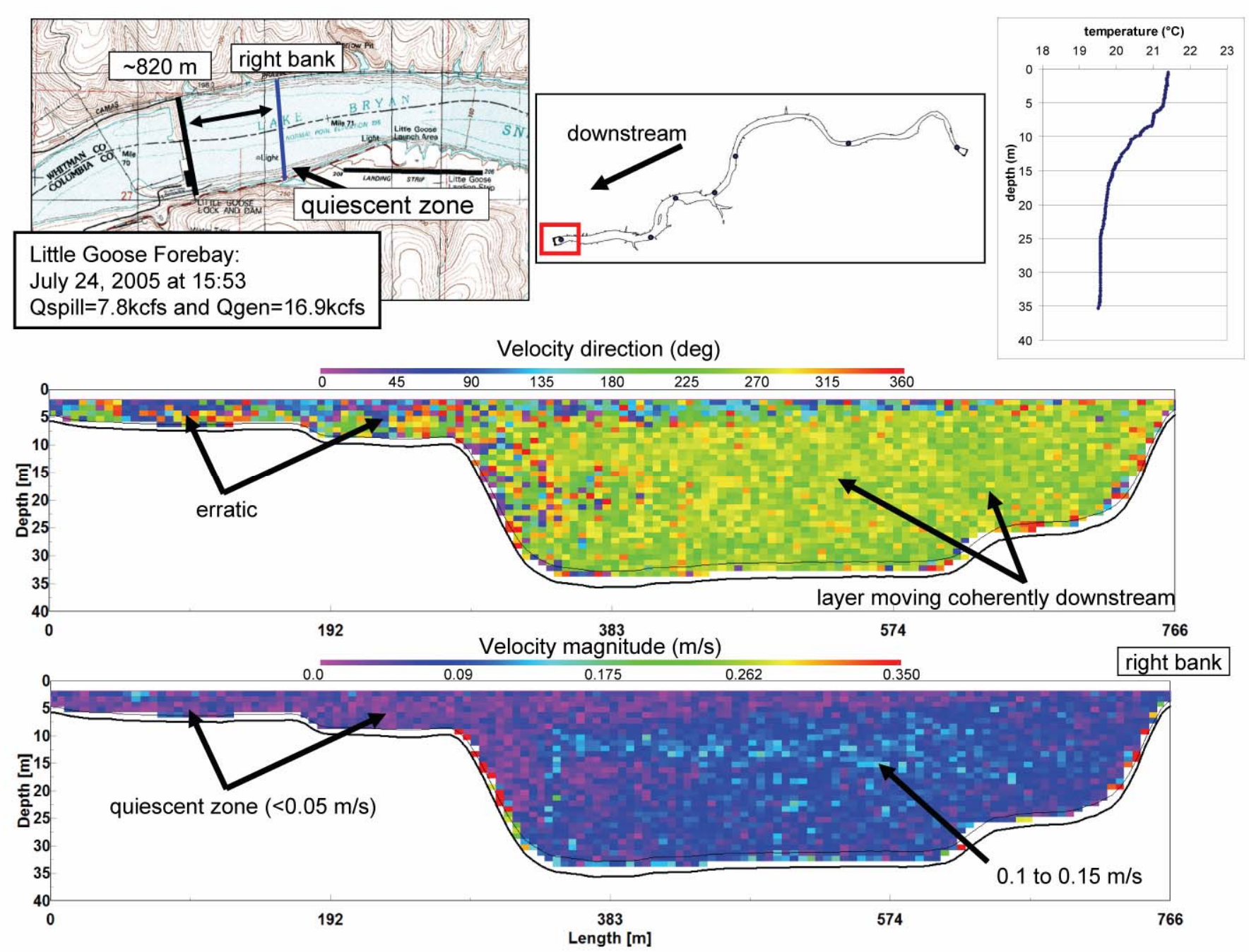

Figure B.1. ADCP transect in the Little Goose Forebay 

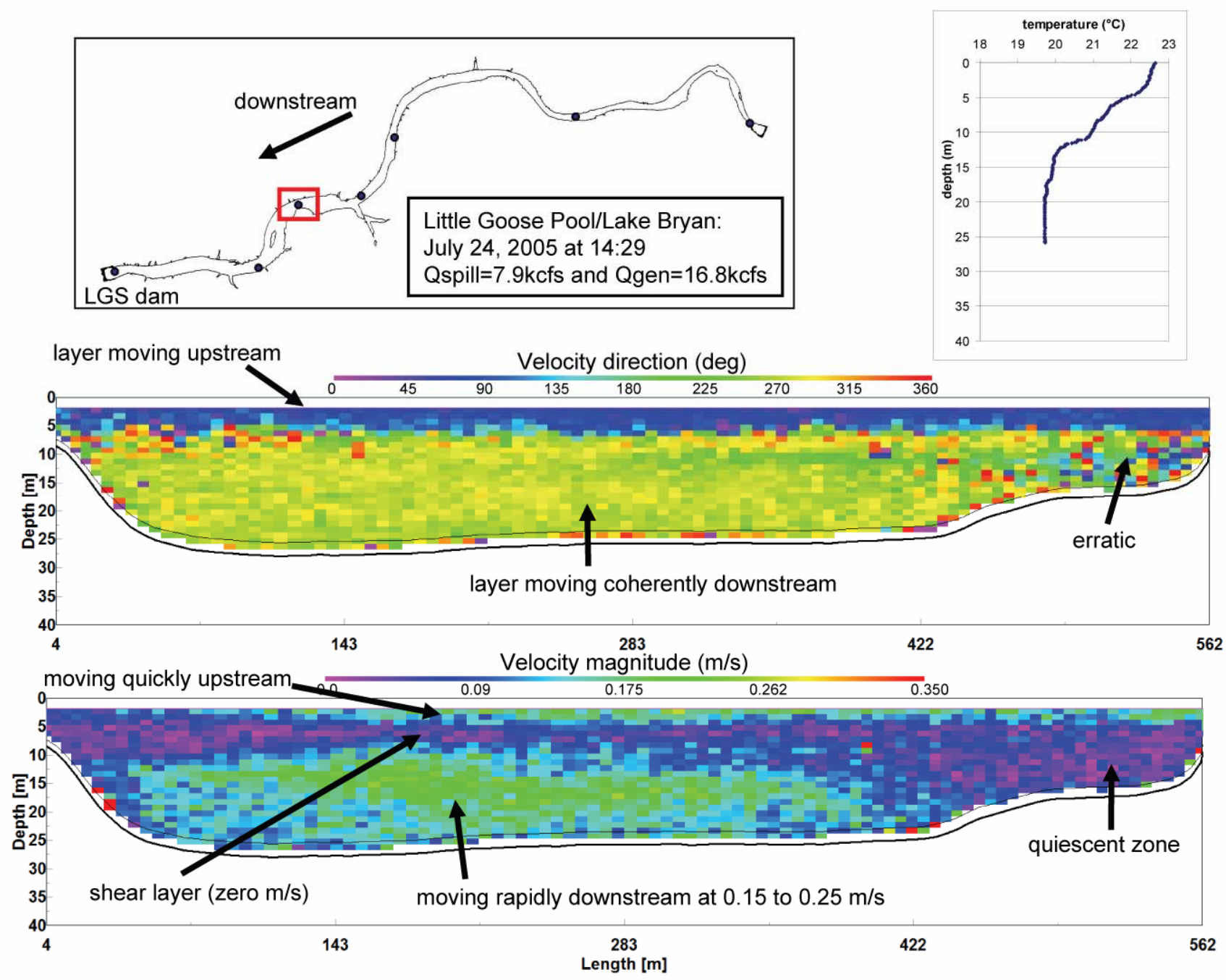

Figure B.2. ADCP transect in the reservoir upstream of Little Goose Dam at the mid-pool temperature logger 2004 site 

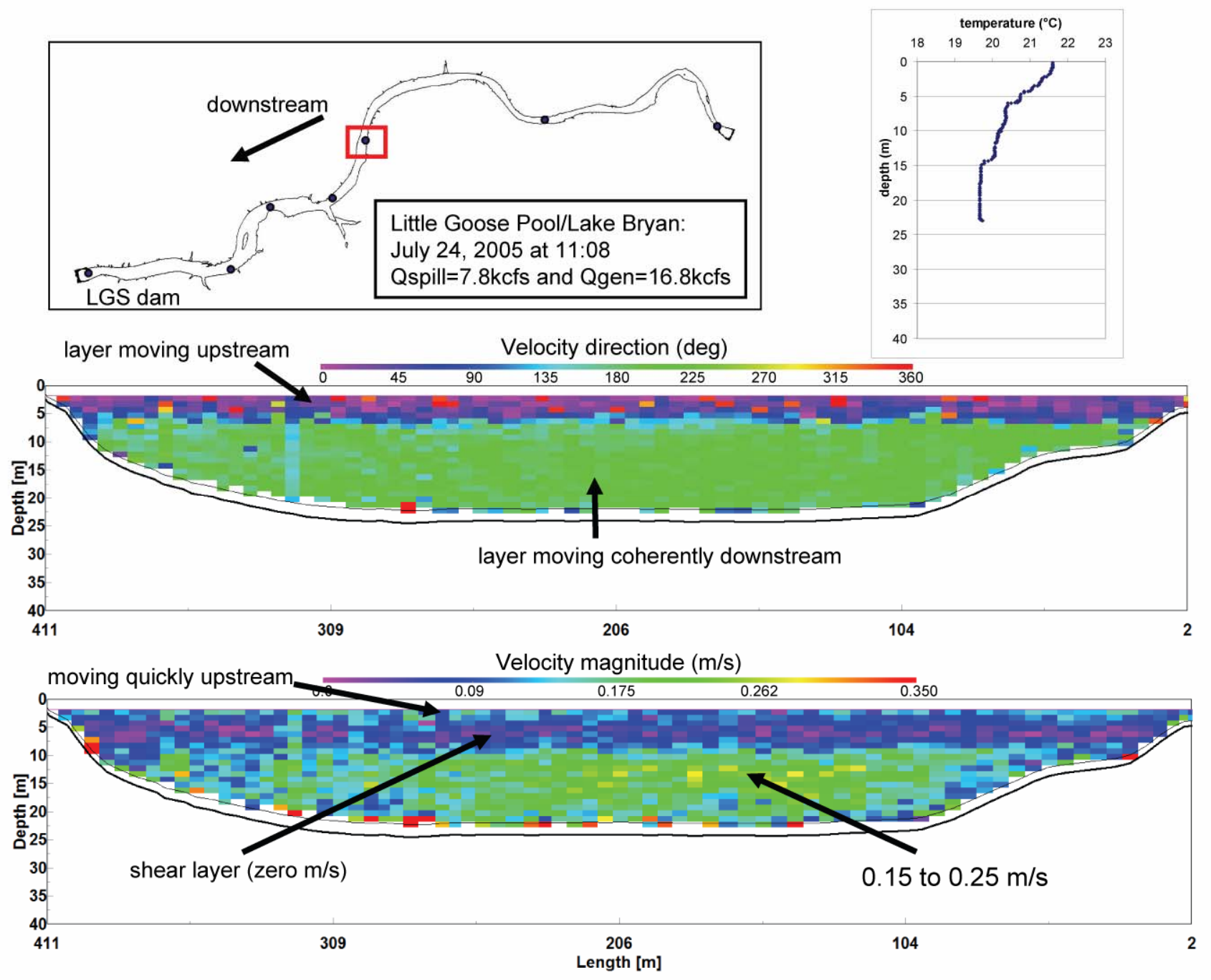

Figure B.3. ADCP transect in the reservoir upstream of Little Goose Dam at the mid-pool temperature logger 2003 site 

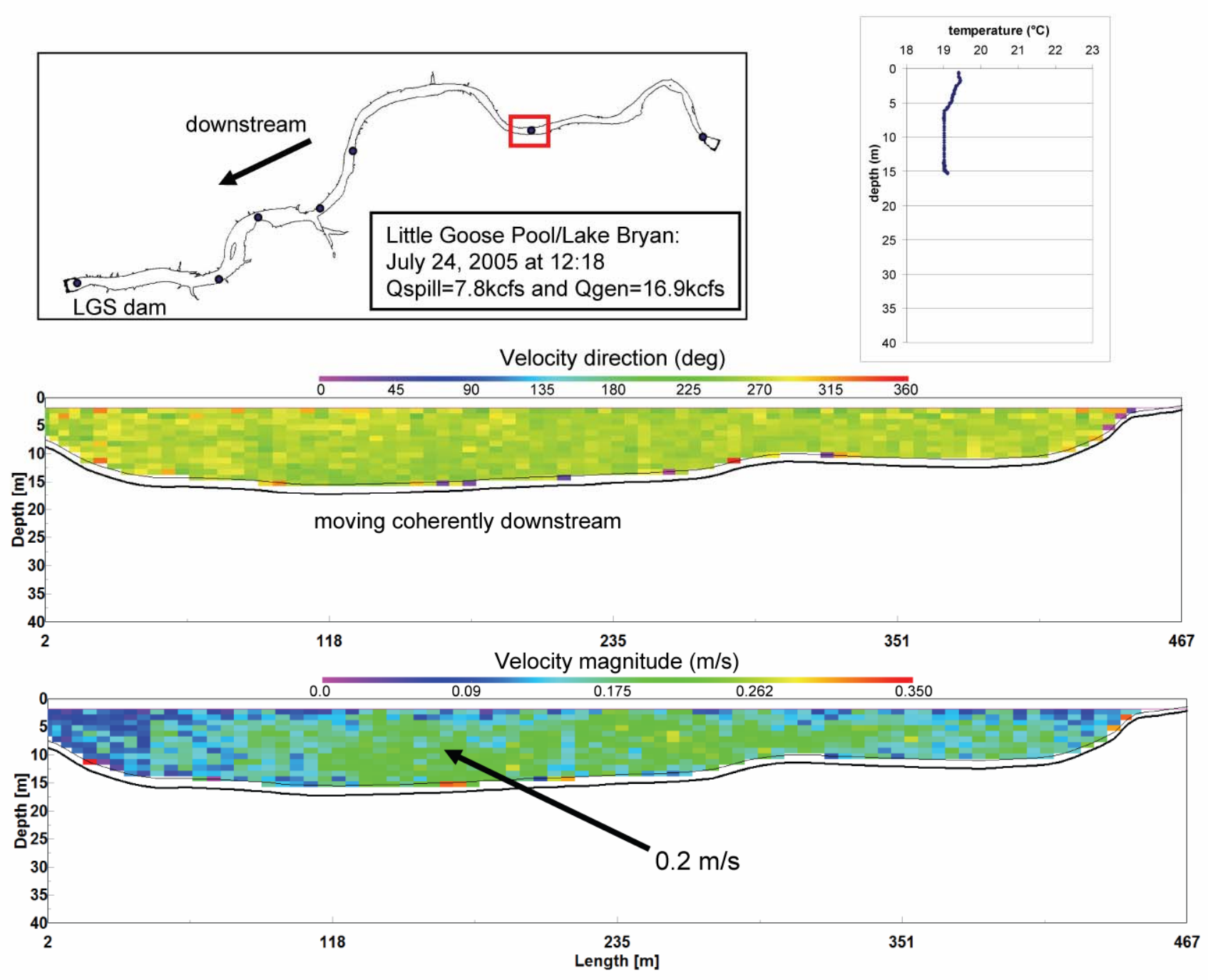

Figure B.4. ADCP transect in the reservoir upstream of Little Goose Dam 

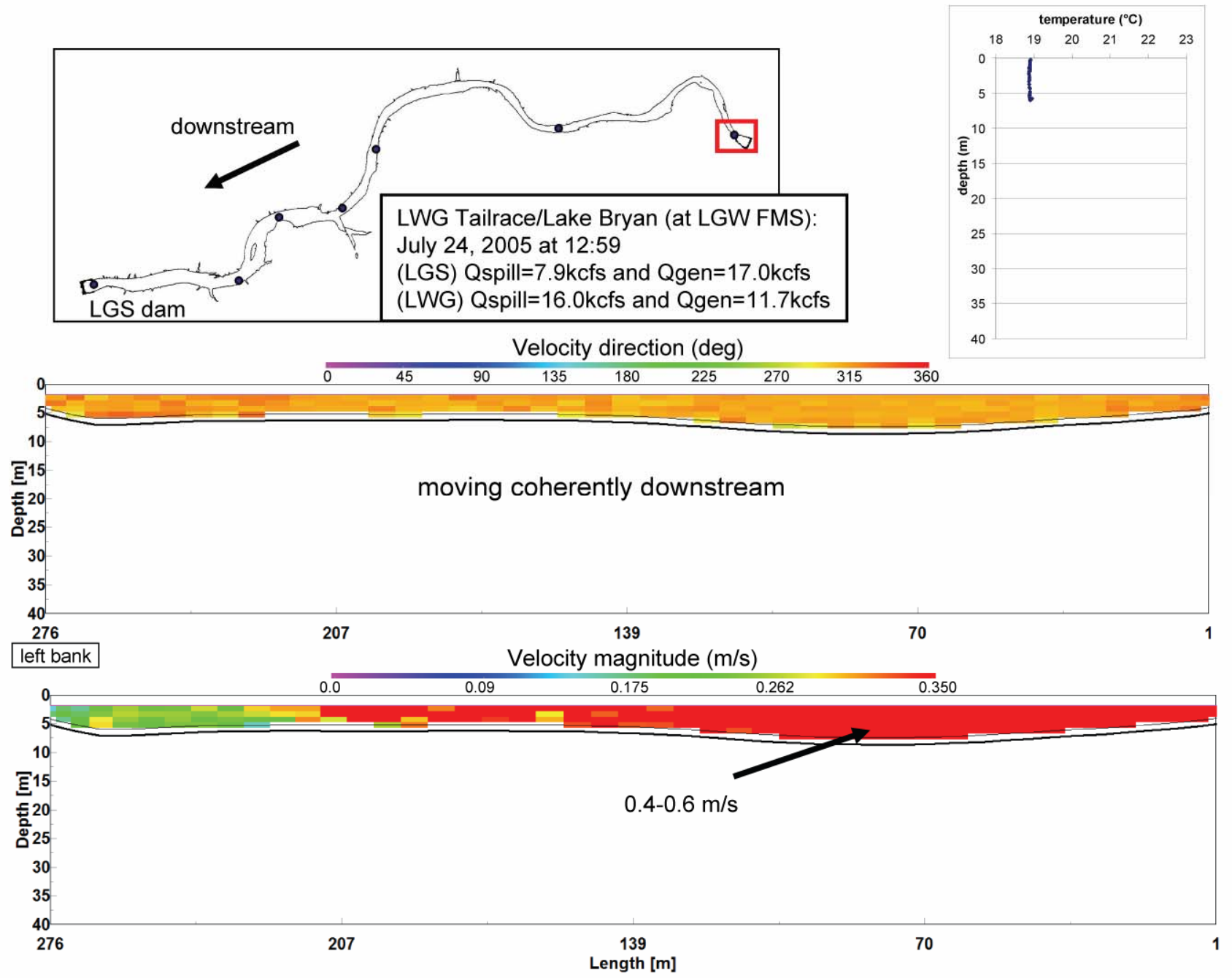

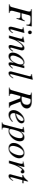

Figure B.5. ADCP transect in the tailrace of Lower Granite Dam near the Fixed Monitoring Station 


\section{B.2 Lower Monumental Reservoir 2005}
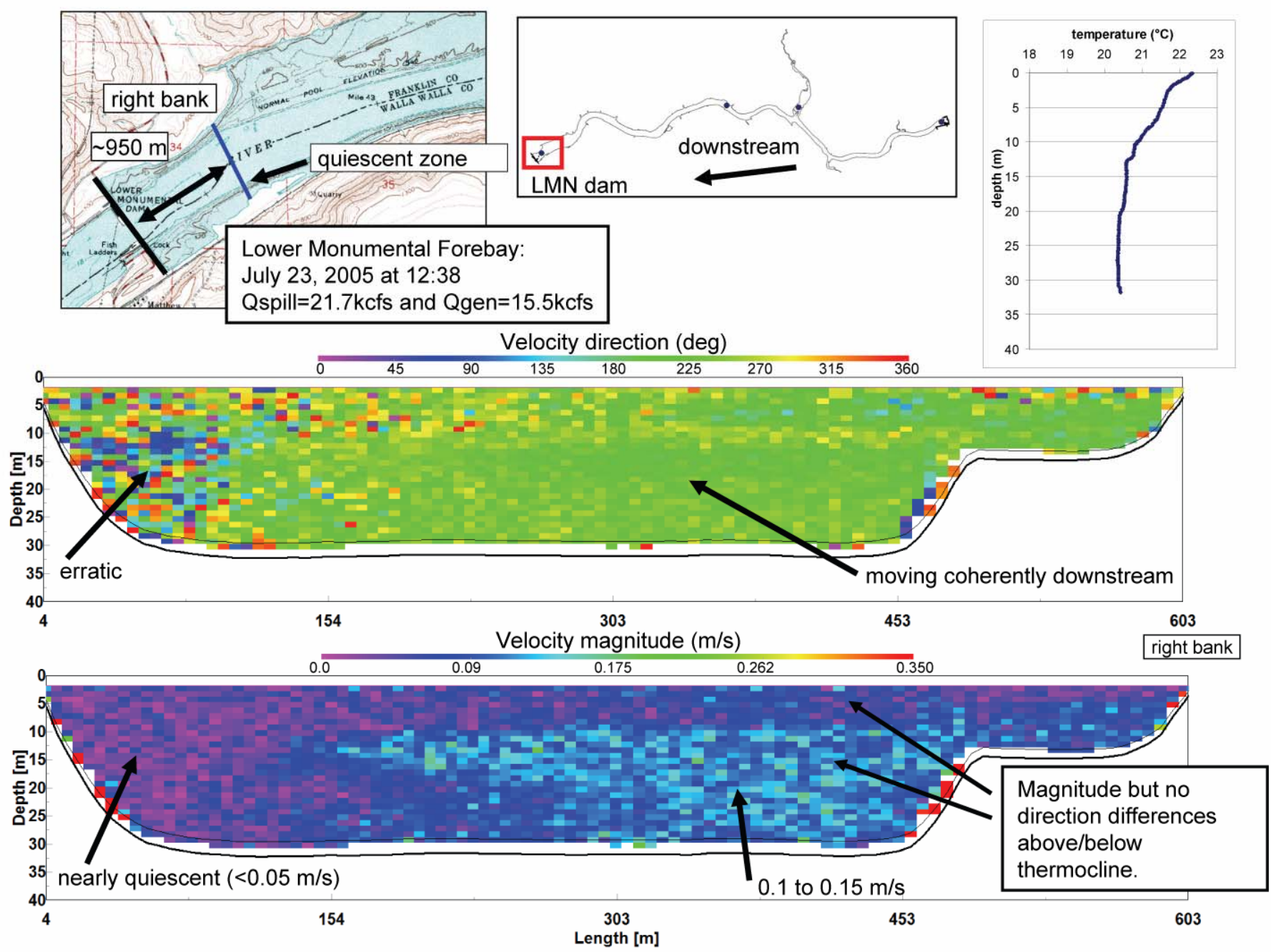

Figure B.6. ADCP transect in the Lower Monumental Forebay 

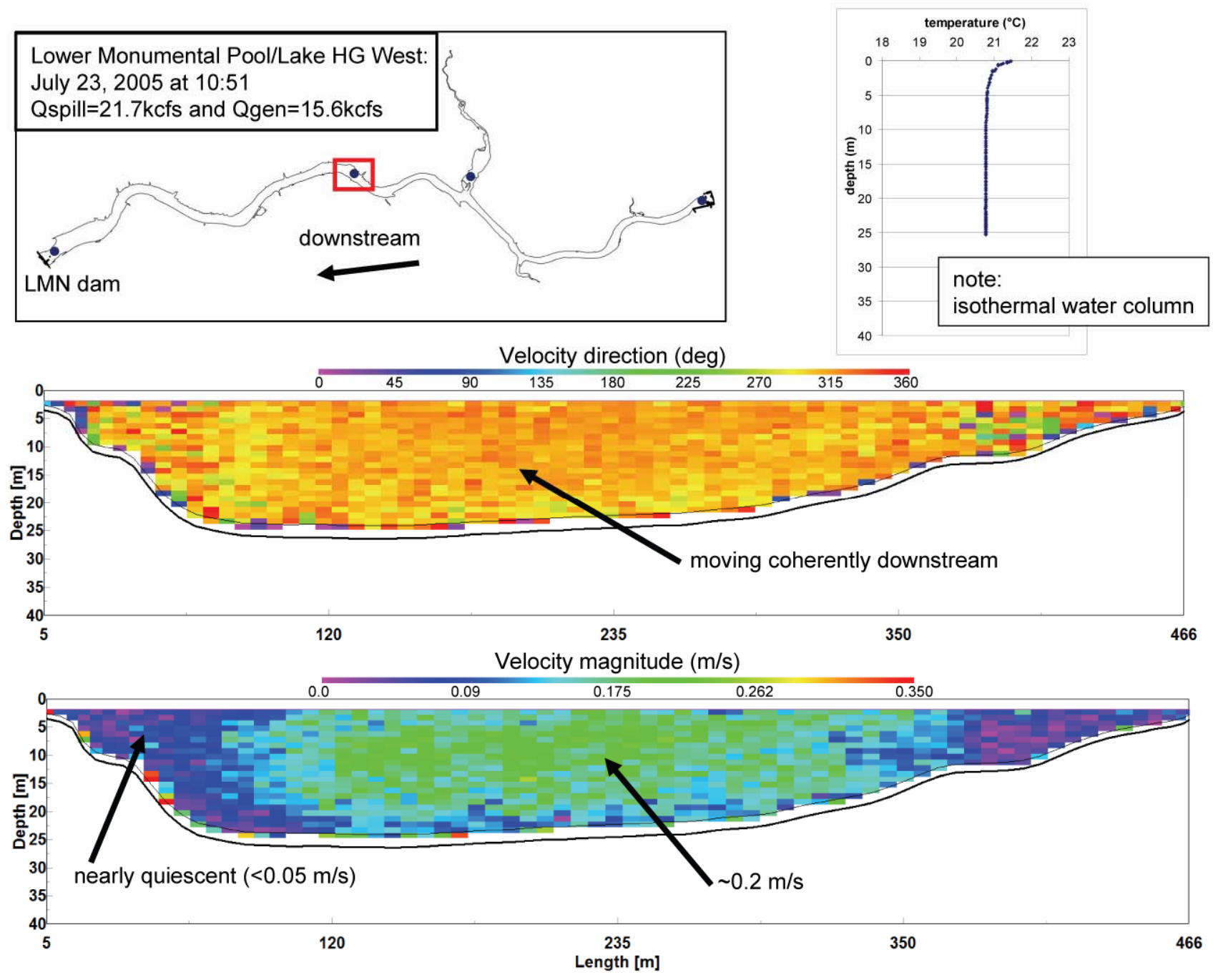

Figure B.7. ADCP transect in the reservoir upstream of Lower Monumental Dam at the mid-pool temperature logger site 

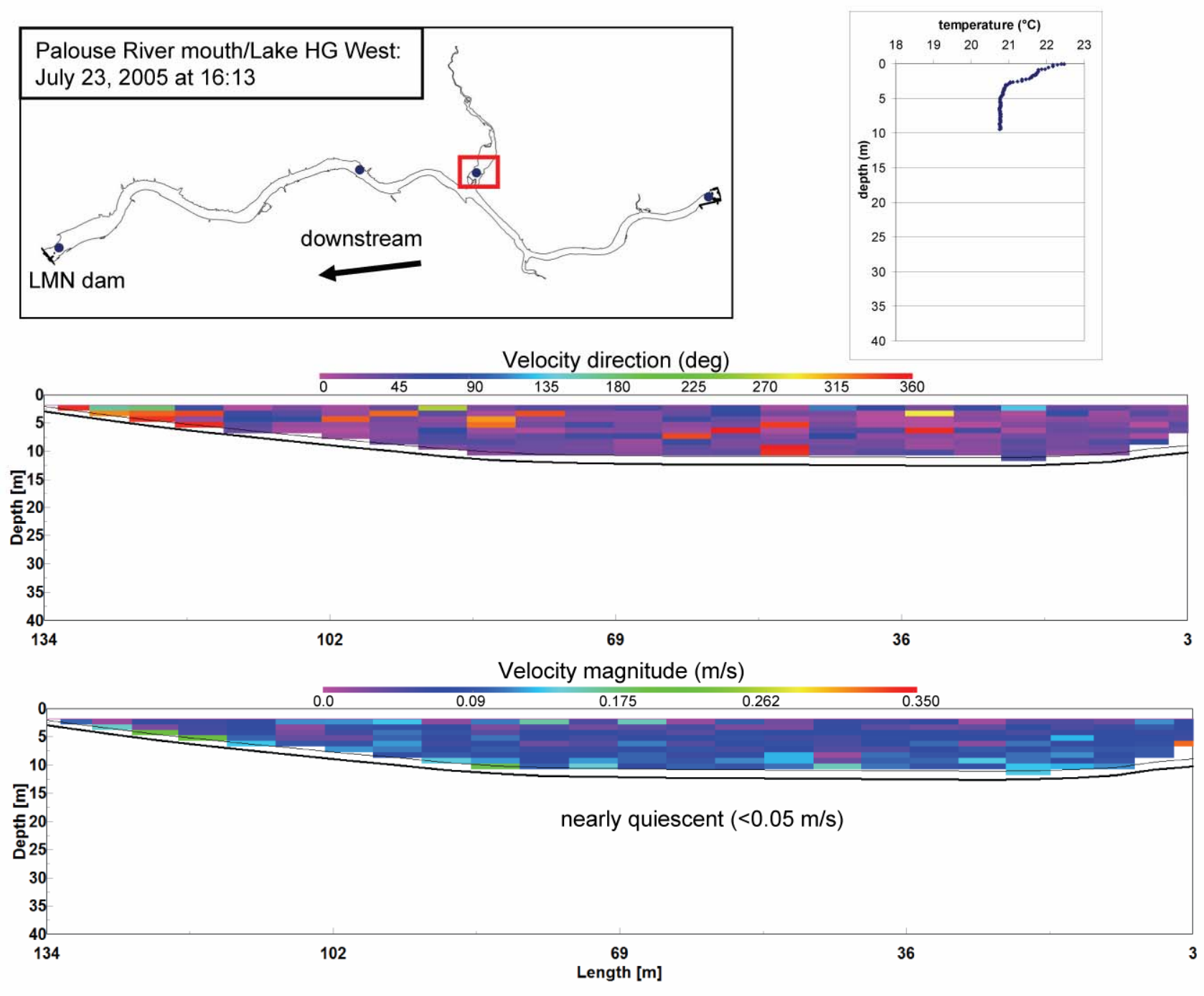

7
7
0
0
8
7
7

Figure B.8. ADCP transect at the mouth of the Palouse River 


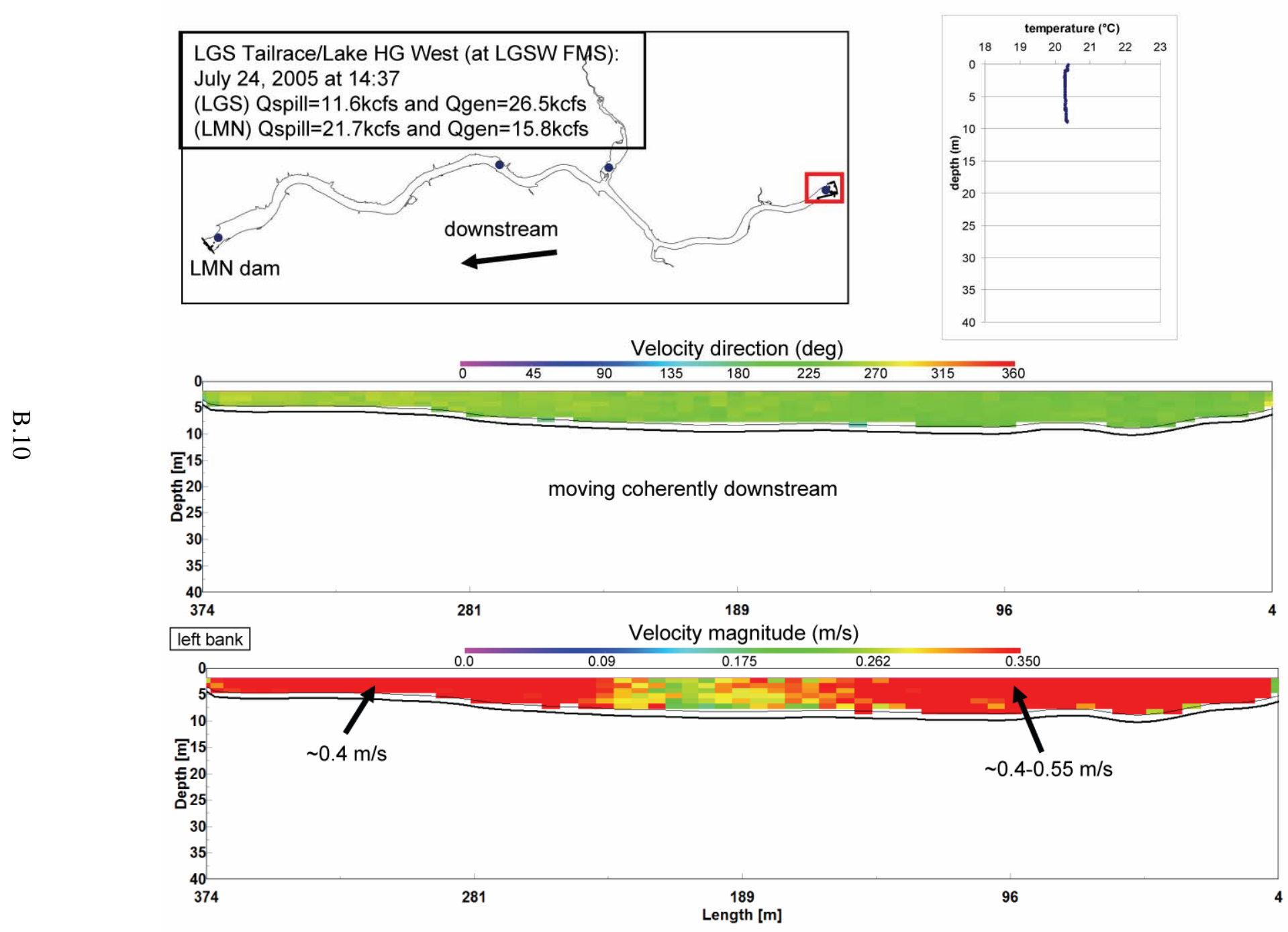

Figure B.9. ADCP transect in the tailrace of Little Goose Dam near the Fixed Monitoring Station 


\section{Appendix C}

\section{CE-QUAL-W2 Calibration and Validation Model Results}




\section{Appendix C \\ CE-QUAL-W2 Calibration and Validation Model Results}

Results generated by the 2D laterally-averaged numerical model CE-QUAL-W2 for the four lower Snake River reservoirs are displayed in the following figures. Each figure in this appendix displays a measured time-series of water temperature and the corresponding model computed time-series at the same depth and location.

\section{C.1 Lower Granite Reservoir Water Temperature Results}

Lower Granite temperature results are displayed for the 2002 through 2004 study periods in locations were the river can be expected to behave two-dimensionally (Site 4 and downstream). Upstream of Site 4, the river was three-dimensional, and results were not compared in these zones. A three-dimensional model was developed to compute hydraulic conditions in this river reach (see Section 3.5). In addition to the PNNL sites shown in Figure C.1, data from an additional site labeled 'BRZ site' are from Carroll and Barko (2005). These data were collected in the forebay BRZ, just upstream of Lower Granite Dam.

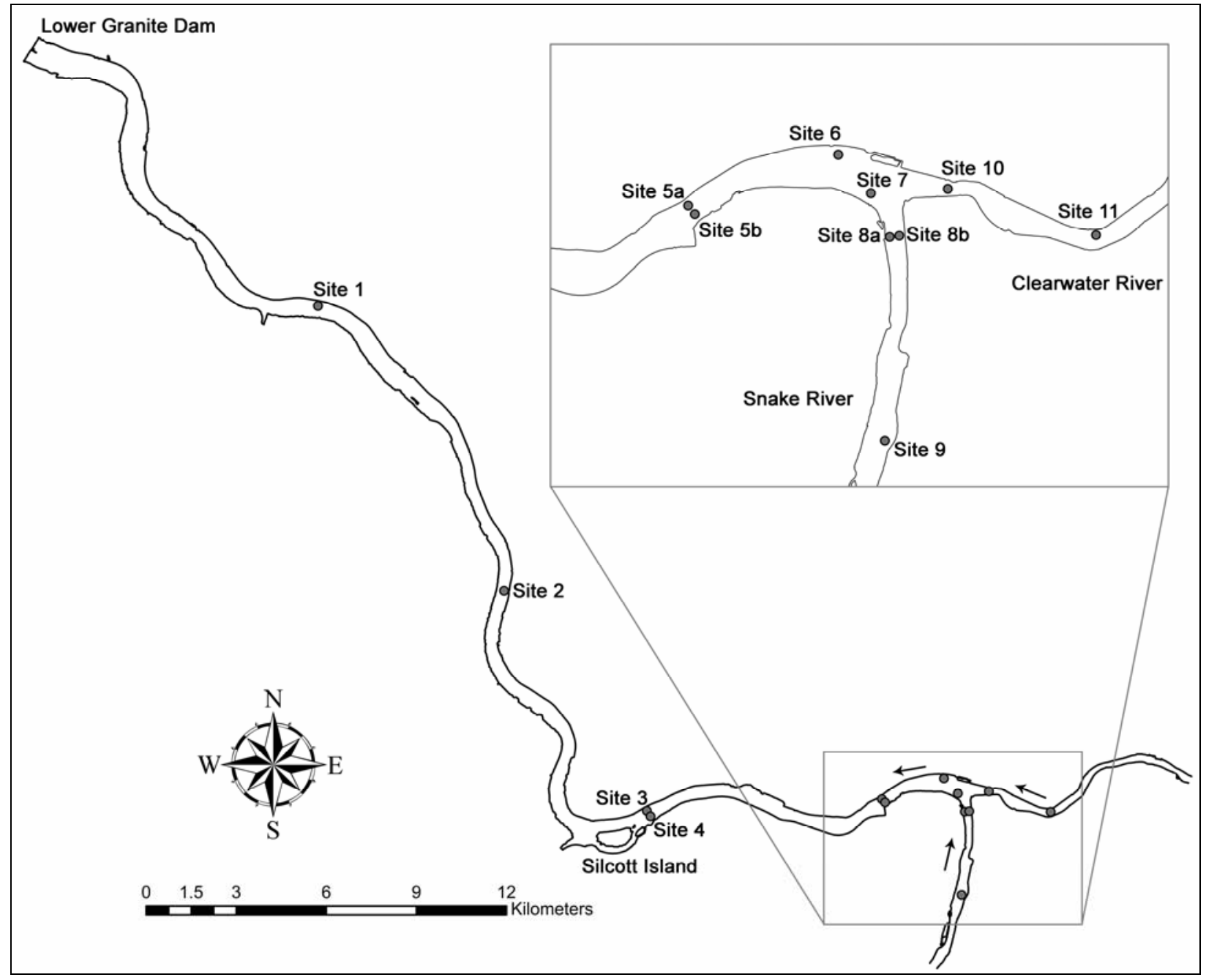

Figure C.1 Temperature logger monitoring sites in Lower Granite Reservoir 


\section{C.1.1 Lower Granite 2002}
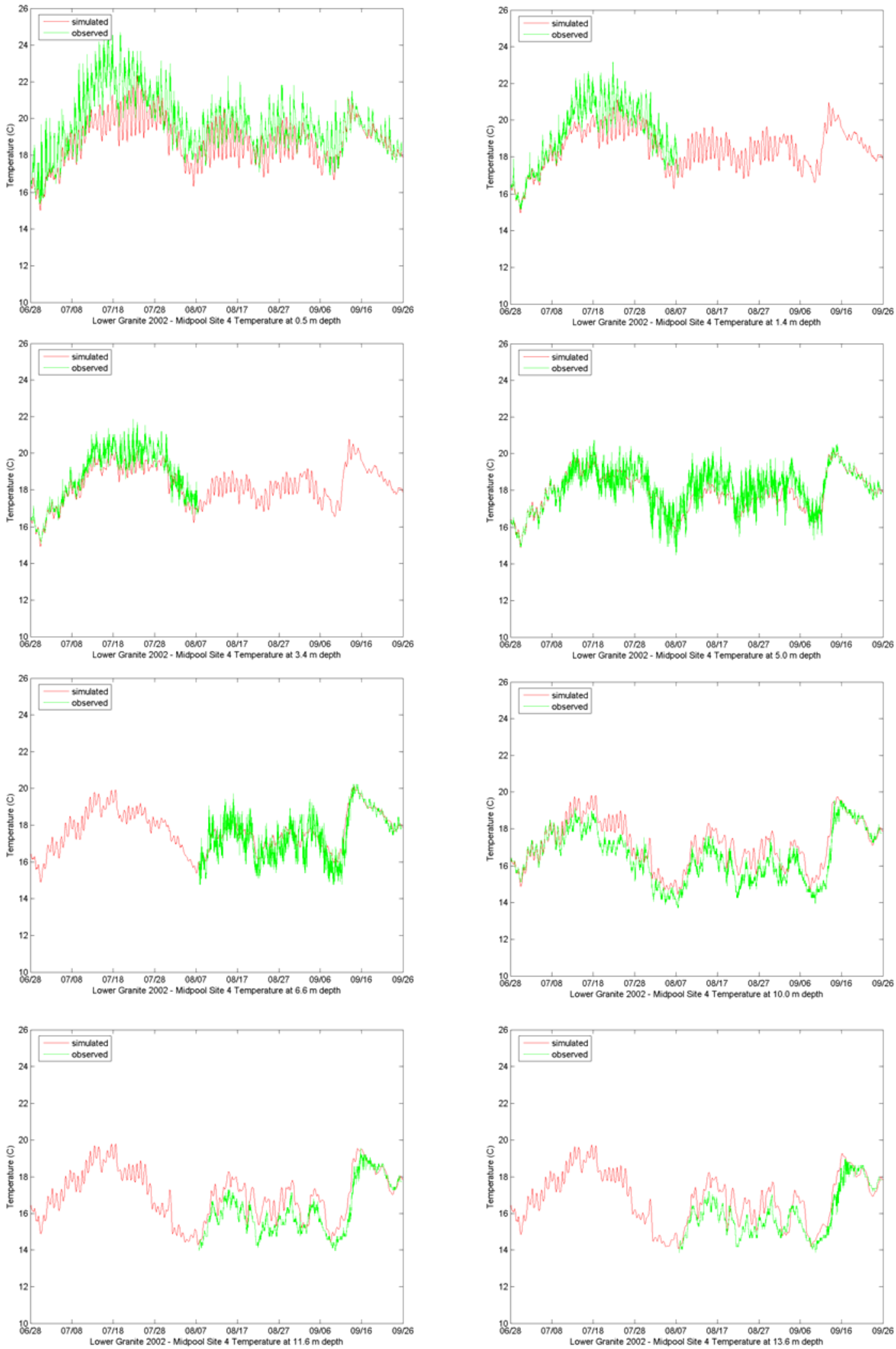

Figure C.2 Observed and simulated temperatures at LWG Site 4, 2002 

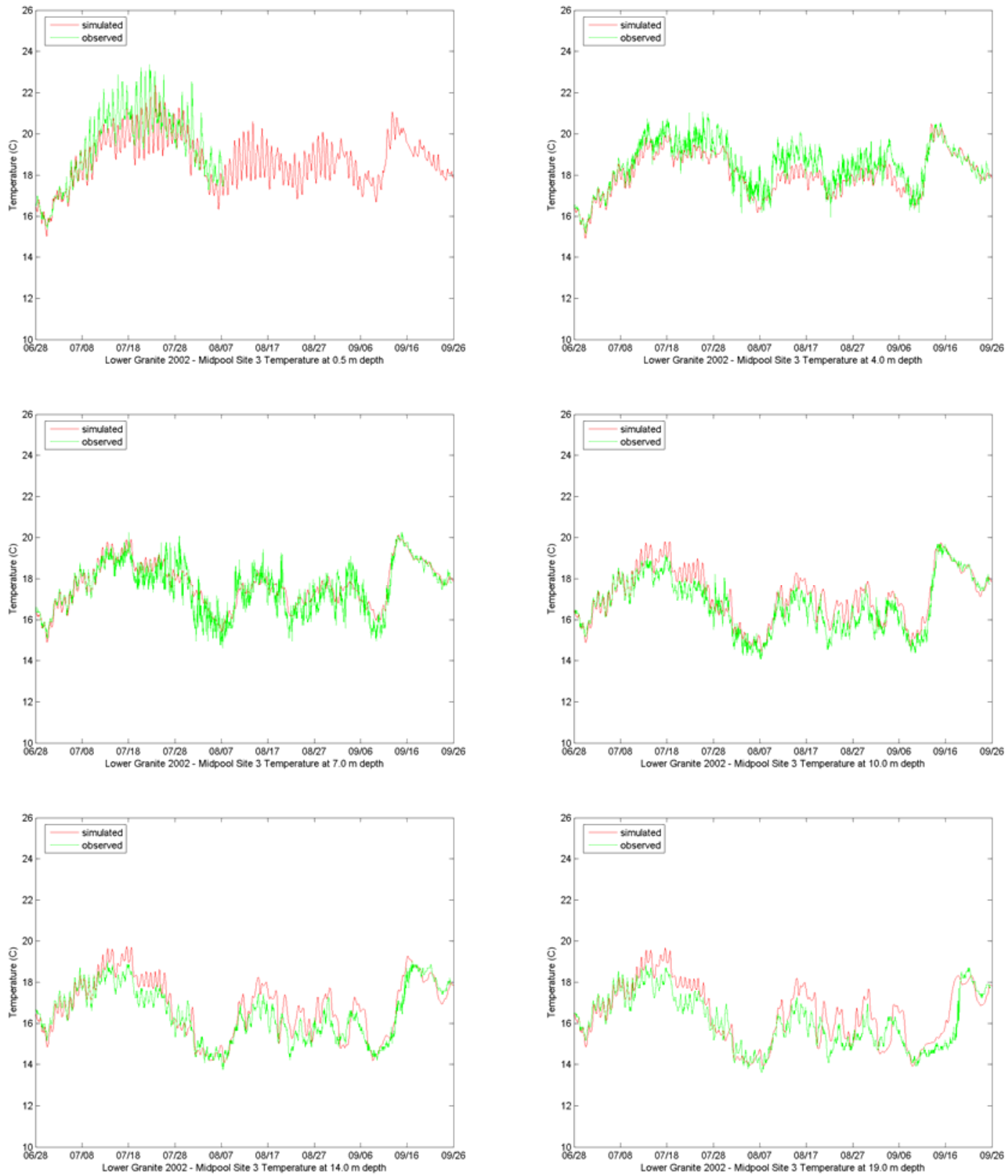

Figure C.3 Observed and Simulated temperatures at LWG Site 3, 2002 

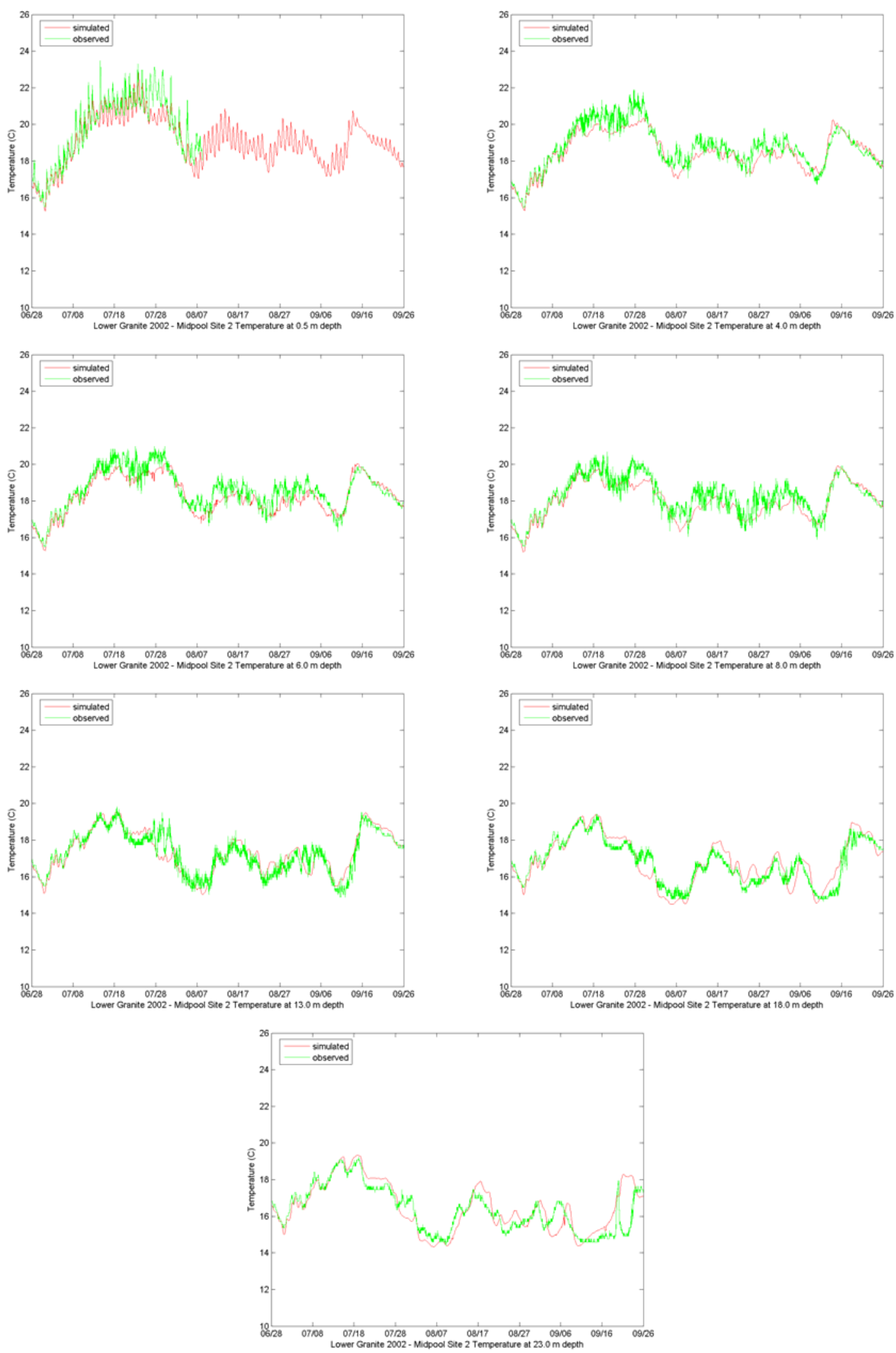

Figure C.4 Observed and Simulated temperatures at LWG Site 2, 2002 

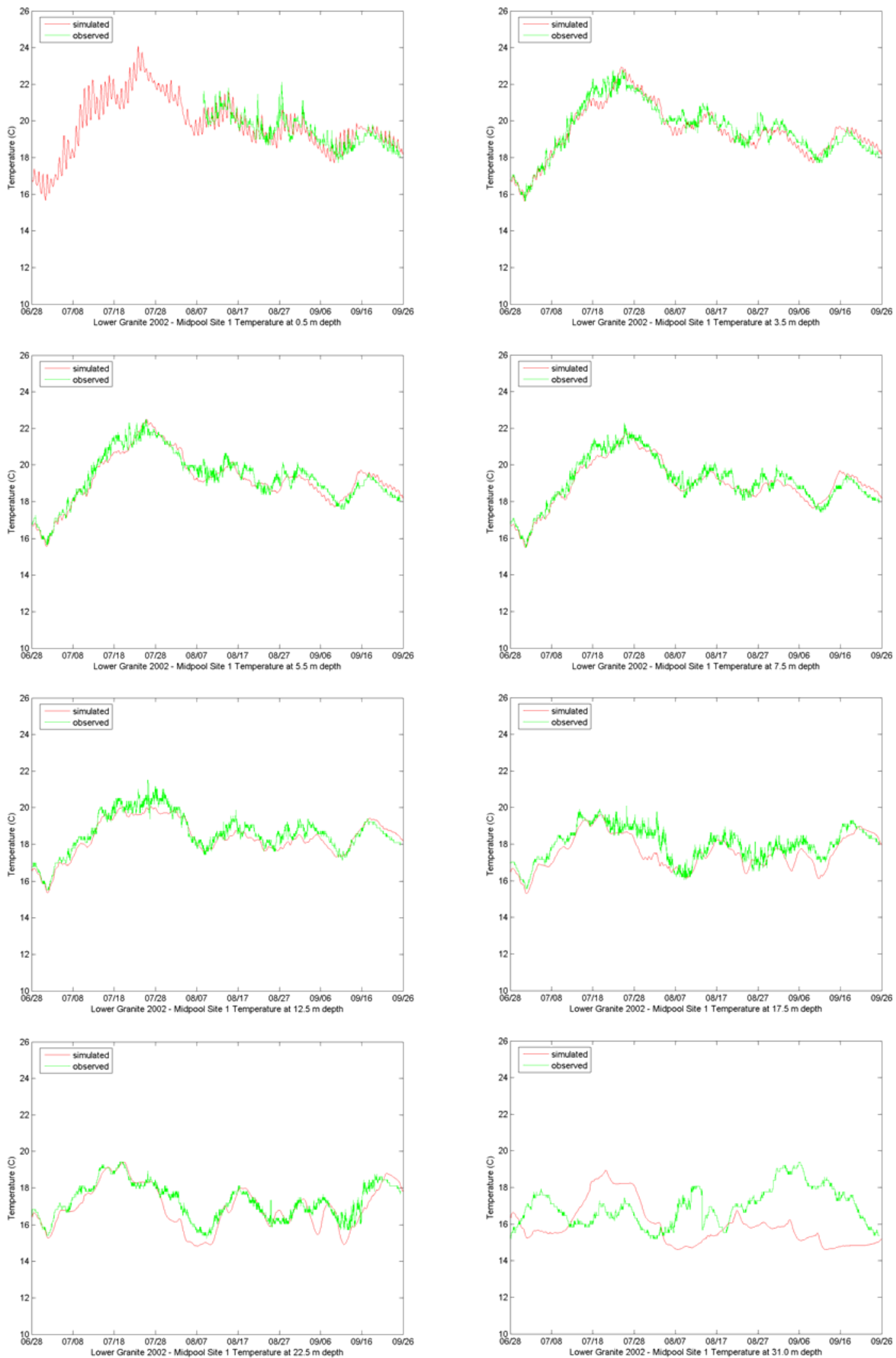

Figure C.5 Observed and Simulated temperatures at LWG Site 1, 2002 

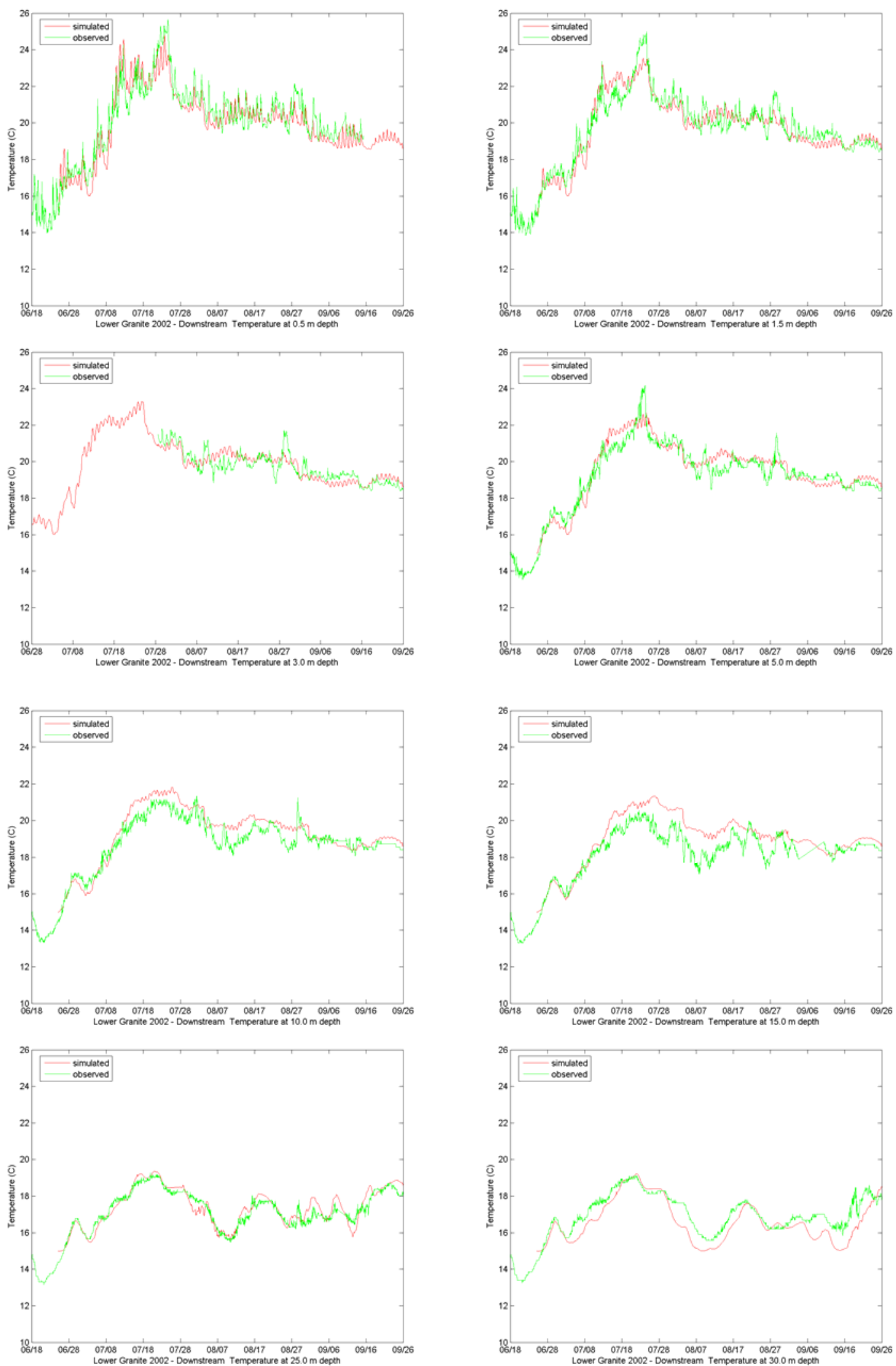

Figure C.6 Observed and Simulated temperatures at LWG forebay BRZ, 2002 


\section{C.1.2 Lower Granite 2003}
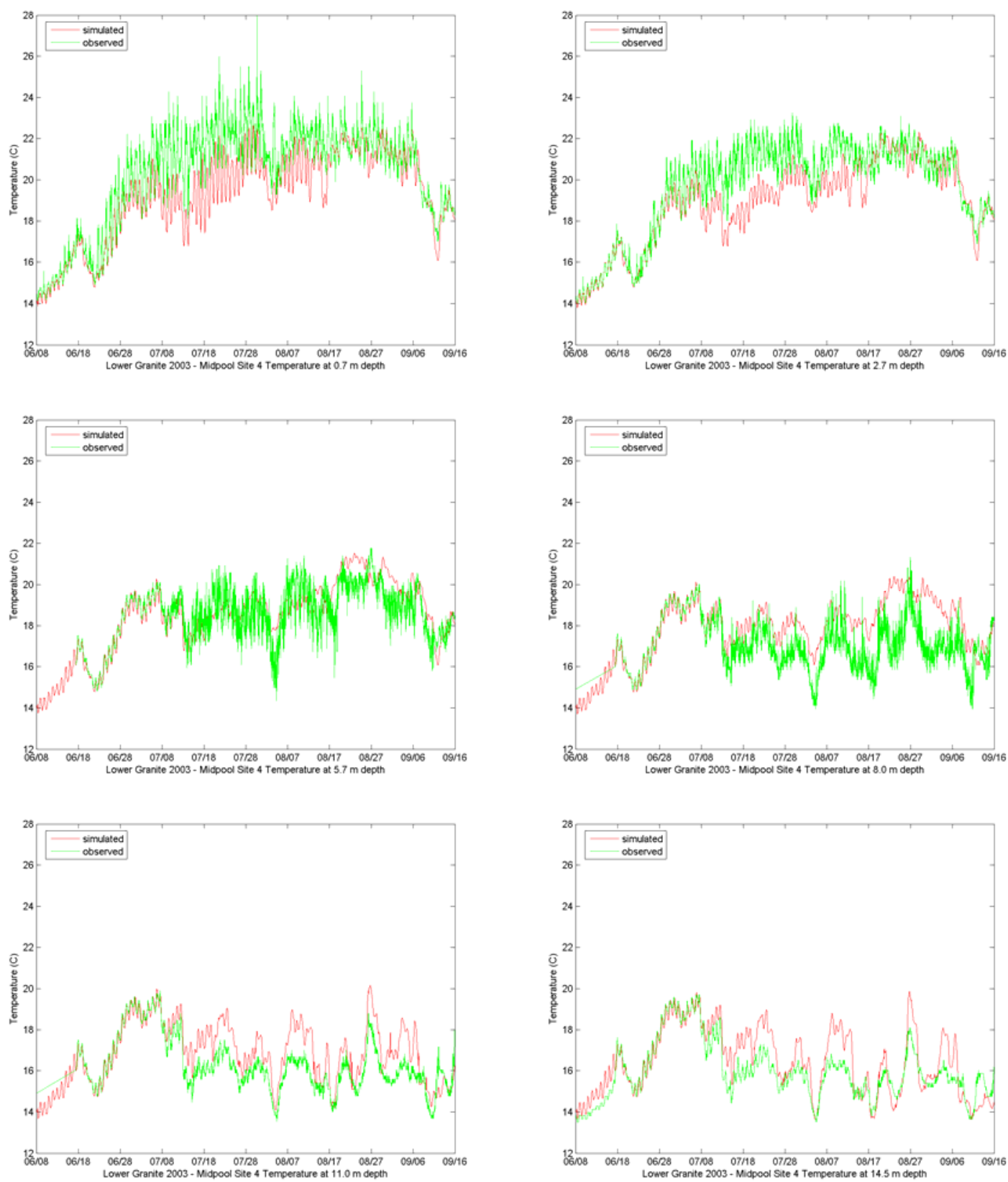

Figure C.7 Observed and Simulated temperatures at LWG Site 4, 2003 

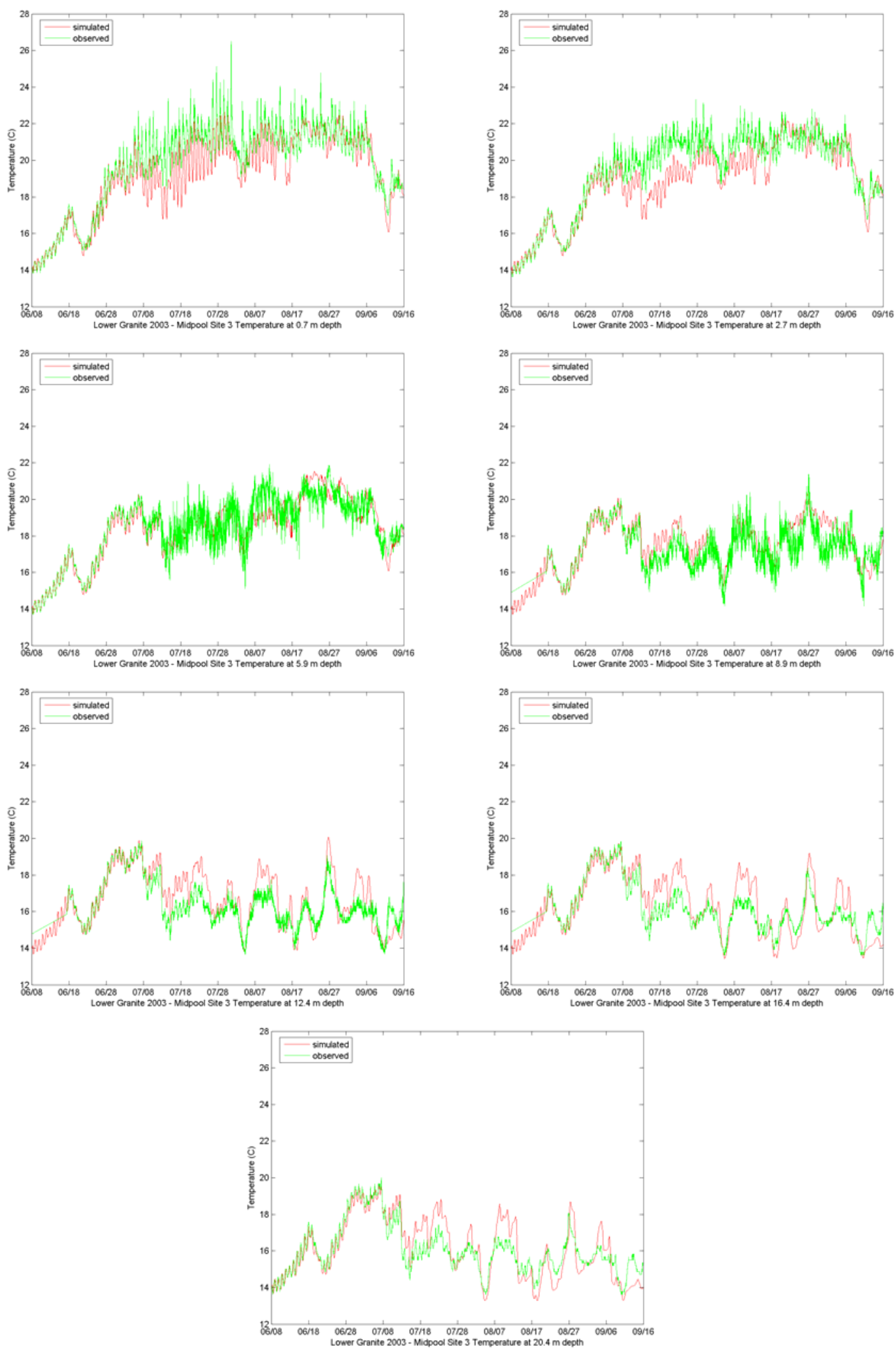

Figure C.8 Observed and Simulated temperatures at LWG Site 3, 2003 

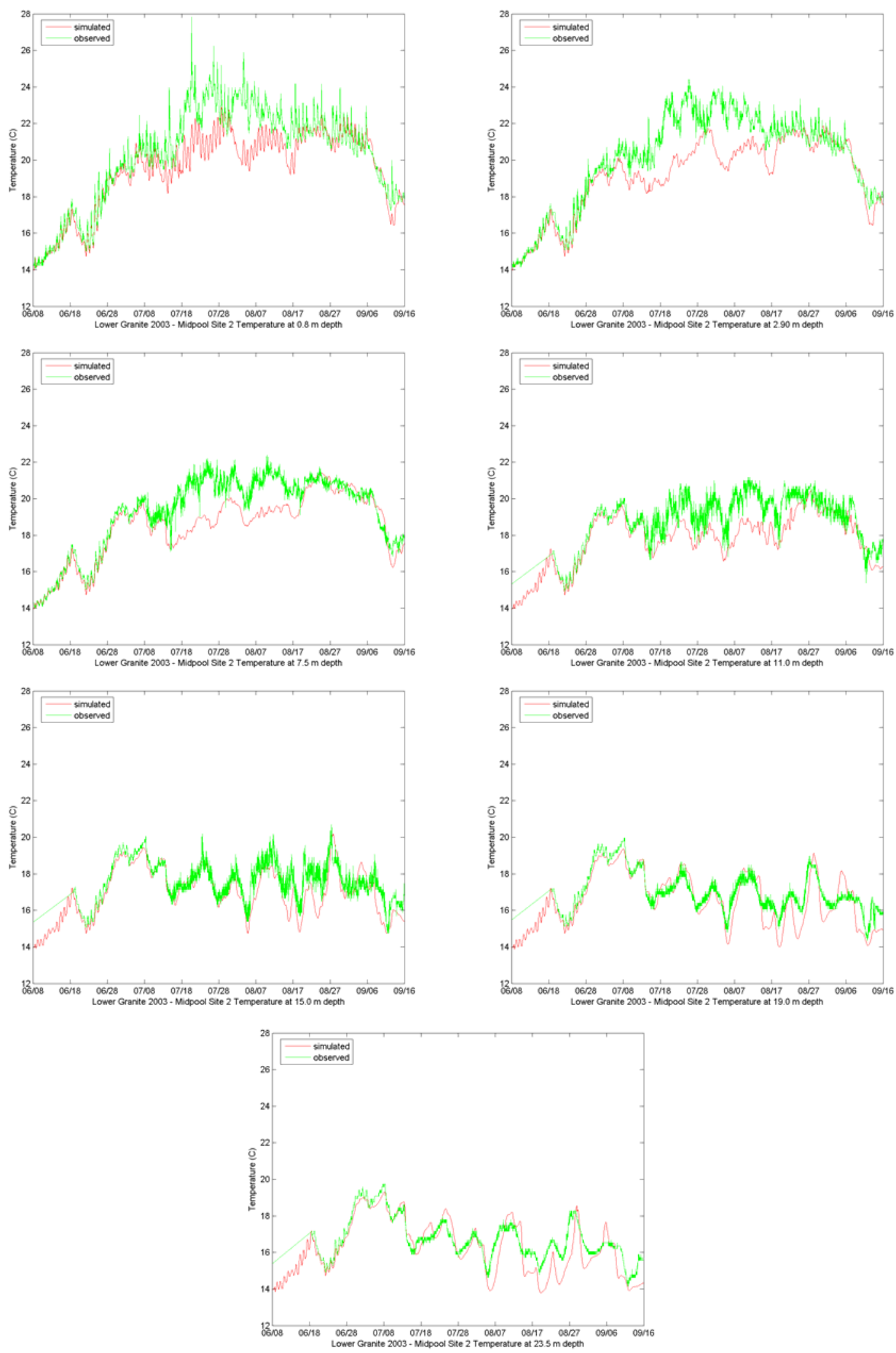

Figure C.9 Observed and Simulated temperatures at LWG Site 2, 2003 

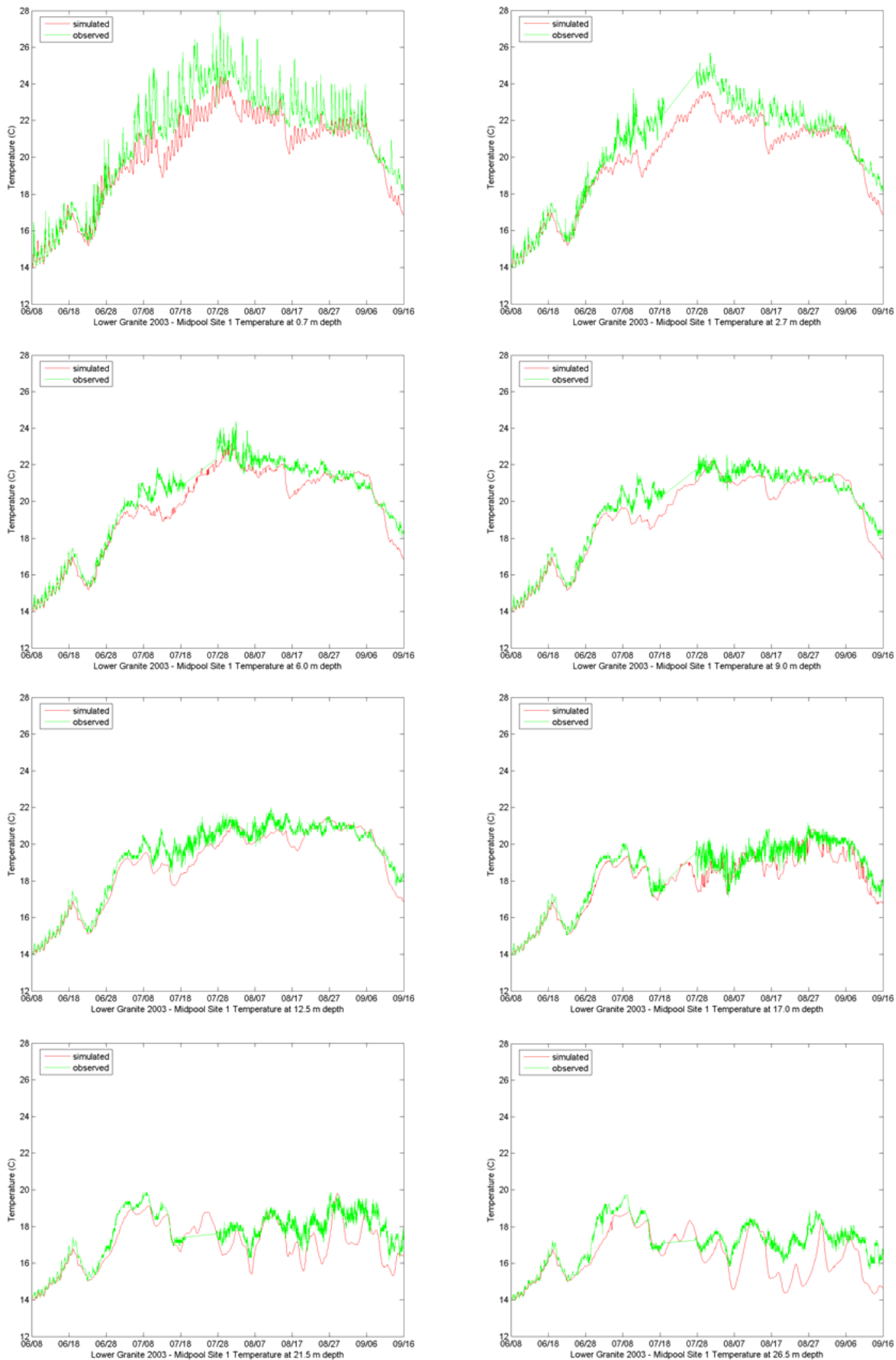

Figure C.10 Observed and Simulated temperatures at LWG Site 1, 2003 

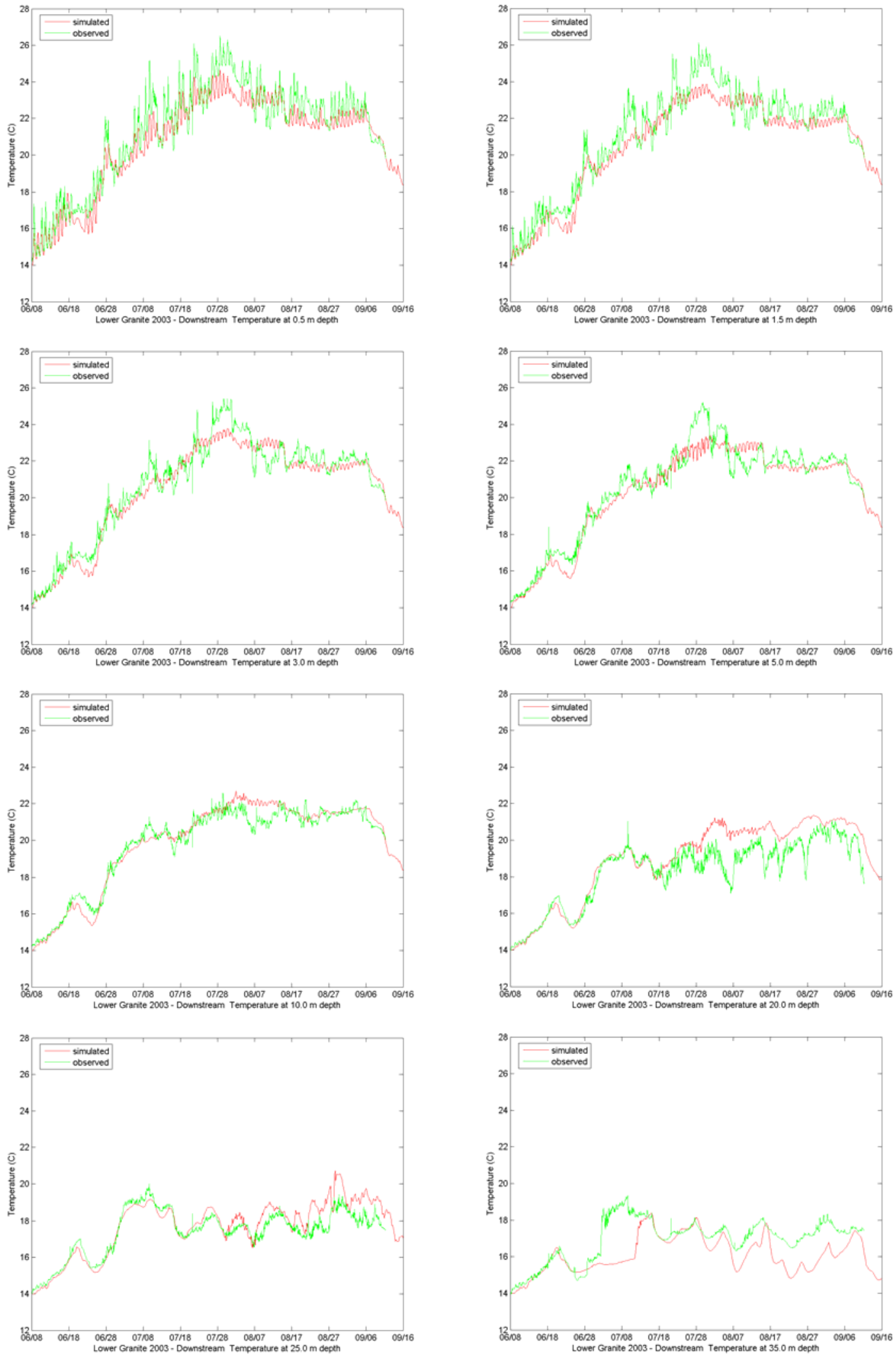

Figure C.11 Observed and Simulated temperatures at LWG Site 1, 2003 


\section{C.1.3 Lower Granite 2004}
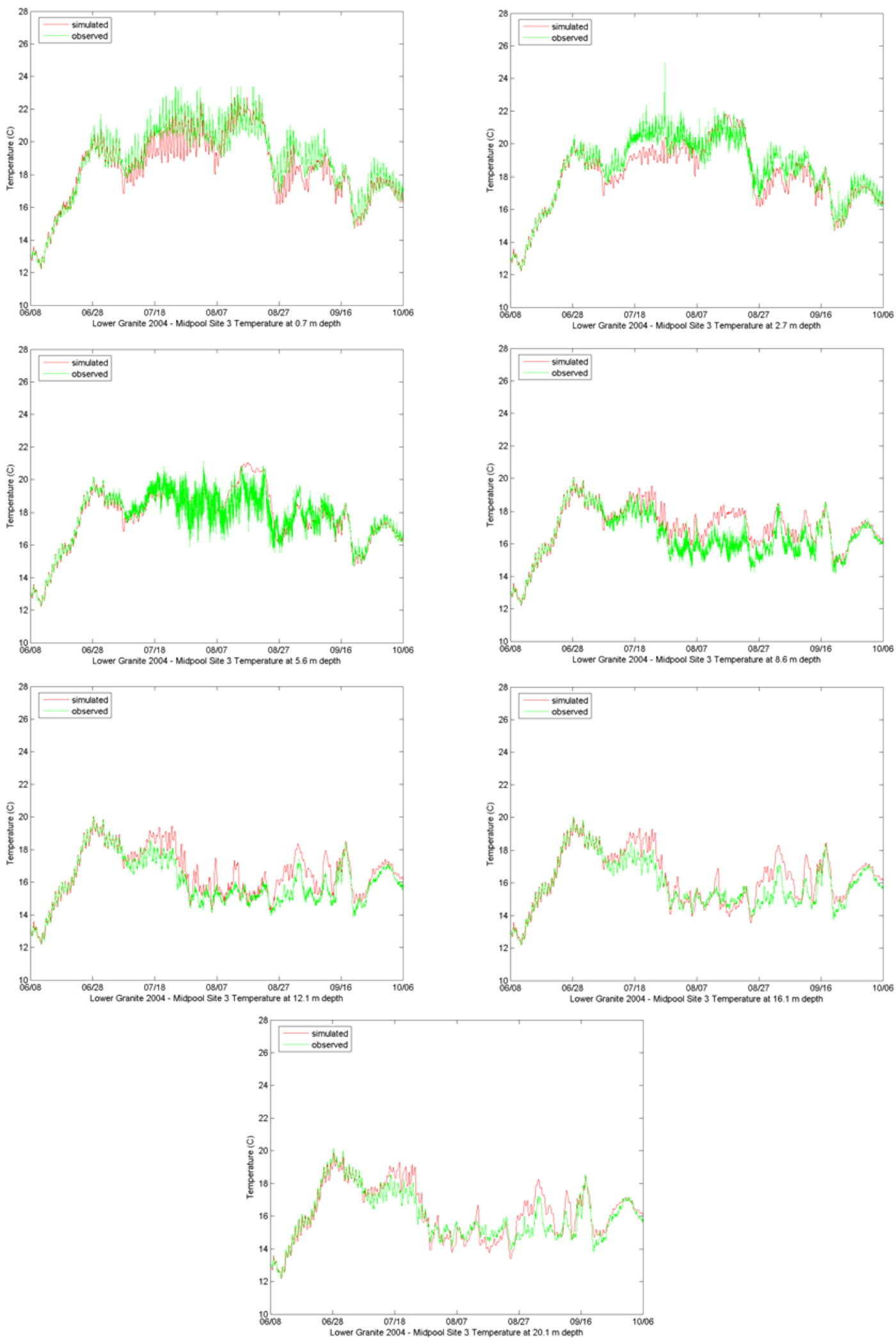

Figure C.12 Observed and Simulated temperatures at LWG Site 3, 2004 

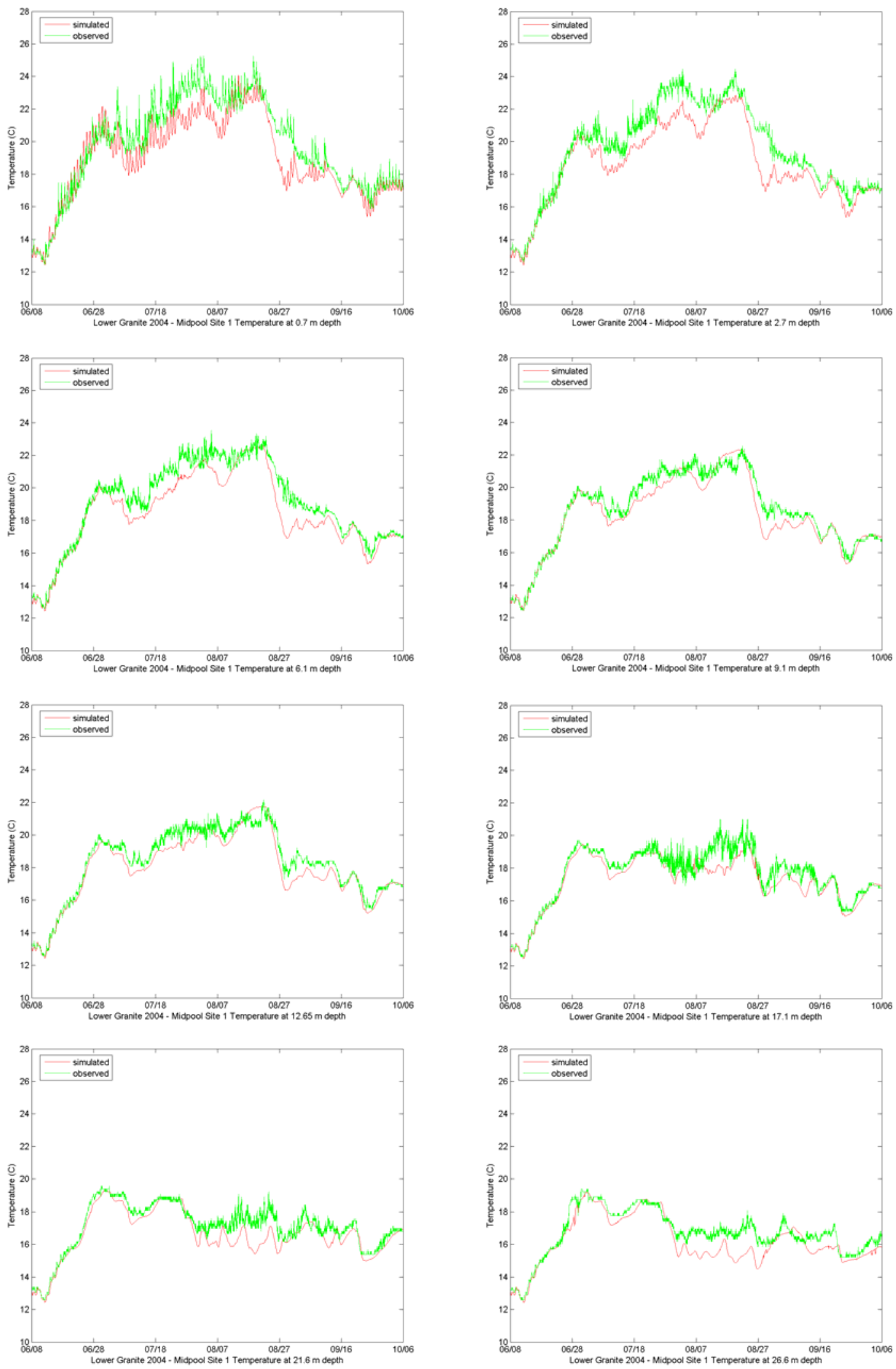

Figure C.13 Observed and Simulated temperatures at LWG Site 1, 2004 

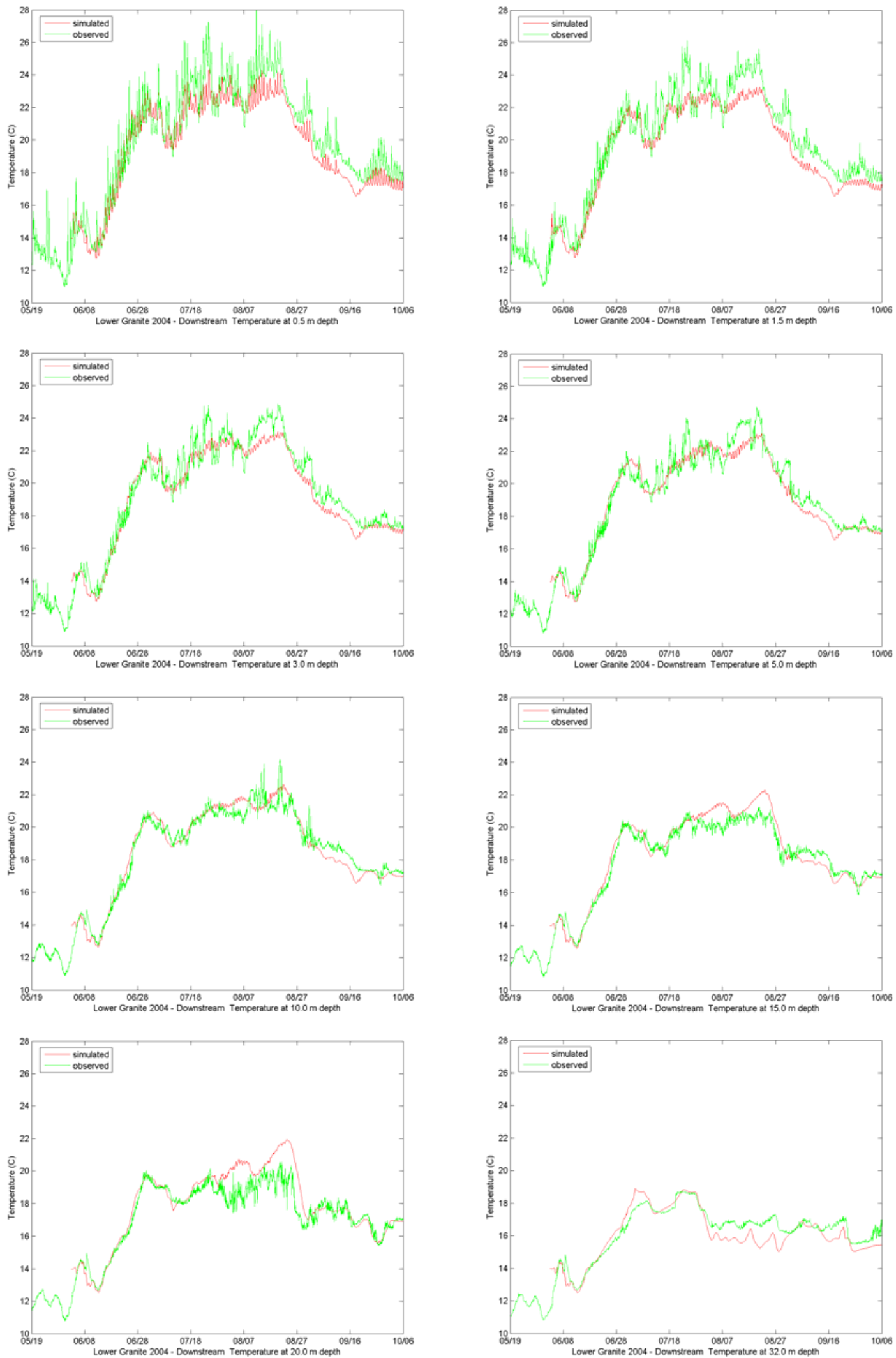

Figure C.14 Observed and Simulated temperatures at LWG forebay BRZ, 2004 


\section{C.2 Little Goose Temperature Results}

\section{C.2.1 Little Goose 2005}

Water temperature readings of Little Goose Reservoir during field season 2005 were obtained with a conductivity-temperature-depth probe (CTD). These measurements were used to validate the model's ability to simulate wind-setup and the hydraulic circulation shown in Figure 4.4 (see Section 4.1). Figure C.15 shows the locations of observed temperature measurements.

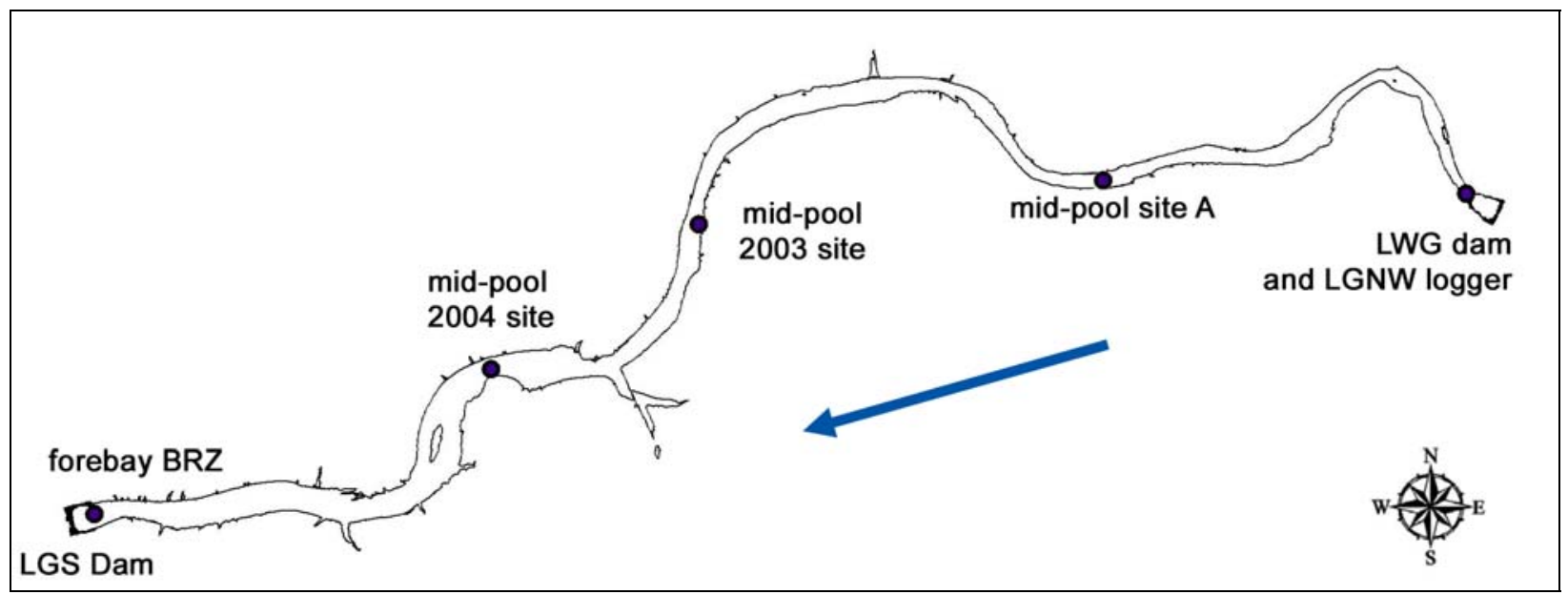

Figure C.15 Temperature measurement locations in Little Goose Reservoir during Field Season 2005 

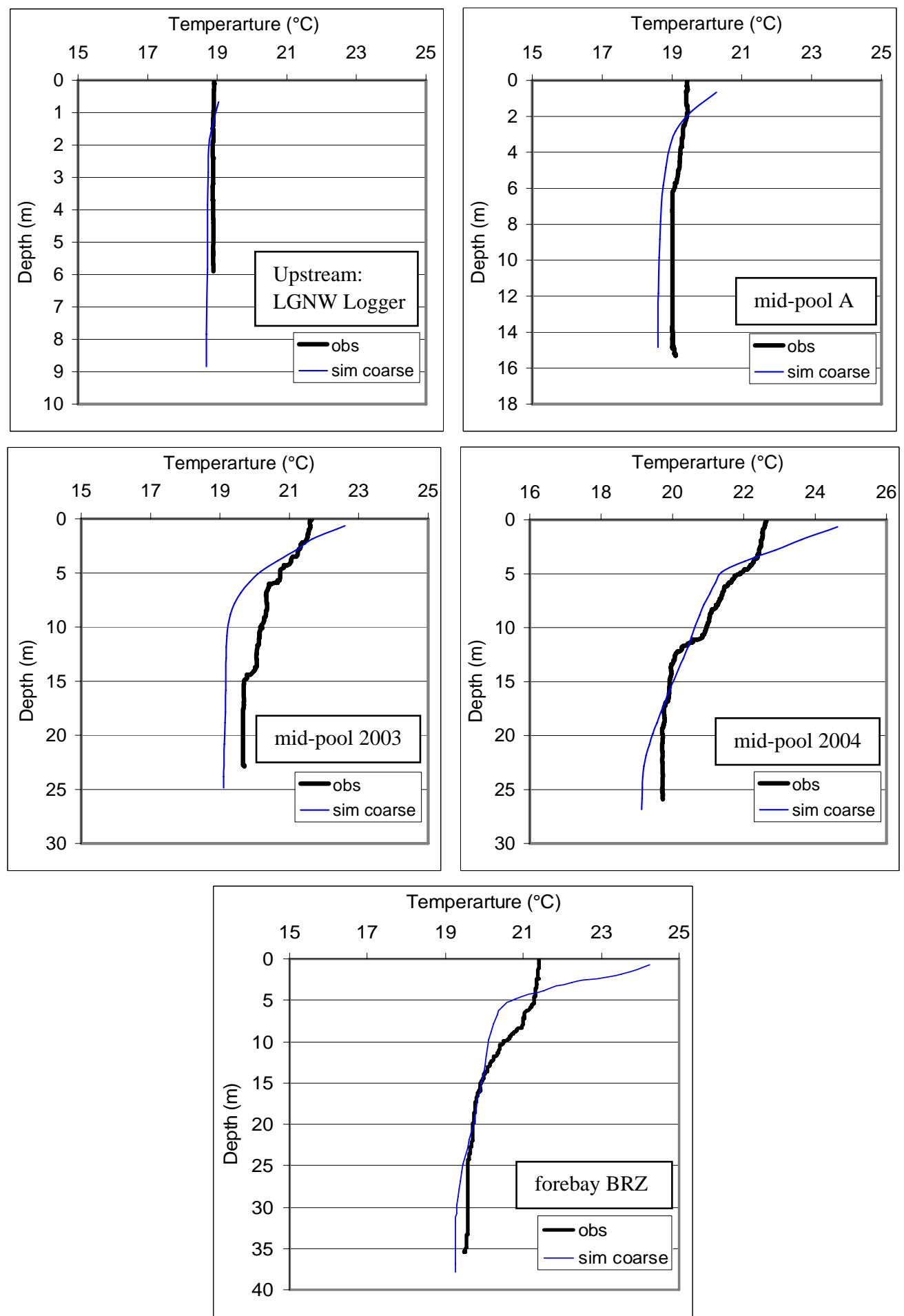

Figure C.16 Comparison of simulated and observed water temperatures on July 24, 2005. Observed data, 'obs', are from CTD profiles while 'sim coarse' are CE-QUAL-W2 model simulation results using the coarse $(804 \mathrm{~m})$ numerical grid. 


\section{C.2.2 Little Goose 2002}
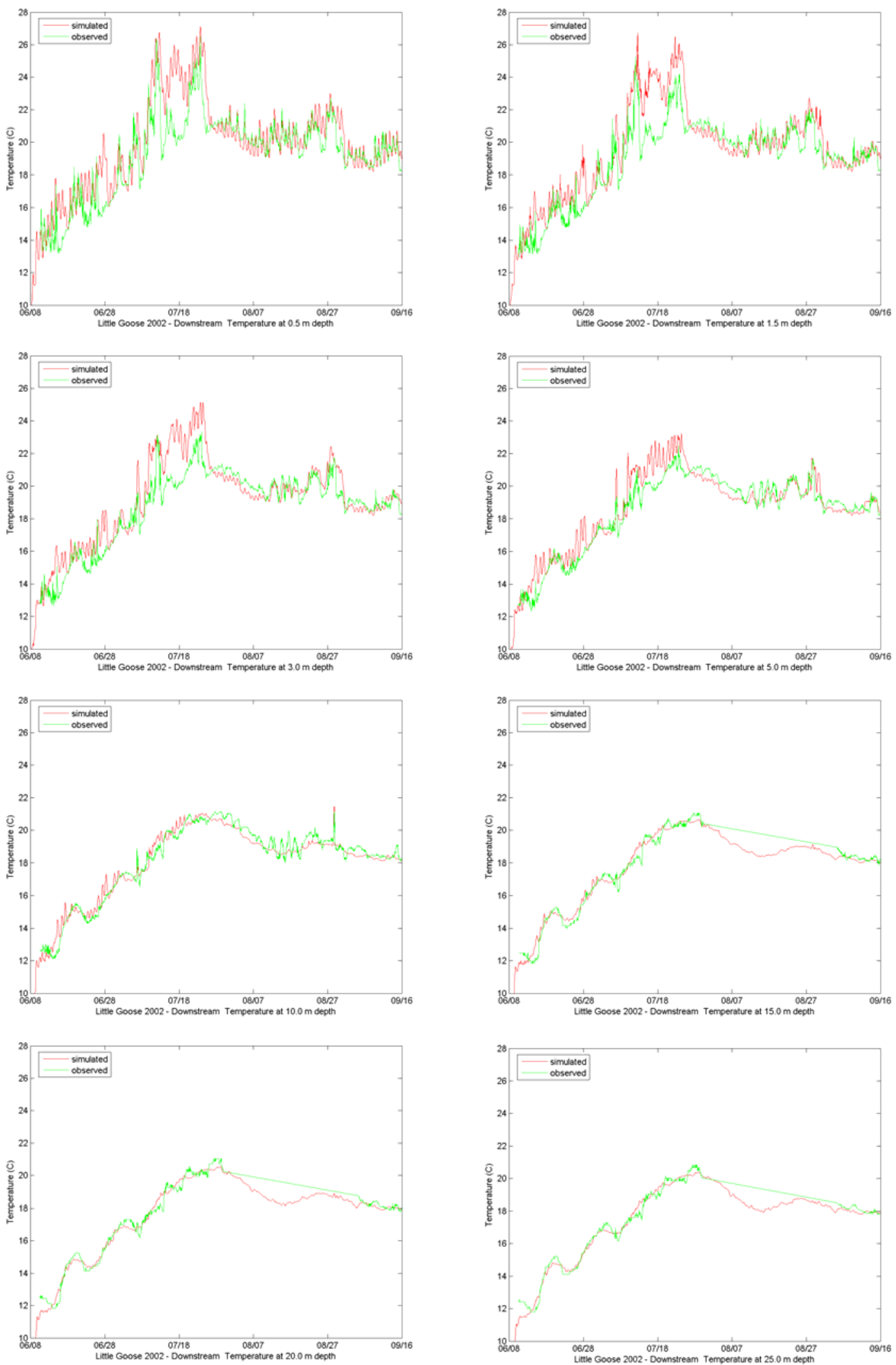

Figure C.17 Observed and Simulated temperatures at LGS forebay BRZ, 2002 


\section{C.2.3 Little Goose 2003}
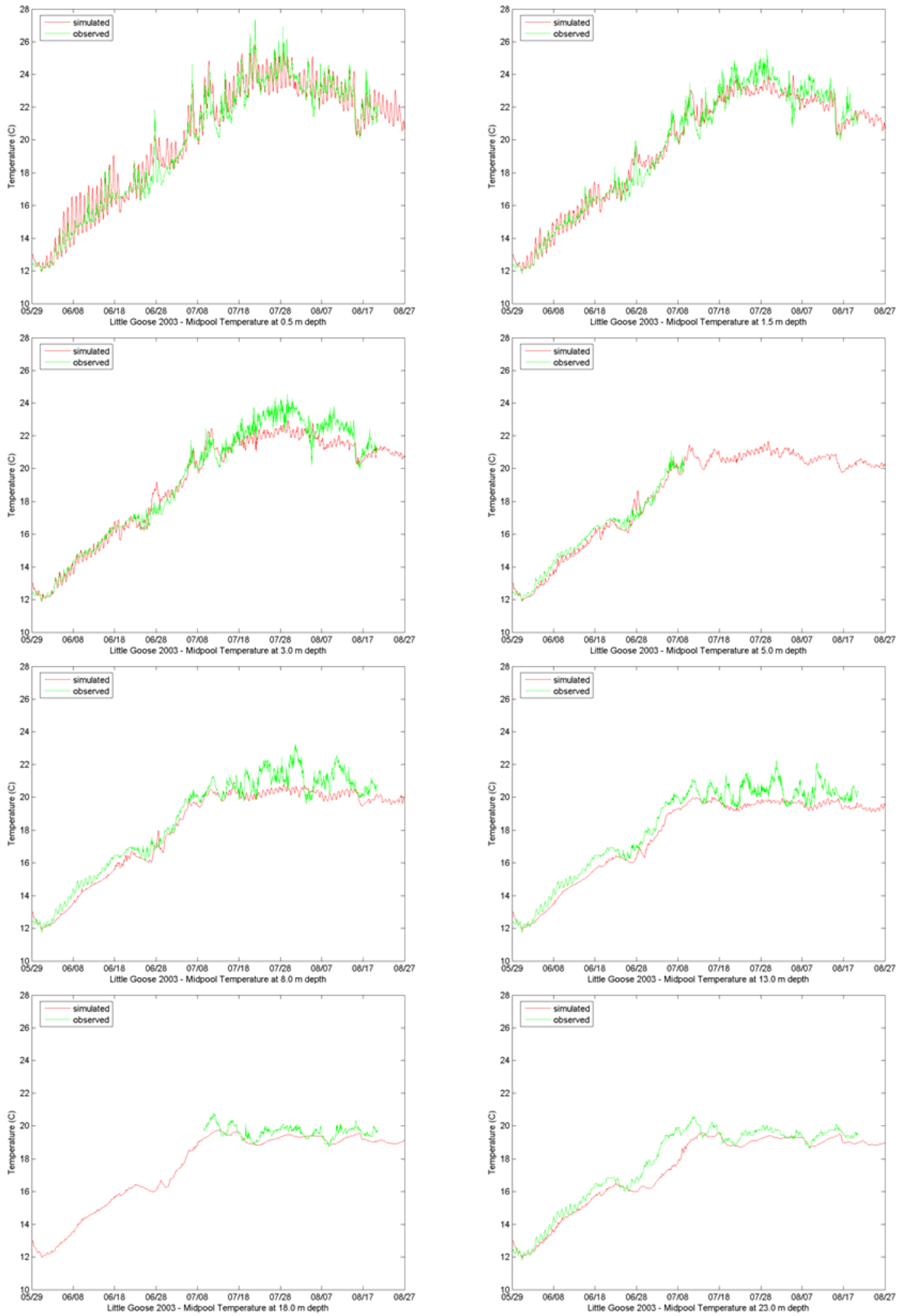

Figure C.18 Observed and Simulated temperatures at LGS Mid-pool, 2003 

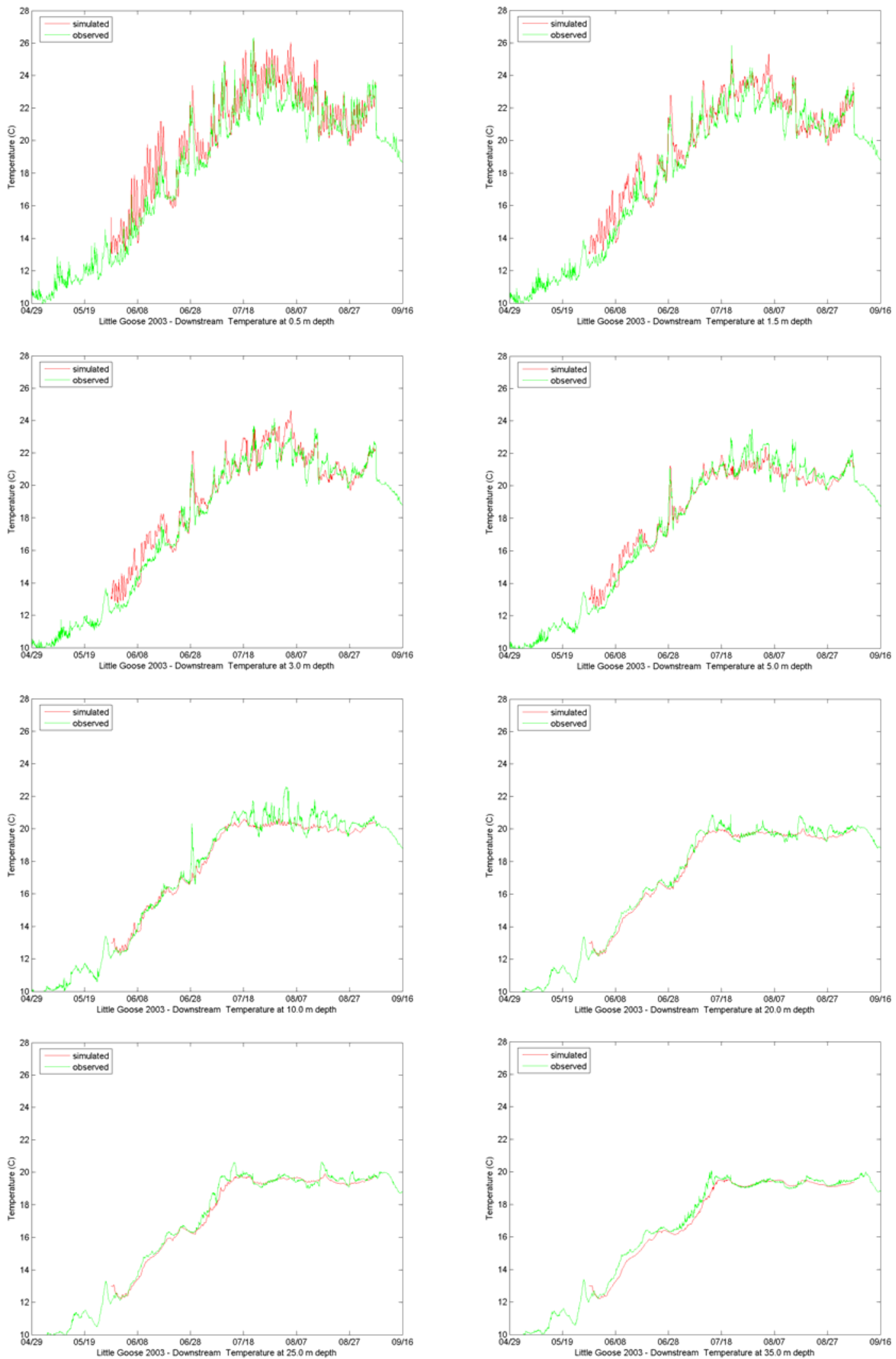

Figure C.19 Observed and Simulated temperatures at LGS BRZ, 2003 


\section{C.2.4 Little Goose 2004}
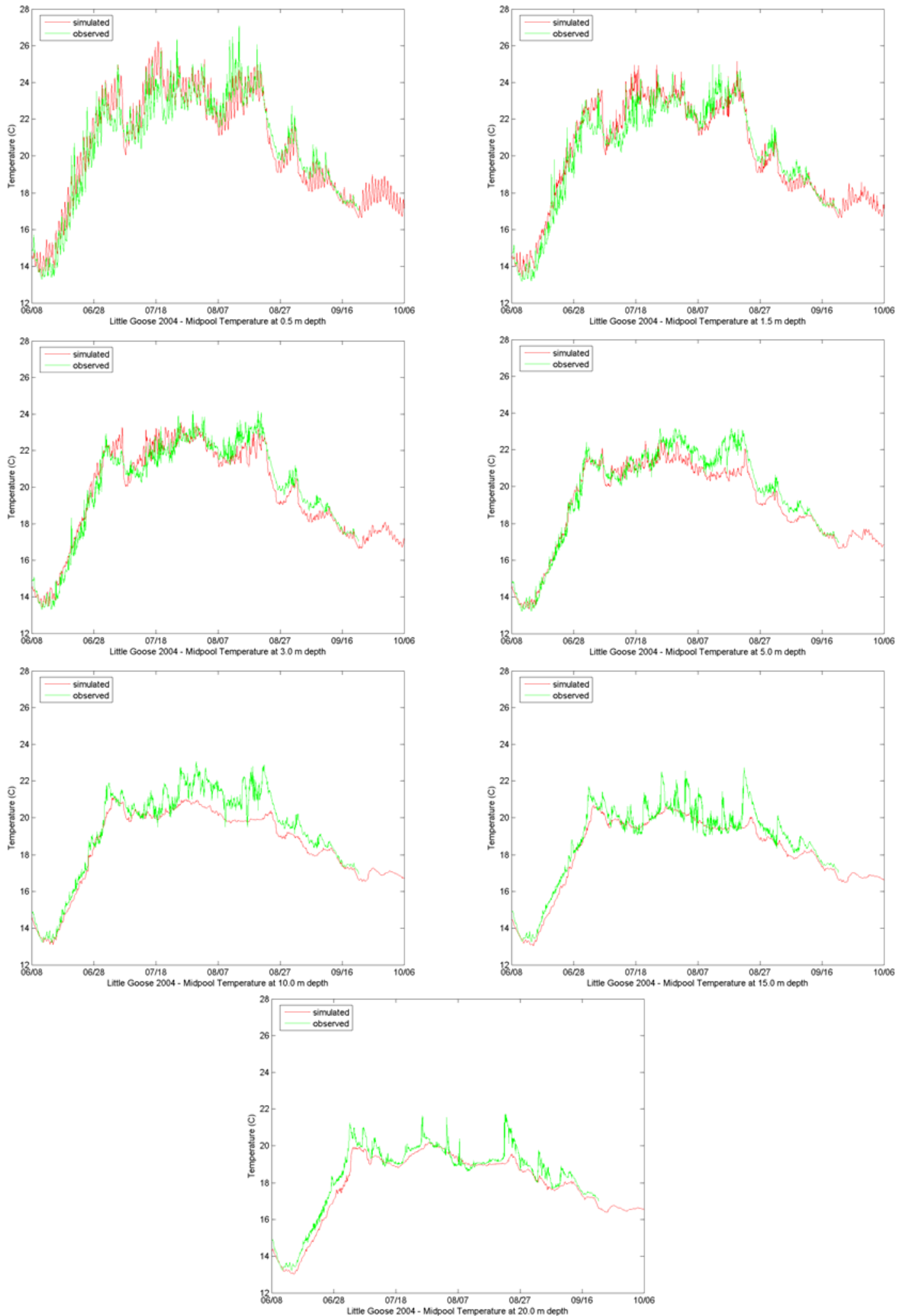

Figure C.20 Observed and Simulated temperatures at LGS Mid-pool, 2004 

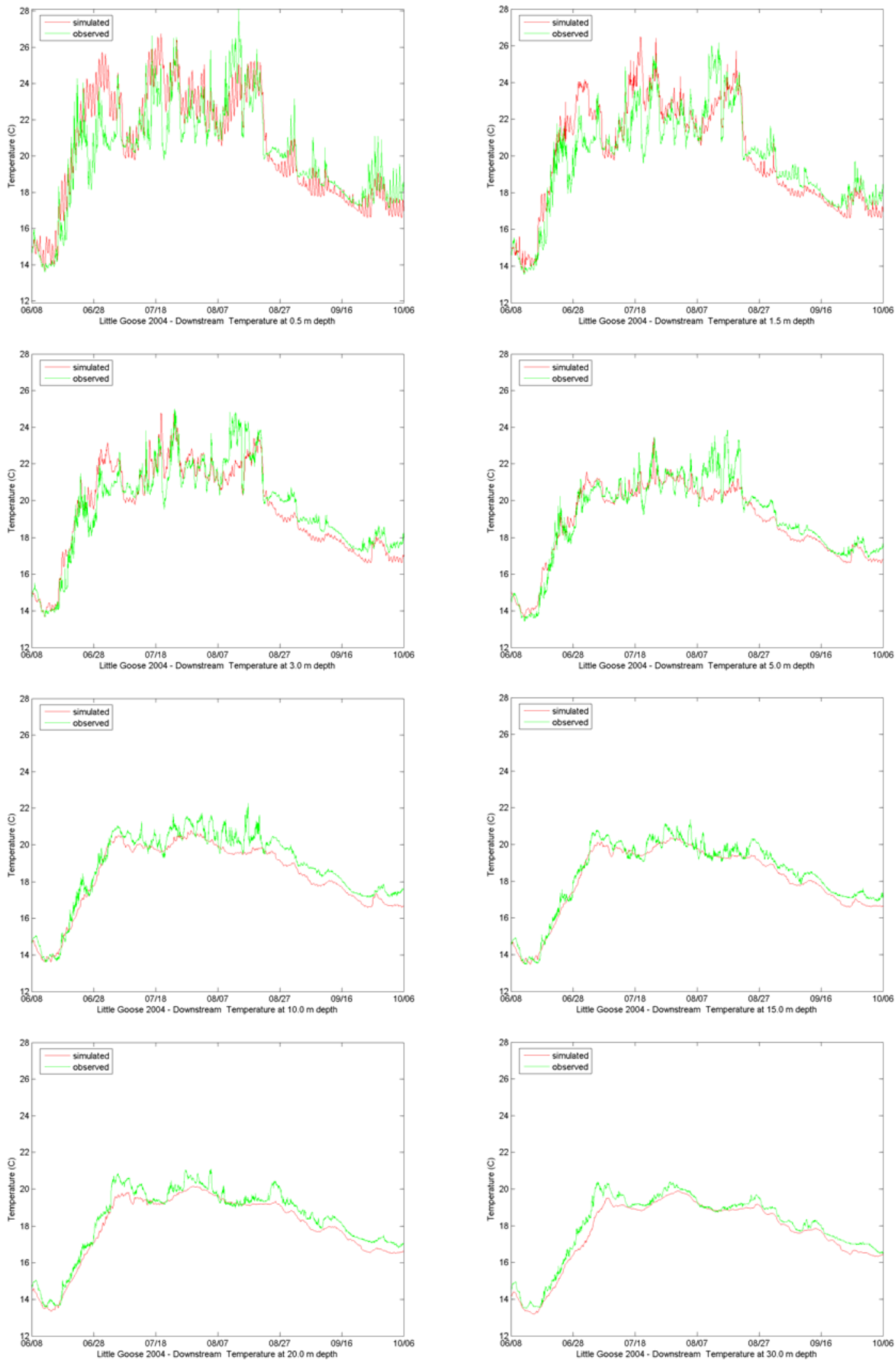

Figure C.21 Observed and Simulated temperatures at LGS BRZ, 2004 


\section{C.3 Lower Monumental Temperature Results}

\section{C.3.1 Lower Monumental 2002}
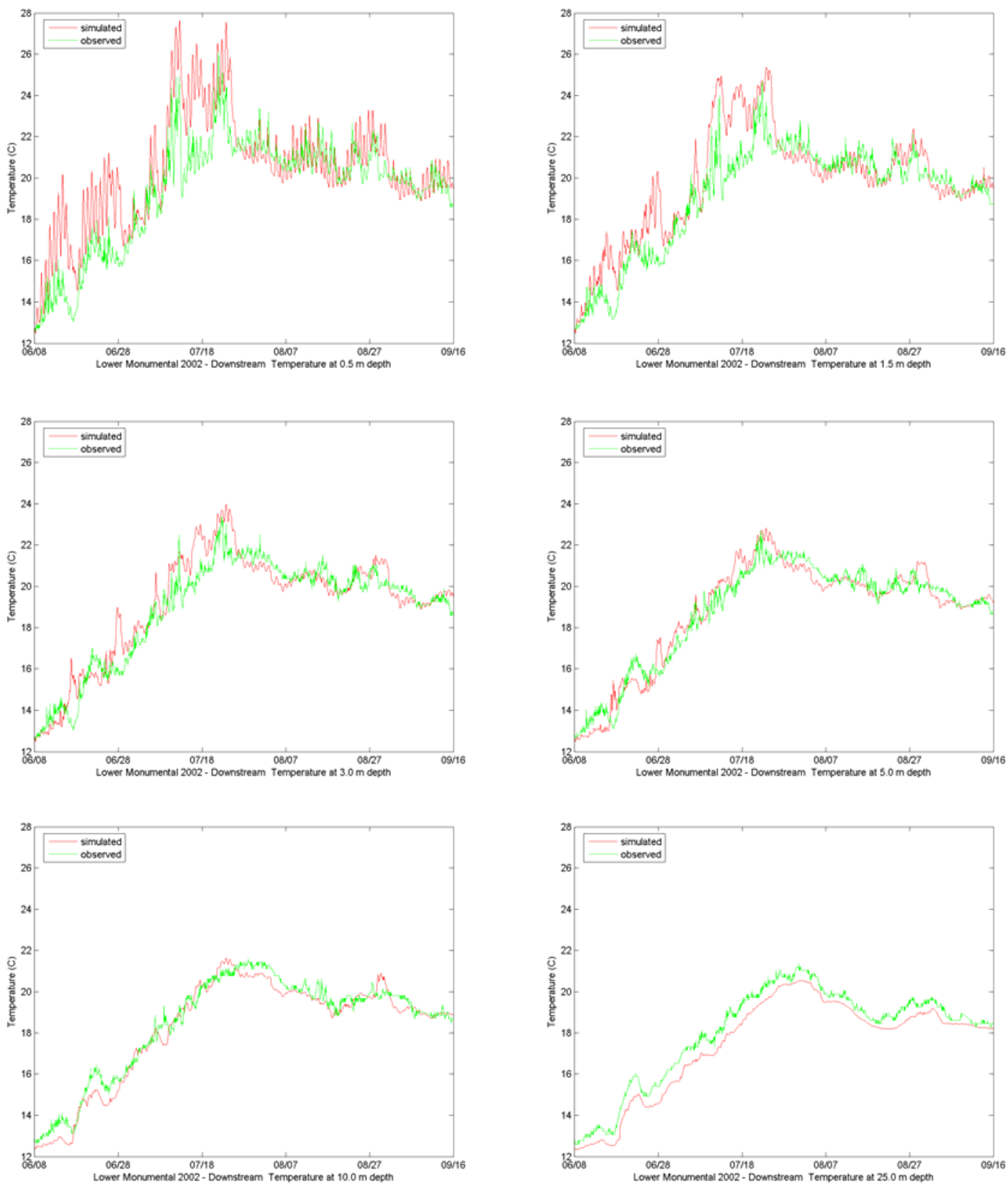

Figure C.22 Observed and Simulated temperatures at LMN BRZ, 2002 


\section{C.3.2 Lower Monumental 2003}
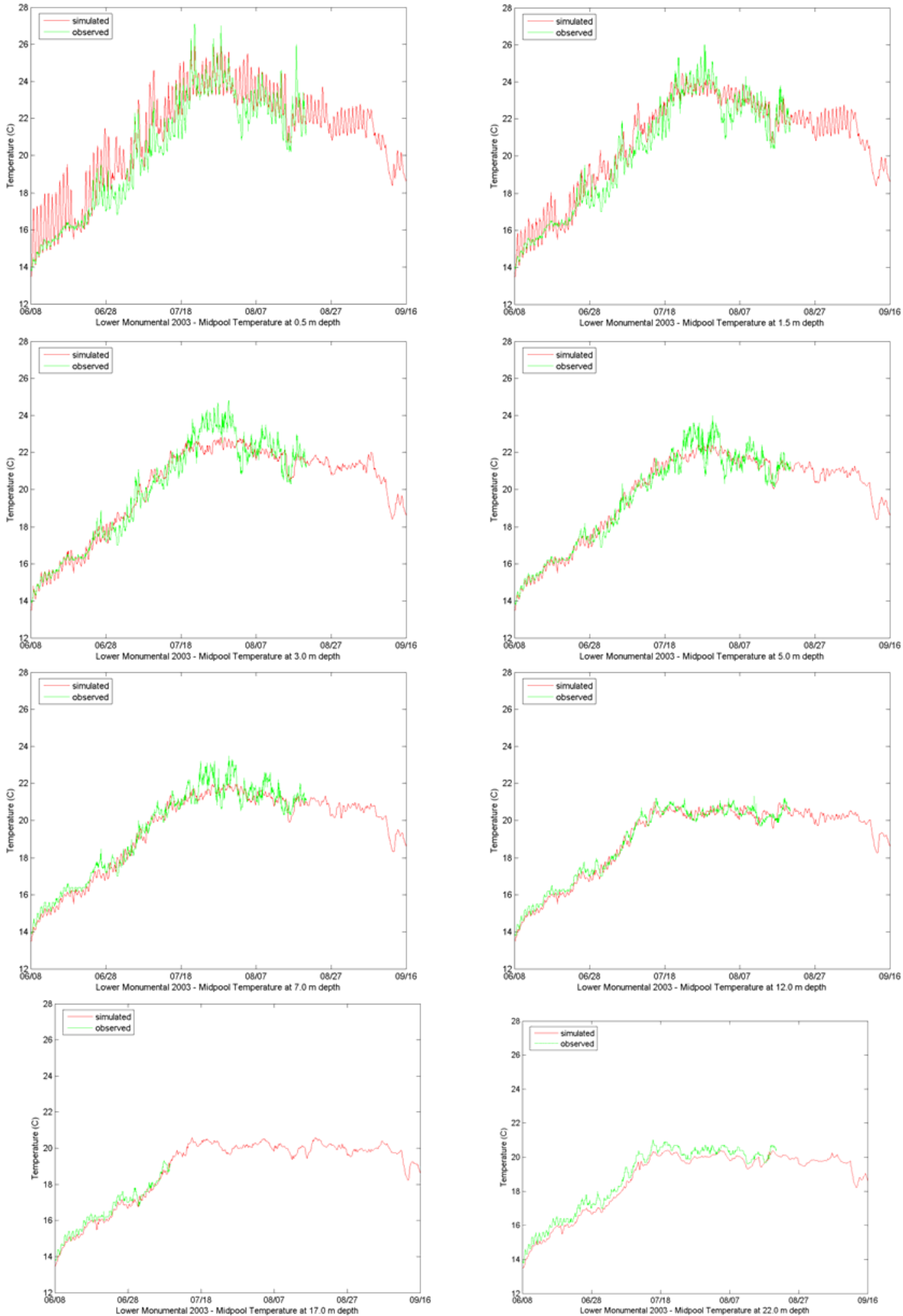

Figure C.23 Observed and Simulated temperatures at LMN Mid-pool, 2003 

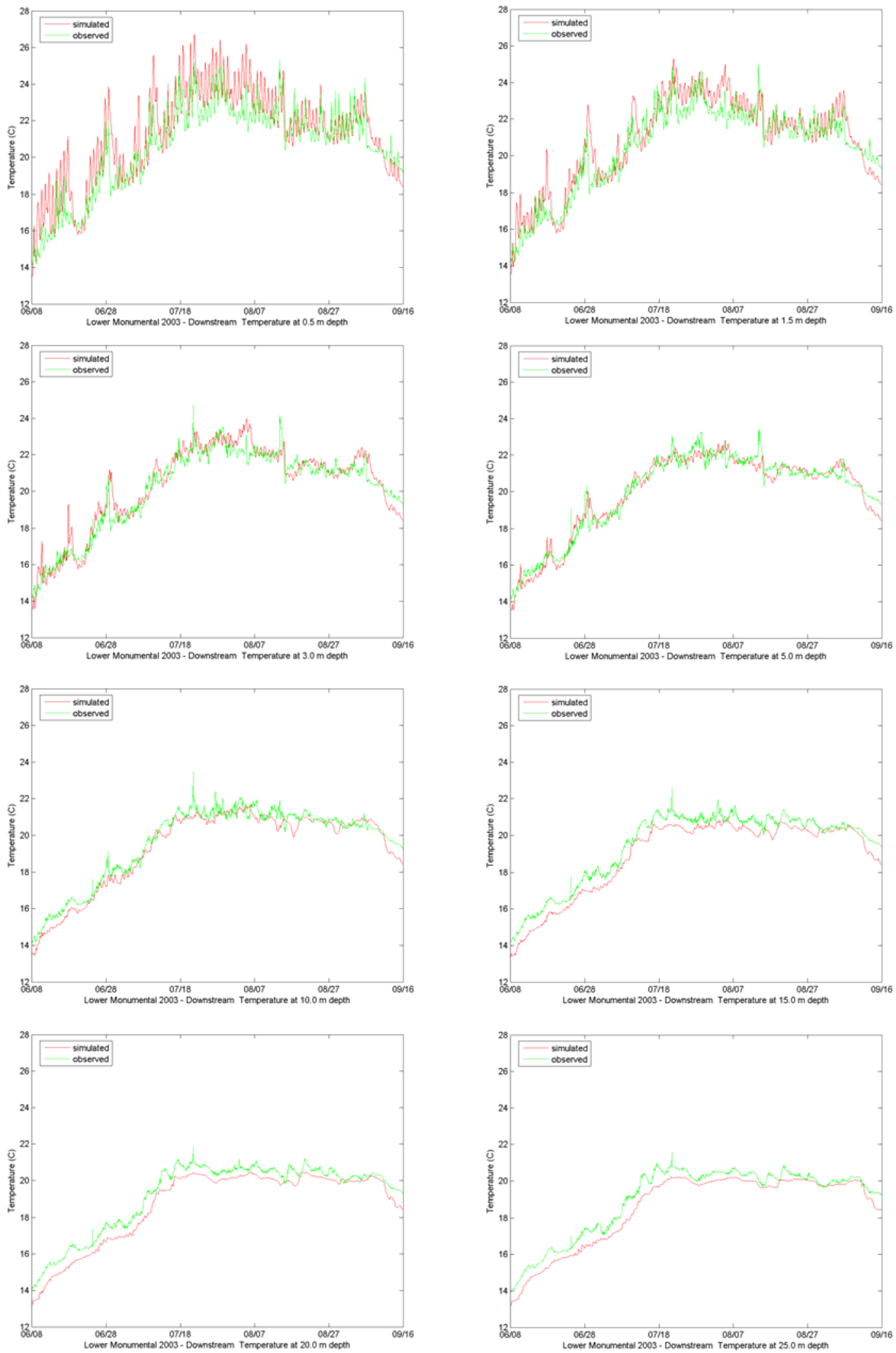

Figure C.24 Observed and Simulated temperatures at LMN BRZ, 2003 


\section{C.3.3 Lower Monumental 2004}
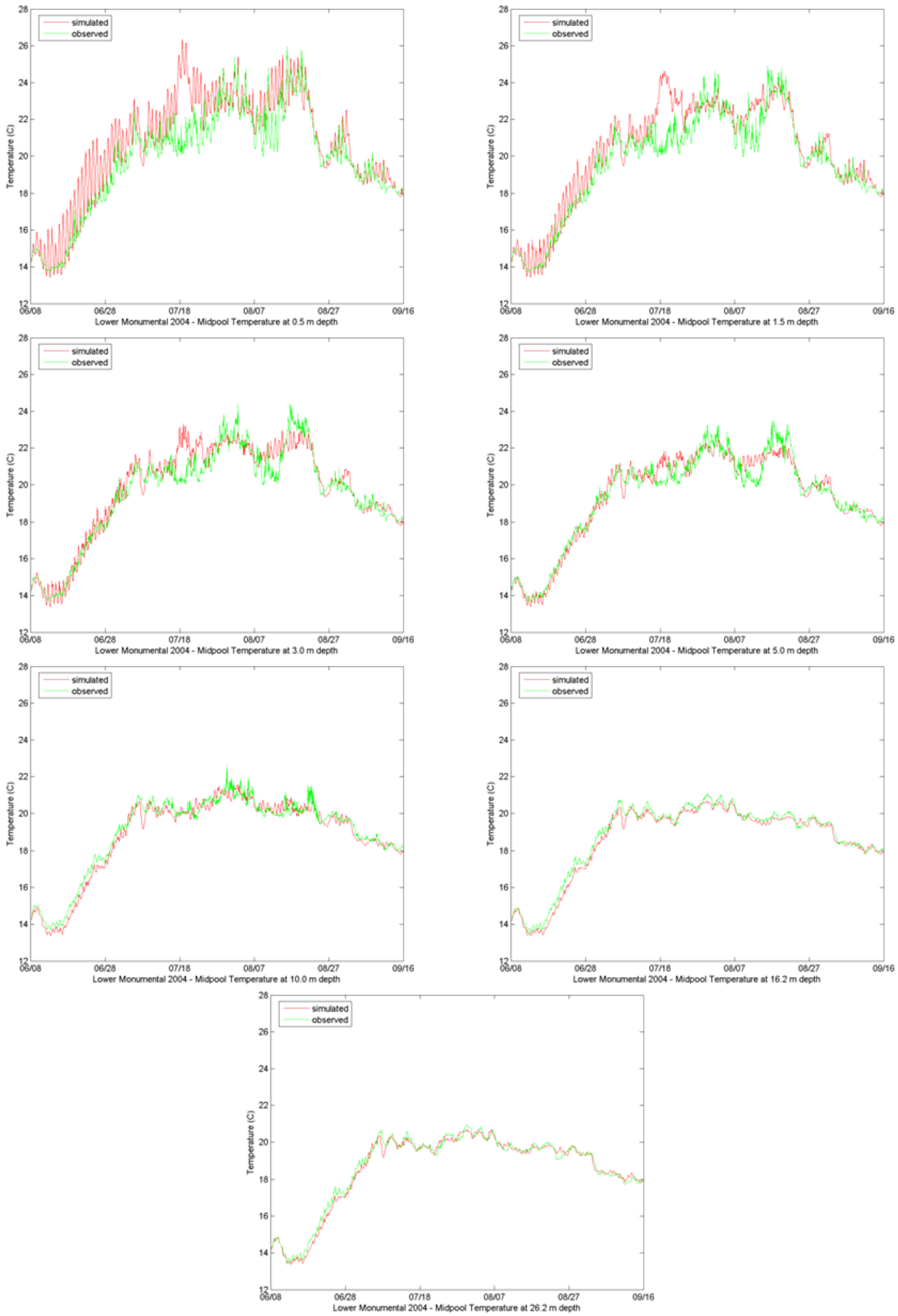

Figure C.25 Observed and Simulated temperatures at LMN Mid-pool, 2004 

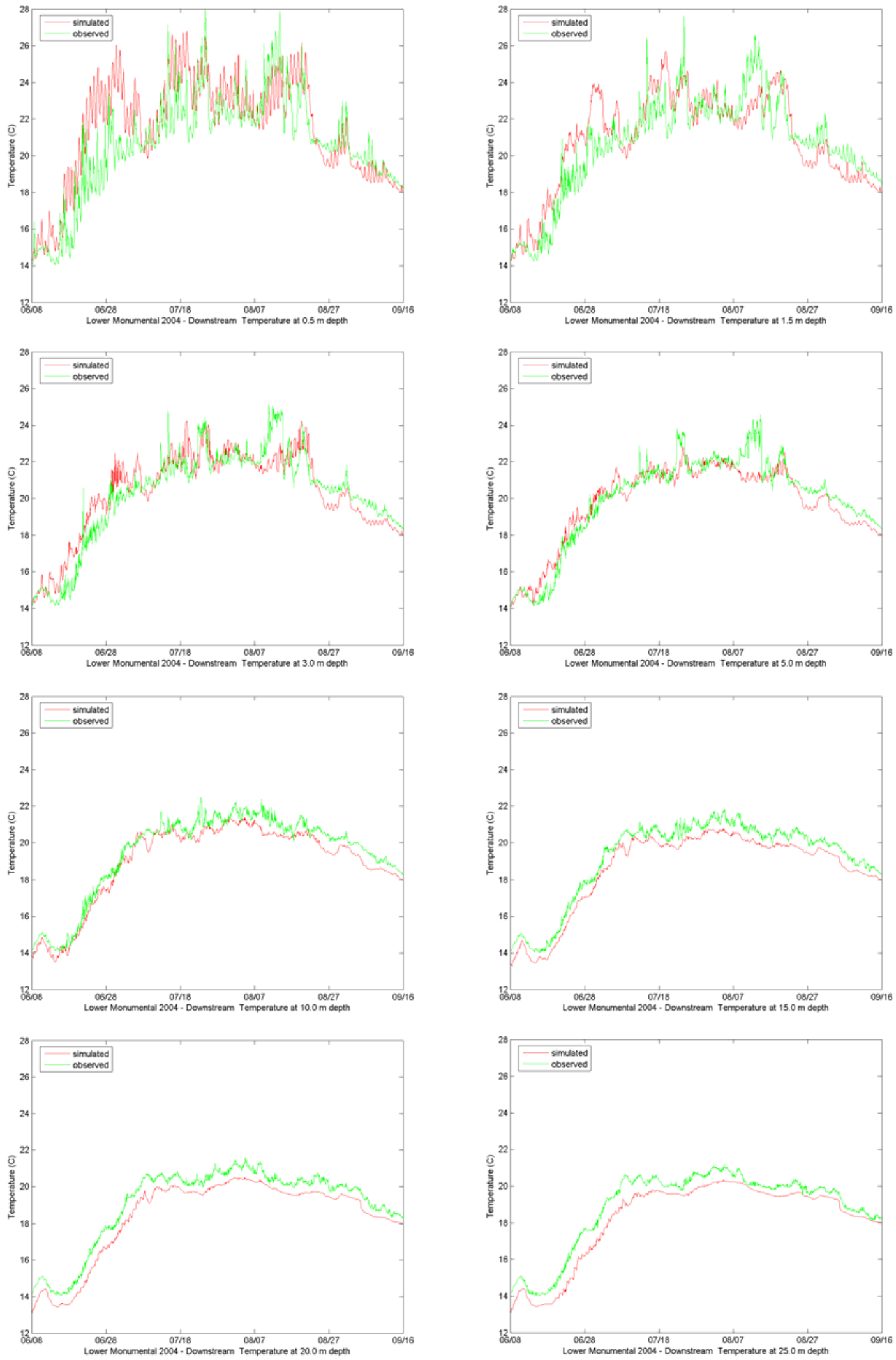

Figure C.26 Observed and Simulated temperatures at LMN BRZ, 2004 


\section{C.4 Ice Harbor Temperature Results}

\section{C.4.1 Ice Harbor 2002}
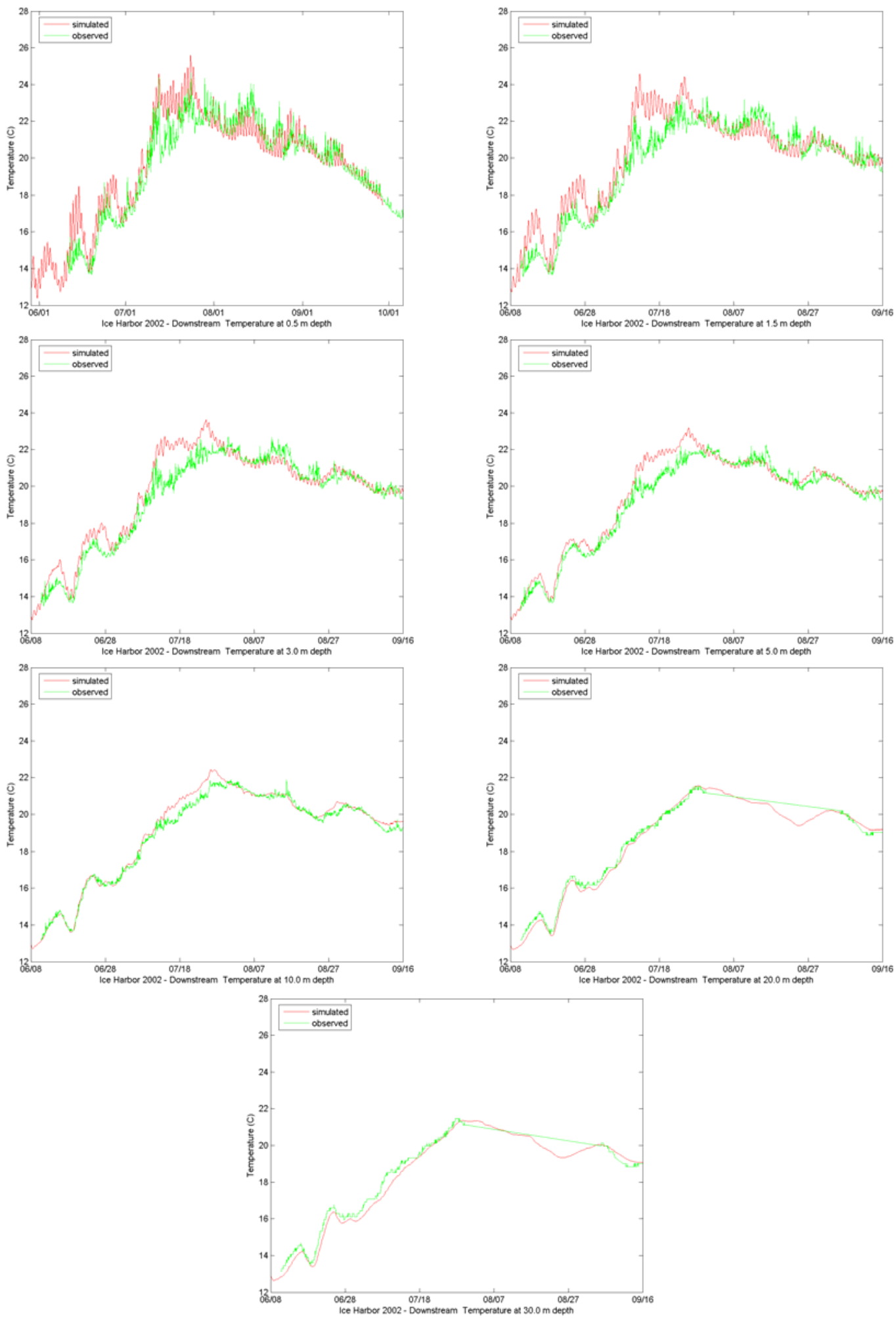

Figure C.27 Observed and simulated temperatures at IHR forebay BRZ, 2002 


\section{C.4.2 Ice Harbor 2003}
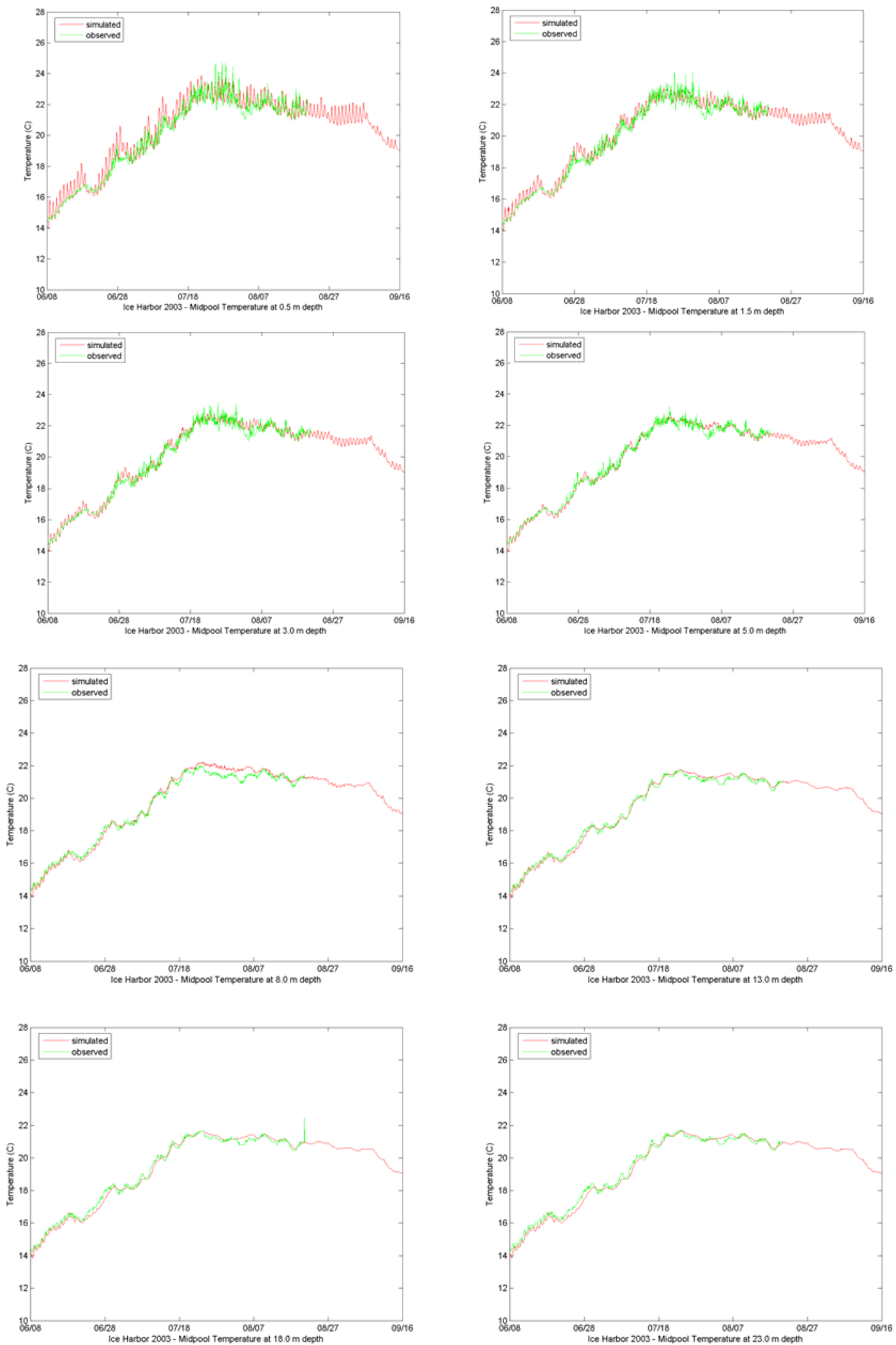

Figure C.28 Observed and simulated temperatures at IHR Mid-pool, 2003 

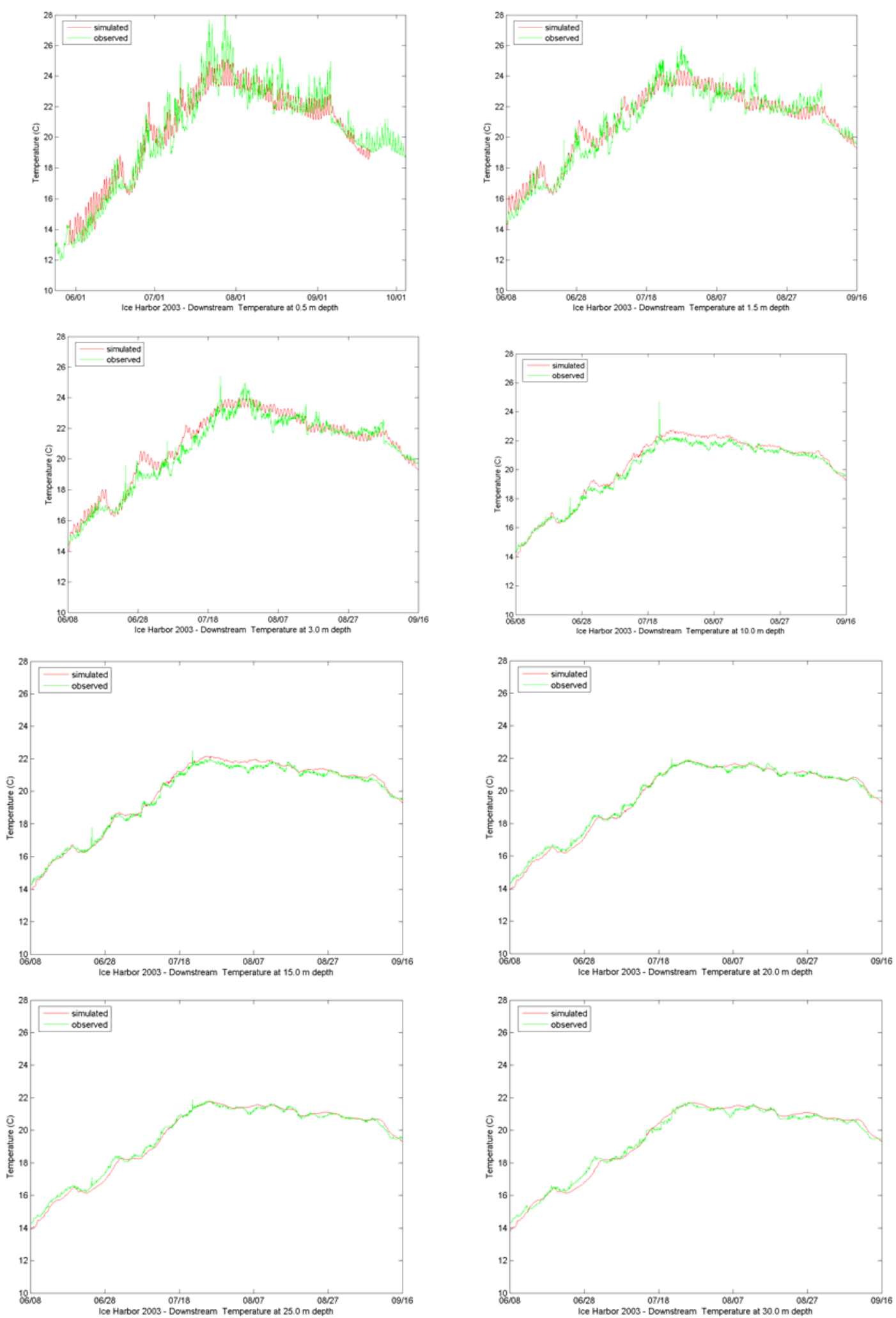

Figure C.29 Observed and simulated temperatures at IHR forebay BRZ, 2003 


\section{C.4.3 Ice Harbor 2004}
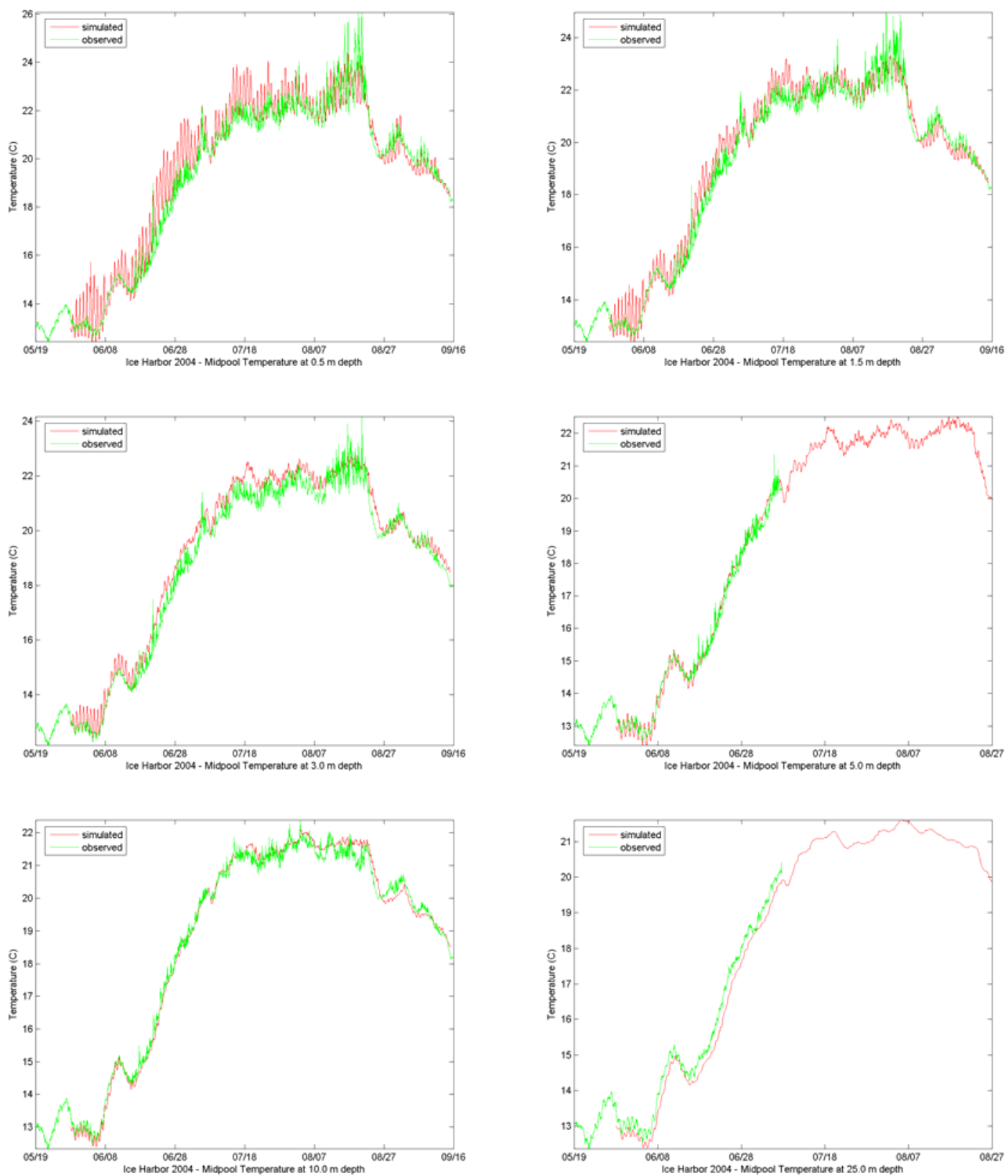

Figure C.30 Observed and simulated temperatures at IHR Mid-pool, 2004 

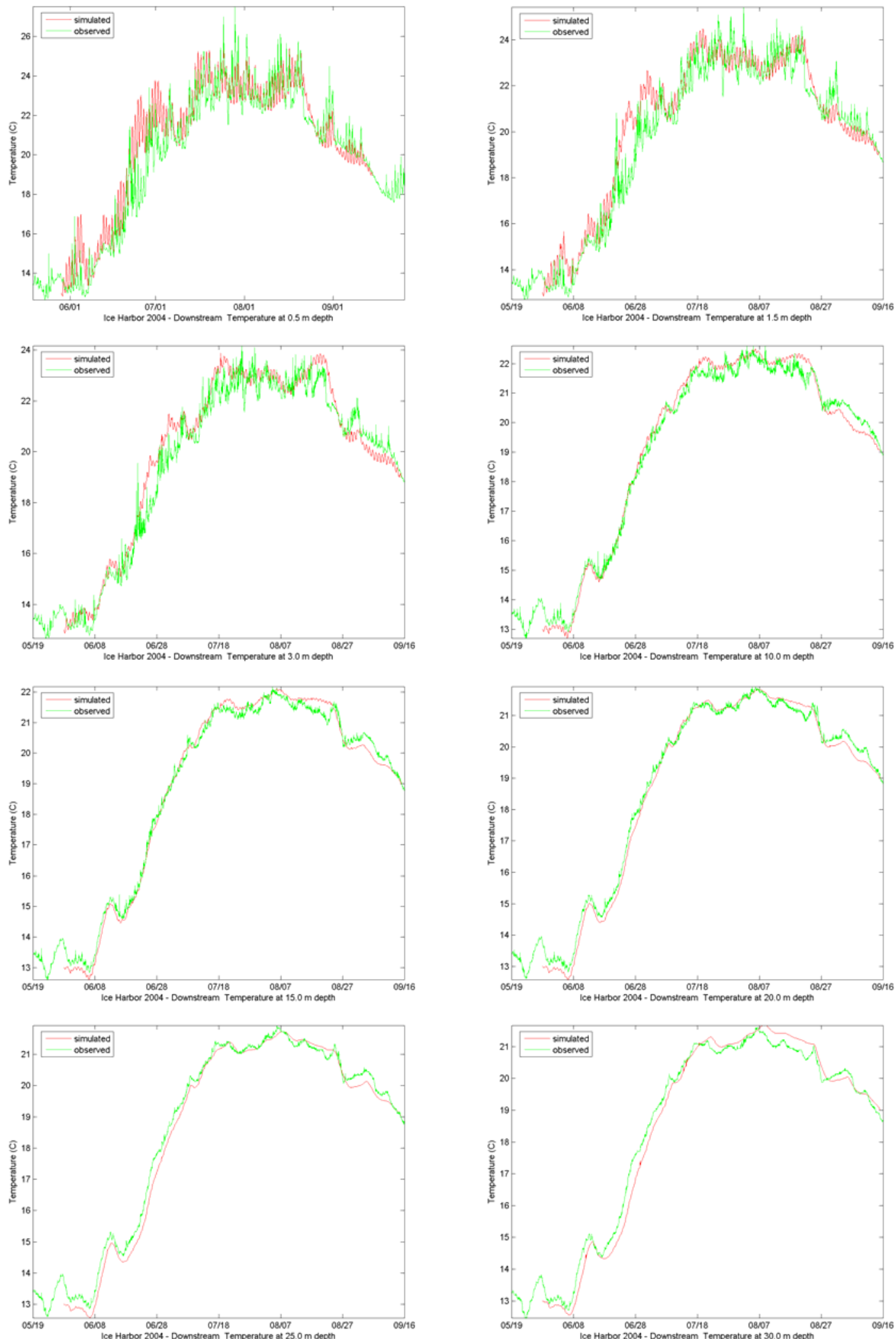

Figure C.31 Observed and simulated temperatures at IHR forebay BRZ, 2004 


\section{Appendix D}

\section{PIT-Tag Computed Migration Rates for Juvenile Fall Chinook Salmon}




\section{Appendix D}

\section{PIT-Tag Computed Migration Rates for Juvenile Fall Chinook Salmon}

\section{D.1 Background}

Migration rates for juvenile fall Chinook salmon passing through the lower Snake River were estimated for both wild and hatchery fall Chinook salmon using publicly available passive integrated transponder (PIT) tag data. These data were obtained from DART (2005), and the database of PIT tags was culled to include only juvenile migrants passing through the dams between July 1 and September 30 . It was noted during the analysis that some fish migrated through two or more reservoirs without being detected at the intermediate dams. Because the FINS model analysis (Section 6.3) was interested in migration rates on only a reservoir-by-reservoir basis, the only fish used in the analysis were ones detected at both the upstream and immediate downstream dam. Table D.1 displays the number of wild and hatchery juvenile fall Chinook salmon that met these criteria.

Table D.1. Number of juvenile fall Chinook salmon detected using PIT tags between July 1 and September 30

\begin{tabular}{|c|c|c|c|}
\hline \multicolumn{5}{|c|}{ Wild Fall Chinook Salmon } \\
\hline & Year 2002 & Year 2003 & Year 2004 \\
\hline LGS & 0 & 0 & 53 \\
\hline LMN & 0 & 0 & 23 \\
\hline \multicolumn{4}{|c|}{ Hatchery Fall Chinook Salmon } \\
\hline & Year 2002 & Year 2003 & Year 2004 \\
\hline LGS & 1942 & 498 & 178 \\
\hline LMN & 847 & 427 & 174 \\
\hline
\end{tabular}

\section{D.2 Wild Fall Chinook Salmon}

During the 2004 study period, 53 wild fall Chinook salmon were detected at both Lower Granite and Little Goose dams. During the same period, 23 juvenile migrants were detected at Little Goose and Lower Monumental dams. Table D.2 depicts summary statistics, while Figures D.1 and D.2 display histograms of migration rate. Migration rate was computed by dividing the reservoir length by the elapsed time between PIT tag detections.

Table D.2. Migration rates for wild fish passing through Little Goose and Lower Monumental reservoirs in 2004

\begin{tabular}{|c|c|c|}
\cline { 2 - 3 } \multicolumn{1}{c|}{} & $\begin{array}{c}\text { Mean } \\
\text { (km/day) }\end{array}$ & $\begin{array}{c}\text { Median } \\
(\mathrm{km} / \text { day })\end{array}$ \\
\hline 2004 LGS & 3.7 & 2.8 \\
\hline 2004 LMN & 5.7 & 5.2 \\
\hline
\end{tabular}




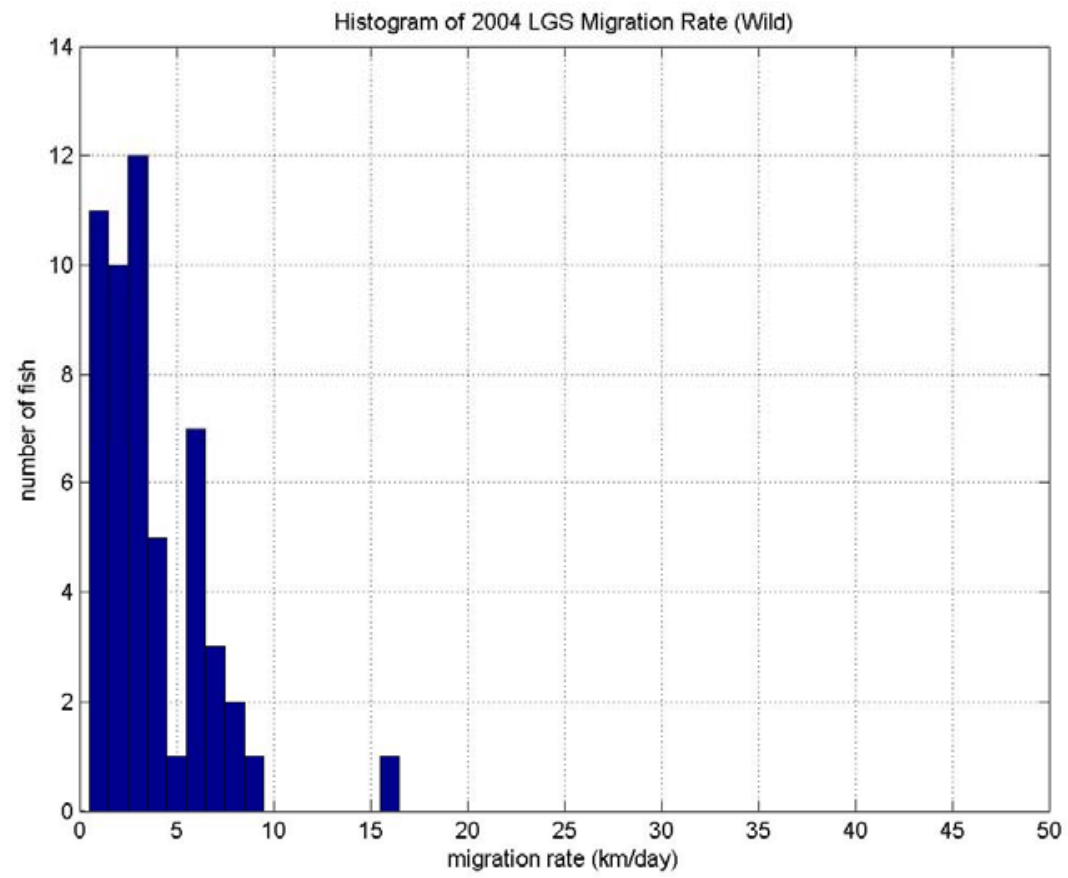

Figure D.1. Migration rate histogram for wild juvenile fall Chinook salmon passing through the reservoir upstream of Little Goose Dam. Note: total number of fish observed is 53.

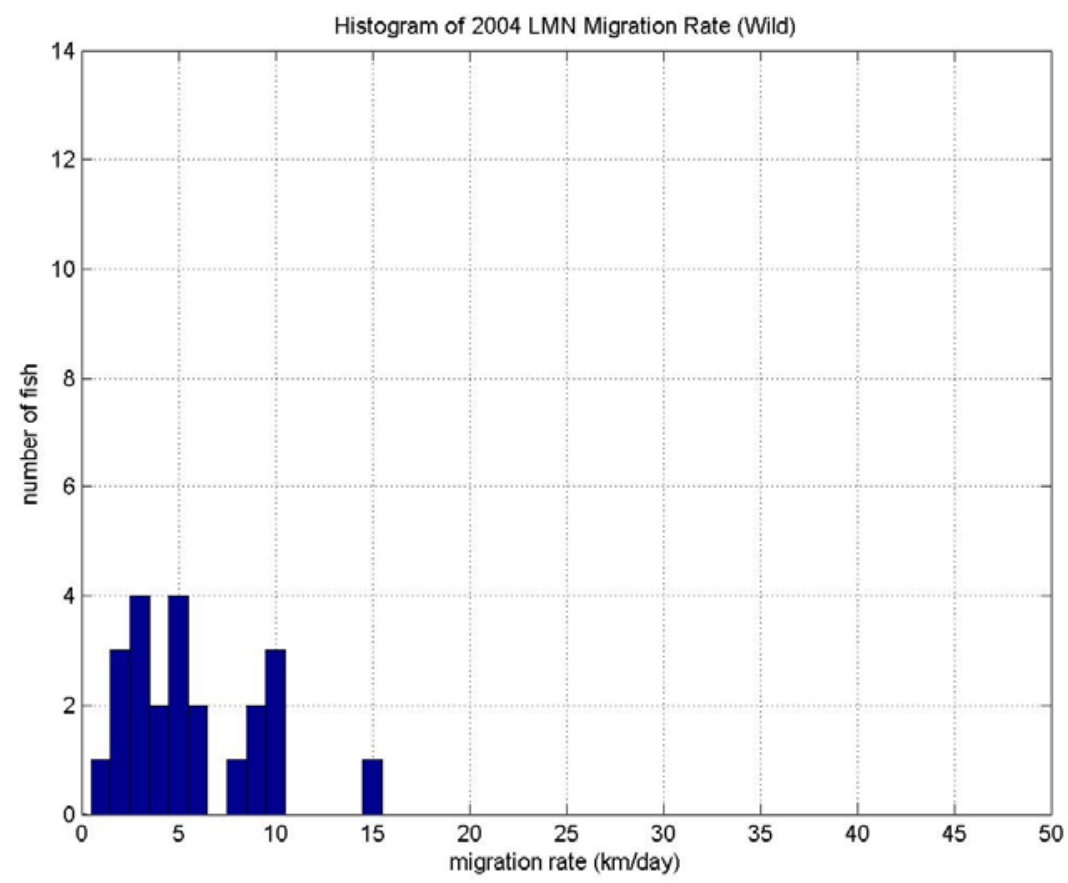

Figure D.2. $\quad$ Migration rate distribution for wild juvenile fall Chinook salmon passing through the reservoir upstream of Lower Monumental Dam. Note: total number of fish observed is 23. 
Connor et al. (2003) used a beach seine to capture juvenile fall Chinook salmon at two reaches of the free-flowing reach of the Snake River between Hells Canyon and Lower Granite dams. These fish were PIT-tagged and released, and their migrational behavior was observed. This paper reports migration rates for Little Goose Reservoir. The weighted-average migration rate was 11.8 km/day.

Table D.3. Travel rates for wild fish passing through Little Goose Reservoir.

Source: Connor et al. (2003), sum of upper and lower reaches.

\begin{tabular}{|c|c|c|c|}
\hline Year & $\begin{array}{c}\text { Migration Rate } \\
\text { (km/day) }\end{array}$ & $\begin{array}{c}\text { Fish } \\
\text { Count }\end{array}$ & $\begin{array}{c}\text { Range } \\
\text { (min to max) }\end{array}$ \\
\hline 1996 & 13.5 & 44 & 1.4 to 30 \\
\hline 1997 & 8.4 & 49 & 0.8 to 30 \\
\hline 1998 & 17.7 & 289 & 1.2 to 60 \\
\hline 1999 & 12.4 & 187 & 1.3 to 60 \\
\hline 2000 & 10.7 & 153 & 0.9 to 30 \\
\hline 2001 & 8.3 & 91 & 0.6 to 30 \\
\hline
\end{tabular}

\section{D.3 Hatchery Fall Chinook Salmon}

PIT-tagged hatchery fall Chinook salmon passage information was obtained from DART (2005), and the data were culled to the period July 1 through September 30. Mean migration rates, travel times, and number of fish counted for the 6-year period between 1995 and 2000 are shown in Table D.4. The median travel rate for this period was $10.4 \mathrm{~km} /$ day in the reservoir upstream of Little Goose Dam and 9.6 km/day in the reservoir upstream of Lower Monumental Dam.

Table D.4. Travel time summary for PIT-tagged hatchery fish rates for the reservoirs upstream of Little Goose and Lower Monumental Reservoirs

\begin{tabular}{|c|c|c|c|c|c|c|}
\cline { 2 - 7 } \multicolumn{1}{c|}{} & \multicolumn{3}{c|}{ Little Goose Reservoir } & \multicolumn{3}{c|}{ Lower Monumental Reservoir } \\
\hline Year & $\begin{array}{c}\text { Migration } \\
\text { Rate (km/day) }\end{array}$ & $\begin{array}{c}\text { Travel Time } \\
\text { (days) }\end{array}$ & $\begin{array}{c}\text { Fish } \\
\text { Count }\end{array}$ & $\begin{array}{c}\text { Migration } \\
\text { Rate (km/day) }\end{array}$ & $\begin{array}{c}\text { Travel Time } \\
\text { (days) }\end{array}$ & $\begin{array}{c}\text { Fish } \\
\text { Count }\end{array}$ \\
\hline 1995 & 7.91 & 7.1 & 1030 & 7.61 & 5.9 & 1043 \\
\hline 1996 & 11.02 & 5.1 & 1257 & 10.2 & 4.4 & 610 \\
\hline 1997 & 6.94 & 8.1 & 3493 & 8.8 & 5.1 & 3317 \\
\hline 1998 & 17.55 & 3.2 & 9957 & 14.0 & 3.2 & 7942 \\
\hline 1999 & 11.02 & 5.1 & 1633 & 11.2 & 4.0 & 144 \\
\hline 2000 & 7.7 & 7.3 & 967 & 5.8 & 7.7 & 405 \\
\hline
\end{tabular}

Histograms detailing migration rates for juvenile migrants passing during the study years of this project (2002 through 2004) are shown in Figures D.3 through D.8. Data contained in these figures have been aggregated to produce the summary histograms shown in Figures D.9 and D.10 and the summary statistics in Table D.5. 


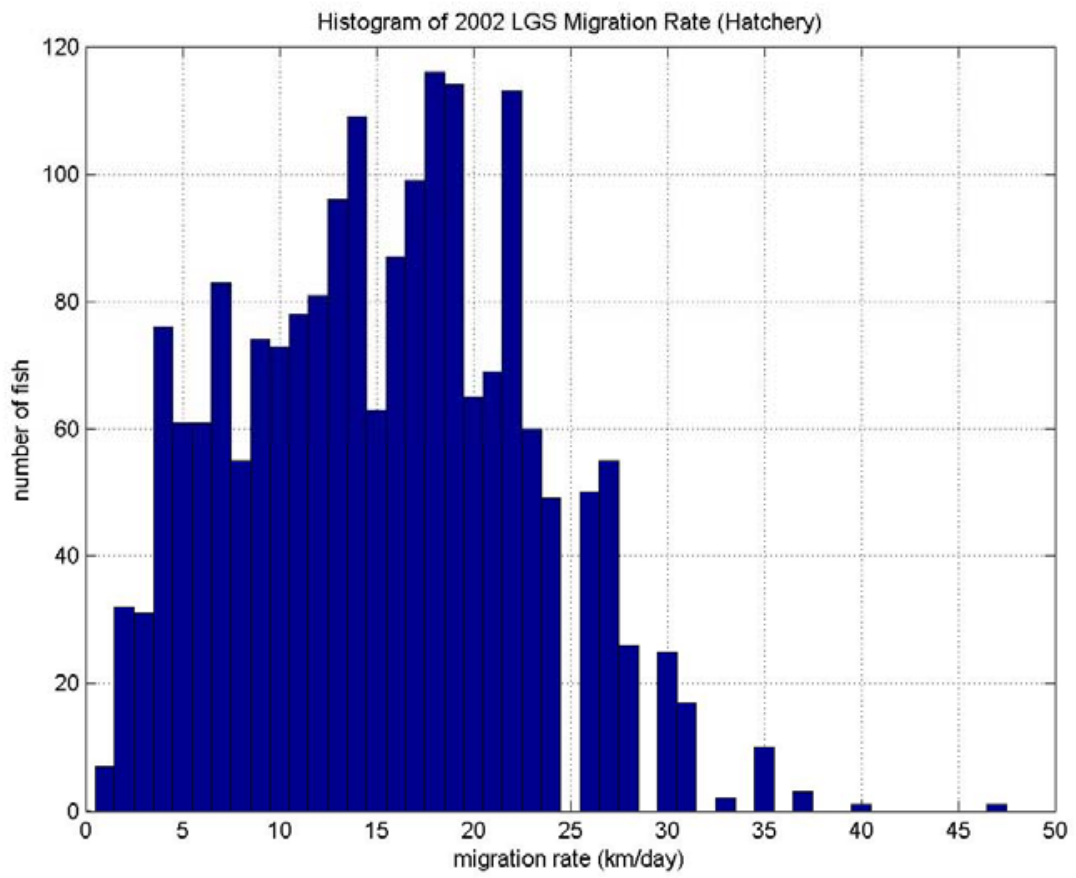

Figure D.3. 2002 migration rate distribution for hatchery juvenile fall Chinook salmon passing through the reservoir upstream of Little Goose Dam

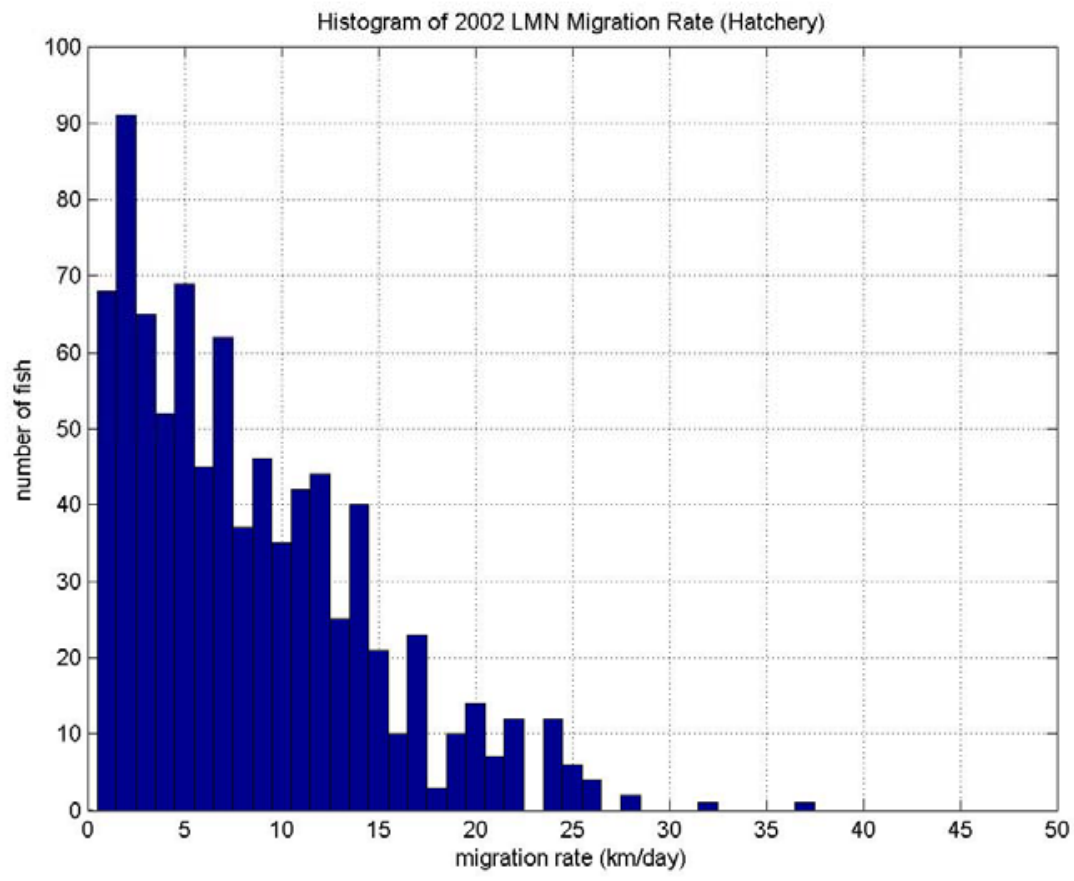

Figure D.4. 2002 migration rate distribution for wild juvenile fall Chinook salmon passing through the reservoir upstream of Lower Monumental Dam 


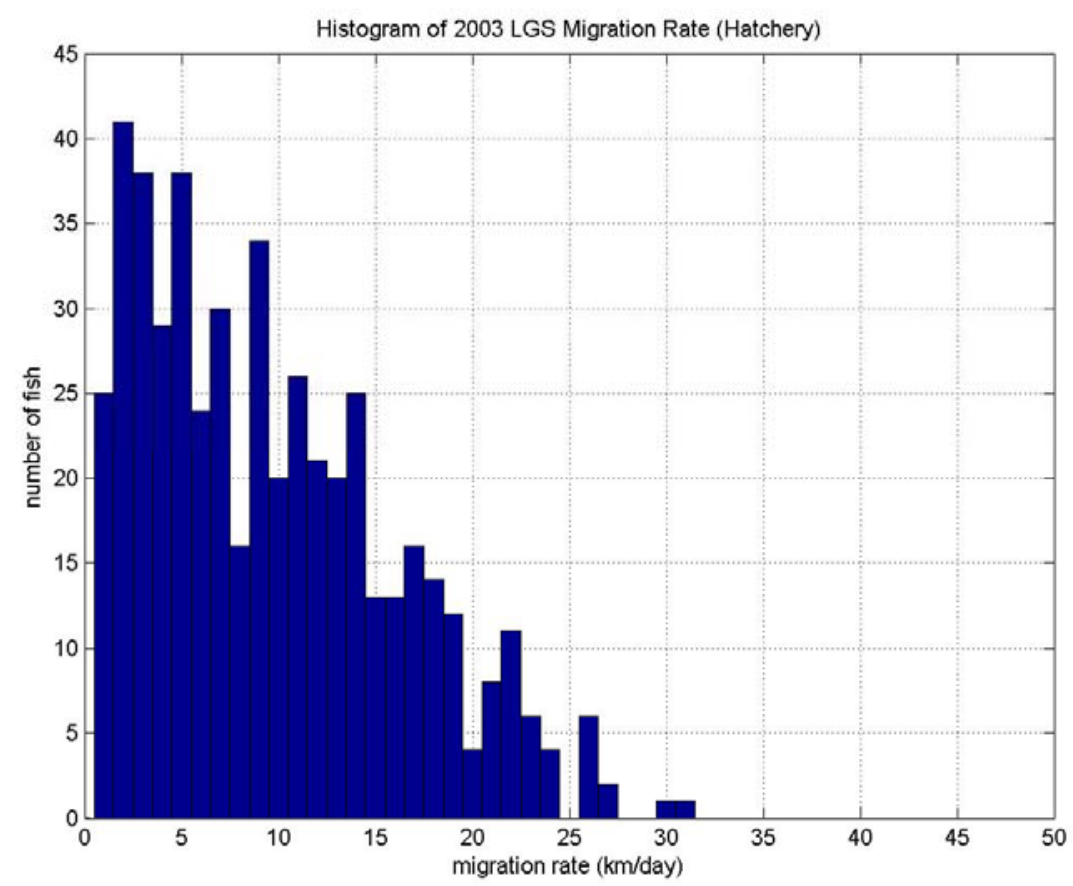

Figure D.5. 2003 migration rate distribution for hatchery juvenile fall Chinook salmon passing through the reservoir upstream of Little Goose Dam

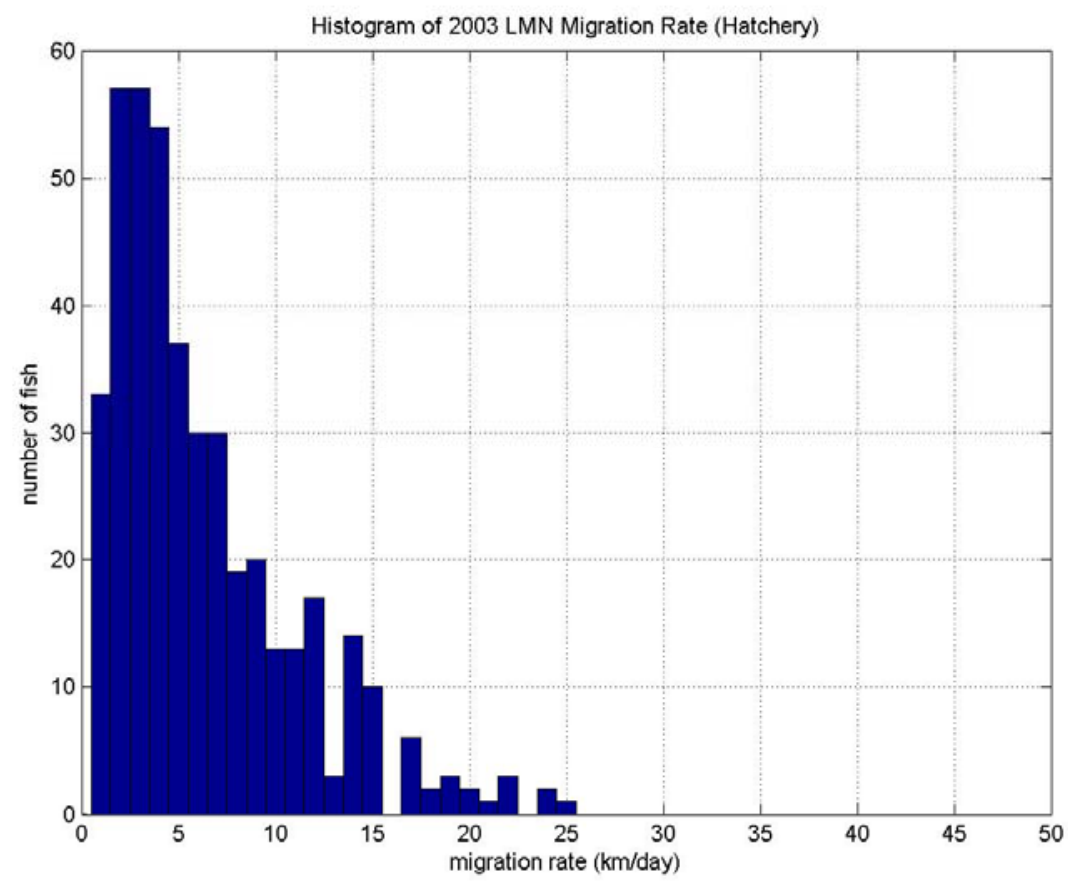

Figure D.6. 2003 migration rate distribution for wild juvenile fall Chinook salmon passing through the reservoir upstream of Lower Monumental Dam 


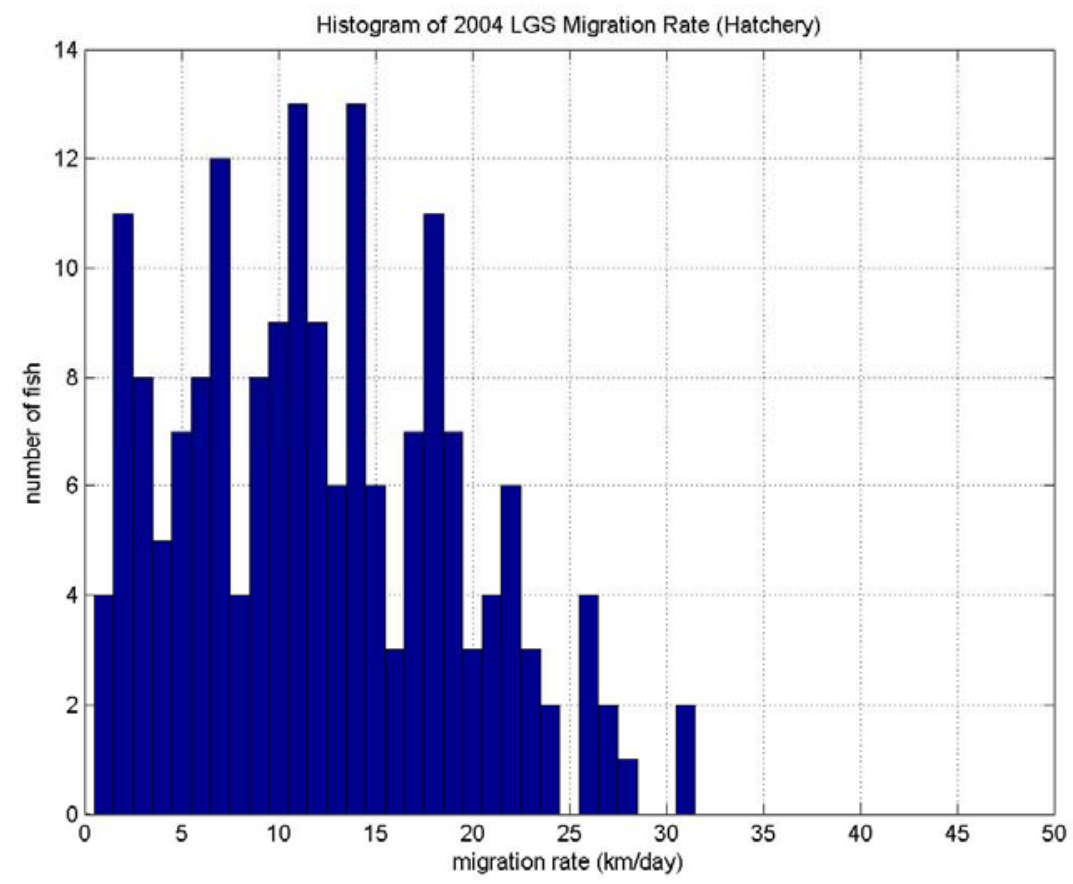

Figure D.7. 2004 migration rate distribution for hatchery juvenile fall Chinook salmon passing through the reservoir upstream of Little Goose Dam

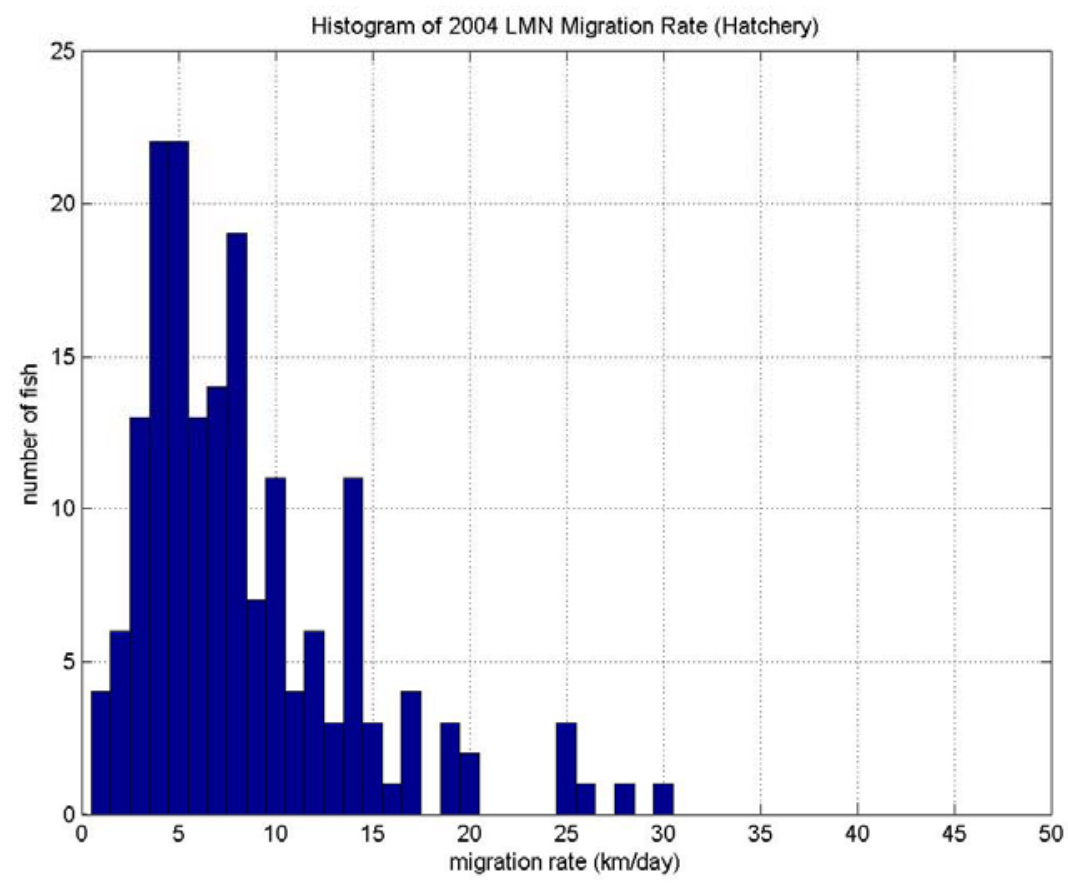

Figure D.8. 2004 migration rate distribution for wild juvenile fall Chinook salmon passing through the reservoir upstream of Lower Monumental Dam 


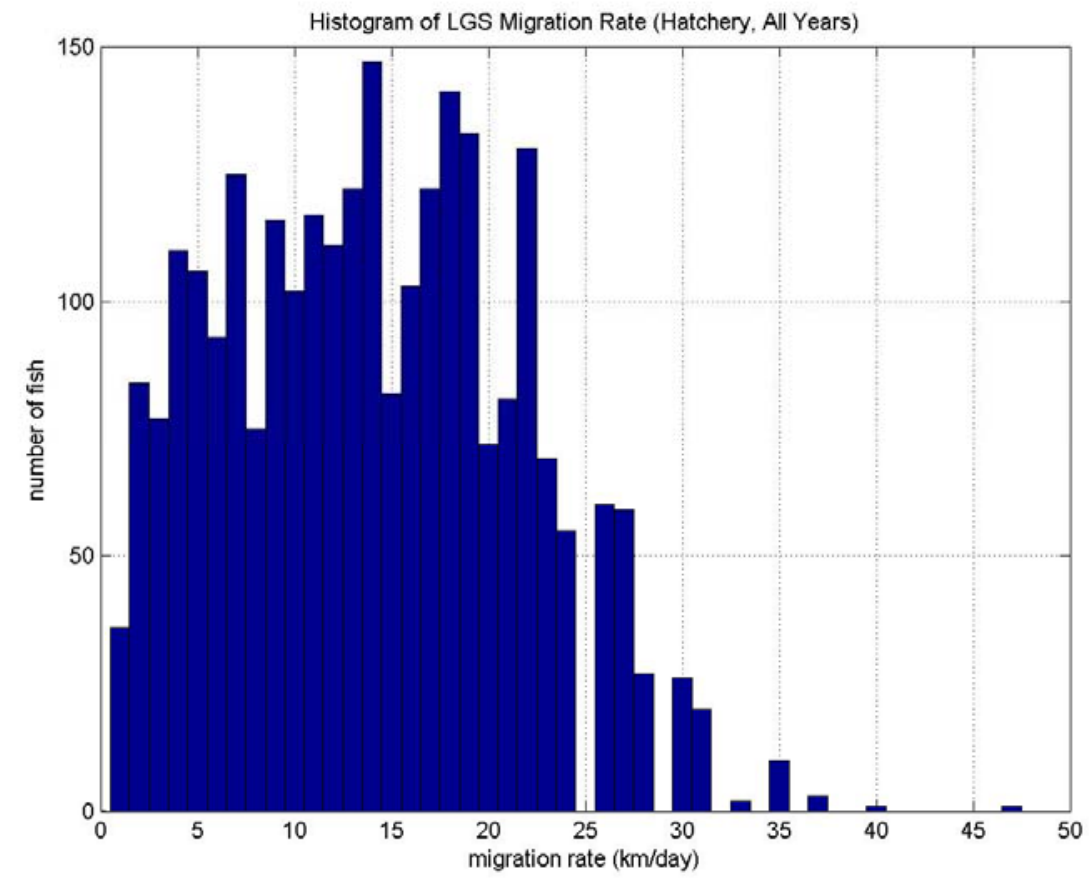

Figure D.9. Migration rate distribution for hatchery juvenile fall Chinook salmon passing through the reservoir upstream of Little Goose Dam: summary 2002-2004

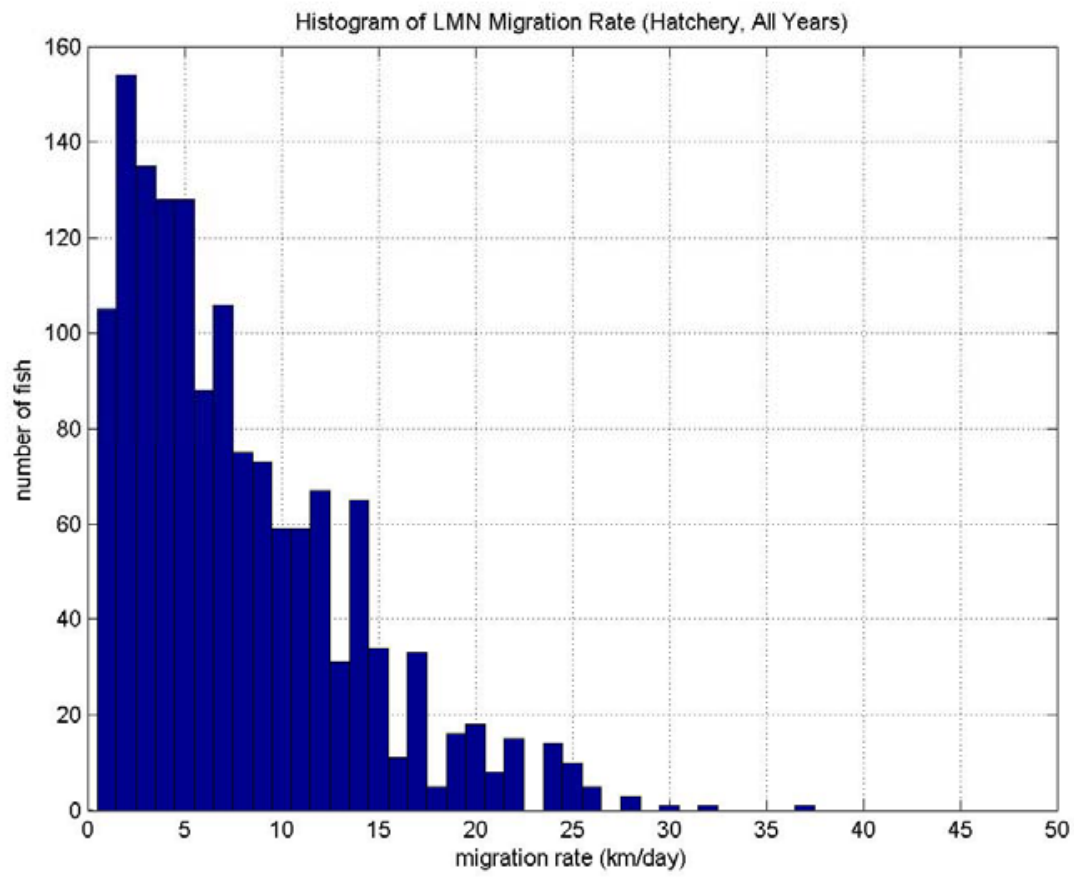

Figure D.10. Migration rate distribution for wild juvenile fall Chinook salmon passing through the reservoir upstream of Lower Monumental Dam: summary 2002-2004 
Table D.5. Summary of migration rates (km/day) for Little Goose and Lower Monumental reservoirs. Mean, median, standard deviation (std), and range of migration rates.

\begin{tabular}{|c|c|c|c|c|}
\hline & Mean & Median & Std & Range \\
\hline 2002 LGS Hatchery & 15.3 & 15.2 & 7.3 & 46.0 \\
\hline 2003 LGS Hatchery & 9.7 & 8.6 & 6.5 & 30.4 \\
\hline 2004 LGS Hatchery & 12.2 & 11.6 & 7.0 & 30.3 \\
\hline All LGS Hatchery & 14.0 & 13.7 & 7.5 & 46.0 \\
\hline & & & & \\
\hline 2002 LMN Hatchery & 8.4 & 7.0 & 6.2 & 36.8 \\
\hline 2003 LMN Hatchery & 6.3 & 4.9 & 4.8 & 24.4 \\
\hline 2004 LMN Hatchery & 8.4 & 7.1 & 5.5 & 28.8 \\
\hline All LMN Hatchery & 7.8 & 6.3 & 5.8 & 36.9 \\
\hline
\end{tabular}

\section{D.4 Results}

The migration rates of both wild and hatchery juvenile fall Chinook salmon were computed using PIT tags for Little Goose and Lower Monumental reservoirs. Average reservoir passing rates are presented in Table D.5. Smith et al. (2003) studied the influence of river conditions on survival and travel time of fall Chinook salmon in the Snake River from 1995 to 2000 using Lyons Ferry Hatchery fish that were PITtagged and released into the free-flowing section of the Snake River upstream of Lower Granite Dam. Median travel times for these fish were 5.3 days and 4.3 days for the reservoirs upstream of Little Goose and Lower Monumental dams, respectively. The values are similar to those for hatchery fish released during 2002 through 2004. Values computed for wild fish in 2004 were different, with much smaller migration rates and longer travel times through the reservoir. Sample sizes, however, for the wild fish group were very low (see Table D.1)

Table D.6. Summary of median travel rates and migration times for wild and hatchery juvenile fall Chinook salmon passing through Little Goose and Lower Monumental reservoirs. Note: for wild fish, sample sizes were low (see Table D.1).

\begin{tabular}{|c|c|c|c|c|}
\cline { 2 - 5 } \multicolumn{1}{c|}{} & \multicolumn{2}{c|}{ Wild (2004 only) } & \multicolumn{2}{c|}{ Hatchery (2002 through 2004) } \\
\cline { 2 - 5 } \multicolumn{1}{c|}{} & $\begin{array}{c}\text { Migration Rate } \\
(\mathrm{km} / \text { day) }\end{array}$ & $\begin{array}{c}\text { Travel Time } \\
\text { (days) }\end{array}$ & $\begin{array}{c}\text { Migration Rate } \\
(\mathrm{km} / \text { day) }\end{array}$ & $\begin{array}{c}\text { Travel Time } \\
\text { (days) }\end{array}$ \\
\hline LGS $(60 \mathrm{~km})$ & 2.8 & 21.4 & 13.7 & 4.4 \\
\hline LMN $(46 \mathrm{~km})$ & 5.2 & 8.8 & 6.3 & 7.3 \\
\hline
\end{tabular}

